NIST Technical Note 1947

\title{
A Study on the Performance of Current Smoke Alarms to the New Fire and Nuisance Tests Prescribed in ANSI/UL 217-2015
}


NIST Technical Note 1947

\section{A Study on the Performance of Current Smoke Alarms to the New Fire and Nuisance Tests Prescribed in ANSI/UL 217-2015}

Thomas G.Cleary Fire Research Division Engineering Laboratory

This publication is available free of charge from: https://doi.org/10.6028/NIST.TN.1947

December 2016

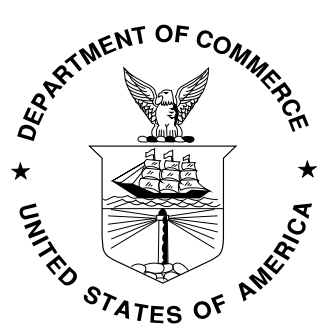

U.S. Department of Commerce Penny Pritzker, Secretary

National Institute of Standards and Technology Willie May, Under Secretary of Commerce for Standards and Technology and Director 
Certain commercial entities, equipment, or materials may be identified in this document in order to describe an experimental procedure or concept adequately. Such identification is not intended to imply recommendation or endorsement by the National Institute of Standards and Technology, nor is it intended to imply that the entities, materials, or equipment are necessarily the best available for the purpose.

National Institute of Standards and Technology Technical Note 1947 Natl. Inst. Stand. Technol. Tech. Note 1947, 94 pages (December 2016) CODEN: NTNOEF

This publication is available free of charge from: https://doi.org/10.6028/NIST.TN.1947 


\begin{abstract}
Research was conducted on the performance of currently available smoke alarms to the new fire and cooking nuisance source tests specified in ANSI/UL 217-2015, Standard for Safety of Smoke Alarms. The standard calls for additional room-scale fire tests with smoldering and flaming polyurethane foam and a broiling hamburgers cooking test. The objectives of this research was to assess whether the new performance tests will foster a demonstrable enhancement in smoke alarm performance compared to a wide range of currently available smoke alarms and whether the single nuisance source test is representative of a range of cooking nuisance scenarios. There were 45 distinct smoke alarm models from seven different manufacturers used in the study. There were 14 ionization sensor models, 14 photoelectric sensor models, seven combination photoelectric and carbon monoxide sensor models, four combination ionization and carbon monoxide sensor models, four combination ionization and photoelectric sensor models, and two combination photoelectric and thermal sensor models. Six units of each model were used in the experiments for a total of 270 individual smoke alarms used in the study. The sensitivity of each alarm was measured in a smoke box with cotton wick smoke per the ANSI/UL 217-2012. The measured sensitivities across the different models covered nearly the entire range of allowed sensitivities. Analysis of these results showed that no current smoke alarm model would likely meet the new test performance levels required in the ANSI/UL 217-2015. Three models, all photoelectric sensor alarms, came closest to meeting the requirements. It was concluded that an across the board increase to the level of performance specified in ANSI-UL 217-2015 would significantly improve the overall performance of smoke alarms by expanding the range of fire scenarios alarms must respond to while requiring resistance to nuisance alarms. The changes introduced in ANSI/UL 217-2015, which include the new performance fire tests and the new nuisance resistance test, may represent significant challenges for manufacturers to meet the requirements by simply using both photoelectric and ionization sensors, or designing alarms that perform as well against the new fire tests as combination ionization / photoelectric models examined. The aerosol generation rate between the cooking nuisance sources varied significantly as did the relationship between the light obscuration and measuring ionization chamber values. Toasting bread produced essentially no measurable obscuration, thus alarms with only photoelectric, carbon monoxide, and thermal sensors typically did not alarm during those experiments. However, ionization alarms did respond to toasting bread aerosols at about the same measuring ionization chamber level as the broiling hamburgers experiments. As a nuisance test, the broiling hamburgers test challenged the majority of smoke alarms included in this study, and therefore may be considered a conservative test. Ultimately, cooking nuisance experiments on a range of smoke alarms that ANSI/UL 217-2015 will confirm the appropriateness of the broiling hamburgers cooking nuisance scenario as the model test.
\end{abstract}




\section{Acknowledgements}

The author acknowledges Michael Selepak, Lauean DeLauter, Anthony Chakalis, Mariusz Zarzecki, Amy Mensch, and Maylin Odenthal for smoke box and test room fabrication, and assisting with the data collection. The research was funded in part by the US Consumer Products Safety Commission, with Arthur Lee as the technical monitor. 


\section{Table of Contents}

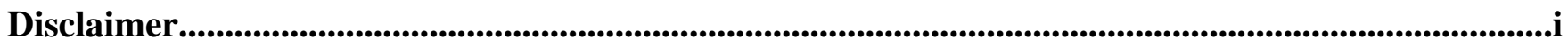

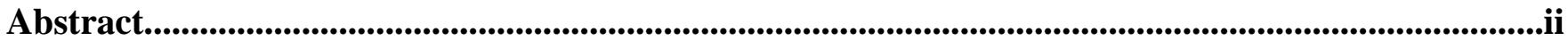

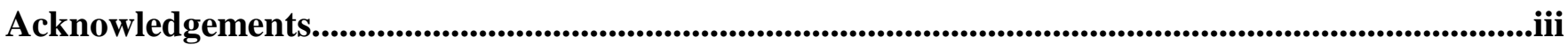

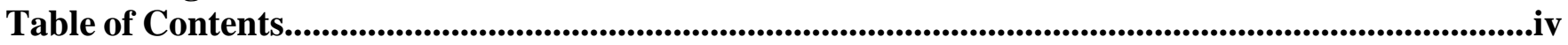

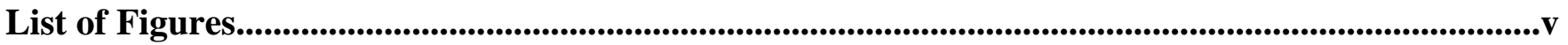

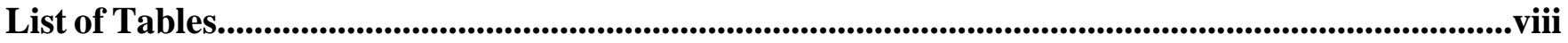

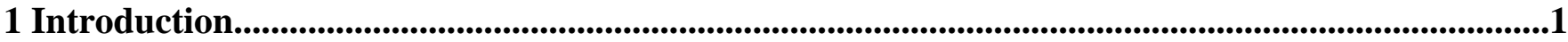

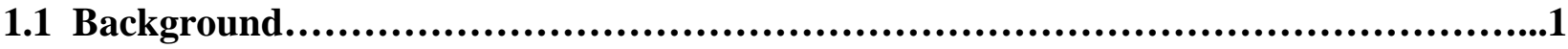

1.2 Research Objectives.............................................................................3

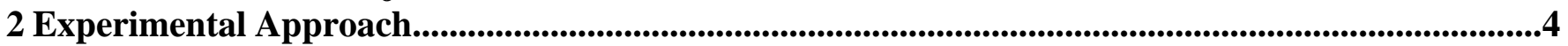

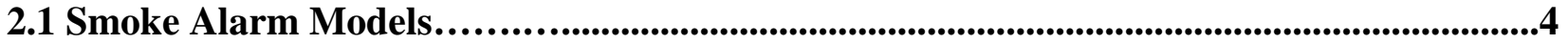

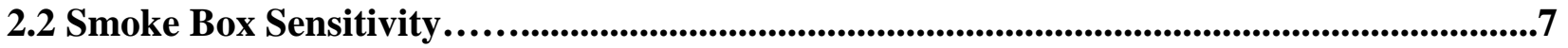

2.3 UL 217 Test Room Experiments..................................................................................10

2.3.1 Flaming Polyurethane Foam..........................................................15

2.2.2 Smoldering Polyurethane.....................................................16

2.2.3 Broiling Hamburgers............................................................18

2.2.4 Frying Hamburger........................................................21

2.2.5 Stir-frying Vegetables...........................................................21

2.2.6 Toasting Bread..................................................................22

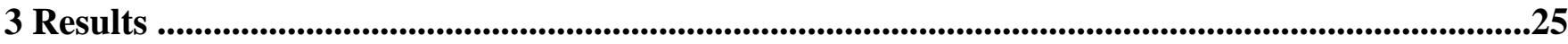

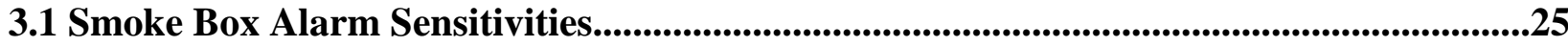

3.2 Test Room Fire and Cooking Source Profiles..................................................................43

3.2.1 Flaming Polyurethane Foam......................................................43

3.2.2 Smoldering Polyurethane Foam.................................................46

3.2.3 Broiling Hamburgers..............................................................52

3.2.4 Frying Hamburger..................................................................56

3.2.5 Stir-frying Vegetables...........................................................59

3.2.6 Toasting Bread................................................................61

3.3 Test Room Alarm Results .....................................................................................62

3.3.1 Ionization Alarm Model Response Results...................................62

3.3.2 Ionization / Photoelectric and Ionization / Carbon Monoxide Combination

Alarm Model Response Results..........................................................................66

3.3.3 Photoelectric Alarm Model Response Results..................................69

3.3.4 Photoelectric / Carbon Monoxide and Photoelectric / Thermal

Combination Alarm Model Response Results.........................................72

4 Analysis of Current Smoke Alarm Performance..................................................76

4.1 Smoke Alarm Performance in the New Fire and Nuisance Tests.........................76

4.2 Smoke Alarm Performance in the Cooking Nuisance Source Tests.........................79

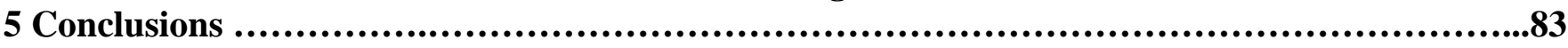

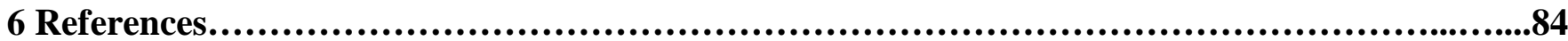




\section{List of Figures}

Figure 1. Schematic diagram of the NIST smoke box.........................................

Figure 2. Photo of the NIST smoke box with the top and side doors open............................8

Figure 3. Beam light transmission versus time for three cotton wick experiments......................9

Figure 4. Beam light transmission versus MIC current for three cotton wick experiments................10

Figure 5. Outside view of test room under the $9.1 \mathrm{~m}$ square hood...................................

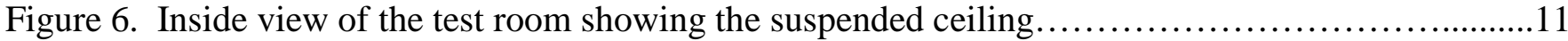

Figure 7. Schematic diagram of the fire test room .............................................13

Figure 8. Schematic diagram of the cooking nuisance test room................................14

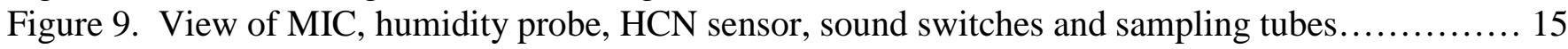

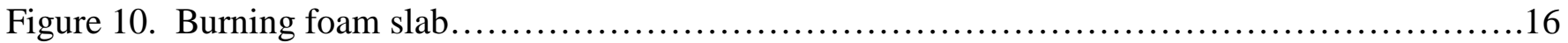

Figure 11. The NIST radiant panel foam smoldering device...................................17

Figure 12. Lit cigarette resting on cotton duck fabric centered on foam sample.......................17

Figure 13. Hamburger patties conforming to the Standard's specifications............................18

Figure 14. Location of the electric range in the cooking nuisance test room...........................19

Figure 15. Frozen hamburger patties on the broiling pan.......................................19

Figure 16. Location of broiling pan inside oven..............................................20

Figure 17. Oven door position during the broiling hamburgers experiments.........................20

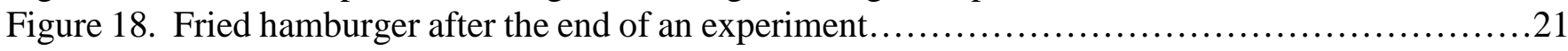

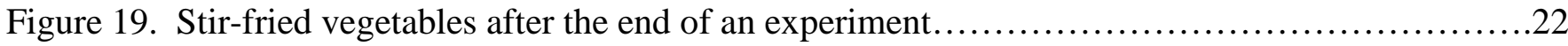

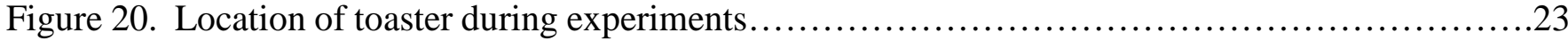

Figure 21. Darker sides of toasted bread after the end of an experiment.............................23

Figure 22. Lighter sides of toasted bread after the end of an experiment.............................24

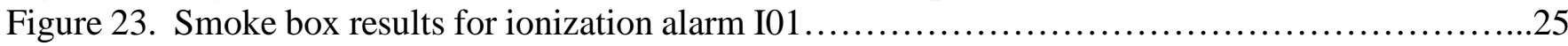

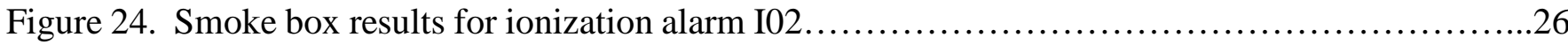

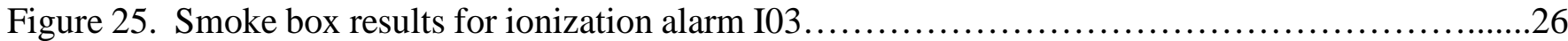

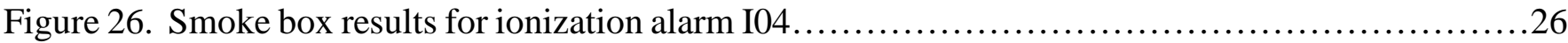

Figure 27. Smoke box results for ionization alarm I05..........................................27

Figure 28. Smoke box results for ionization alarm I06.........................................27

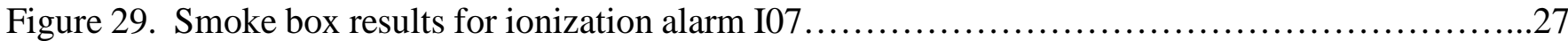

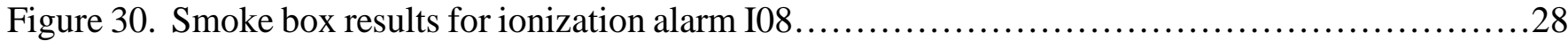

Figure 31. Smoke box results for ionization alarm I09........................................28

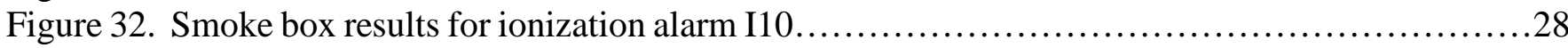

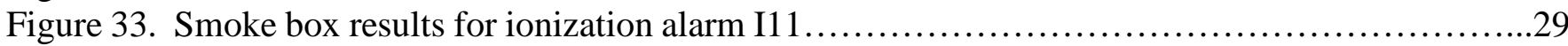

Figure 34. Smoke box results for ionization alarm I12..........................................29

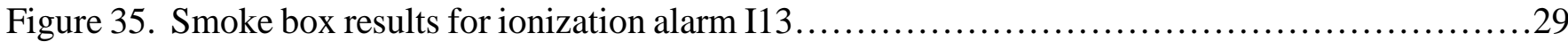

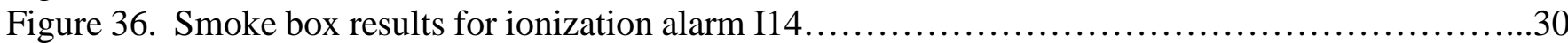

Figure 37. Average MIC current of the ionization alarm model results.............................30

Figure 38. Smoke box results for ionization / carbon monoxide alarm ICO01 .........................31

Figure 39. Smoke box results for ionization / carbon monoxide alarm ICO02 .........................31

Figure 40. Smoke box results for ionization / carbon monoxide alarm ICO03 ...........................31

Figure 41. Smoke box results for ionization / carbon monoxide alarm ICO04 ........................32

Figure 42. Smoke box results for ionization / photoelectric alarm IP01 ..............................32

Figure 43. Smoke box results for ionization / photoelectric alarm IP02 .............................32

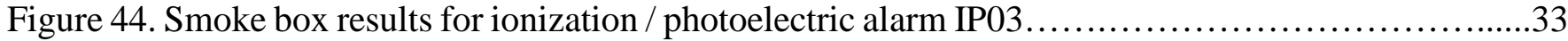

Figure 45. Smoke box results for ionization / photoelectric alarm IP04 ..............................33 


\section{List of Figures cont.}

Figure 46. Average MIC current of the IP and ICO alarm model results............................34

Figure 47. Smoke box results for photoelectric alarm P01 .........................................34

Figure 48. Smoke box results for photoelectric alarm P02 ........................................35

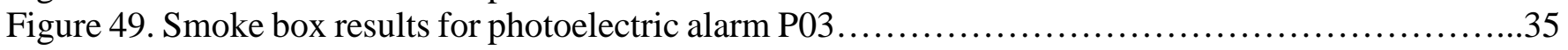

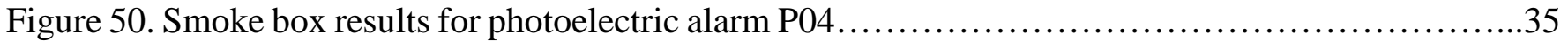

Figure 51. Smoke box results for photoelectric alarm P05 ........................................

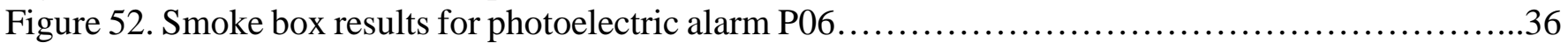

Figure 53. Smoke box results for photoelectric alarm P07 ........................................36

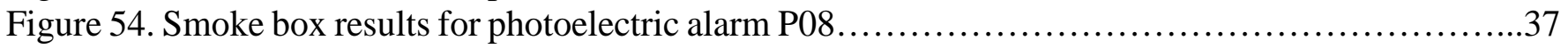

Figure 55. Smoke box results for photoelectric alarm P09.........................................

Figure 56. Smoke box results for photoelectric alarm P10 ........................................

Figure 57. Smoke box results for photoelectric alarm P11 ........................................38

Figure 58. Smoke box results for photoelectric alarm P12.......................................38

Figure 59. Smoke box results for photoelectric alarm P14 ......................................38

Figure 60. Average beam obscuration of the photoelectric alarm model results........................39

Figure 61. Smoke box results for photoelectric / carbon monoxide alarm PCO01.....................40

Figure 62. Smoke box results for photoelectric / carbon monoxide alarm PCO02 ....................40

Figure 63. Smoke box results for photoelectric / carbon monoxide alarm PCO03......................40

Figure 64. Smoke box results for photoelectric / carbon monoxide alarm PCO04......................41

Figure 65. Smoke box results for photoelectric / carbon monoxide alarm PCO05.....................41

Figure 66. Smoke box results for photoelectric / carbon monoxide alarm PCO06.....................41

Figure 67. Smoke box results for photoelectric / carbon monoxide alarm PCO07.....................42

Figure 68. Smoke box results for photoelectric / thermal alarm PT01..............................42

Figure 69. Smoke box results for photoelectric / thermal alarm PT02 .............................42

Figure 70. Average beam obscuration of the PCO and PT alarm model results........................43

Figure 71. Beam light transmission for flaming foam experiments...............................44

Figure 72. Beam light transmission versus MIC current for flaming foam experiments..................44

Figure 73. Temperature and relative humidity for a flaming foam experiment..........................45

Figure 74. Carbon dioxide concentration for a flaming foam experiment............................45

Figure 75. Carbon monoxide and HCN concentration for a flaming foam experiment.................46

Figure 76. Beam light transmission for smoldering foam experiments.............................47

Figure 77. Beam light transmission versus MIC current for smoldering foam experiments...............47

Figure 78. Temperature and relative humidity for a smoldering foam experiment.....................48

Figure 79. Carbon dioxide concentration for a smoldering foam experiment..........................48

Figure 80. Carbon monoxide and HCN concentration for a smoldering foam experiment...............49

Figure 81. Beam light transmission for different smoldering foam initiations.........................50

Figure 82. Beam light transmission versus MIC current for different smoldering foam initiations..........50

Figure 83. Post-experiment view for smoldering initiated by radiant panels...........................51

Figure 84. Post experiment view for smoldering initiated by a cigarette on fabric.....................51

Figure 85. Post experiment view for smoldering initiated by a cigarette on fabric with radiant heating...52

Figure 86. Beam obscuration for broiling hamburgers experiments...............................53

Figure 87. MIC current for broiling hamburgers experiments..................................53

Figure 88. Beam light transmission versus MIC current for broiling hamburgers experiments.............54

Figure 89. Temperature and relative humidity for a broiling hamburger experiment.....................55

Figure 90. Carbon monoxide concentration for a broiling hamburger experiment......................55 


\section{List of Figures cont.}

Figure 91. Power to the oven broiler element during a broiling hamburger experiment.................56

Figure 92. Beam obscuration for frying hamburger experiments...................................56

Figure 93. MIC current for frying hamburger experiments......................................57

Figure 94. Beam obscuration versus MIC current for frying hamburger experiments....................57

Figure 95. Temperature and relative humidity for a frying hamburger experiment......................58

Figure 96. Power to the range top element during a frying hamburger experiment.....................58

Figure 97. Beam obscuration for stir-frying vegetables experiments...............................59

Figure 98. MIC current for stir-frying vegetables experiments.....................................59

Figure 99. Beam obscuration versus MIC current for stir-frying vegetables experiments.................60

Figure 100. Temperature and relative humidity for a stir-frying vegetables experiment................61

Figure 101. MIC current for toasting bread experiments........................................61

Figure 102. Temperature and relative humidity for a toasting bread experiment........................62

Figure 103. Flaming foam test experimental results for ionization alarms...........................63

Figure 104. Smoldering foam test experimental results for ionization alarms........................63

Figure 105. Broiling hamburgers test experimental results for ionization alarms......................64

Figure 106. Frying hamburger experimental results for ionization alarms............................64

Figure 107. Stir-frying vegetables experimental results for ionization alarms.......................65

Figure 108. Toasting bread experimental results for ionization alarms..............................65

Figure 109. Flaming foam test experimental results for IP and ICO alarms..........................66

Figure 110. Smoldering foam test experimental results for IP and ICO alarms.......................667

Figure 111. Broiling hamburgers test experimental results for IP and ICO alarms....................67

Figure 112. Frying hamburger experimental results for IP and ICO alarms.........................68

Figure 113. Stir-frying vegetables experimental results for IP and ICO alarms......................68

Figure 114. Toasting bread experimental results for IP and ICO alarms............................69

Figure 115. Flaming foam test experimental results for photoelectric alarms..........................70

Figure 116. Smoldering foam test experimental results for photoelectric alarms......................70

Figure 117. Broiling hamburgers test experimental results for photoelectric alarms.....................71

Figure 118. Frying hamburger experimental results for photoelectric alarms.........................71

Figure 119. Stir-frying vegetables experimental results for photoelectric alarms......................72

Figure 120. Flaming foam test experimental results for PCO and PT alarms........................73

Figure 121. Smoldering foam test experimental results for PCO and PT alarms.......................73

Figure 122. Broiling hamburgers test experimental results for PCO and PT alarms......................74

Figure 123. Frying hamburger experimental results for PCO and PT alarms...........................74

Figure 124. Stir-frying vegetables experimental results for PCO and PT alarms.......................75

Figure 125. Ceiling smoke obscuration versus time for three cooking scenarios......................80

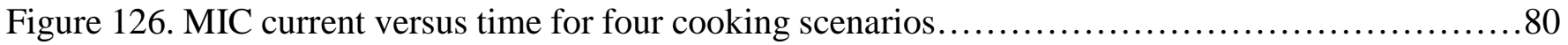

Figure 127. Average beam obscuration for photoelectric alarm models for three cooking scenarios.......81

Figure 128. Average MIC current of ionization alarm models for four cooking scenarios.................82 


\section{List of Tables}

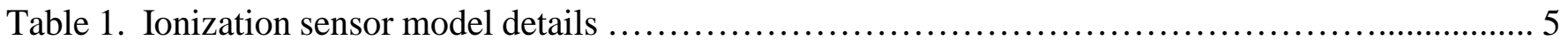

Table 2. Ionization / carbon monoxide sensor model details ........................................ 5

Table 3. Ionization / photoelectric sensor model details ............................................ 5

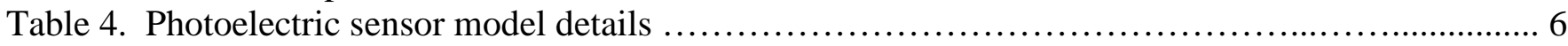

Table 5. Photoelectric / carbon monoxide sensor model details .................................... 6

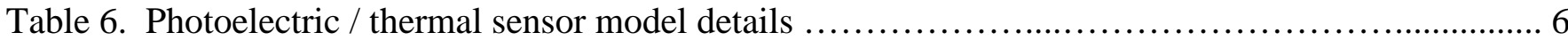

Table 7. Number of experiments where alarms met the threshold limits and the performance ranking at each threshold level for photoelectric, photoelectric / carbon monoxide and photoelectric / thermal sensor models .............................................................77

Table 8. Number of experiments where alarms met the threshold limits and the performance ranking at each threshold level for ionization, ionization / carbon monoxide and ionization /

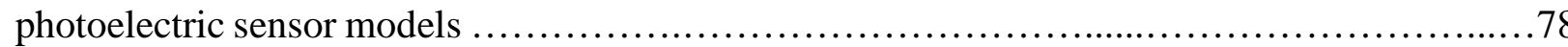




\section{Introduction}

With the adoption of ANSI/UL 217-2015 [1], smoke alarms and detectors subject to that standard will have to pass two new fire tests and a new cooking nuisance test in the near future. These tests were added to address concerns about the efficacy of smoke alarms related to their ability to respond in a timely manner to a wider range of fire sources and their ability to resist responding to common nuisance alarm sources at some level. This introduction describes how the changes in the Standard came about, and the motivation and objectives of this research.

\subsection{Background}

The Home Smoke Alarm Tests project (aka “Dunes II”), conducted by the National Institute of Standards and Technology (NIST) in the early 2000's, documented smoke alarm performance results for flaming and smoldering upholstered furniture and mattress fire experiments and some common nuisance source scenarios [2]. Consistent with previous scientific studies, the general trends from the NIST research showed that properly installed and maintained ionization and photoelectric alarms provided sufficient warning for many fire scenarios to save lives for a large segment of the population. However, ionization alarms typically took much longer to respond to smoldering fires than photoelectric alarms, whilst photoelectric alarms typically took a little longer to respond to flaming fires. This observation is not surprising as each sensing technology has its advantages. This raised a question though; which technology is best? Since it is incrementally beneficial to have more warning of a hazardous fire, especially for more vulnerable populations (such as the elderly and occupants with mobility limitations) and fires may smolder for long times or transition rapidly to flaming or initially start as a flaming fire it is desirable to have the earliest possible alarm response to all fires. These observations led NIST and other fire safety organizations to recommend installing both types of alarms, or combination ionization / photoelectric alarms in residential settings. This recommendation was also made in the 2013 Edition of NFPA 72 National Fire Alarm and Signaling Code which stated: "The use of both technologies generally offers the advantage of providing a faster response to both flaming and smoldering fires, and is recommended for those who desire a higher level of protection than the minimum requirements of this Code” [3]. A preferred solution to identifying then recommending or requiring specific technologies is to require the desired performance levels in the appropriate standard as a technology-independent solution. This would enable innovation in smoke alarm design including use of new and emerging technologies.

After the release of the NIST Home Smoke Alarm Tests report, a task group was formed by the UL 217 Standards Technical Panel to look at adding additional fire tests using common materials. Previous research detailed in the Underwriters Laboratories (UL)-Fire Protection Research Foundation's Smoke Characterization Project, identified differences in the smoke properties of flaming and smoldering fire smokes from polyurethane foam compared to flaming and smoldering fire smokes from the then current UL 217 test fires respectively [4]. The fact that polyurethane foam is a major fuel component in upholstered furniture, and that the smokes from polyurethane foam combustion differed from the smokes in the then current UL 217 fire tests, the task group chose to focus on developing flaming and smoldering polyurethane foam tests in the UL fire test room to complement the existing tests in the Standard.

Researchers at UL led the development of new fire tests consisting of flaming and smoldering polyurethane foam and presented their results to the members of the Standards Technical Panel task 
group as the research progressed. Much debate focused on the need for the addition of both smoldering and flaming polyurethane foam fires and the actual test acceptance criteria. During this time, NIST research was focused on specifying the acceptance criteria for new tests to ensure an enhanced performance level. NIST Technical Note 1837 provided guidance on setting the performance criteria for flaming and smoldering polyurethane test fires to assure improved overall smoke alarm performance in detecting fires [5]. The analysis included the results from full-scale flaming and smoldering fire smoke alarm sensitivity tests conducted by NIST [6] and an available safe egress time analysis methodology applied to the experimental data [7].

Nuisance alarms caused by smoking, cooking and condensed water vapor "shower steam" have been recognized as problematic primarily by inducing occupants to disable or remove offending smoke alarms. The Home Smoke Alarm Tests project included research on smoke alarm activations to common nuisance sources. The results showed instances where both ionization and photoelectric alarms would activate when exposed to normal cooking and smoking activities. The propensity for each type of alarm to activate depended on the specific scenario. The results suggested that nuisance alarms could be substantially reduced by moving the location of an alarm that frequently experiences nuisance alarms well away from cooking appliances while at the same time keeping the alarm within the area to be protected. It was also observed that ionization alarms had a propensity to respond when exposed to nuisance aerosols produced in the early stages of some cooking activities, prior to any noticeable smoke production.

The Consumer Product Safety Commission, CPSC, conducted an experimental study on the frequency and causes of residential cooking nuisance alarms by monitoring several smoke alarms near kitchens in 9 households for 30 days [8]. The results showed a considerable reduction in nuisance alarms as the distance from the cooking appliance increased from $1.5 \mathrm{~m}$ to $6.0 \mathrm{~m}$. While all types of alarms studied (photoelectric, ionization and combination ionization / photoelectric alarms) responded to cooking nuisance sources, combination alarms tended to respond more frequently than photoelectric or ionization alarms. Additionally, certain types of cooking activities like sautéing, pan frying, and stir-frying tended to cause more nuisance alarms than other types of cooking.

These research results led to changes in NFPA 72, The National Fire Alarm and Signaling Code that specifically addressed nuisance alarms in households in the 2010 Edition by specifying alarm location

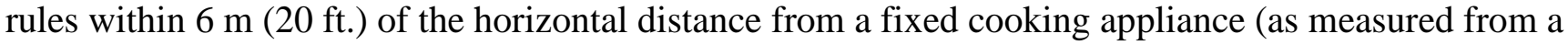
ceiling location above) to the smoke alarm [9]. The 2013 Edition specifically required that smoke alarms in such locations be resistant to cooking nuisance sources by 2016 [10]. This particular requirement did much to push the development of test(s) to determine cooking nuisance alarm resistance. With no product standard in place, the compliance date was updated in the 2016 Edition to 2019 [11].

NIST, with CPSC support, conducted experiments on smoke alarm performance in kitchen fires and nuisance alarm scenarios [12]. Several cooking nuisance scenarios were developed based in the CPSC experimental study [8] including: frying bacon, frying a frozen hamburger, stir-frying vegetables, pan grilling a cheese sandwich, baking a frozen pizza, broiling a frozen hamburger and toasting bread or bagels. The research showed the propensity of an alarm to activate appeared to be a function of the type of alarm, its sensitivity, its distance from the cooking activity and the cooking event itself. For instance, only one specific ionization alarm activated during the six light toasting experiments, while most alarms 
within $4.5 \mathrm{~m}$ of the toaster activated during the six experiments where very dark toast was produced regardless of the sensing technology.

Nuisance test development was initially slower by comparison to the foam fire tests, but the addition of the NFPA 72 nuisance resistance requirement to cooking nuisance alarms led many to argue for the simultaneous addition of new fire and nuisance resistance tests to ANSI/UL 217. The Fire Protection Research Foundation funded a study with industry support to look into developing nuisance source tests for possible adoption into the ANSI/UL 217 Standard which specified a subset of the cooking experiments studied by NIST to be conducted in a room similar to the fire test room specified in ANSI/UL 217-2012. The research was carried out by Jensen Hughes and the report was issued in August 2015[13].

Meanwhile, researchers at UL conducted their own cooking nuisance test research in their fire test room. They also examined a subset of the NIST experiments, and settled on a single cooking nuisance source test that consisted of broiling two hamburgers beneath an electric heating element in a residential range located in a modified ANSI/UL 217-2012 fire test room.

UL submitted a proposed change to ANSI/UL 217-2012 that included adding both flaming and smoldering fire tests, and a cooking nuisance test that consisted of broiling hamburgers. The proposed change reached a consensus of the voting members of the Standards Technical Panel and the new tests were included in ANSI/UL 217-2015 Standard for Smoke Alarms issued in October, 2015. Testing laboratories decide the effective date for implementation whence smoke alarms must meet the new requirements to receive a listing. The effective date is expected to be several years from the Standard's issue date to allow manufacturers time to re-design products.

\subsection{Research Objectives}

During the development of the new test requirements, limited information was gathered on the performance of existing smoke alarms to the new, as then proposed, tests. NIST and CPSC wanted to conduct experiments using the proposed tests to measure the performance of a large number of existing smoke alarms. This was motivated by a desire to more fully understand the degree of performance enhancement that might be realized by a complete change in smoke alarm design due to adding new tests to the standard. Prior to the start of this research project, the proposed tests were adopted in ANSI-UL 217-2015.

The objective of the research detailed in this study is:

To gather data for a snapshot of current smoke alarm models on their performance to new ANSI/UL 2172015 tests and additional cooking scenarios, and analyze the data to answer the questions:

To what extent will the new tests challenge current smoke alarm designs?

What is the potential performance enhancement of new smoke alarm designs?

How adequate is a single nuisance source test in representing a broad range of cooking activities? 


\section{Experimental Approach}

The experimental approach was to gather a wide range of currently available smoke alarms representing a range of designs and sensing technologies, test each alarm's sensitivity in the smoke box, and use the alarms in full-scale ANSI/UL 217 test room experiments. The room experiments consisted of the new flaming and smoldering polyurethane foam fire tests and the new broiling hamburgers cooking nuisance test along with additional cooking nuisance tests: frying hamburger, stir-frying vegetables and toasting bread.

Additionally, data was gathered on the particle size distribution and light scattering characteristics of smoke and aerosol samples collected at the smoke alarm installation location for the fire and cooking nuisance sources, and a limited number of other fire tests conducted in the test room. This data is not included in this report but will be presented in a separate publication.

\subsection{Smoke Alarm Models}

An important aspect of this study is to survey a wide-range of smoke alarms representing the current technologies available. No individual alarms nor manufacturers are identified; NIST does not conduct such product testing. The smoke alarms examined here included 45 separate models from seven manufacturers. Two smoke alarm models were new un-used smoke alarms purchased in 2008 and 43 models were purchased from retail establishments from November 2015 through January 2016. Fourteen models contained ionization sensors, 14 models contained photoelectric sensors, four models contained both ionization and photoelectric sensors, seven models contained photoelectric and carbon monoxide sensors, four models contained ionization and carbon monoxide sensors and two models contained photoelectric and thermal sensors. Some of the alarms with carbon monoxide sensors apparently used the carbon monoxide sensor in determining the smoke alarm response, while others used the sensor for a separate carbon monoxide alarm function. Of the 45 models, 16 were powered by $120 \mathrm{~V}$ AC with battery back-up and the remaining 29 models were battery powered including 10-year battery powered models. The specific battery power used was not identified to maintain model anonymity. Six units of each model were acquired for the study, thus a total of 270 smoke alarms were used in the experiments. Six full-scale experiments were conducted in triplicate and each smoke alarm unit was exposed to only three repeated full-scale experiments.

The smoke alarms are identified in terms of sensing technologies, power source, month and year of manufacture and any indication an accompanying user's guide of “intelligence” such as implying signal processing or combining of sensor outputs to modify the alarm's sensitivity from a single fixed singlesensor sensitivity. Tables 1-6 show the identifying codes used in this report and various details of each particular model. 
Table 1. Ionization sensor model details

\begin{tabular}{|c|c|c|c|}
\hline Model ID Code & $\begin{array}{c}\text { Month, Year of } \\
\text { Manufacture }\end{array}$ & Power Source & Intelligent Alarm \\
\hline I01 & May, 2008 & Battery & no \\
\hline I02 & October, 2015 & Battery & no \\
\hline I03 & April, 2015 & Battery & no \\
\hline I04 & September, 2015 & Battery & yes \\
\hline I05 & July 2015 & 120 V AC plus battery backup & no \\
\hline I06 & December, 2014 & Battery & no \\
\hline I07 & July, 2015 & no \\
\hline I08 & July, 2015 & 120 V AC plus battery backup & no \\
\hline I09 & July, 2015 & 120 V AC plus battery backup & no \\
\hline I10 & July, 2015 & 120 V AC plus battery backup & no \\
\hline I11 & May, 2015 & 120 V AC plus battery backup & yes \\
\hline I12 & December, 2013 & Battery & yes \\
\hline I13 & December, 2014 & 120 V AC plus battery backup & Battery \\
\hline I14 & May, 2015 & & \\
\hline & & & \\
\hline
\end{tabular}

Table 2. Ionization / carbon monoxide model details

\begin{tabular}{|c|c|c|c|}
\hline Model ID Code & $\begin{array}{c}\text { Month/Year of } \\
\text { Manufacture }\end{array}$ & Power Source & Intelligent Alarm \\
\hline ICO01 & October, 2015 & Battery & yes \\
\hline ICO02 & June, 2014 & 120 V AC plus battery backup & no \\
\hline ICO03 & April, 2012 & Battery & yes \\
\hline ICO04 & August, 2015 & 120 V AC plus battery backup & no \\
\hline
\end{tabular}

Table 3. Ionization / photoelectric model details

\begin{tabular}{|c|c|c|c|}
\hline Model ID Code & $\begin{array}{c}\text { Month/Year of } \\
\text { Manufacture }\end{array}$ & Power Source & Intelligent Alarm \\
\hline PI01 & April, 2015 & Battery & no \\
\hline PI02 & September, 2015 & Battery & no \\
\hline PI03 & August, 2014 & Battery & no \\
\hline PI04 & May, 2015 & 120 V AC plus battery backup & \\
\hline
\end{tabular}


Table 4. Photoelectric sensor model details

\begin{tabular}{|c|c|c|c|}
\hline Model ID Code & $\begin{array}{c}\text { Month/Year of } \\
\text { Manufacture }\end{array}$ & Power Source & Intelligent Alarm \\
\hline P01 & July, 2015 & Battery & no \\
\hline P02 & November, 2014 & Battery & no \\
\hline P03 & February, 2015 & 120 V AC plus battery backup & no \\
\hline P04 & August, 2015 & Battery & no \\
\hline P05 & July, 2015 & Battery & no \\
\hline P06 & October, 2015 & 120 V AC plus battery backup & no \\
\hline P07 & January, 2016 & 120 V AC plus battery backup & no \\
\hline P08 & April, 2015 & Battery & no \\
\hline P09 & January, 2016 & 120 V AC plus battery backup & no \\
\hline P10 & May, 2015 & Battery & no \\
\hline P11 & July, 2012 & Battery & no \\
\hline P12 & October, 2007 & Battery & no \\
\hline P13 & Not dated & Battery & no \\
\hline P14 & Not dated & Battery & \\
\hline
\end{tabular}

Table 5. Photoelectric / carbon monoxide sensor models

\begin{tabular}{|c|c|c|c|}
\hline Model ID Code & $\begin{array}{c}\text { Month/Year of } \\
\text { Manufacture }\end{array}$ & Power Source & Intelligent Alarm \\
\hline PCO01 & September, 2015 & Battery & no \\
\hline PCO02 & April, 2015 & Battery & no \\
\hline PCO03 & November, 2015 & Battery & no \\
\hline PCO04 & October, 2015 & 120 V AC plus battery backup & no \\
\hline PCO05 & October, 2013 & Battery & no \\
\hline PCO06 & September, 2015 & Battery & yes \\
\hline PCO07 & January, 2016 & 120 V AC plus battery backup & no \\
\hline
\end{tabular}

Table 6. Photoelectric / thermal sensor model details

\begin{tabular}{|c|c|c|c|}
\hline Model ID Code & $\begin{array}{c}\text { Month/Year of } \\
\text { Manufacture }\end{array}$ & Power Source & Intelligent Alarm \\
\hline PT01 & Not dated & Battery & no \\
\hline PT02 & November, 2015 & 120 V AC plus battery backup & no \\
\hline
\end{tabular}




\subsection{Smoke Box Sensitivity}

ANSI/UL 217-2012 requires listed smoke alarms to be tested in a smoke box that re-circulates smoldering cotton wick smoke or an equivalent smoke-like aerosol source. Measurements include the level of smoke obscuration and the response of a reference measuring ionization chamber (MIC). Smoke alarms listed to the standard must respond to the smoke within a specified range of the measured values. For obscuration the range is $0.50 \% / \mathrm{ft}(1.63 \% / \mathrm{m})$ to $4.00 \% / \mathrm{ft}(12.53 \% / \mathrm{m})$. Throughout the this report the units of obscuration are reported in English units of \%/ft as is industry practice in the United States. For the MIC, the range is $93 \mathrm{pA}$ to $37.5 \mathrm{pA}$ where the initial clean-air MIC current is adjusted to $100 \mathrm{pA}$. NIST constructed a smoke box to the specifications given in ANSI/UL 217-2012. A new measuring ionization chamber for use in this study was purchased in 2015, and was first used in the smoke box sensitivity testing and then in the full-scale room experiments. A schematic drawing of the smoke box is shown in Figure 1 and pictures of the device in Figure 2.

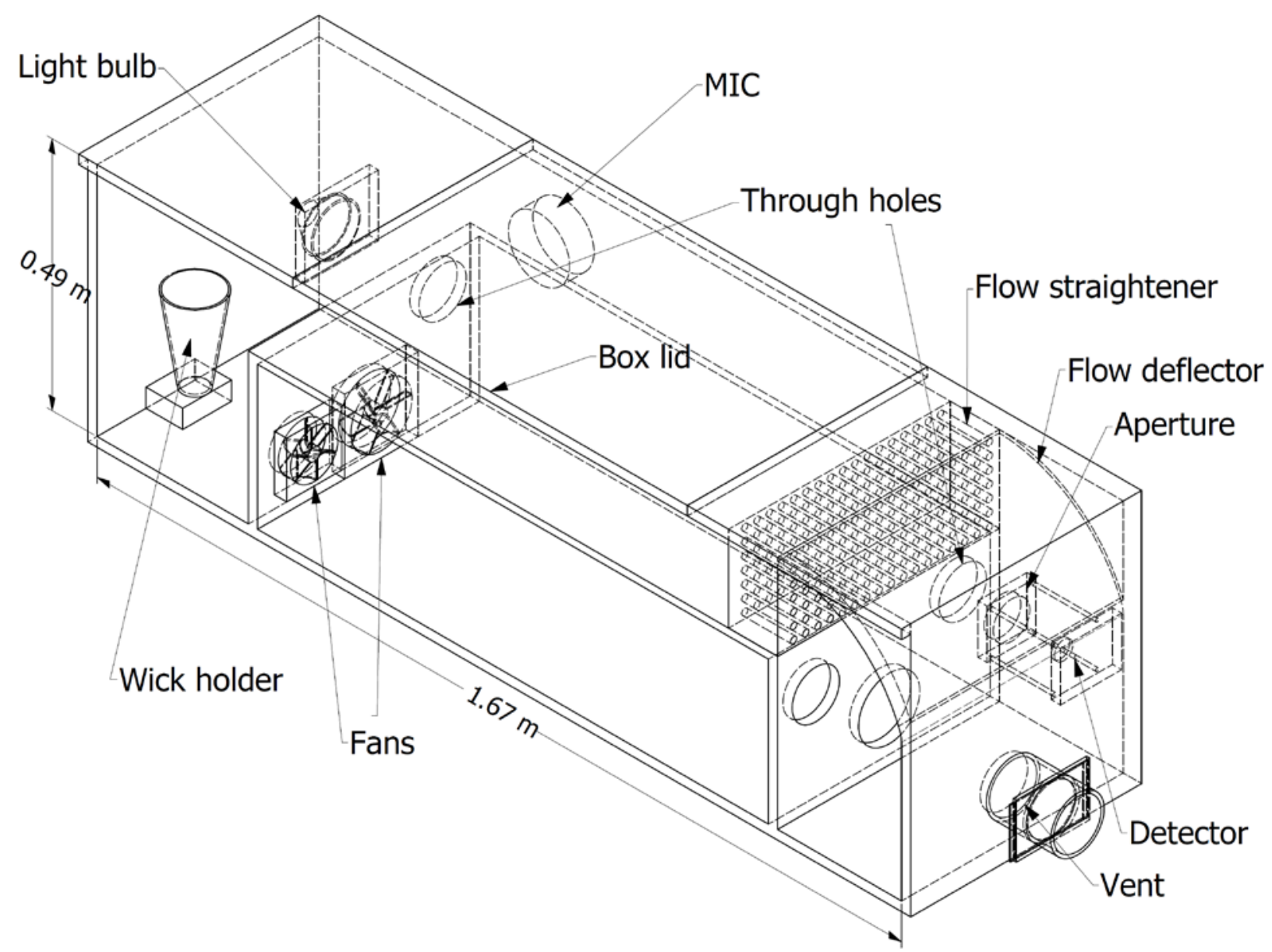

Figure 1. Schematic diagram of the NIST smoke box. 

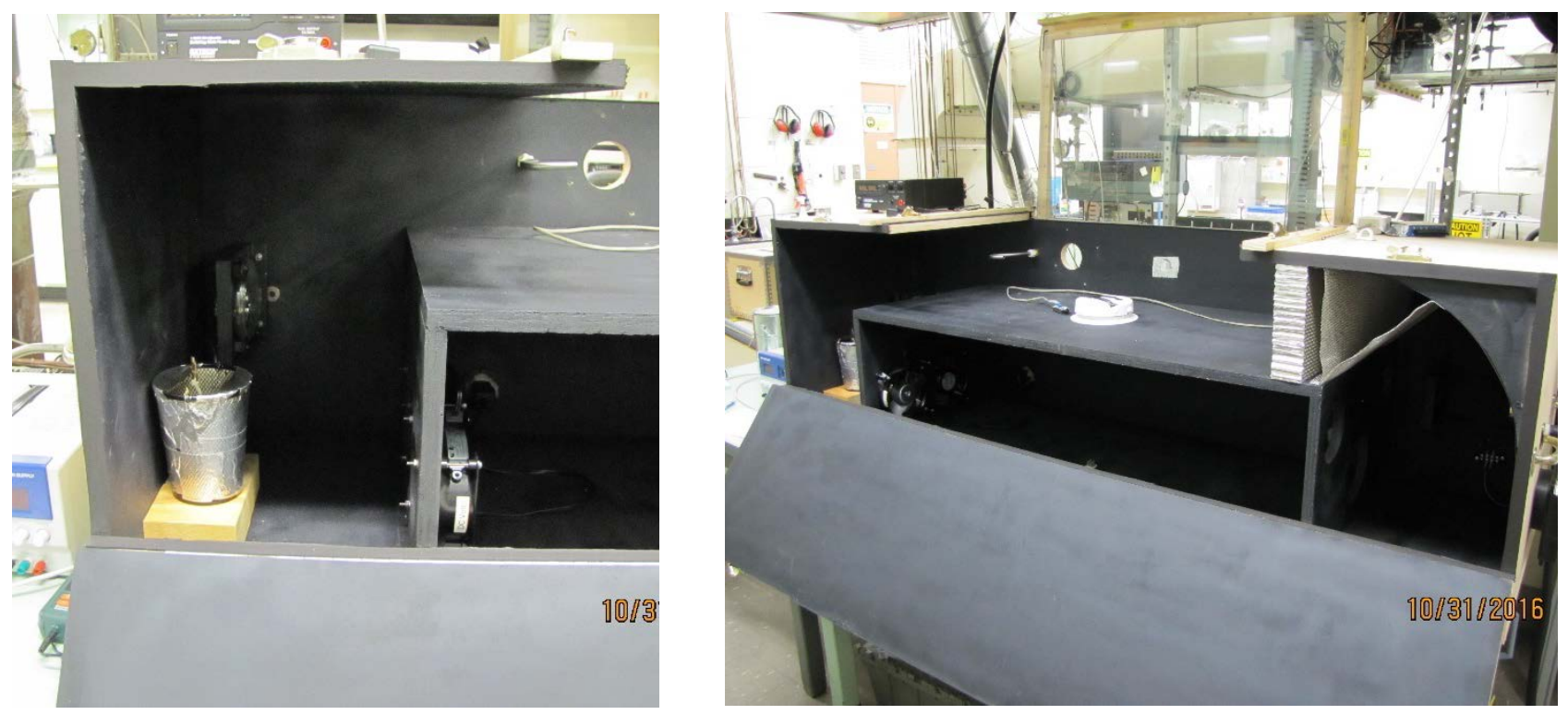

Figure 2. Photos of the NIST smoke box with the top and side doors open.

The flow velocity was fixed at nominally at $0.16 \mathrm{~m} / \mathrm{s} \pm 0.01 \mathrm{~m} / \mathrm{s}$ (32 fpm $\pm 2 \mathrm{fpm}$ ) as specified in the Standard and verified prior to each smoke box test with a thermal anemometer. The MIC was adjusted to a flow rate of $25 \mathrm{l} / \mathrm{min} \pm 5 \mathrm{l} / \mathrm{min}$ and its current output adjusted to $100 \mathrm{pA}$. The combined standard uncertainty $\left(\mathrm{u}_{\mathrm{c}}(\mathrm{y})\right)$ in the MIC current is estimated as $0.2 \mathrm{pA}$. The MIC response is traceable to the reference MIC output maintained by the manufacturer, Delta, Hørsholm Denmark for every MIC produced. They are the only commercial manufacturer of MICs worldwide. The smoke box light extinction was calibrated against neutral density, optical gelatin Wratten filters with optical densities (OD) of $0.1,0.2$ and 0.5 corresponding to light transmissions of $79.4 \%, 63.1 \%$ and $31.6 \%$, and obscurations of $14.0 \% / \mathrm{m}(4.5 \% / \mathrm{ft}), 26.1 \% / \mathrm{m}(8.8 \% / \mathrm{ft})$ and $53.1 \% / \mathrm{m}(20.6 \% / \mathrm{ft})$ respectively. The recorded light transmission values fluctuated approximately $0.5 \%$ or less about the mean value including the no filter light transmission readings. The percent differences between the mean measured and computed transmissions was $0.5 \%, 1.0 \%$, and $1.9 \%$ or less for the three filters 0.1 OD, 0.2 OD and 0.3 OD respectively. The relative combined standard uncertainty $\left(\mathrm{u}_{\mathrm{c}, \mathrm{r}}(\mathrm{y})\right)$ for light transmission for the three increasing optical densities was estimated as $1.0 \%$, $2.0 \%$ and $3.7 \%$ using a coverage factor of 2. Fitting the uncertainties against (100 - \% light transmission) with a straight line yields an equation for the relative combined standard uncertainty of $\mathrm{u}_{\mathrm{c}, \mathrm{r}}(\mathrm{y})=0.054 \times(100$-light transmission \%). In terms of obscuration $(\% / \mathrm{ft})$ the relative combined standard uncertainty was $4.0 \%$ or less. The relative combined standard uncertainty of the obscuration meter as installed in the fire test room was the same.

Wicks were dried in an oven at $45{ }^{\circ} \mathrm{C}$ for $72 \mathrm{~h}$ then stored in a desiccant jar at room temperature until used for a test. Before the ignition of the cotton wick, the ambient temperature, atmospheric pressure and relative humidity in the laboratory were recorded. The wick was allowed to smolder for $30 \mathrm{~s}$ before placing in the smoke box.

Prior to testing, smoke alarms were powered from their primary power source for at least 24 h. Every smoke alarm was tested in its worst-case orientation in the smoke box to establish a sensitivity level to the cotton smolder smoke. The worst-case orientation was defined by the angular position of the alarm 
where the smoke sensor was opposite from the incoming smoke direction. For the photoelectric / ionization dual alarms, the angular position that put the both sensors equally as far from the incoming smoke direction was chosen. For one alarm with a centered smoke sensor, a fixed orientation was used for every unit of that model tested. A single unit of each model was tested in the worst-case orientation two more times, then tested once with the smoke box flow velocity increased by a factor of two and finally tested in the best-case orientation (rotated $180^{\circ}$ ).

Several trial runs were conducted to fix the smoldering smoke conditions to meet the bounding conditions of a valid smoke box experiment as given in ANSI/UL 217. The approximate conditions are shown in Figure 3 and 4 . The results of three smoldering wick experiments without smoke alarms present are shown along with the bounding curves. Each valid smoke box experiment produced conditions that fall within the boundary of the curves shown. Tests were terminated after the smoke alarm under test responded, or after the wick was completely consumed.

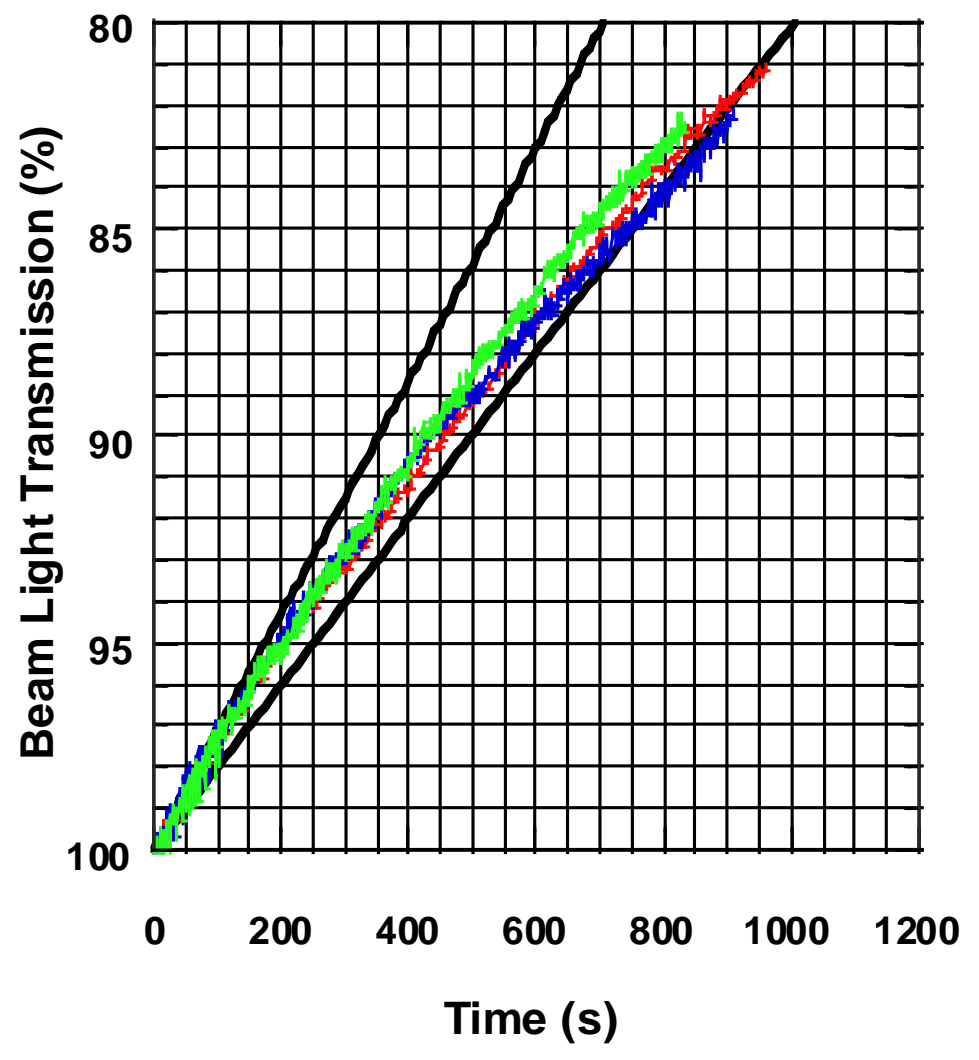

Figure 3. Beam light transmission versus time for three cotton wick experiments. Thick lines are the upper and lower bounds from the Standard, thin lines are experimental results. $\mathrm{u}_{\mathrm{c}, \mathrm{r}}($ beam $)=0.054 \times(100-$ light transmission \%) \%. 


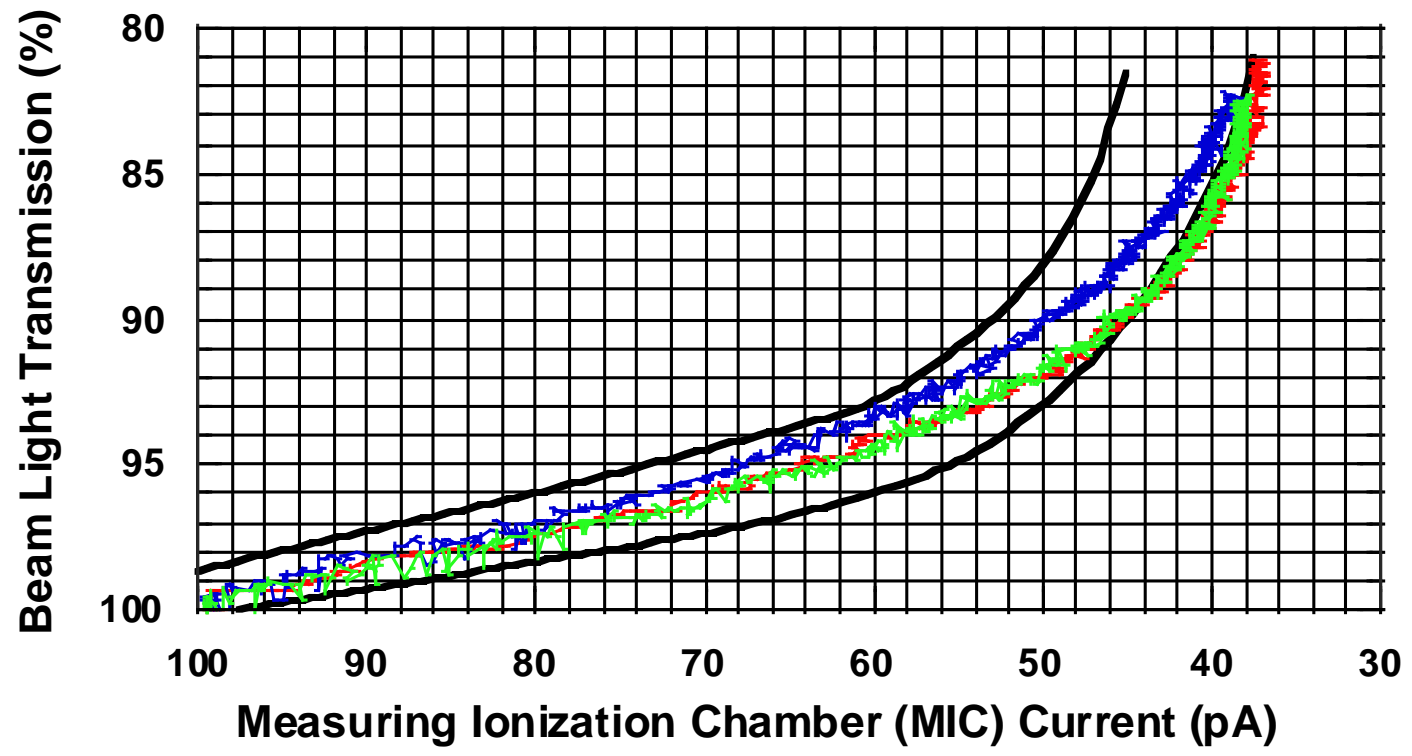

Figure 4. Beam light transmission versus MIC current for three cotton wick experiments. Thick curves are the bounding curves from the Standard, thin lines are experimental results. $\mathrm{u}_{\mathrm{c}}(\mathrm{MIC})=0.2 \mathrm{pA}$.

\subsection{UL 217 Room Experiments}

NIST constructed a test room that met the physical dimensions of the test room described in ANSI/UL 217. The overall room dimensions were $10.8 \mathrm{~m}$ by $7.32 \mathrm{~m}$ by $3.66 \mathrm{~m}$ high room with a single layer of 13 $\mathrm{mm}$ thick ( 0.5 inch) gypsum wall board on the walls and ceiling finished by taping and mudding joints with joint compound. The floor was plywood with a cover of $6 \mathrm{~mm}$ thick non-combustible cement board. The ceiling floor and long walls were supported by a rigid metal frame used in previous NIST studies. End walls framed with doors on both sides were attached to the structure to form the enclosure. This room was modified to meet the dimensions in the Standard for both the fire tests and the cooking nuisance test. The fire test room configuration included an additional wall lengthwise to reduce the

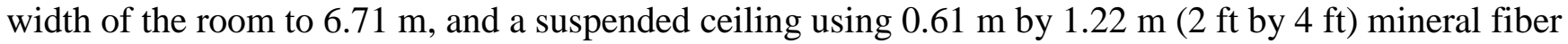
acoustic tiles to a height of $3.05 \mathrm{~m}$. The cooking nuisance test room configuration added a wall to reduce the overall length from $10.8 \mathrm{~m}$ to $9.2 \mathrm{~m}$. Pictures of the test room are shown in Figures 5 and 6. Two exterior weather-stripped doors located opposite each other on the $6.71 \mathrm{~m}$ long wall were used for access and venting after the end of a test. The room was lit by four $1.2 \mathrm{~m}$ long LED light fixtures equally spaced along a long wall approximately $2.1 \mathrm{~m}$ above the floor. All experiments were conducted with these lights off. 


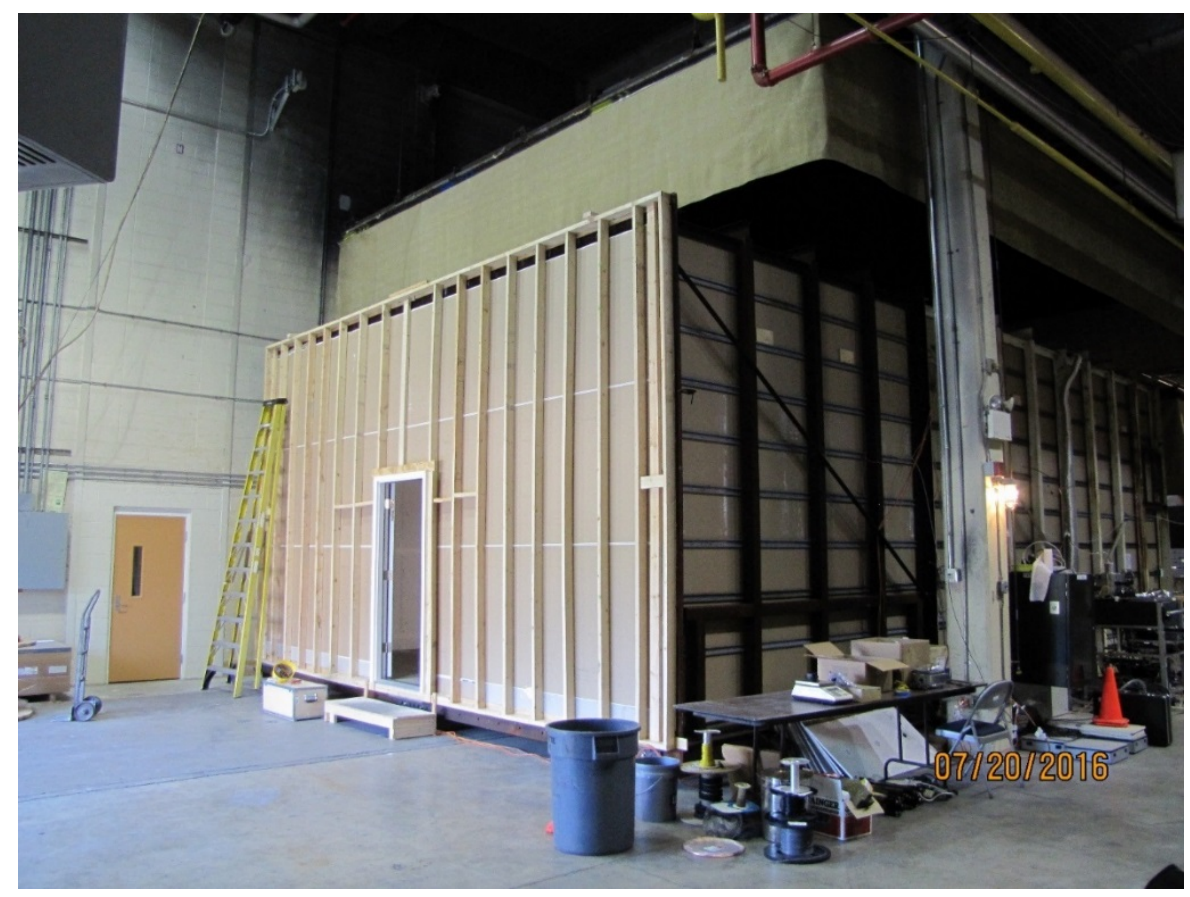

Figure 5. Outside view of test room under the $9.1 \mathrm{~m}$ square hood.

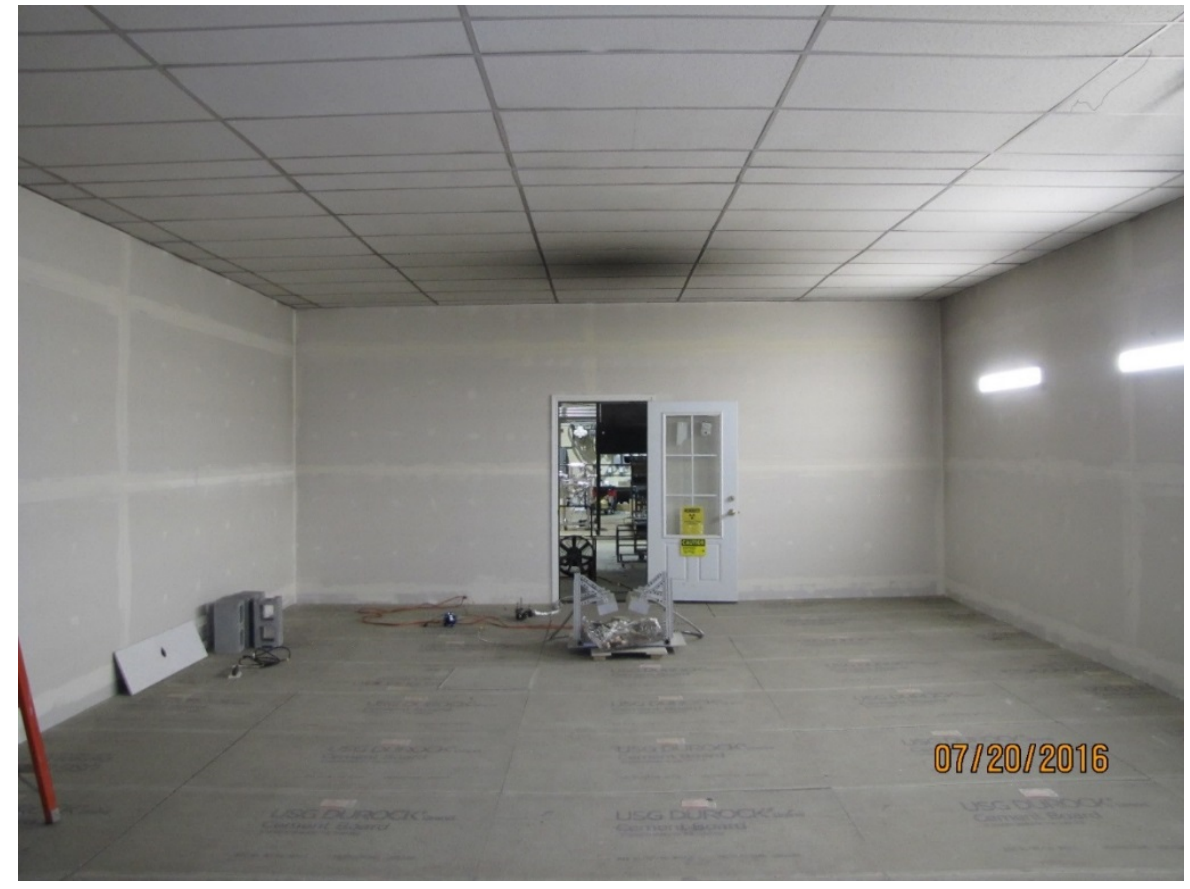

Figure 6. Inside view of the test room showing the suspended ceiling. 
Schematics of the fire test room configuration and cooking nuisance room configuration are shown in Figures 7 and 8. The schematics include the location of measurement devices and alarms. The room was instrumented as specified in the Standard. A light source and photocell $1.52 \mathrm{~m}$ apart and approximately $10 \mathrm{~cm}$ from the ceiling recorded the ceiling beam obscuration. The MIC is located behind the beam along the room width centerline. Additional instrumentation was installed at the ceiling location included a humidity / temperature probe, a hydrogen cyanide sensor, sampling line for carbon monoxide / carbon dioxide analyzer, thermocouples extending $2.5 \mathrm{~cm}$ below the ceiling, and a sampling line for aerosol measurements (Figure 9). The combined standard uncertainty for the relative humidity measurement was estimated at $\mathrm{u}_{\mathrm{c}}(\mathrm{RH})=5.0 \%$. The combined standard uncertainty for the thermistor which is part of the humidity probe and the thermocouples was estimated at $\mathrm{u}_{\mathrm{c}}(\mathrm{T})=1.0{ }^{\circ} \mathrm{C}$. The combined standard uncertainty for the hydrogen cyanide, carbon monoxide, and carbon dioxide concentration measurements were estimated at $\mathrm{u}_{\mathrm{c}}(\mathrm{HCN})=0.1 \mathrm{ppm}$ vol, $\mathrm{u}_{\mathrm{c}}(\mathrm{CO})=2 \mathrm{ppm}$ vol and $\mathrm{u}_{\mathrm{c}}(\mathrm{CO} 2)=0.005 \%$ vol respectively.

Smoke alarms were mounted to acoustic tiles in groups of three spaced as shown in Figure 9. They were individually orientated such that the best and worst case orientation axis aligned with the long axis of the room. Three tiles were installed side by side (left, center, right) so nine smoke alarms were monitored during each experiment. For fire experiments, the tiles were installed in the worst case orientation relative to the fire source location, and for cooking nuisance experiments they were installed in the best case orientation relative to the cooking appliance location. Over each of the three repeated fire or cooking nuisance experiments the ceiling tiles with smoke alarms exchanged locations so that each one occupied the left, center and right location during one of the experiments.

Smoke alarm response was monitored acoustically and visibly. First sound level activated switches were used to monitor the sound output from each of the nine smoke alarms installed in every experiment. The switches change from a low voltage level to a high level if the sound reaching the microphone is above a preset level. The sound from each smoke alarm was carried back to the sound switches via flexible plastic tube (Figure 9). The sound level was adjusted such that the switch changed to an output level of high when the smoke alarm it was monitoring was sounding. This technique worked well when monitoring one smoke alarm in the smoke box, but during the full-scale room experiments crosstalk between the sound switches led to less than $100 \%$ reliability in determining alarm response. As a confirmatory measurement, digital video cameras were pointed at the smoke alarms (one camera for every three adjacent alarms) to determine when the LED indicated alarm response if the alarm had one installed. In cases where no alarm was recorded audibly or crosstalk was suspected, a review of the video record confirmed the state of a particular alarm. 


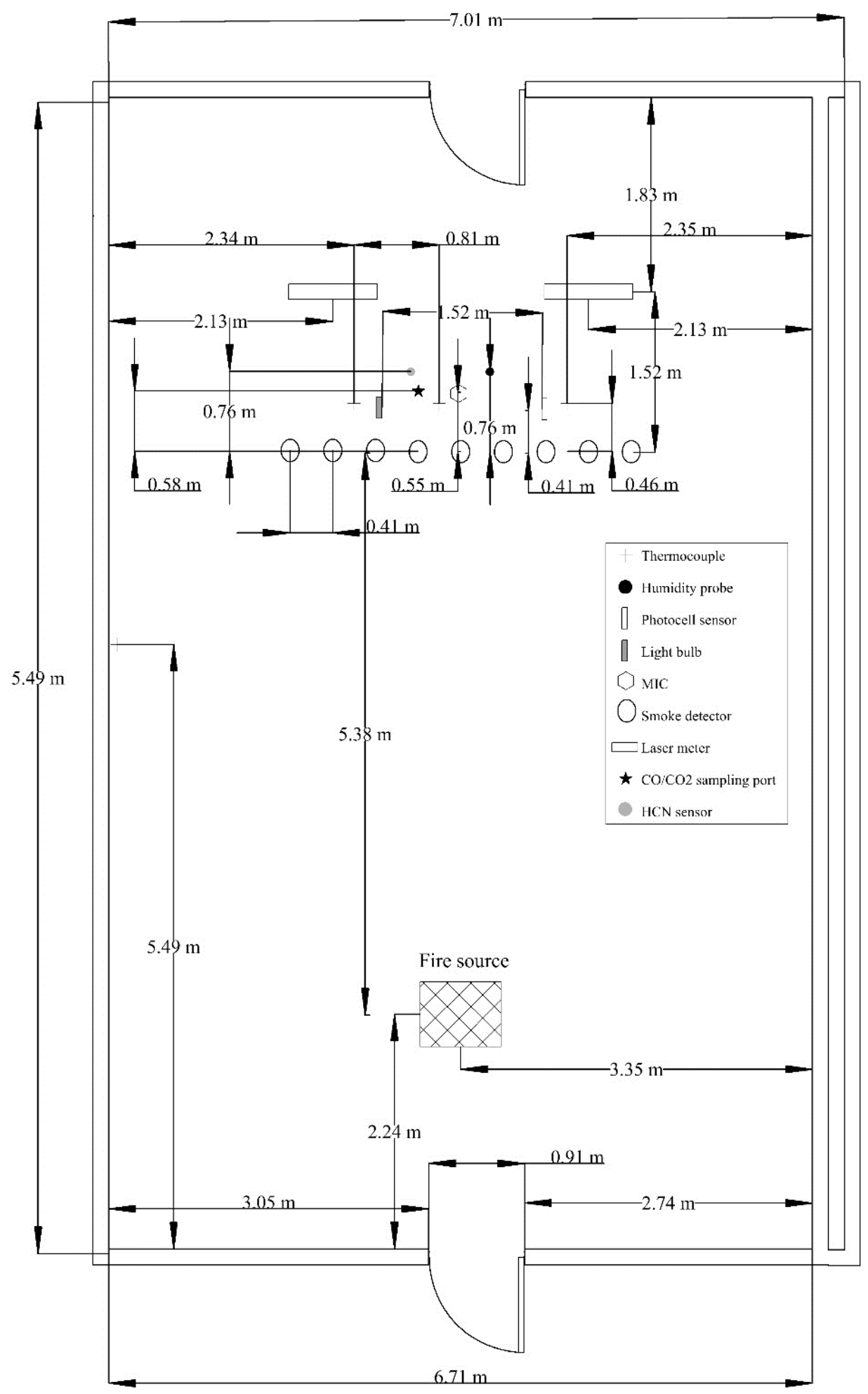

Figure 7. Schematic diagram of the fire test room. 


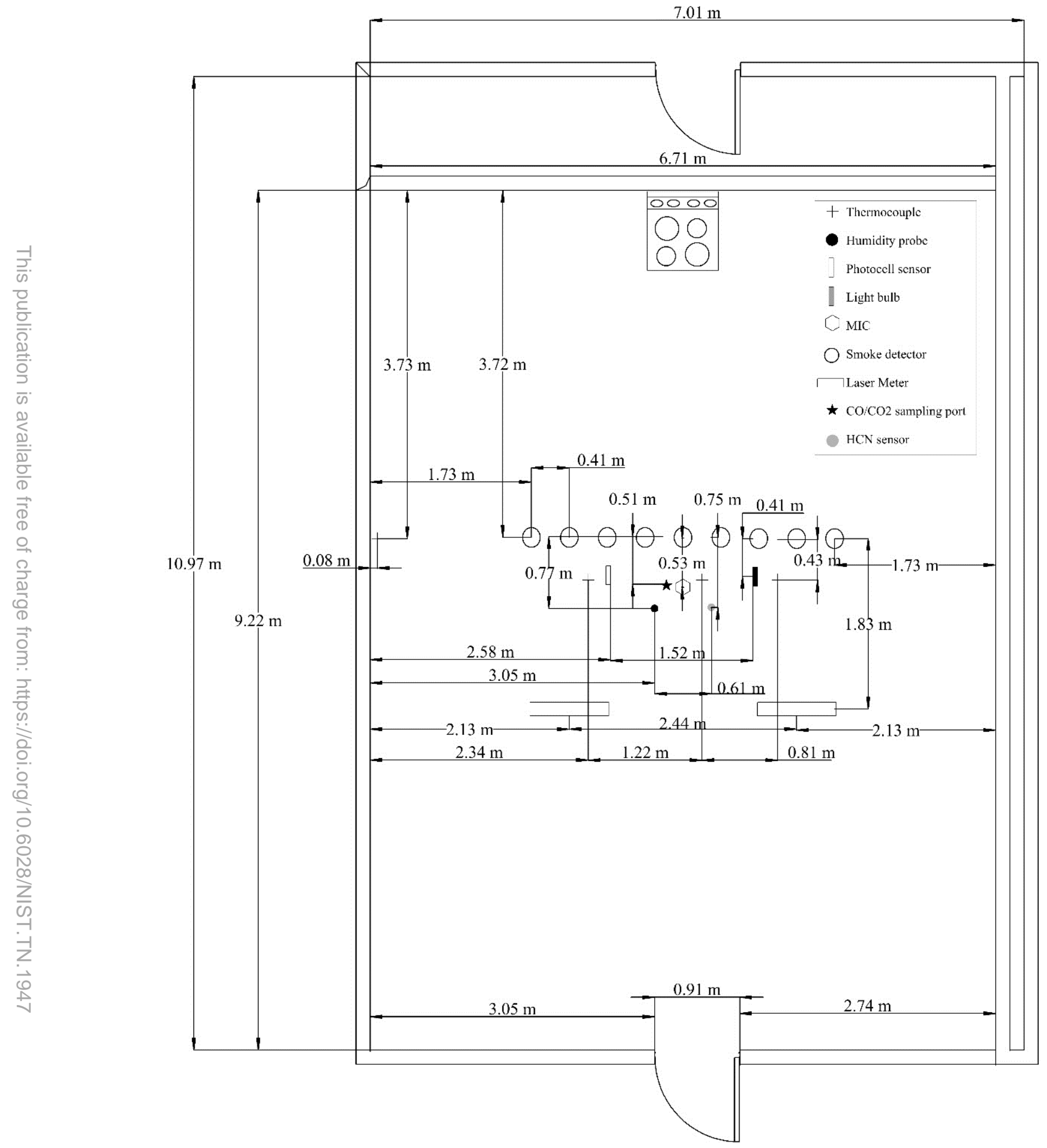

Figure 8. Schematic diagram of the cooking nuisance test room. 

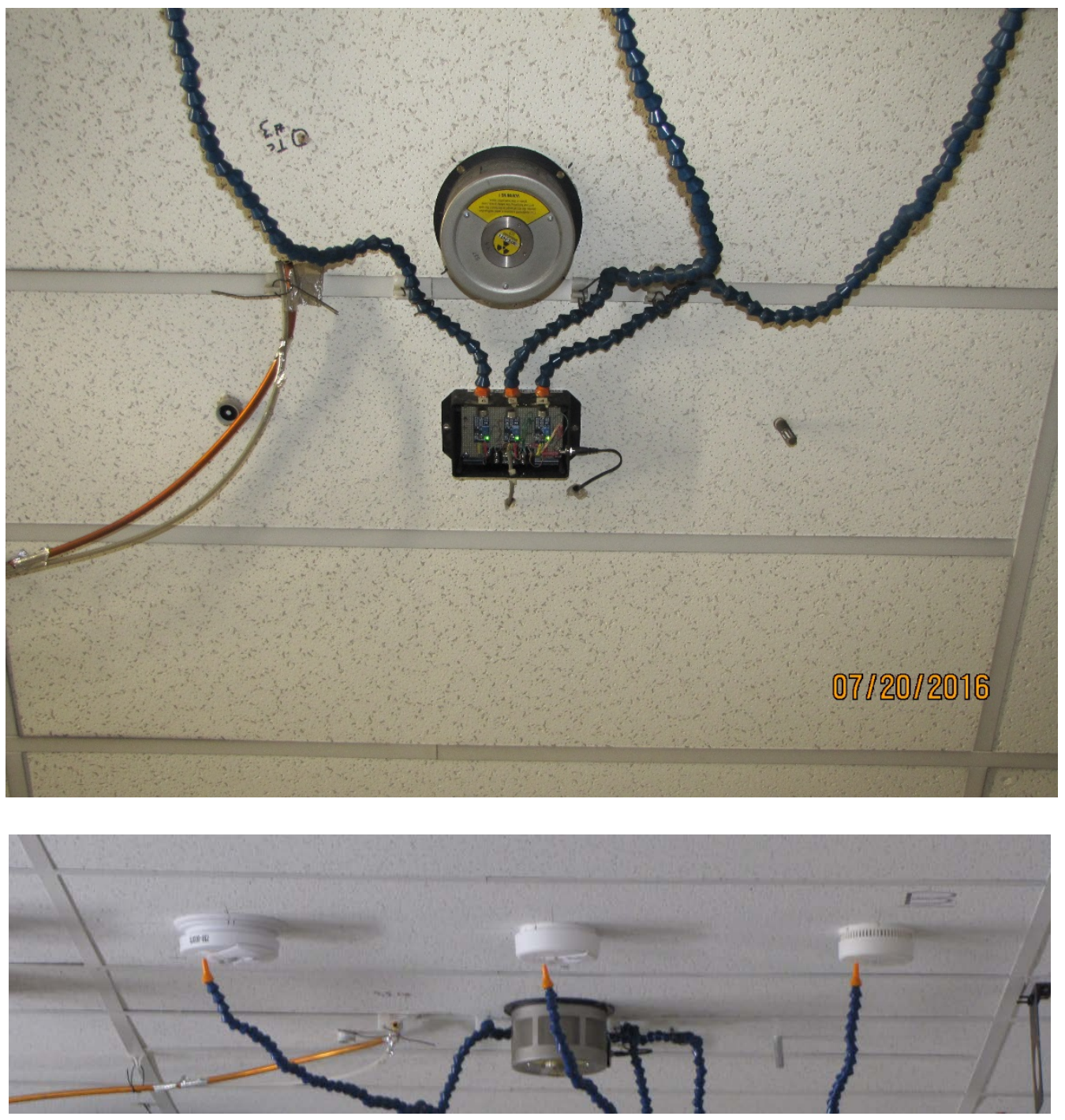

Figure 9. Views of MIC, humidity probe, HCN sensor, sound switches and sampling tubes.

\subsubsection{Flaming Polyurethane Foam Experimental Conditions}

Foam slabs for the flaming and smoldering experiments meeting the specifications in the Standard were procured from the same vendor that supplies Intertek Inc., a nationally recognized testing laboratory (NRTL) that lists smoke alarms to ANSI/UL 217 in the U.S. NIST did not perform confirmatory tests in a cone calorimeter to verify the combustion properties as specified in the Standard. The flaming polyurethane foam experiments were conducted in the manner described in ANSI/UL 217-2015. The foam slabs were non-fire-retarded polyether urethane foam material $43.2 \mathrm{~cm}$ by $36.8 \mathrm{~cm}$ by $7.6 \mathrm{~cm}$. In the fire tests, the foam slab was located on the test room floor at the location marked "fire" on the schematic drawing. Just prior to ignition with a torch, $5 \mathrm{ml}$ of ethanol was poured onto the corner top surface to aid ignition. 
Figure 10 shows a burning foam slab ignited in a corner under a calorimeter hood next to the fire test room. The entire foam slab is consumed by the end of the test.

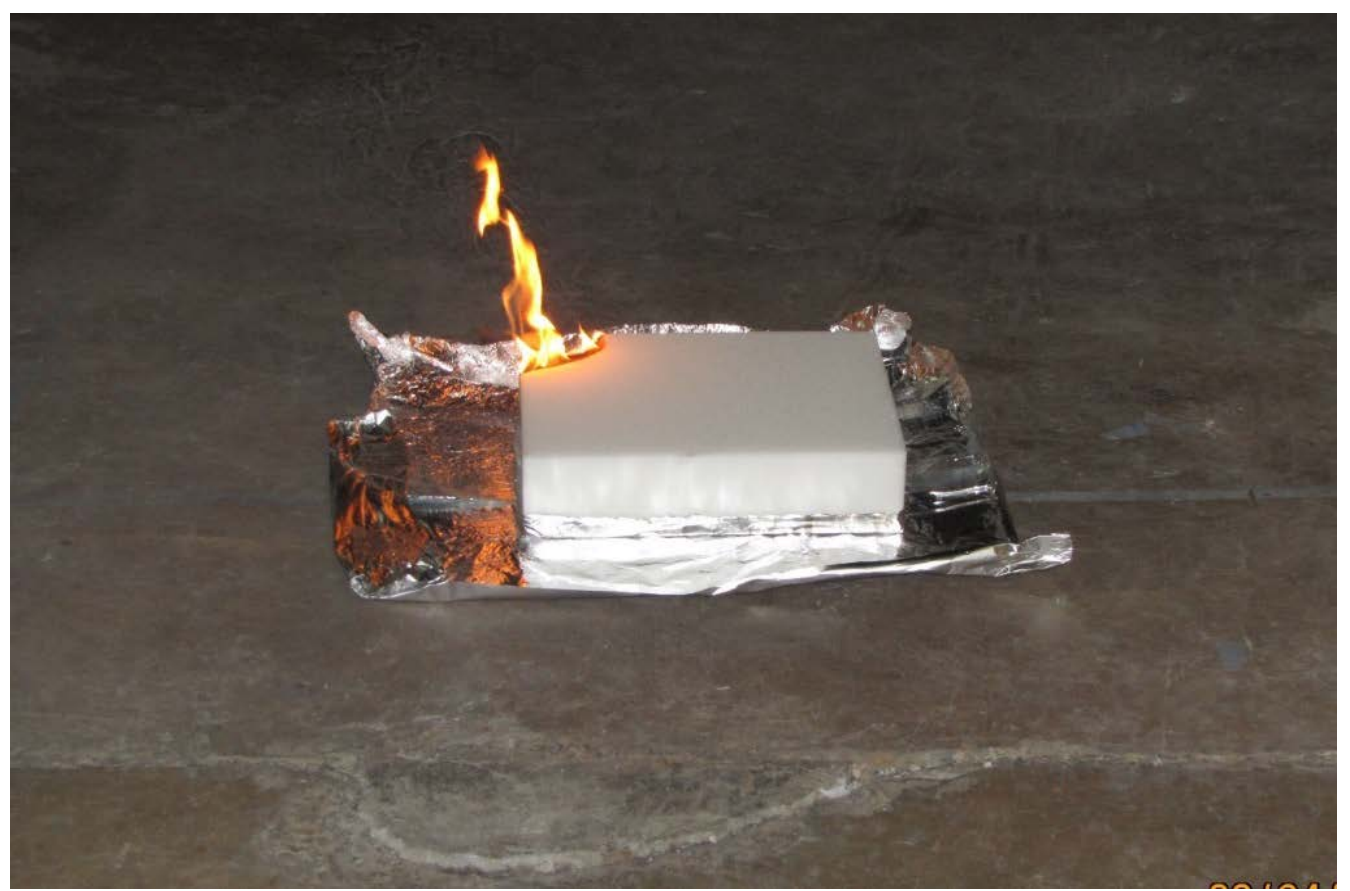

Figure 10. Burning foam slab.

\subsubsection{Smoldering Polyurethane Foam}

The smoldering polyurethane foam experiments were conducted in the manner similar to that described in ANSI/UL 217. A specialized piece of patented equipment was used by UL to develop the smoldering test method. This equipment was not available to NIST so NIST constructed its own radiant panel device to promote smoldering and smoke buildup similar to the Standard's specification. Several trial experiments over a month were conducted to match the smoke profiles in the Standard using the NIST radiant panel. The final procedure represents the closest match that could be achieved in the time allotted. Interestingly, not all smolder smoke from the same smoldering foam is alike in terms of the MIC/Beam profile. The NIST smoldering device is shown in Figure 11. It consists of two rectangular $46 \mathrm{~cm}$ by 15 $\mathrm{cm}, 1080 \mathrm{~W}$ radiant panels arranged in a manner to irradiate the horizontal foam surface somewhat uniformly. The panels are angled approximately 15 degrees from the horizontal with a gap spacing of 7.6 $\mathrm{cm}$ between the face of each panel. The distance from the peak of the radiant surface to the foam sample surface was $13.3 \mathrm{~cm}$. Each radiant heater was powered and controlled by separate process controllers and thermocouples monitoring the back side of the radiant panels. The foam samples were non-fire-retarded polyether urethane foam material $43.2 \mathrm{~cm}$ by $36.8 \mathrm{~cm}$ by $7.6 \mathrm{~cm}$, the same material as the flaming foam samples, only thicker. The foam slabs had a $17.8 \mathrm{~cm}$ diameter cotton duct fabric disk placed in the center. An aluminum plate shutter was placed between the foam surface and the radiant panels, the panels were allowed to heat up to a fixed set point of $300{ }^{\circ} \mathrm{C}$, then the shutter was removed to expose the foam to low level radiant heat flux of about $4 \mathrm{~kW} / \mathrm{m}^{2}$ over the central portion of the horizontal surface. 
The heat flux exposure was not sufficient to visibly discolor or pyrolyze the foam. Immediately after removing the shutter, a lit cigarette (NIST SRM 1196 Standard Cigarette for Ignition Resistance Testing) was placed on the fabric such that the initial coal was centered on the fabric (Figure 12). This procedure insured that smoldering would propagate into the foam sample. Experiments with a cigarette and fabric disk without the radiant heater would smolder at a rate much slower than the experiments with the radiant heater used. Experiments at higher radiant panel heat fluxes were sufficient to smolder the foam, but the resultant smoke profiles deviated significantly from the bounding range in the Standard.

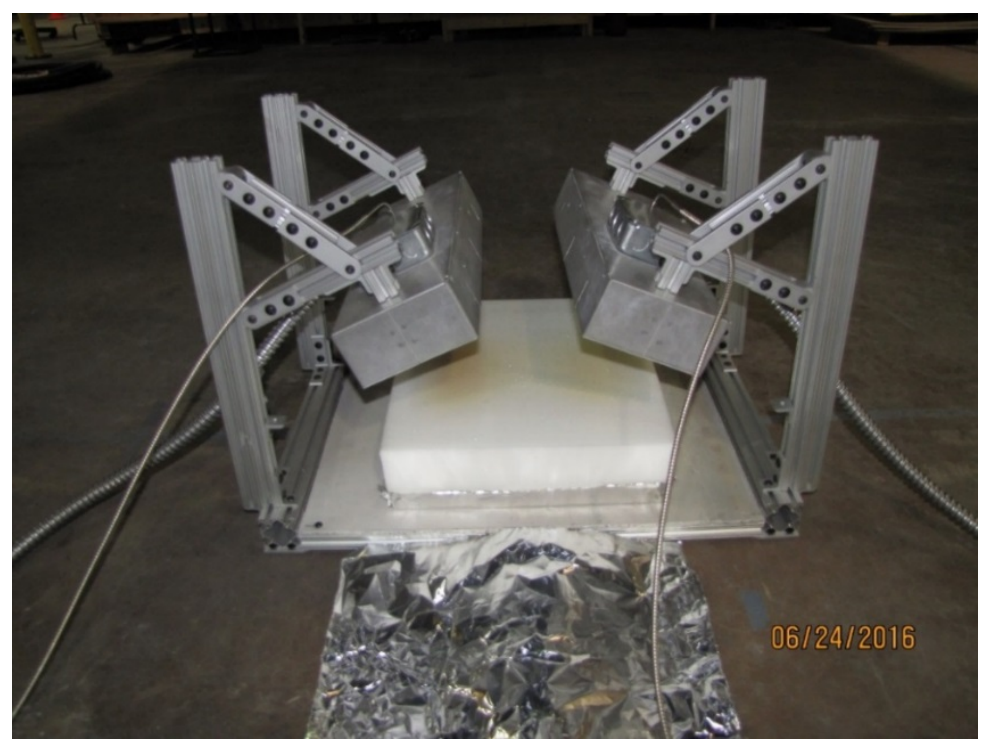

Figure 11. The NIST radiant panel foam smoldering device. Here, the heat flux was sufficient to discolor and pyrolyze the foam sample.

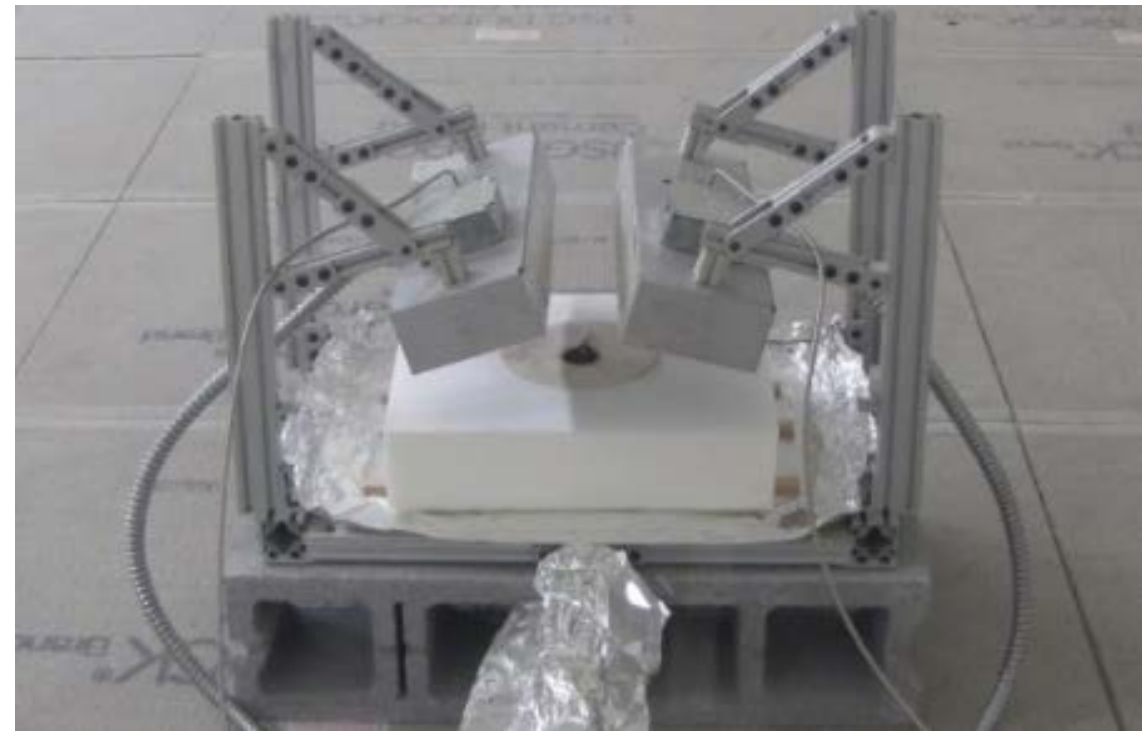

Figure 12. Lit cigarette resting on cotton duck fabric centered on foam sample. This configuration was used in the smoke alarm experiments. 


\subsubsection{Broiling Hamburgers}

The broiling hamburger experiments utilize a specific patty recipe specified in the Standard consisting of $75 \%$ lean beef and $25 \%$ suet by weight. The patties were press-formed in a ring mold to $10.0 \mathrm{~cm}$ in diameter and $1.9 \mathrm{~cm}$ thick. They weighed $175 \mathrm{~g} \pm 3 \mathrm{~g}$ each and were frozen prior to use in the experiments. Figure 13 shows some formed patties prior to freezing.

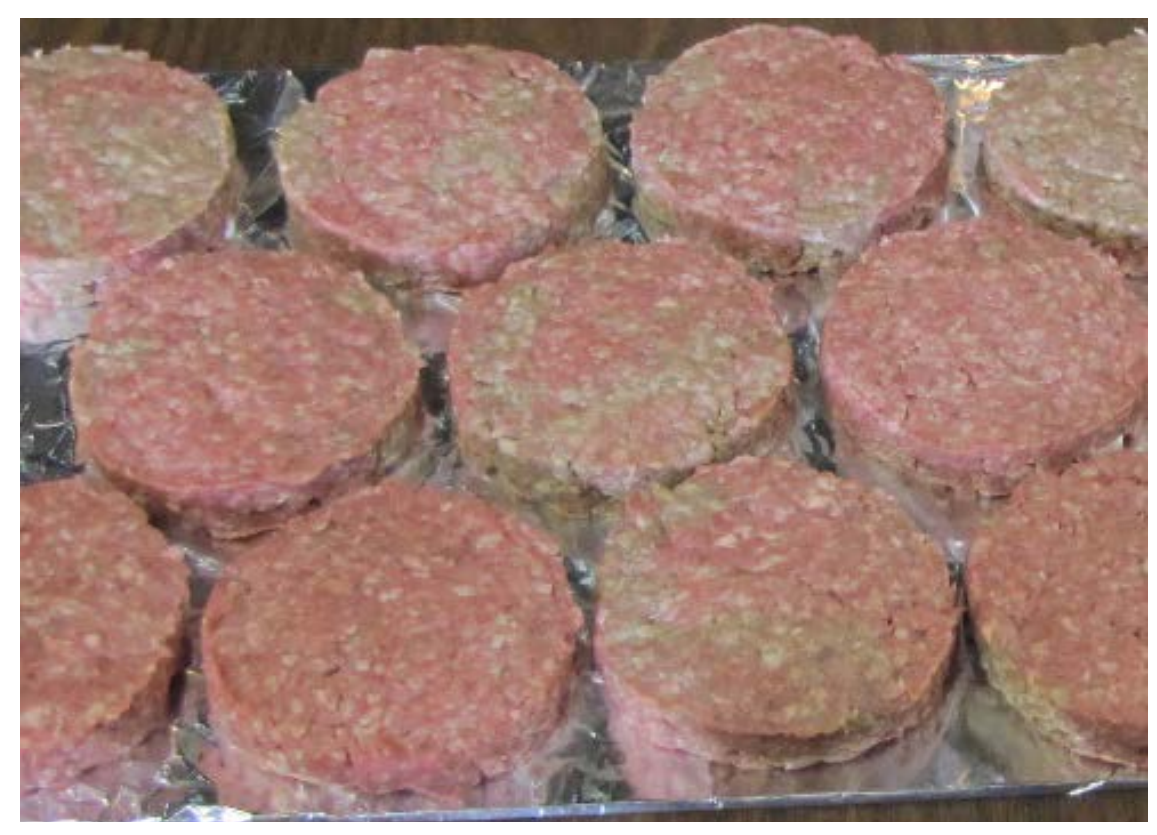

Figure 13. Hamburger patties conforming to the Standard's specifications.

An electric range was used to broil the hamburgers, the range was elevated on a $0.61 \mathrm{~m}$ high platform and centered on the back wall as specified in the Standard (Figure 14). Starting from a cold oven, a broiler pan with two patties arranged as shown in Figure 15, was placed inside the oven as shown in Figure 16, and the door left ajar at a predetermined angle (Figure 17). The broiler element was turned on to high power and the room was evacuated. The power to the broiler was measured to be approximately $3.5 \mathrm{~kW}$ to $3.6 \mathrm{~kW}$ throughout the experiments. An experiment lasted about $1500 \mathrm{~s}$. 


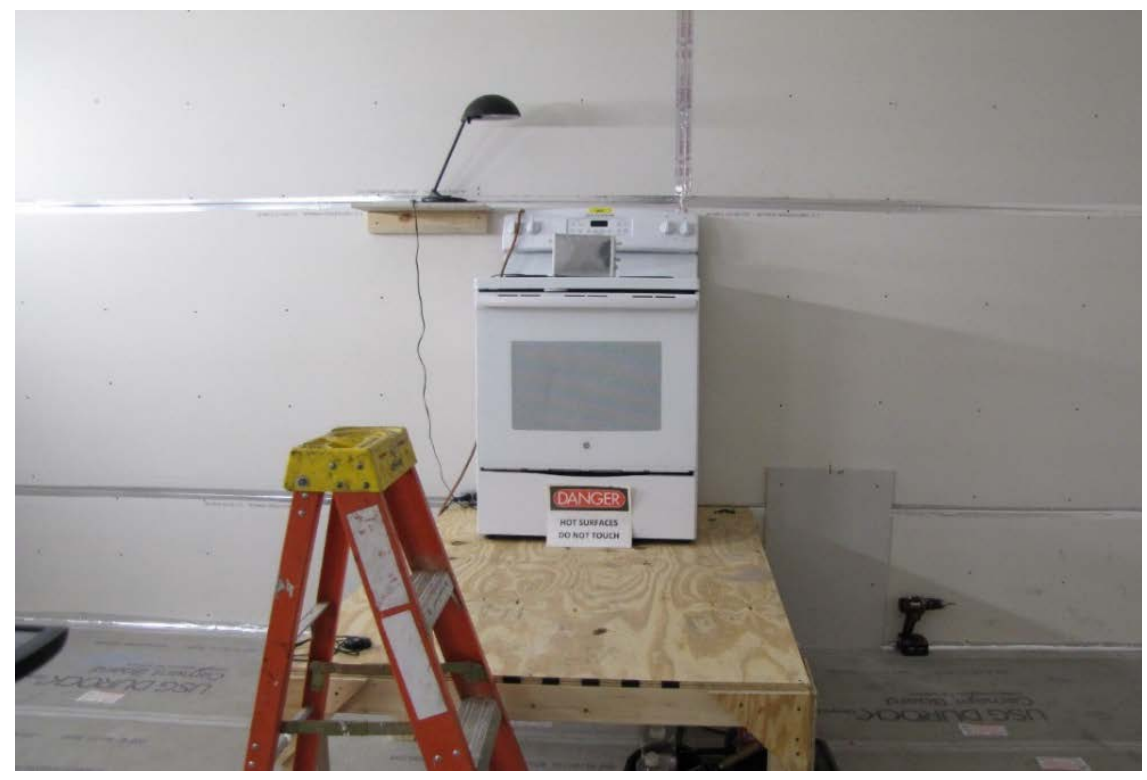

Figure 14. Location of the electric range in the cooking nuisance test room.

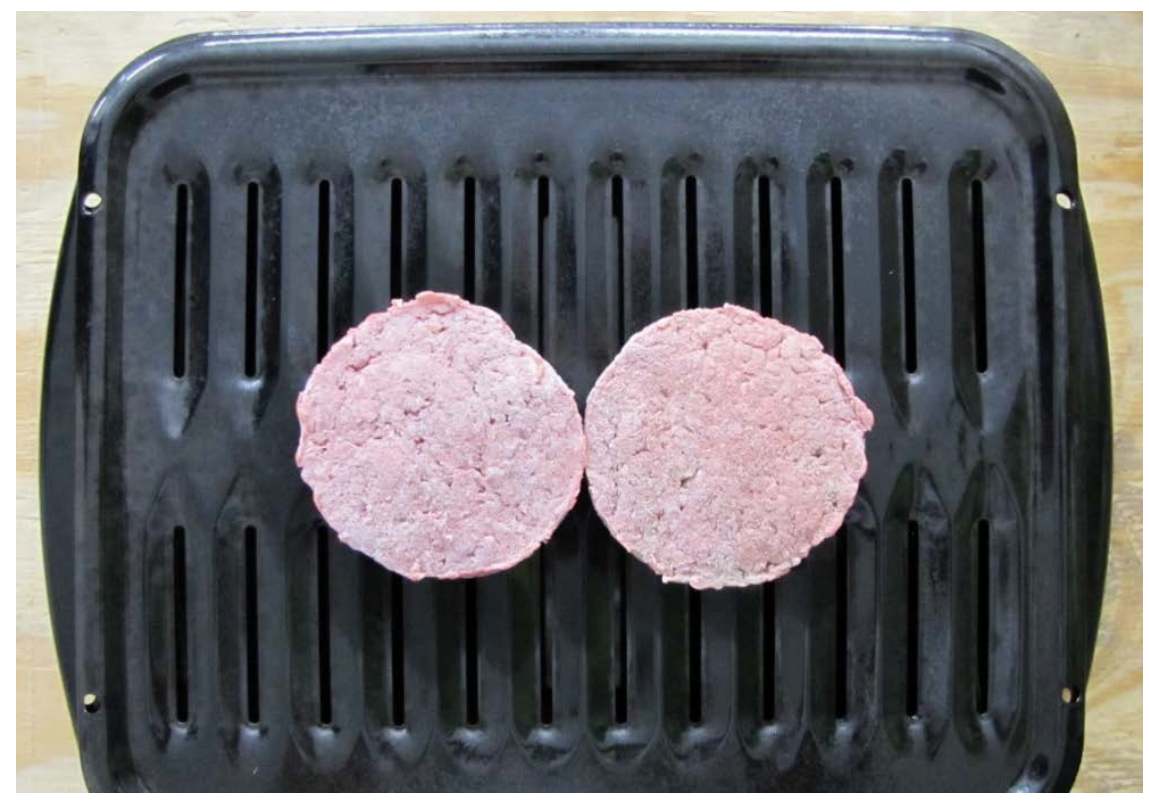

Figure 15. Frozen hamburger patties on the broiling pan. 


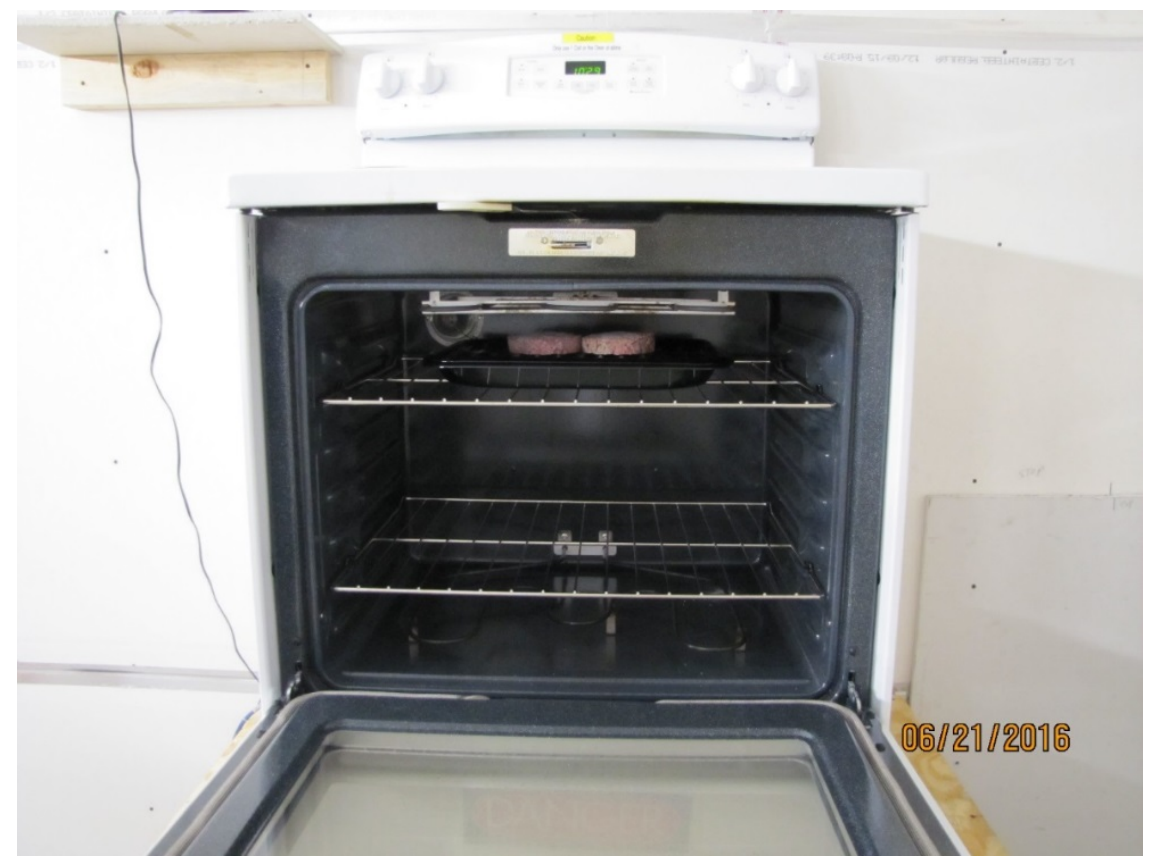

Figure 16. Location of broiling pan inside oven.

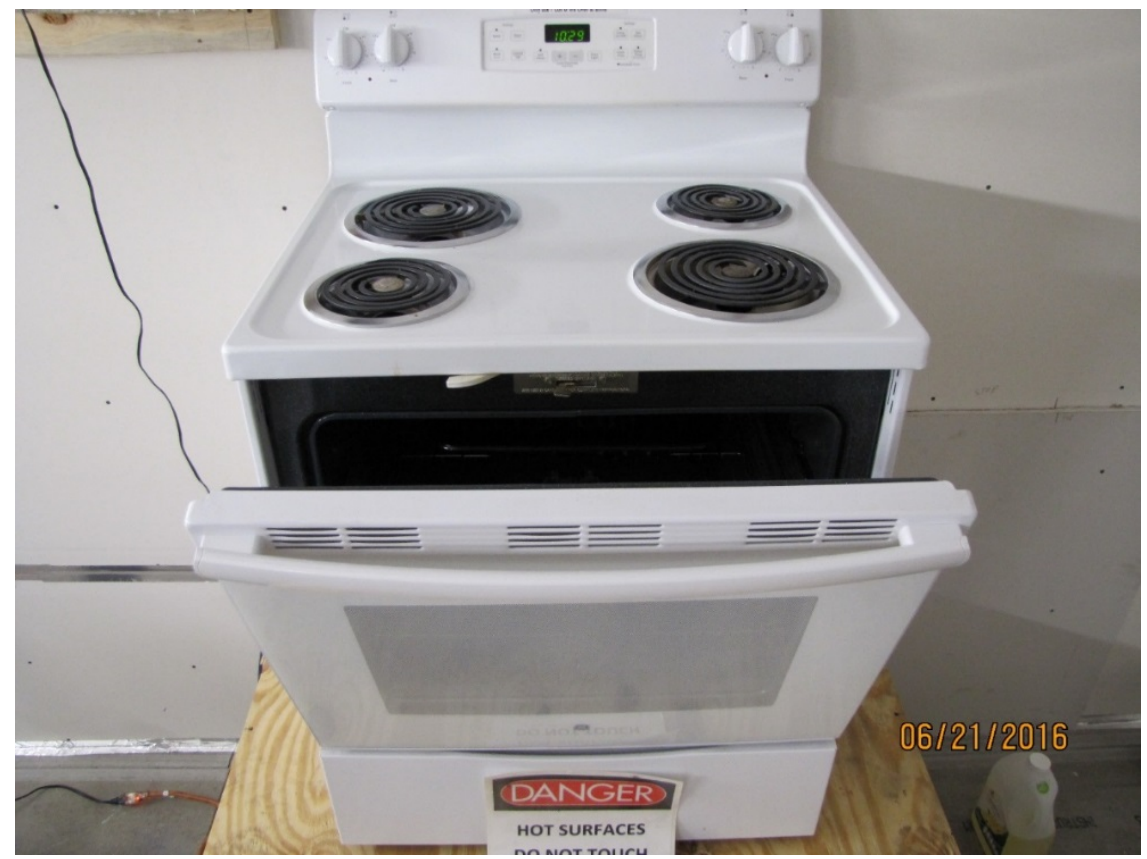

Figure 17. Oven door position during the broiling hamburgers experiments. 


\subsubsection{Frying Hamburger}

A single frozen hamburger of the same specifications as the hamburger patties used in the broiling hamburgers standard tests was fried in a non-stick-coated frying pan on the electric stove portion of the range. A hamburger was placed in the pan on the front-right large burner element. The power was set to the high setting (10 setting) at the start of the experiment. The resultant power at the high setting was constant and approximately $2.4 \mathrm{~kW}$. After $180 \mathrm{~s}$ the power was reduced to the medium setting (6 setting) resulting in a power cycling between 0 and $2.4 \mathrm{~kW}$. After $390 \mathrm{~s}$ from the start of the experiment the patty was flipped. After $600 \mathrm{~s}$ from the start, the burner was turned off. Figure 18 shows a patty after it was cooked.

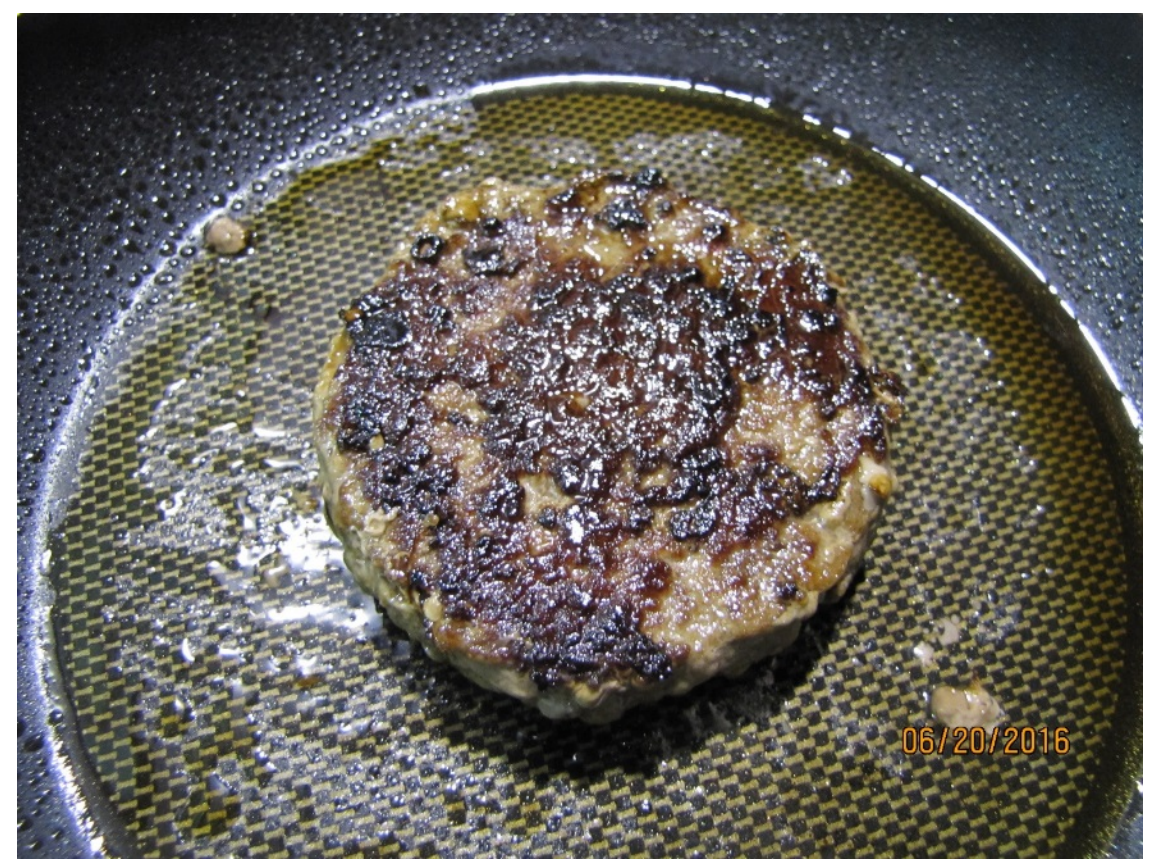

Figure 18. Fried hamburger patty after the end of an experiment.

\subsubsection{Stir-Frying Vegetables}

A mixture of vegetables consisting of $115 \mathrm{~g}$ of onions, $115 \mathrm{~g}$ of carrots, and $70 \mathrm{~g}$ of celery were roughly chopped and set aside. At the beginning of an experiment approximately $15 \mathrm{ml}$ of vegetable oil was placed in a high-walled pan on the front-right large burner element of the stove and the power set to the high setting (10 setting). At $150 \mathrm{~s}$ the vegetables were added and stirred vigorously. At $360 \mathrm{~s}$ the burner power was reduced to the medium setting (6 setting) while stirring continued. At $510 \mathrm{~s}$ the burner was powered off. Figure 19 is a picture of cooked vegetables in the pan after an experiment. 


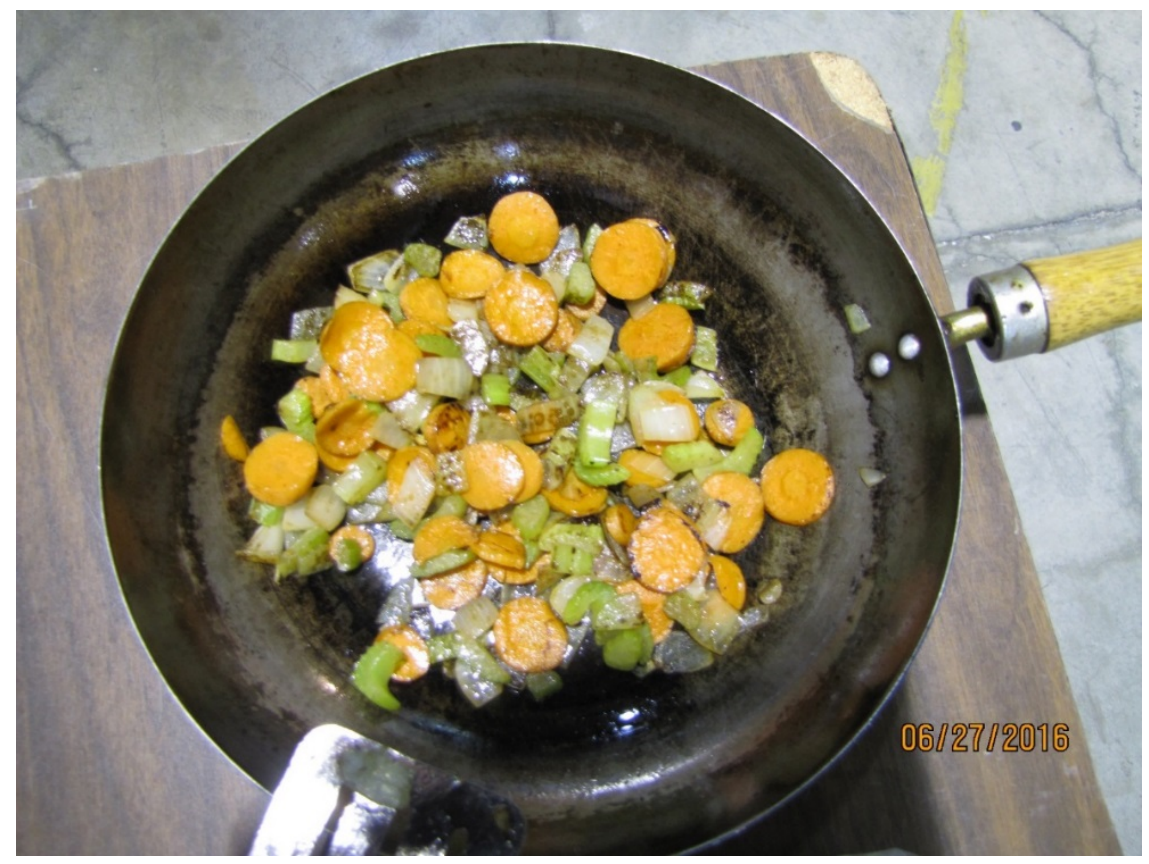

Figure 19. Stir-fried vegetables after the end of an experiment.

\subsubsection{Toasting Bread}

A two-slice toaster was modified by wiring the pop-up mechanism down so the toaster remains on while supplied with power. The toaster was placed on top of the electric range as shown in Figure 20. The toaster was pre-heated before each experiment by powering it for $60 \mathrm{~s}$ outside the test room, then installing it inside the room and conducting an experiment within $300 \mathrm{~s}$ of it being pre-heated. This preheating procedure appeared to establish a more uniform toasting for a fixed toasting time in repeated experiments. After the two bread slices were placed in the toaster, power was applied for $210 \mathrm{~s}$ then the power to the toaster was removed. This sequence produces two slices of toast that were somewhat darker on one side than the other due to variation in the heating elements of the particular toaster used as seen in Figures 21 and 22. 


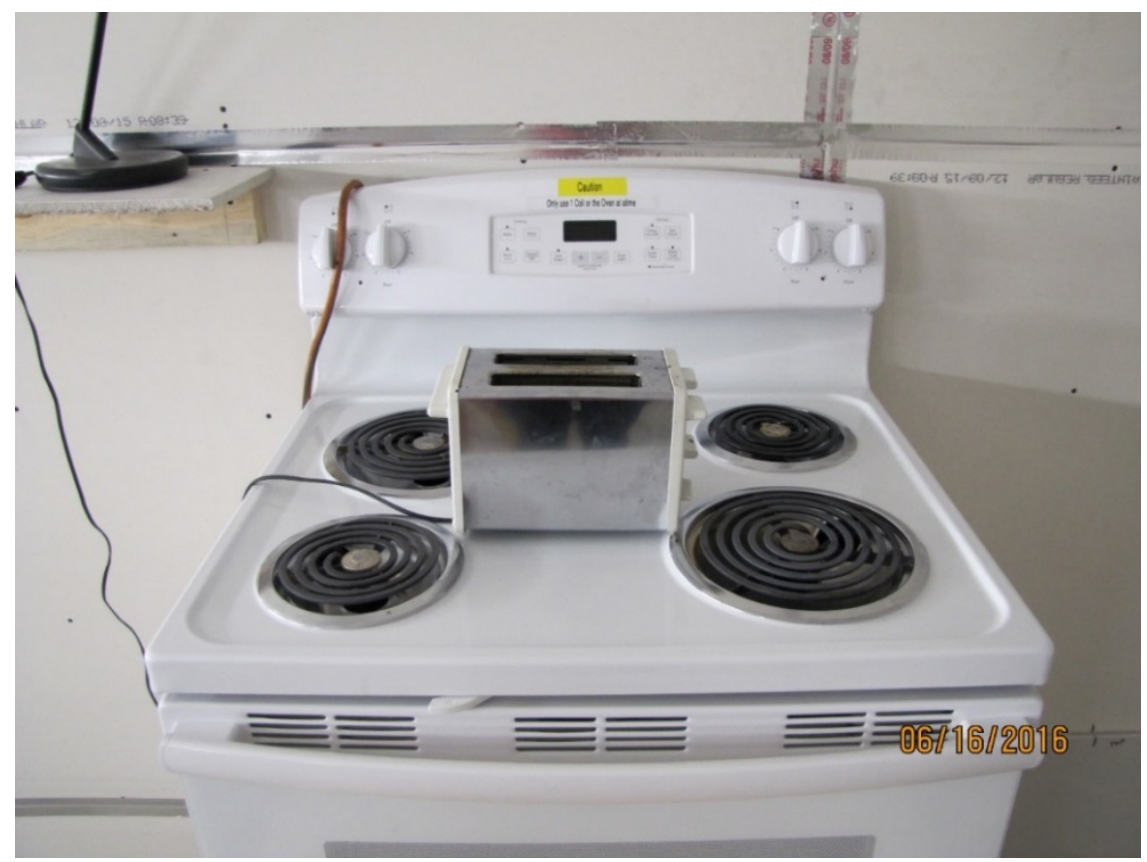

Figure 20. Location of toaster during experiments.

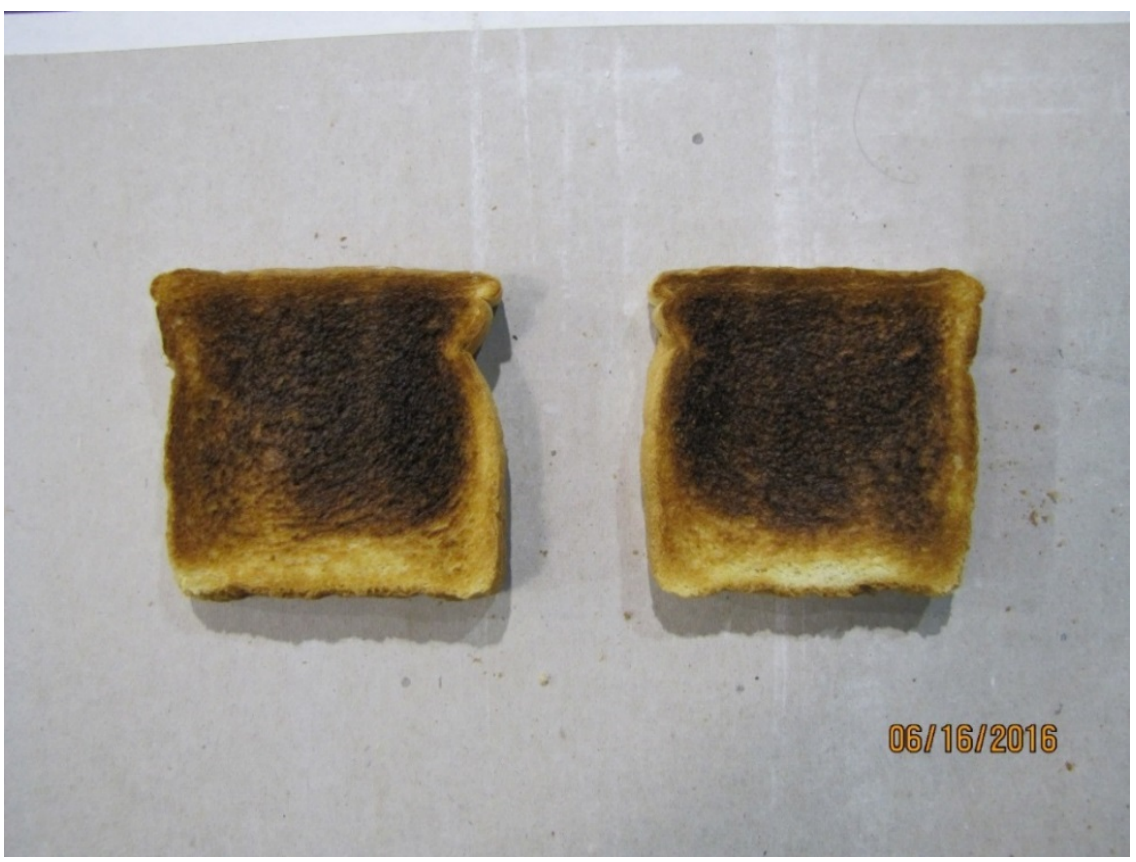

Figure 21. Darker sides of toasted bread after the end of an experiment. 


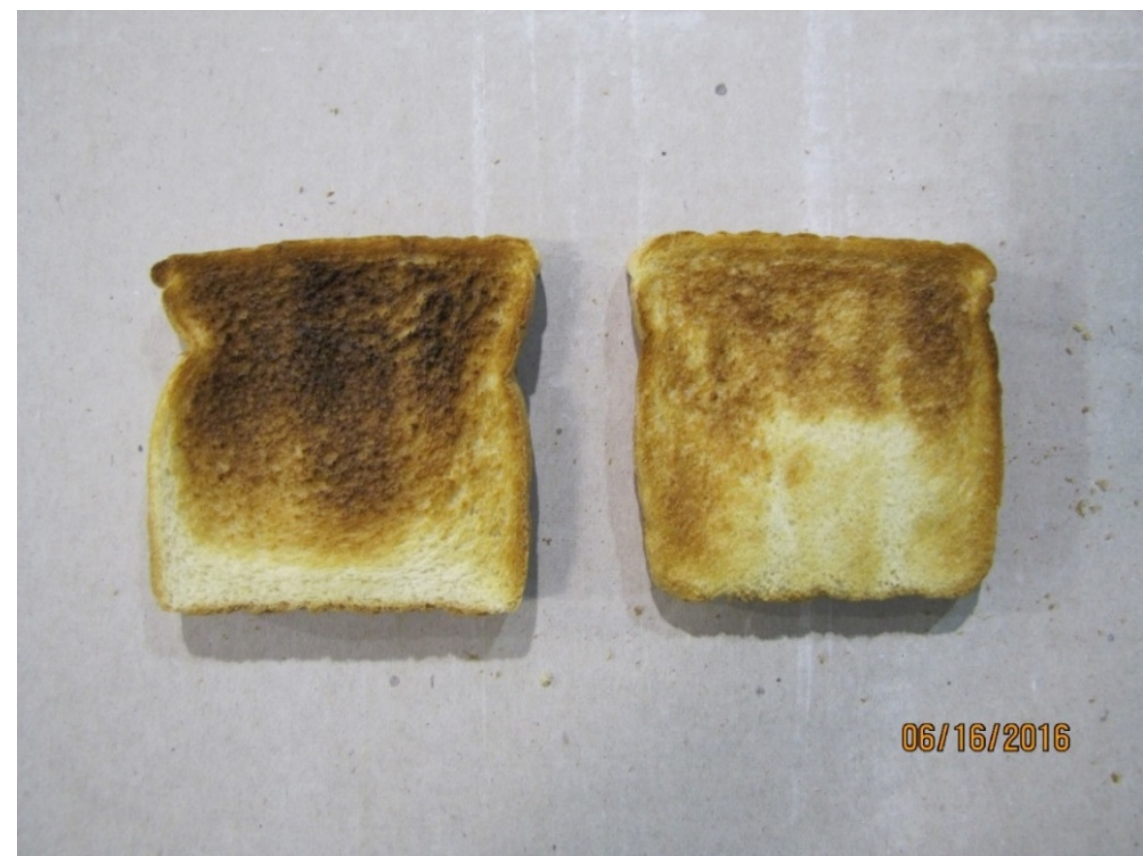

Figure 22. Lighter sides of toasted bread after the end of an experiment. 


\section{$3 \quad$ Results}

Select results for each smoke box experiment are detailed in the following subsection. Data files for each experiment can be found in the companion data documentation located at http://doi.org/10.18434/T4530X.

\subsection{Smoke Box Alarm Sensitivities}

Each smoke alarm was exposed to cotton smolder smoke in the smoke box with the smoke development following the bounding curves given in ANSI/UL 217-2012. The time to audible alarm was logged manually with a timer synchronized to the data acquisition computer and automatically in the data file with the state of a sound switch. The measured sensitivities of each model are presented in the graphs below. Both the obscuration and MIC current at alarm are given. The $\mathrm{x}$ axis represents the identifying unit number of the alarm. The unit number identifies what experimental test scenario the alarm unit was used in. Unit 6 was subjected to three repeated worst-case orientation experiments to indicate the individual alarm model variation for repeated smoke box experiments. Unit 6 was also subject to bestcase and worst-case at twice the flow velocity smoke box experiments to indicate the sensitivity to a change in flow or orientation. Apparent outlier model units with results that deviated significantly from the expected alarm model results were repeated.

For all plots open circles and solid triangles represent beam obscuration values. Open squares and open triangles represent MIC values. Open circles and open squares are worst-case orientation values. Triangles pointing up are best-case orientation values and triangles pointing down are values for worstcase orientation at twice the flow velocity $(0.32 \mathrm{~m} / \mathrm{s} \pm 0.01 \mathrm{~m} / \mathrm{s})$.

The smoke box results for ionization alarm models are presented in Figures 23-36.

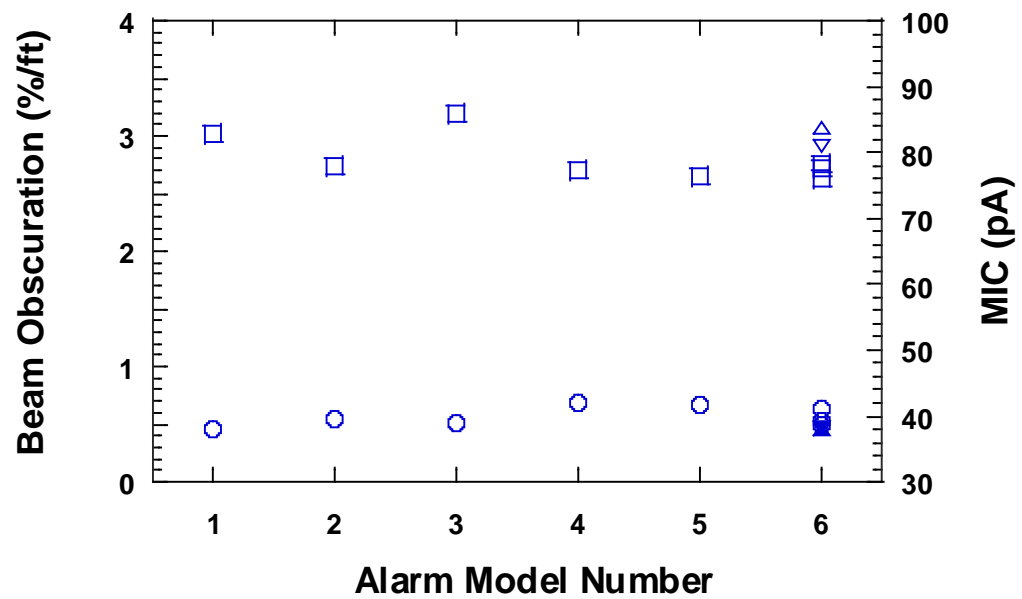

Figure 23. Smoke box results for ionization alarm $\mathrm{I} 01 . \mathrm{u}_{\mathrm{c}, \mathrm{r}}(\mathrm{beam})=4.0 \%, \mathrm{u}_{\mathrm{c}}(\mathrm{MIC})=0.2 \mathrm{pA}$. 


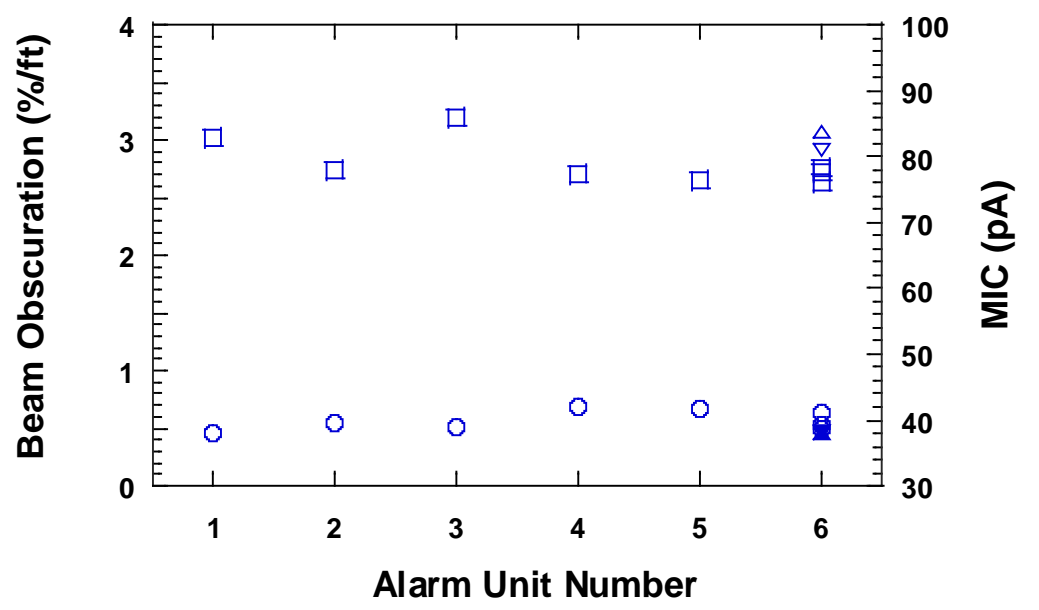

Figure 24. Smoke box results for ionization alarm I02. $\mathrm{u}_{\mathrm{c}, \mathrm{r}}($ beam $)=4.0 \%, \mathrm{u}_{\mathrm{c}}(\mathrm{MIC})=0.2 \mathrm{pA}$.

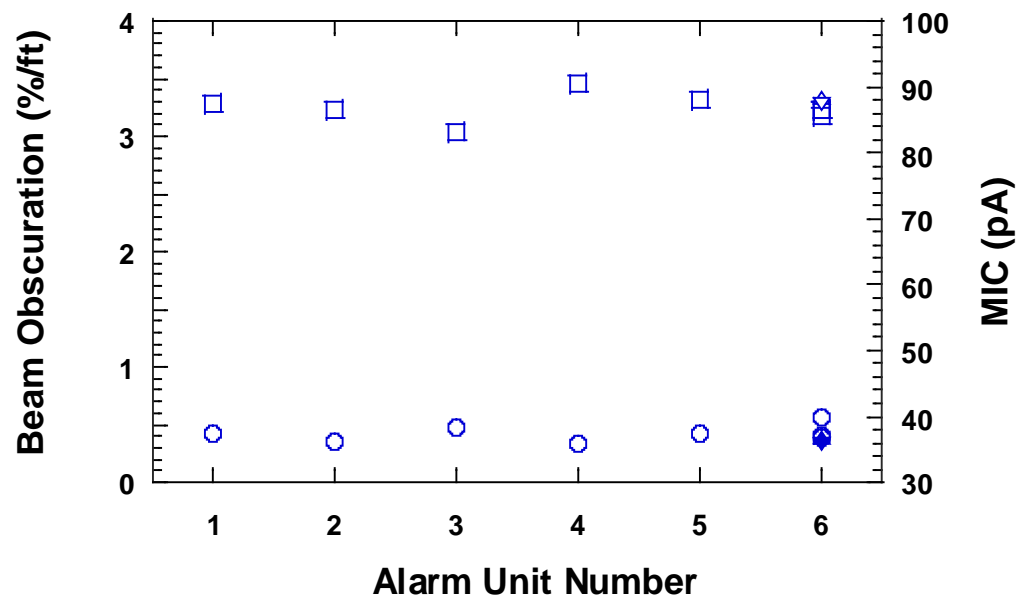

Figure 25. Smoke box results for ionization alarm I03. $\mathrm{u}_{\mathrm{c}, \mathrm{r}}($ beam $)=4.0 \%, \mathrm{u}_{\mathrm{c}}(\mathrm{MIC})=0.2 \mathrm{pA}$.

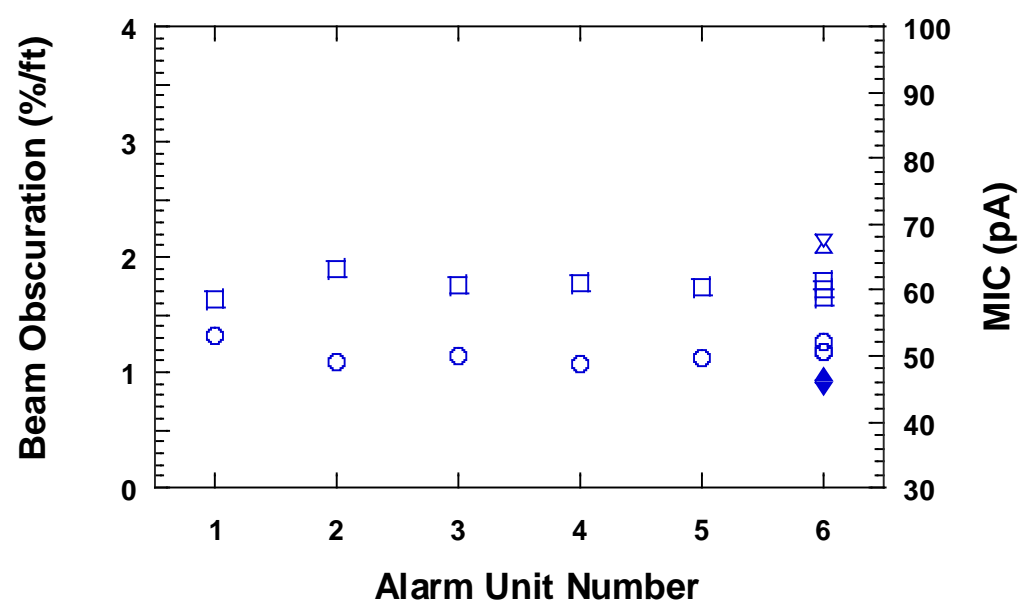

Figure 26. Smoke box results for ionization alarm I04. $\mathrm{u}_{\mathrm{c}, \mathrm{r}}($ beam $)=4.0 \%, \mathrm{u}_{\mathrm{c}}(\mathrm{MIC})=0.2 \mathrm{pA}$. 


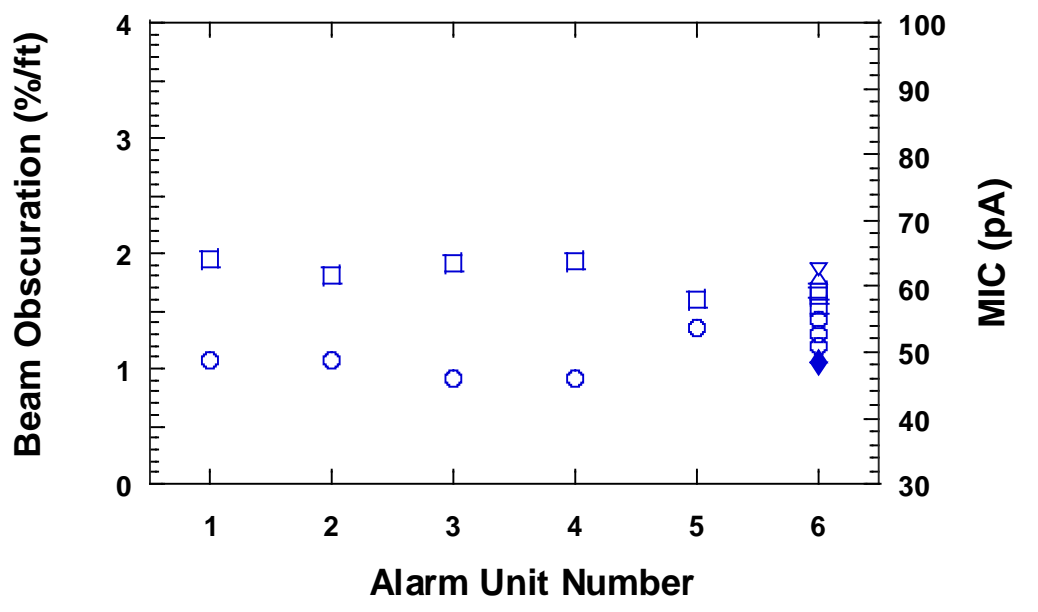

Figure 27. Smoke box results for ionization alarm I05. $\mathrm{u}_{\mathrm{c}, \mathrm{r}}($ beam $)=4.0 \%, \mathrm{u}_{\mathrm{c}}(\mathrm{MIC})=0.2 \mathrm{pA}$.

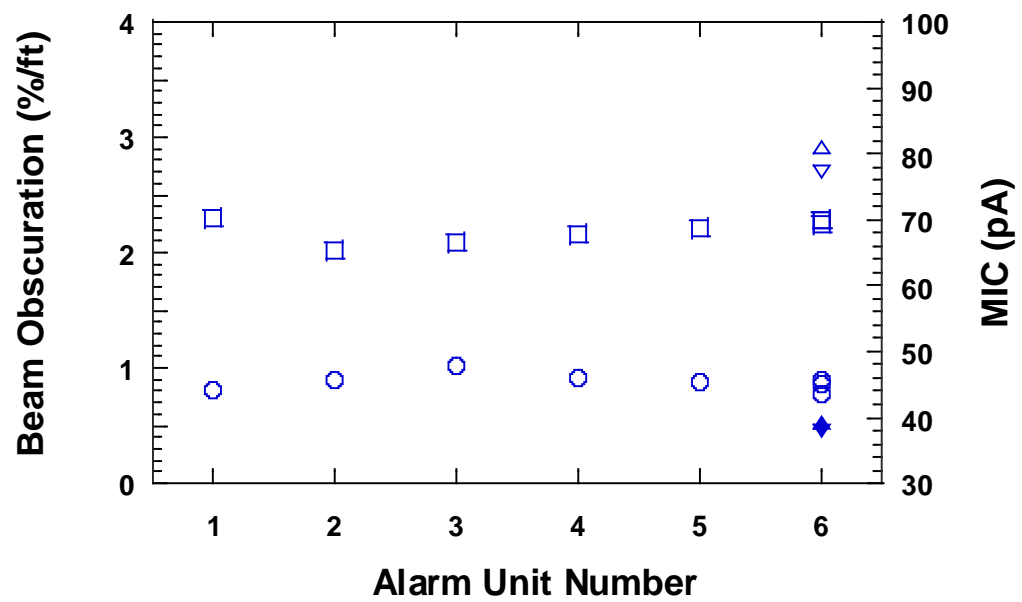

Figure 28. Smoke box results for ionization alarm I06. $\mathrm{u}_{\mathrm{c}, \mathrm{r}}($ beam $)=4.0 \%, \mathrm{u}_{\mathrm{c}}(\mathrm{MIC})=0.2 \mathrm{pA}$.

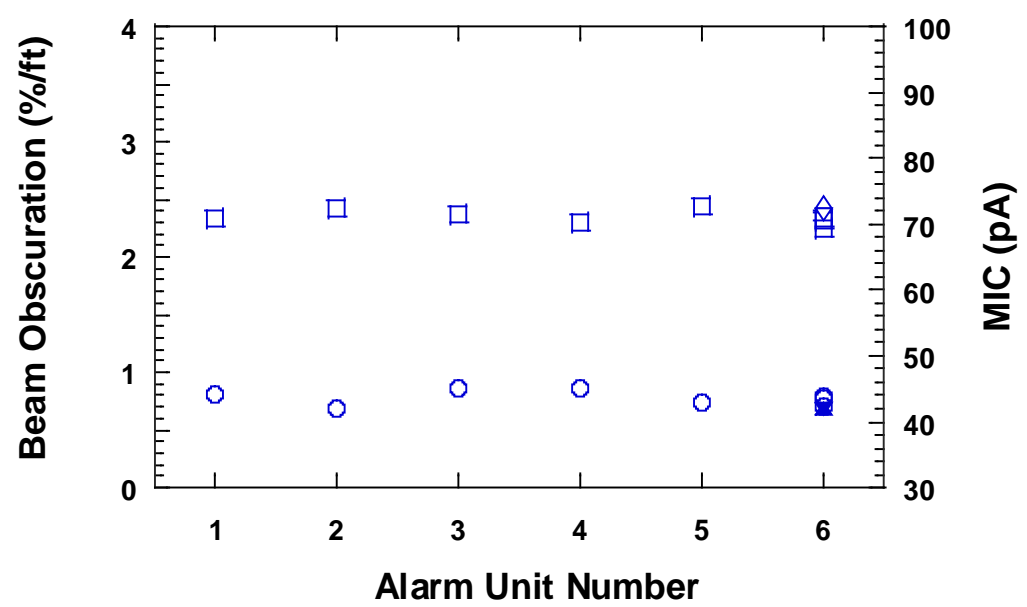

Figure 29. Smoke box results for ionization alarm I07. $\mathrm{u}_{\mathrm{c}, \mathrm{r}}($ beam $)=4.0 \%, \mathrm{u}_{\mathrm{c}}(\mathrm{MIC})=0.2 \mathrm{pA}$. 


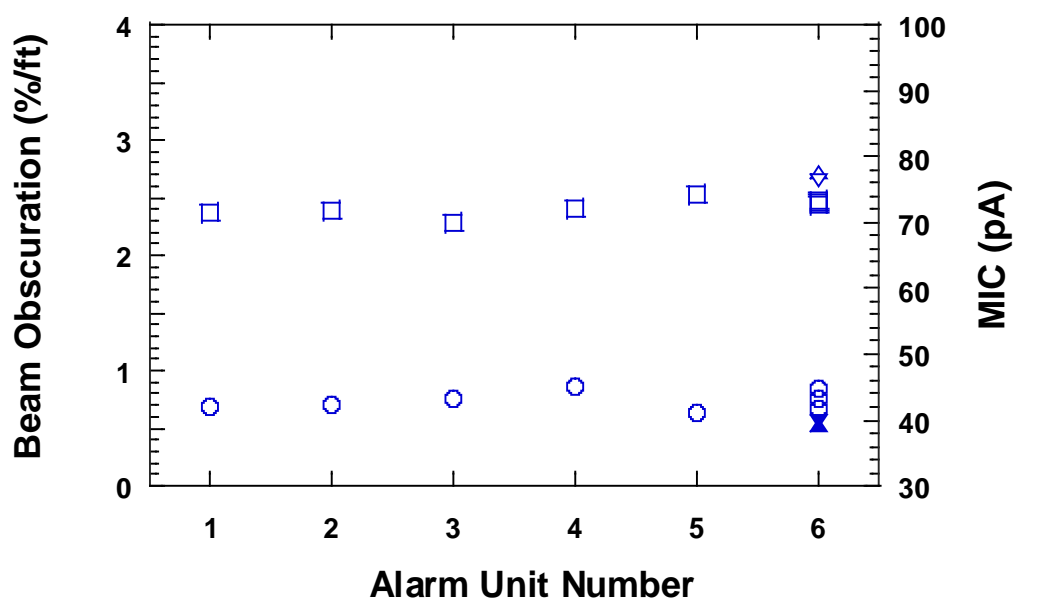

Figure 30. Smoke box results for ionization alarm I08. $\mathrm{u}_{\mathrm{c}, \mathrm{r}}($ beam $)=4.0 \%, \mathrm{u}_{\mathrm{c}}(\mathrm{MIC})=0.2 \mathrm{pA}$.

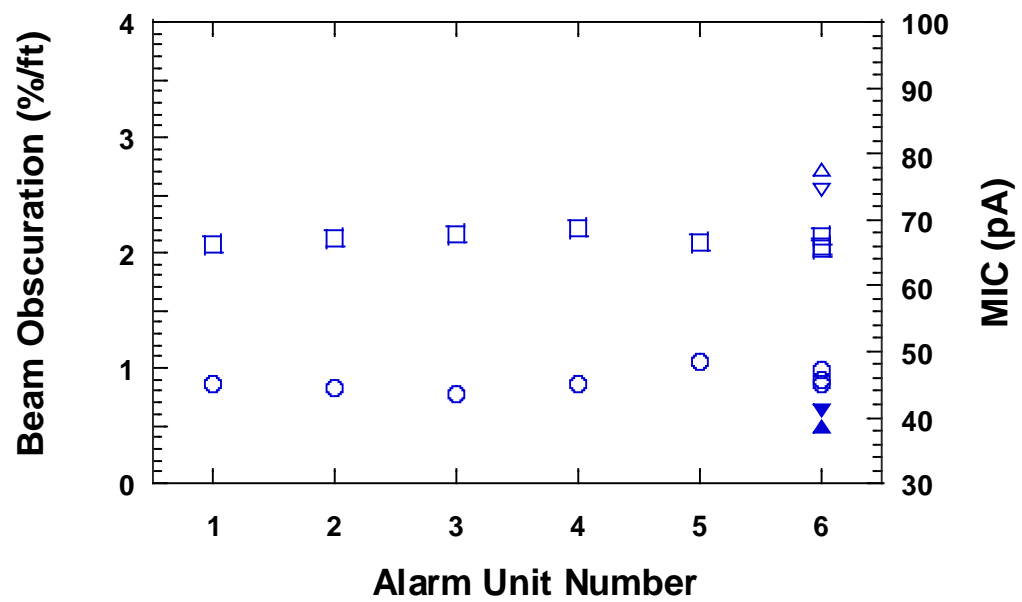

Figure 31. Smoke box results for ionization alarm I09. $\mathrm{u}_{\mathrm{c}, \mathrm{r}}($ beam $)=4.0 \%, \mathrm{u}_{\mathrm{c}}(\mathrm{MIC})=0.2 \mathrm{pA}$.

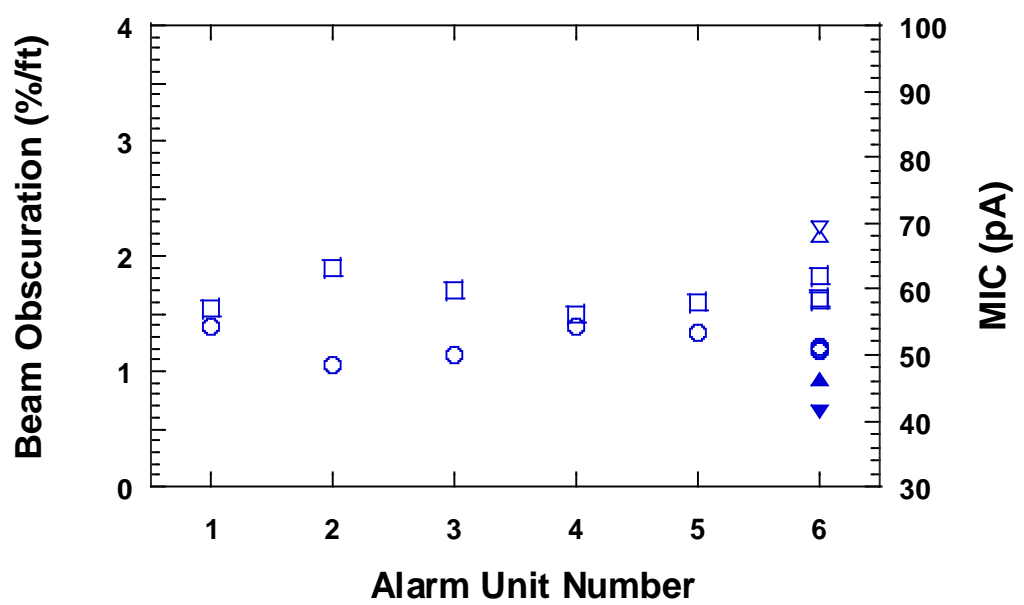

Figure 32. Smoke box results for ionization alarm I10. $\mathrm{u}_{\mathrm{c}, \mathrm{r}}($ beam $)=4.0 \%, \mathrm{u}_{\mathrm{c}}(\mathrm{MIC})=0.2 \mathrm{pA}$. 


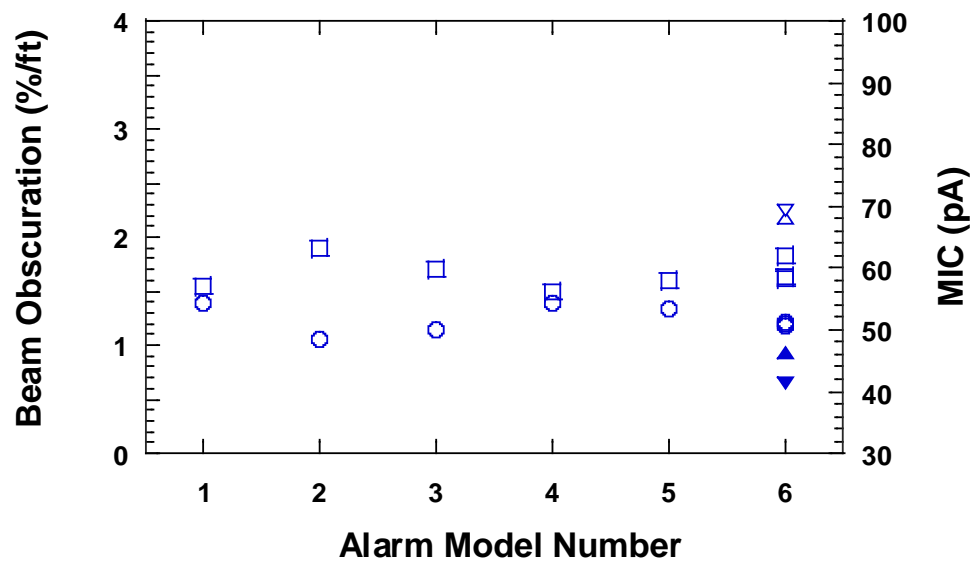

Figure 33. Smoke box results for ionization alarm I11. $\mathrm{u}_{\mathrm{c}, \mathrm{r}}($ beam $)=4.0 \%, \mathrm{u}_{\mathrm{c}}(\mathrm{MIC})=0.2 \mathrm{pA}$.

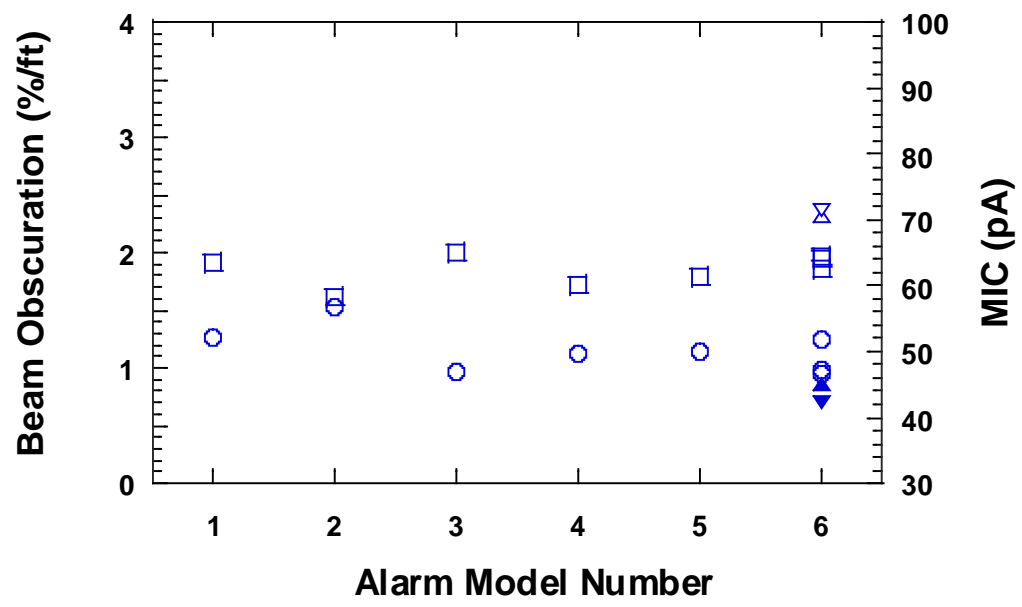

Figure 34. Smoke box results for ionization alarm I12. $\mathrm{u}_{\mathrm{c}, \mathrm{r}}($ beam $)=4.0 \%, \mathrm{u}_{\mathrm{c}}(\mathrm{MIC})=0.2 \mathrm{pA}$.

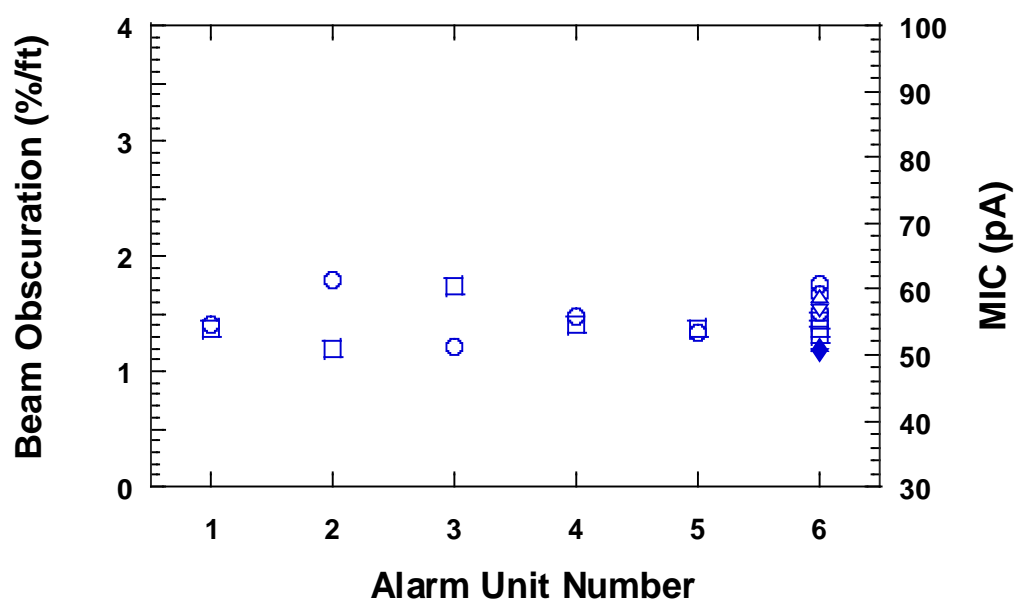

Figure 35. Smoke box results for ionization alarm I13. $\mathrm{u}_{\mathrm{c}, \mathrm{r}}($ beam $)=4.0 \%, \mathrm{u}_{\mathrm{c}}(\mathrm{MIC})=0.2 \mathrm{pA}$. 


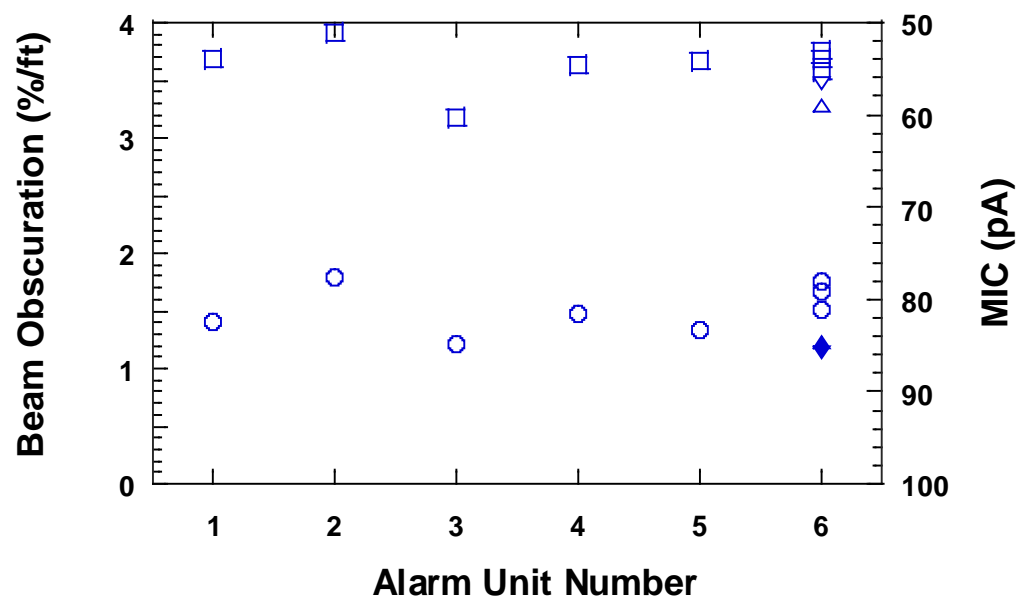

Figure 36. Smoke box results for ionization alarm I14. $\mathrm{u}_{\mathrm{c}, \mathrm{r}}($ beam $)=4.0 \%, \mathrm{u}_{\mathrm{c}}(\mathrm{MIC})=0.2 \mathrm{pA}$.

For smoke alarms that contain ionization sensors, using the MIC current is a better representation of the sensitivity than smoke obscuration. The best-case orientation and worst-case orientation at twice the velocity results were typically close to one another and usually slightly more sensitive than the standard worst-case orientation results. The average MIC current for the worst-case orientation of each ionization alarm model is shown in Figure 37. The error bars are \pm one standard deviation. The maximum and minimum average sensitivity for these models ( $87 \mathrm{pA}$ and $53 \mathrm{pA})$ covers more than $60 \%$ of the entire range allowed in the standard, (93 pA to $37.5 \mathrm{pA})$.

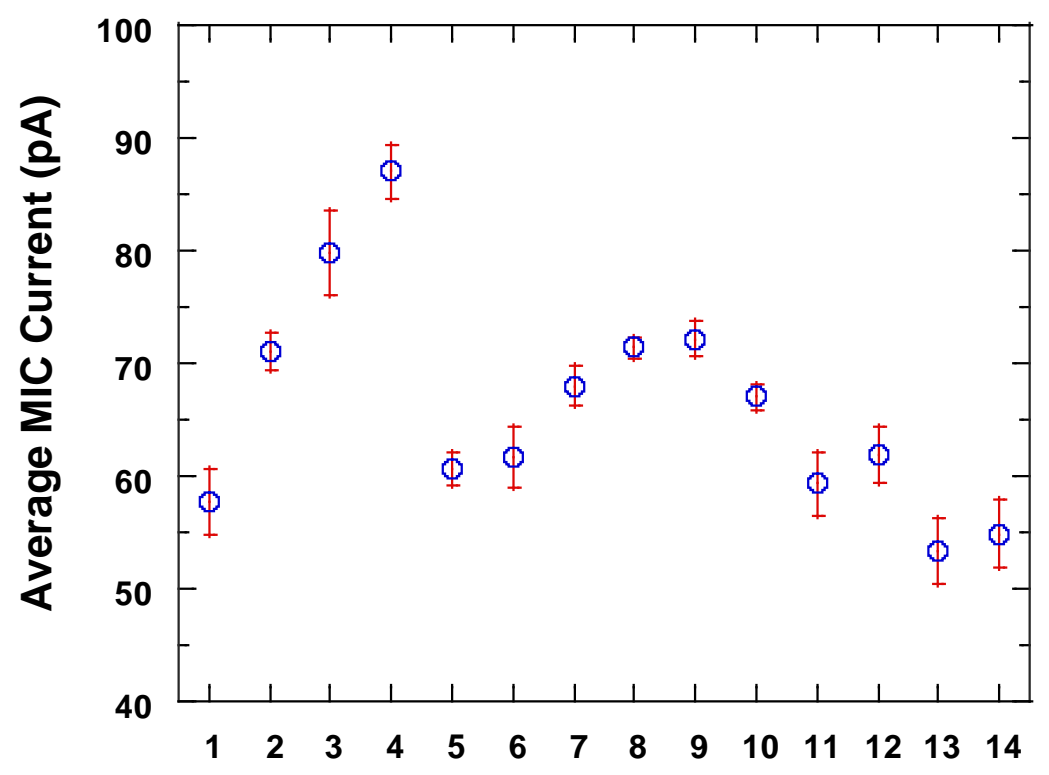

\section{Ionization Alarm Model}

Figure 37. Average MIC current of the ionization alarm model results.

The smoke box results for ionization / carbon monoxide alarm models are presented in Figures 38-41 and for ionization / photoelectric alarm models in Figures 42 - 45. 


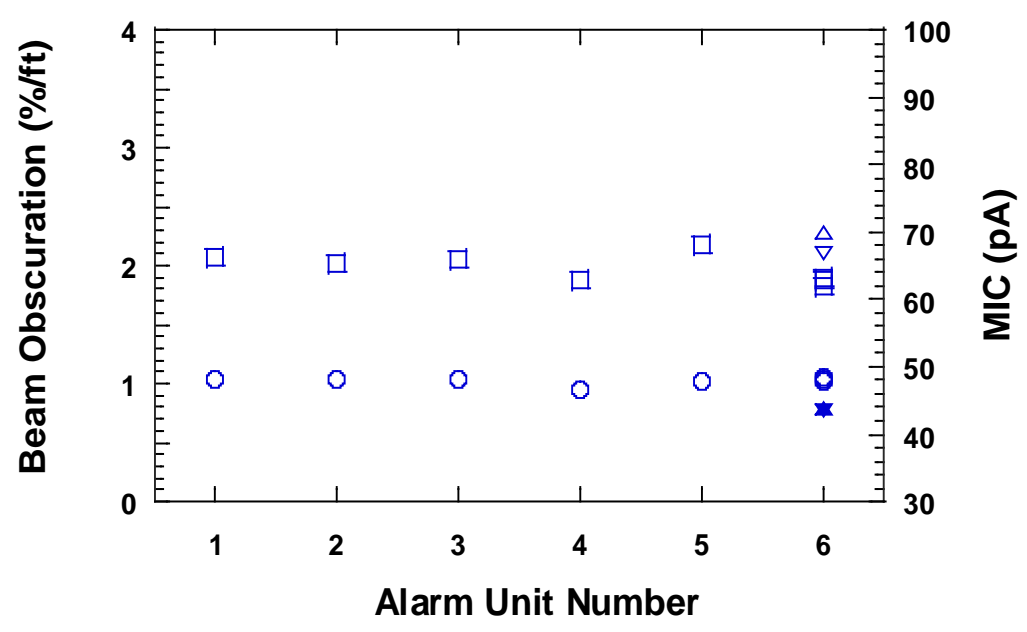

Figure 38. Smoke box results for ionization / carbon monoxide alarm ICO01. $\mathrm{u}_{\mathrm{c}, \mathrm{r}}(\mathrm{beam})=4.0 \%$, $\mathrm{u}_{\mathrm{c}}(\mathrm{MIC})=0.2 \mathrm{pA}$.

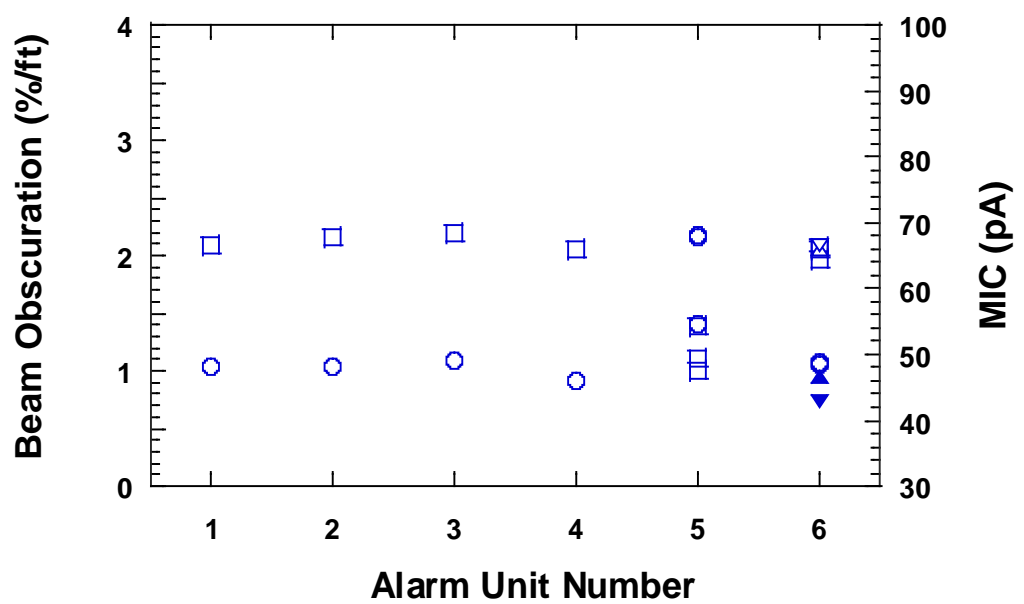

Figure 39. Smoke box results for ionization / carbon monoxide alarm ICO02. $\mathrm{u}_{c, \mathrm{r}}(\mathrm{beam})=4.0 \%$, $\mathrm{u}_{\mathrm{c}}(\mathrm{MIC})=0.2 \mathrm{pA}$.

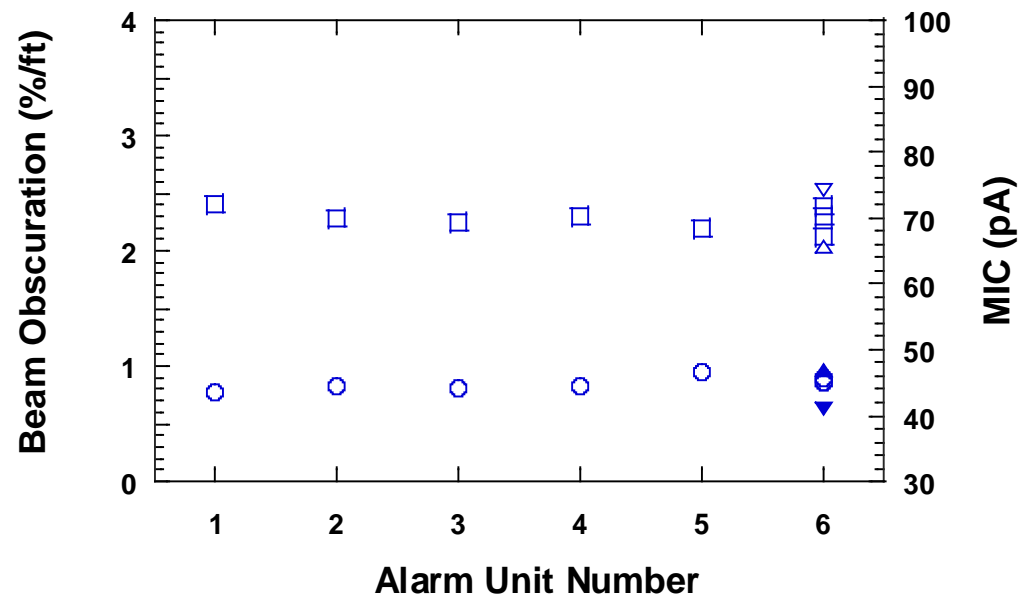

Figure 40. Smoke box results for ionization / carbon monoxide alarm ICO03. $\mathrm{u}_{\mathrm{c}, \mathrm{r}}(\mathrm{beam})=4.0 \%$, 
$\mathrm{u}_{\mathrm{c}}(\mathrm{MIC})=0.2 \mathrm{pA}$

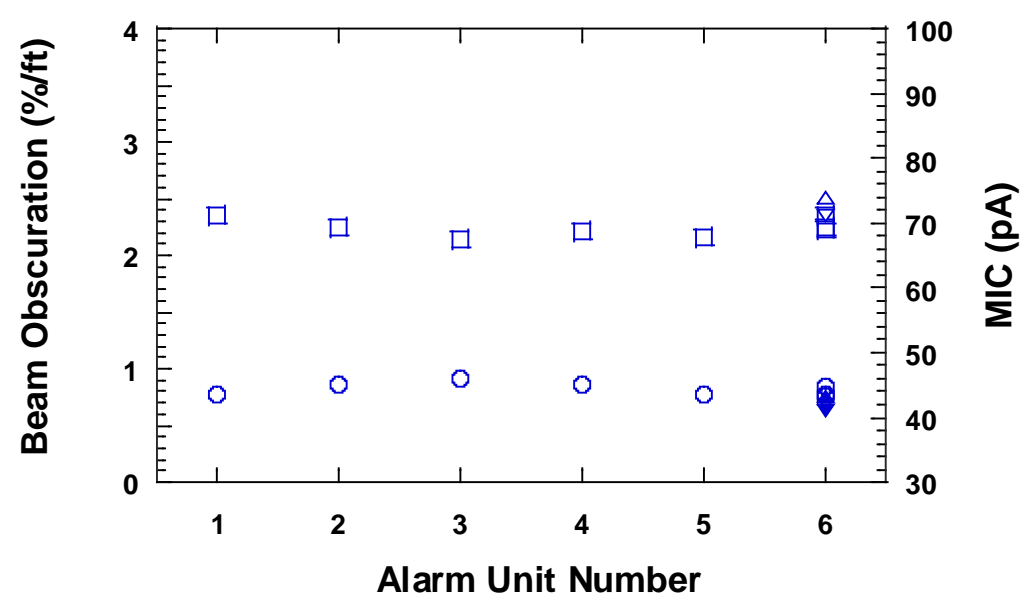

Figure 41. Smoke box results for ionization / carbon monoxide alarm ICO04. $\mathrm{u}_{\mathrm{c}, \mathrm{r}}(\mathrm{beam})=4.0 \%$, $\mathrm{u}_{\mathrm{c}}(\mathrm{MIC})=0.2 \mathrm{pA}$.

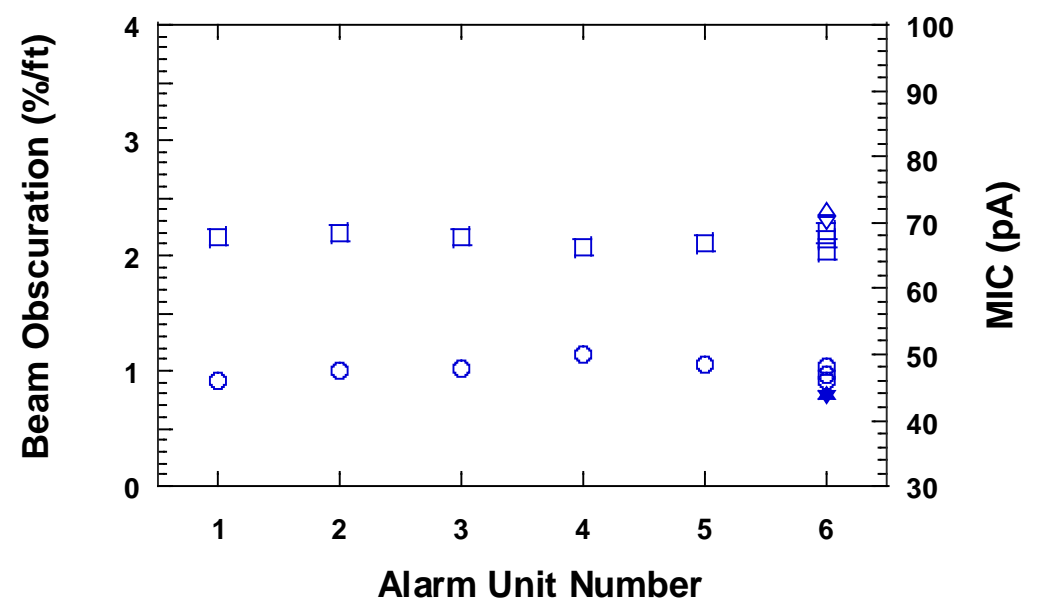

Figure 42. Smoke box results for ionization / photoelectric alarm IP01. $\mathrm{u}_{\mathrm{c}, \mathrm{r}}(\mathrm{beam})=4.0 \%, \mathrm{u}_{\mathrm{c}}(\mathrm{MIC})=0.2$ pA.

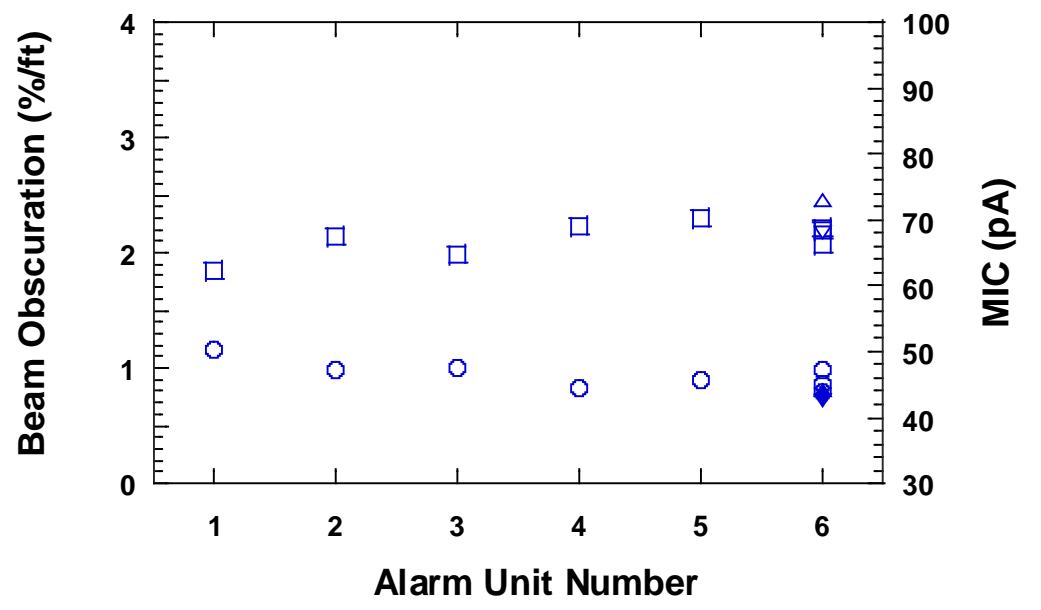

Figure 43. Smoke box results for ionization / photoelectric alarm IP02. $\mathrm{u}_{\mathrm{c}, \mathrm{r}}(\mathrm{beam})=4.0 \%, \mathrm{u}_{\mathrm{c}}(\mathrm{MIC})=0.2$ 
pA.

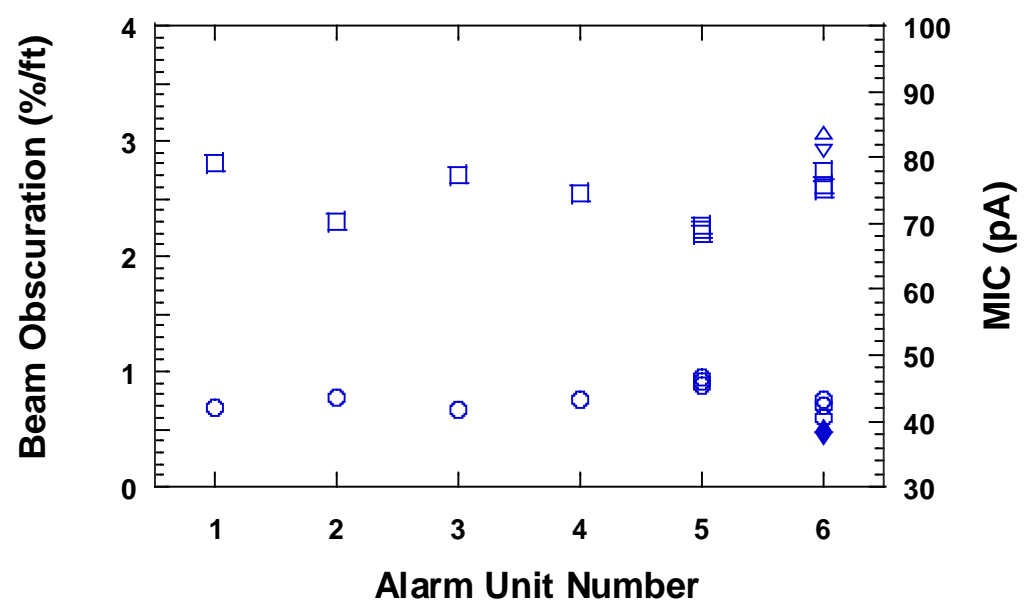

Figure 44. Smoke box results for ionization / photoelectric alarm IP03. $\mathrm{u}_{\mathrm{c}, \mathrm{r}}(\mathrm{beam})=4.0 \%$, $\mathrm{u}_{\mathrm{c}}(\mathrm{MIC})=0.2$ pA.

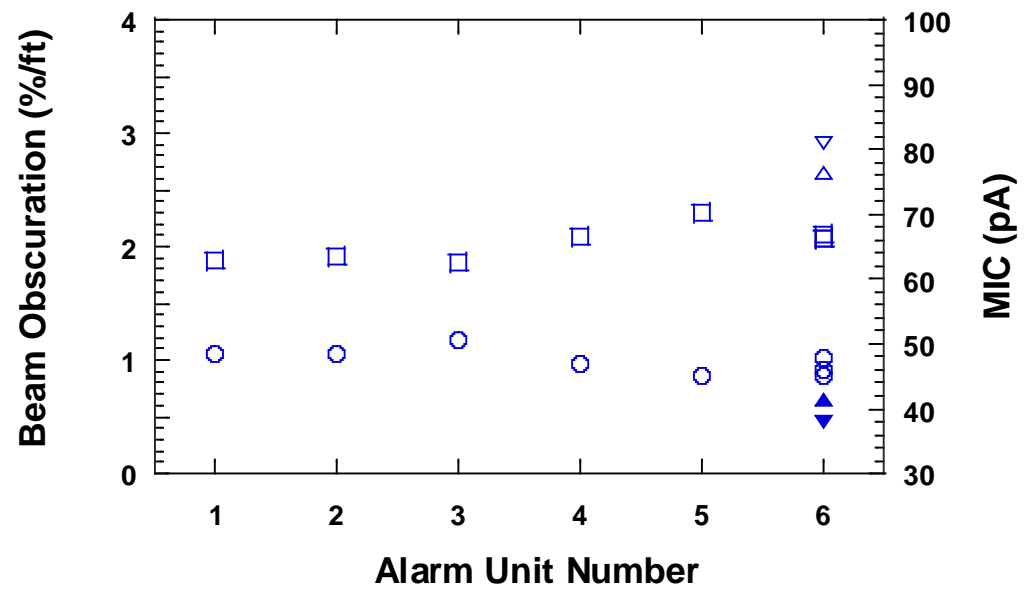

Figure 45. Smoke box results for ionization / photoelectric alarm IP04. $\mathrm{u}_{\mathrm{c}, \mathrm{r}}(\mathrm{beam})=4.0 \%$, $\mathrm{u}_{\mathrm{c}}(\mathrm{MIC})=0.2$ pA.

The best-case orientation and worst-case orientation at twice the velocity results were typically close to one another and typically about the same as the standard worst case orientation results. The average MIC current for the worst-case orientation of each ionization / photoelectric alarm model and each ionization / carbon monoxide model is shown in Figure 46. The error bars are \pm one standard deviation. The maximum and minimum average sensitivity range of these eight models is $74 \mathrm{pA}$ and $64 \mathrm{pA}$, a much tighter range than the ionization models. 


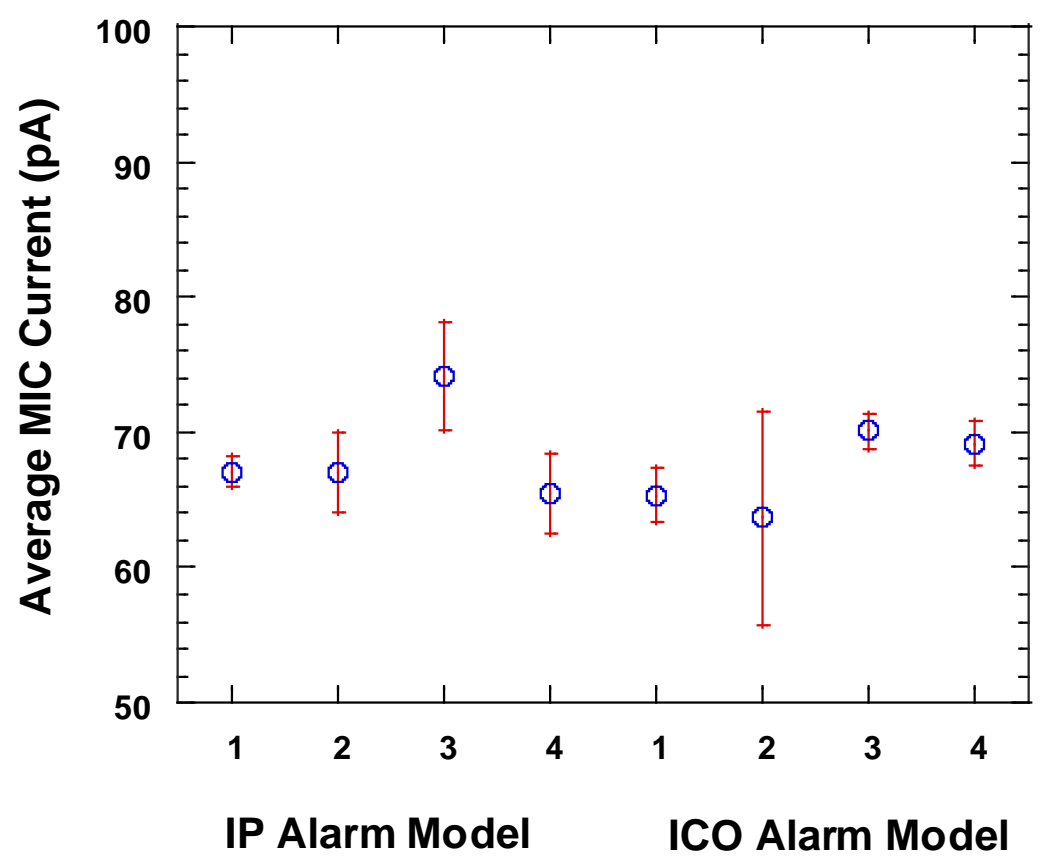

Figure 46. Average MIC current of the IP and ICO alarm model results.

The smoke box results for photoelectric alarm models are presented in Figures 47-59.

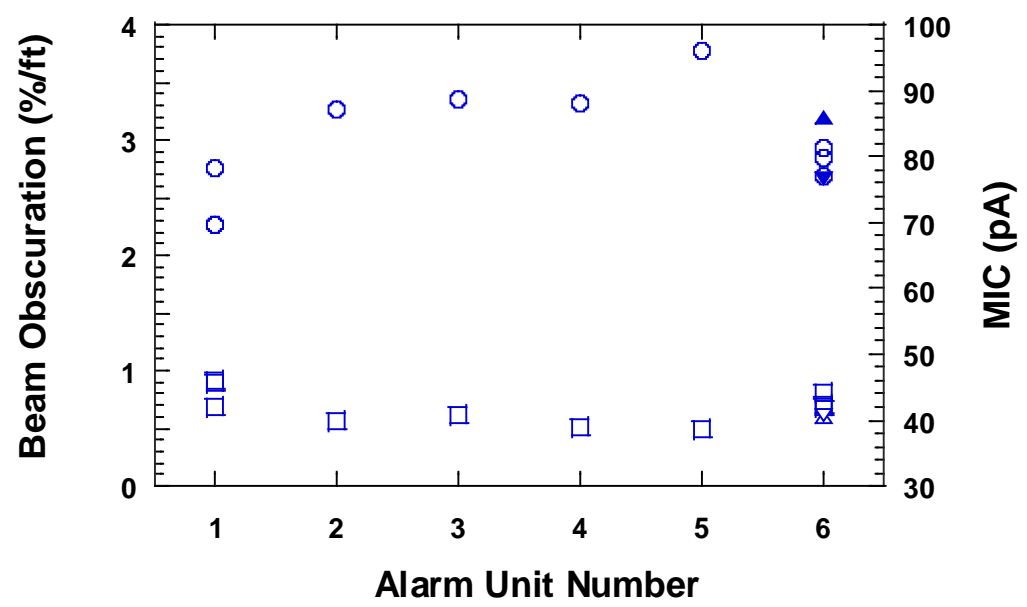

Figure 47. Smoke box results for photoelectric alarm P01. $\mathrm{u}_{\mathrm{c}, \mathrm{r}}($ beam $)=4.0 \%$, $\mathrm{u}_{\mathrm{c}}(\mathrm{MIC})=0.2 \mathrm{pA}$. 


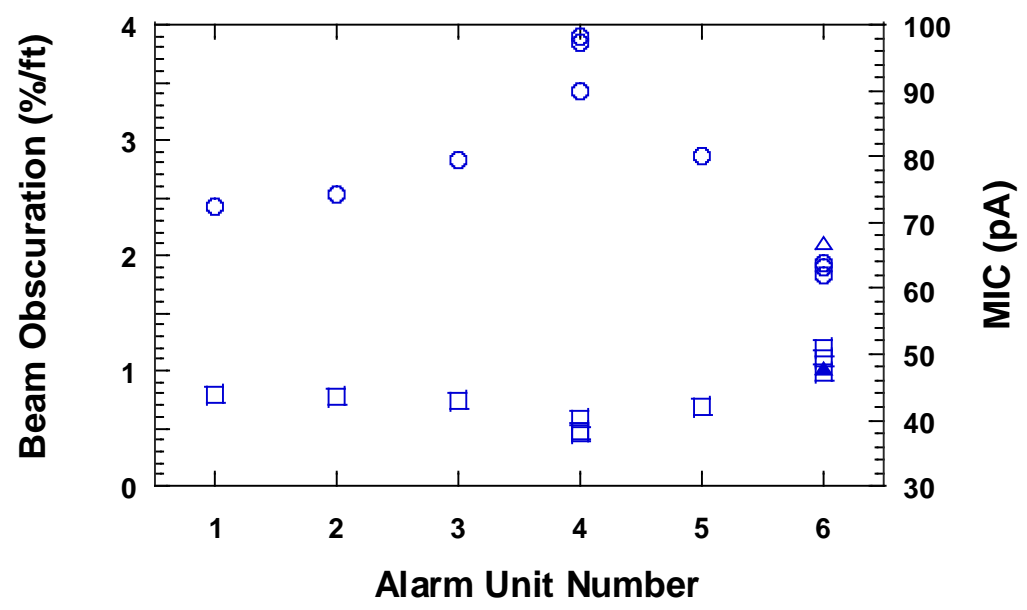

Figure 48. Smoke box results for photoelectric alarm P02. $\mathrm{u}_{\mathrm{c}, \mathrm{r}}($ beam $)=4.0 \%, \mathrm{u}_{\mathrm{c}}(\mathrm{MIC})=0.2 \mathrm{pA}$.

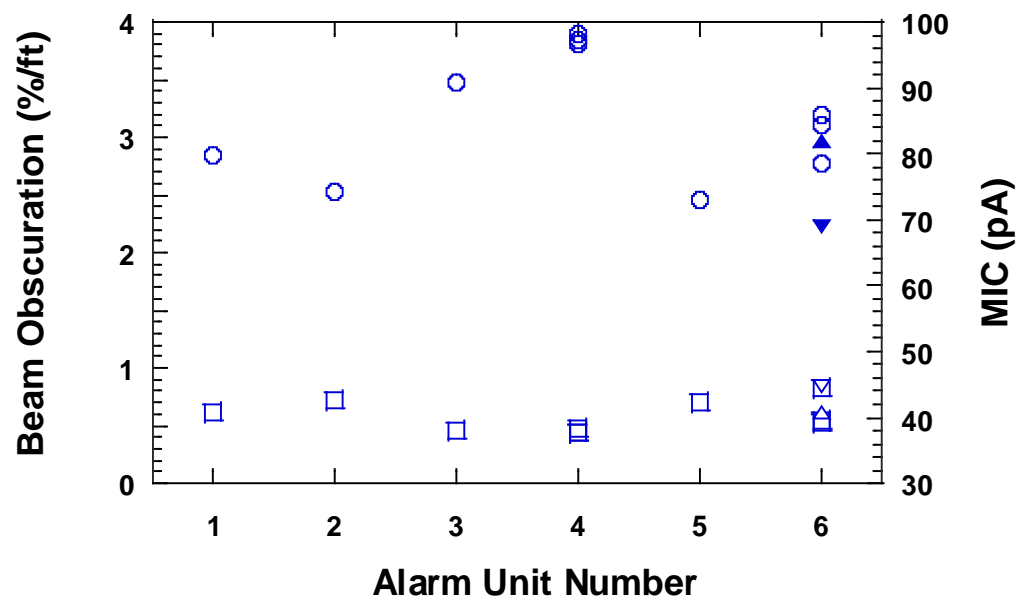

Figure 49. Smoke box results for photoelectric alarm P03. $\mathrm{u}_{\mathrm{c}, \mathrm{r}}($ beam $)=4.0 \%, \mathrm{u}_{\mathrm{c}}(\mathrm{MIC})=0.2 \mathrm{pA}$.

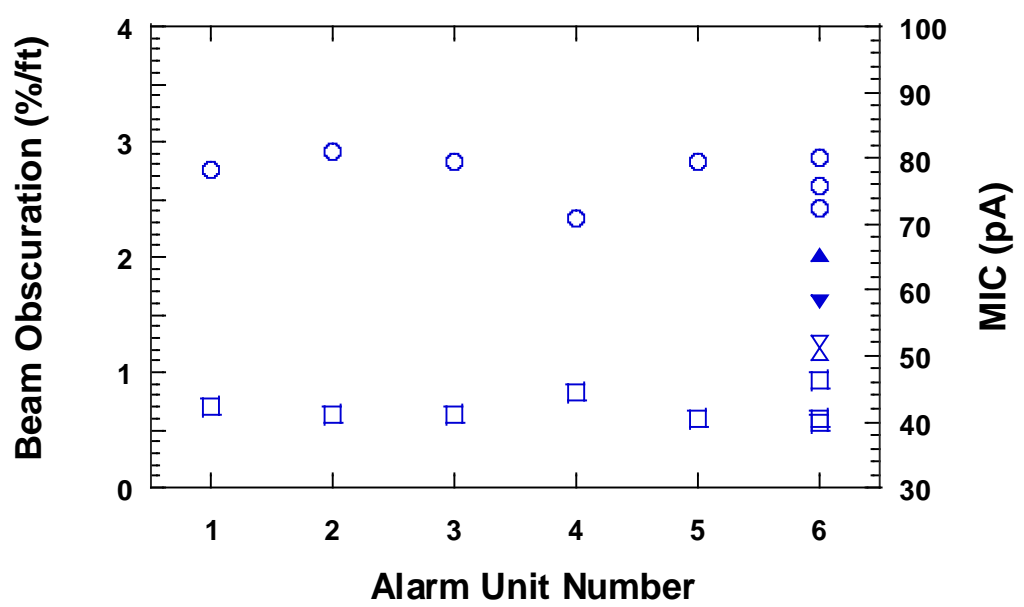

Figure 50. Smoke box results for photoelectric alarm P04. $\mathrm{u}_{\mathrm{c}, \mathrm{r}}($ beam $)=4.0 \%, \mathrm{u}_{\mathrm{c}}(\mathrm{MIC})=0.2 \mathrm{pA}$. 


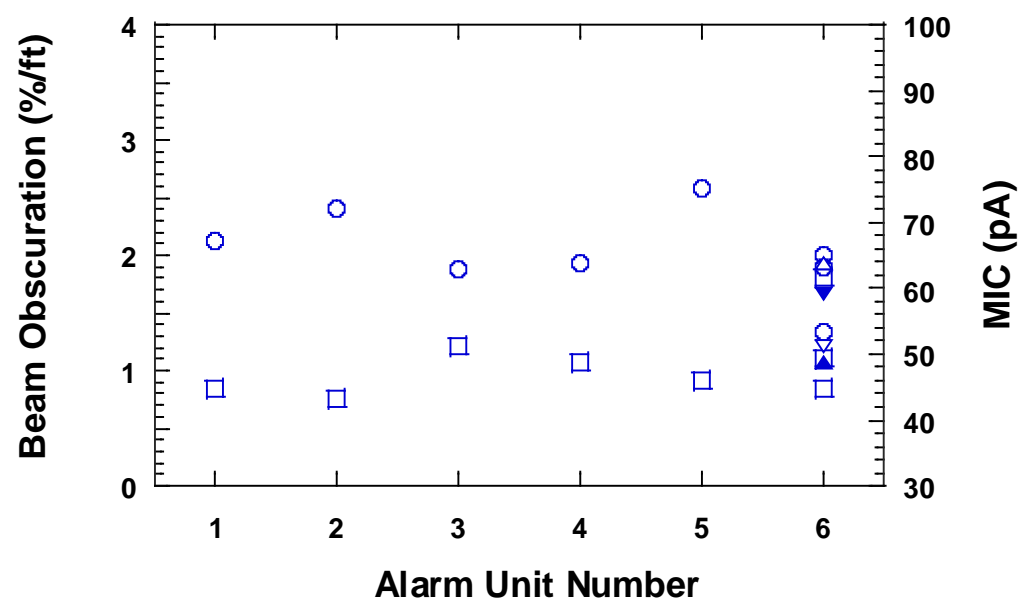

Figure 51. Smoke box results for photoelectric alarm P05. $\mathrm{u}_{\mathrm{c}, \mathrm{r}}($ beam $)=4.0 \%, \mathrm{u}_{\mathrm{c}}(\mathrm{MIC})=0.2 \mathrm{pA}$.

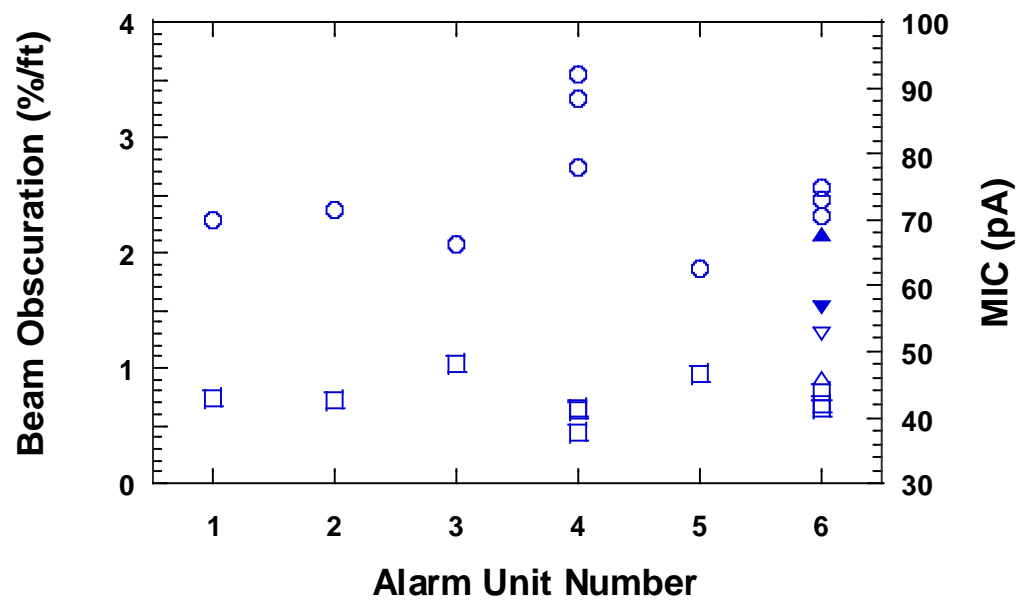

Figure 52. Smoke box results for photoelectric alarm P06. $\mathrm{u}_{\mathrm{c}, \mathrm{r}}($ beam $)=4.0 \%, \mathrm{u}_{\mathrm{c}}(\mathrm{MIC})=0.2 \mathrm{pA}$.

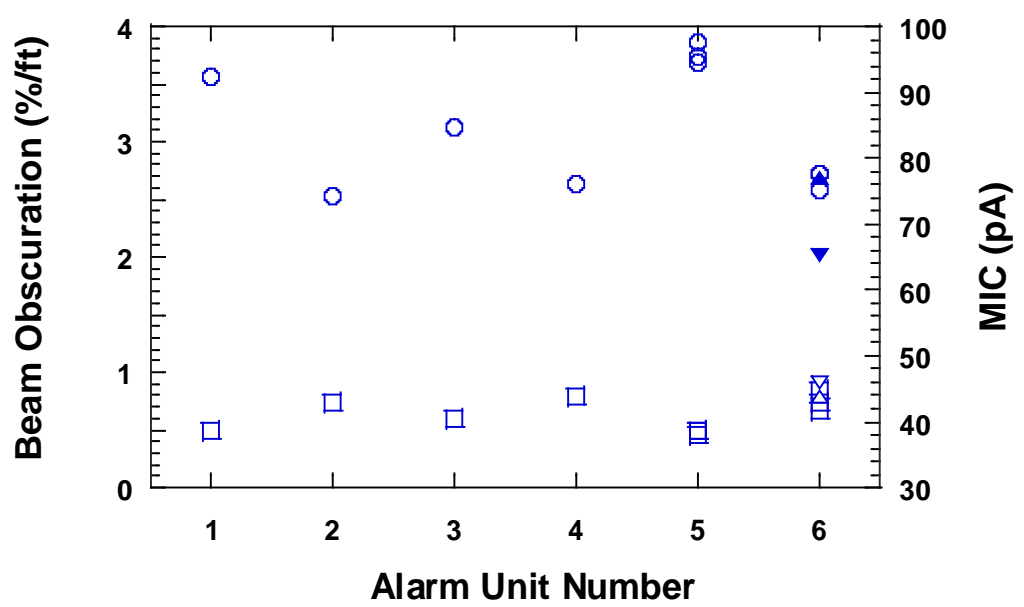

Figure 53. Smoke box results for photoelectric alarm P07. $\mathrm{u}_{\mathrm{c}, \mathrm{r}}($ beam $)=4.0 \%, \mathrm{u}_{\mathrm{c}}(\mathrm{MIC})=0.2 \mathrm{pA}$. 


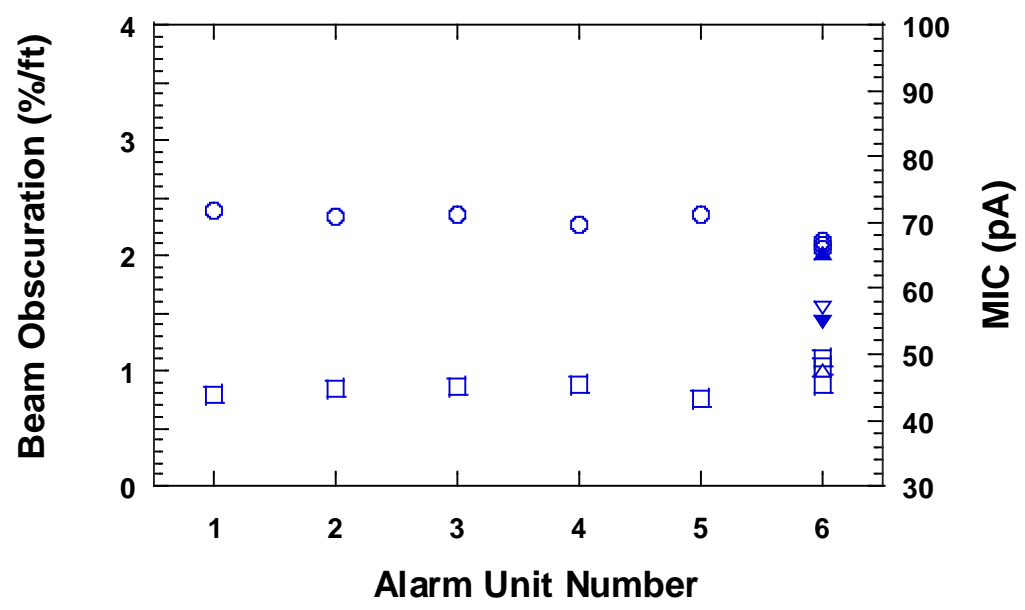

Figure 54. Smoke box results for photoelectric alarm P08. $\mathrm{u}_{\mathrm{c}, \mathrm{r}}($ beam $)=4.0 \%, \mathrm{u}_{\mathrm{c}}(\mathrm{MIC})=0.2 \mathrm{pA}$.

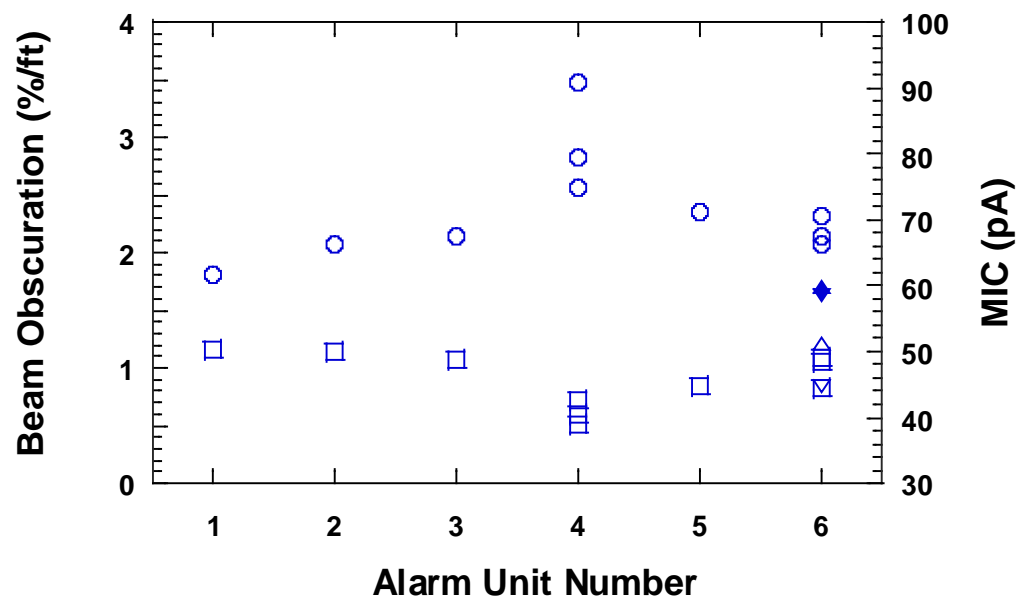

Figure 55. Smoke box results for photoelectric alarm P09. $\mathrm{u}_{\mathrm{c}, \mathrm{r}}($ beam $)=4.0 \%, \mathrm{u}_{\mathrm{c}}(\mathrm{MIC})=0.2 \mathrm{pA}$.

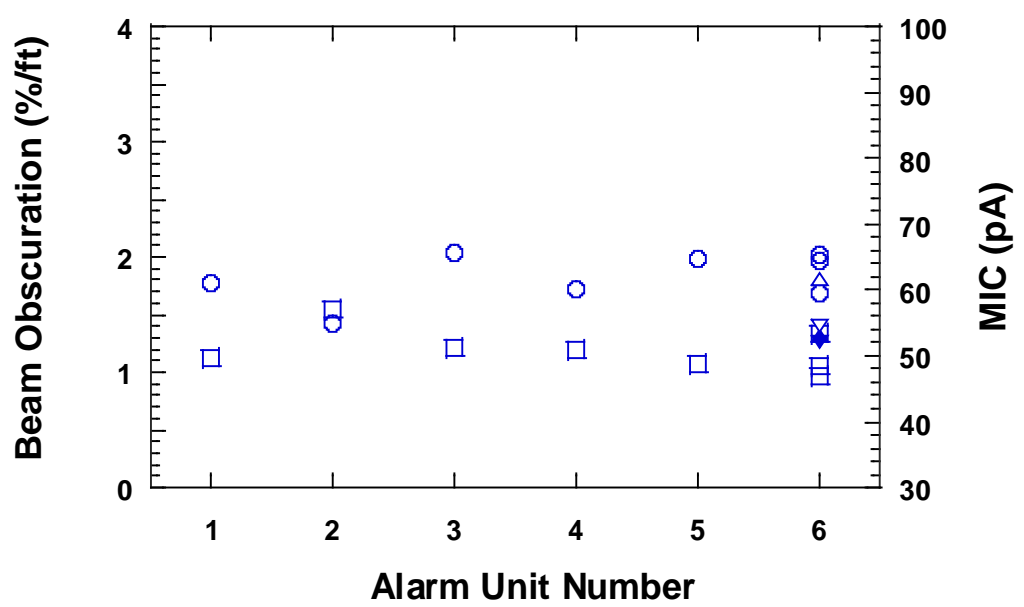

Figure 56. Smoke box results for photoelectric alarm P10. $\mathrm{u}_{\mathrm{c}, \mathrm{r}}($ beam $)=4.0 \%, \mathrm{u}_{\mathrm{c}}(\mathrm{MIC})=0.2 \mathrm{pA}$. 


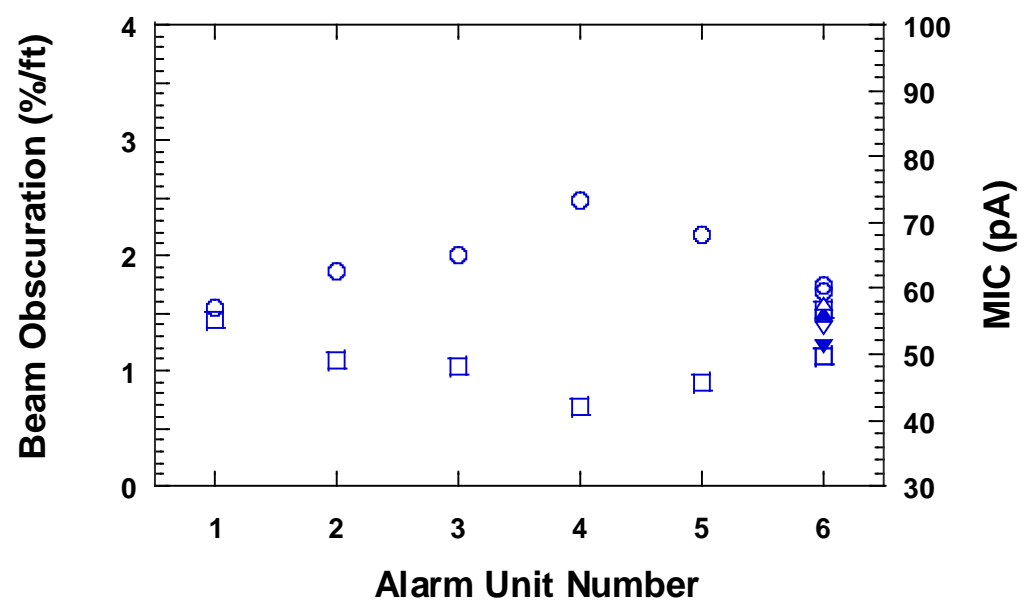

Figure 57. Smoke box results for photoelectric alarm P11. $\mathrm{u}_{\mathrm{c}, \mathrm{r}}($ beam $)=4.0 \%, \mathrm{u}_{\mathrm{c}}(\mathrm{MIC})=0.2 \mathrm{pA}$.

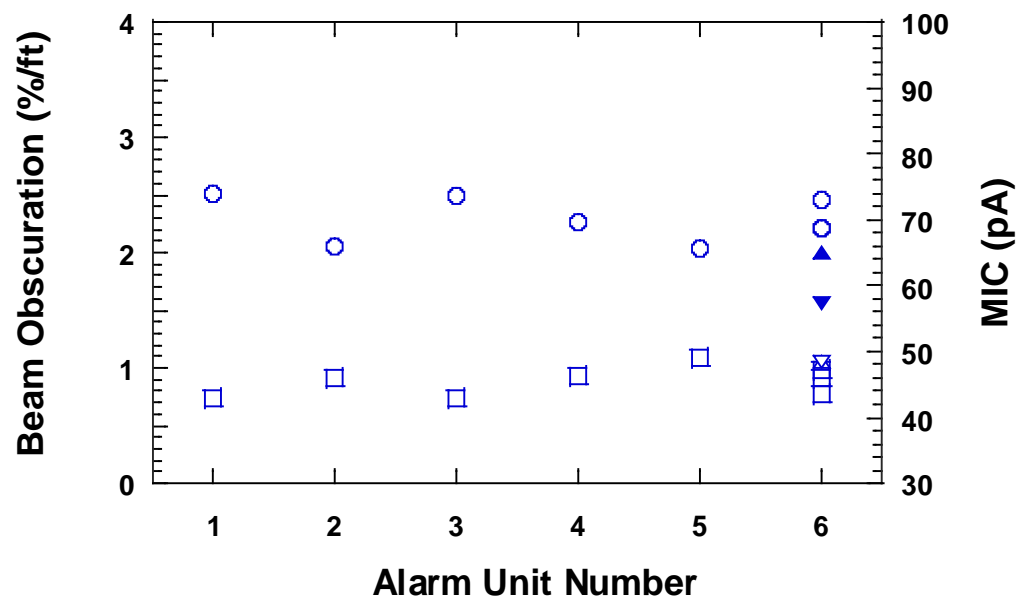

Figure 58. Smoke box results for photoelectric alarm P12. $\mathrm{u}_{\mathrm{c}, \mathrm{r}}($ beam $)=4.0 \%, \mathrm{u}_{\mathrm{c}}(\mathrm{MIC})=0.2 \mathrm{pA}$.

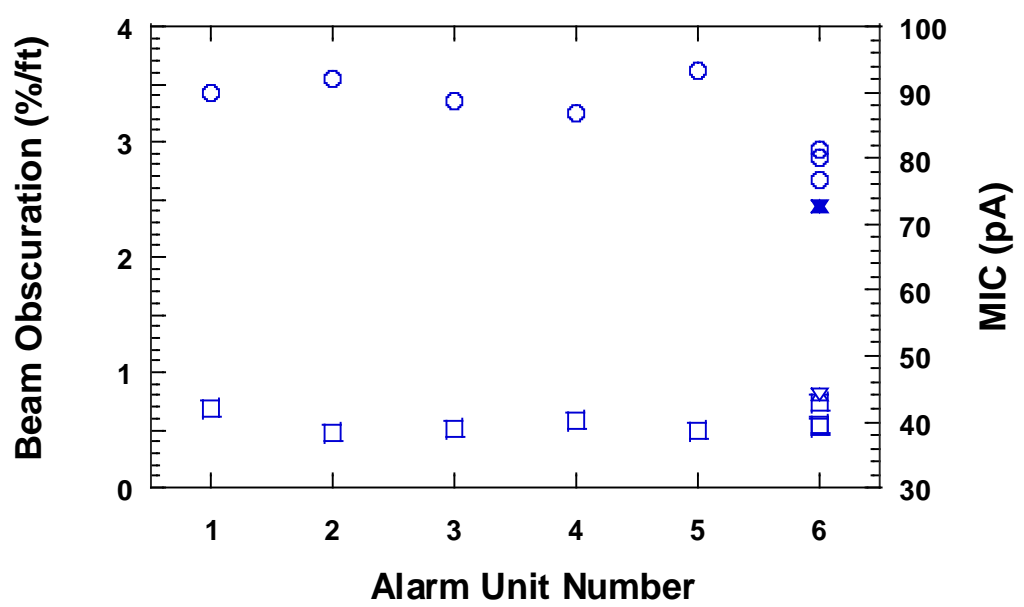

Figure 59. Smoke box results for photoelectric alarm P14. $\mathrm{u}_{\mathrm{c}, \mathrm{r}}($ beam $)=4.0 \%, \mathrm{u}_{\mathrm{c}}(\mathrm{MIC})=0.2 \mathrm{pA}$. 
One photoelectric alarm model, P13, did not alarm in the smoke box experiments. It did respond to smoke being forced into the sensing chamber. It did not have any markings indicating it was listed to ANSI UL/217 nor any listing mark from a testing laboratory. Its response during full-scale experiments was documented, but it was not used in any analysis of smoke alarm performance.

For smoke alarms that contain photoelectric sensors beam obscuration is a better representation of sensitivity than the MIC current. The best-case orientation and worst-case orientation at twice the velocity results were typically more sensitive than the standard worst-case orientation results, with the worst-case orientation at twice the velocity usually more sensitive than the best-case orientation. The average beam obscuration for the worst-case orientation of each photoelectric alarm model is shown in Figure 60 . The error bars are \pm one standard deviation. The maximum and minimum average sensitivity range of these 13 models was $1.8 \% / \mathrm{ft}(5.8 \% / \mathrm{m})$ and $3.3 \% / \mathrm{ft}(10.4 \% / \mathrm{m})$ respectively, about $45 \%$ of the allowable range in the Standard $(0.50 \% / \mathrm{ft}(1.63 \% / \mathrm{m})$ to $4.00 \% / \mathrm{ft}(12.53 \% / \mathrm{m}))$ and skewed to the less sensitive bound.

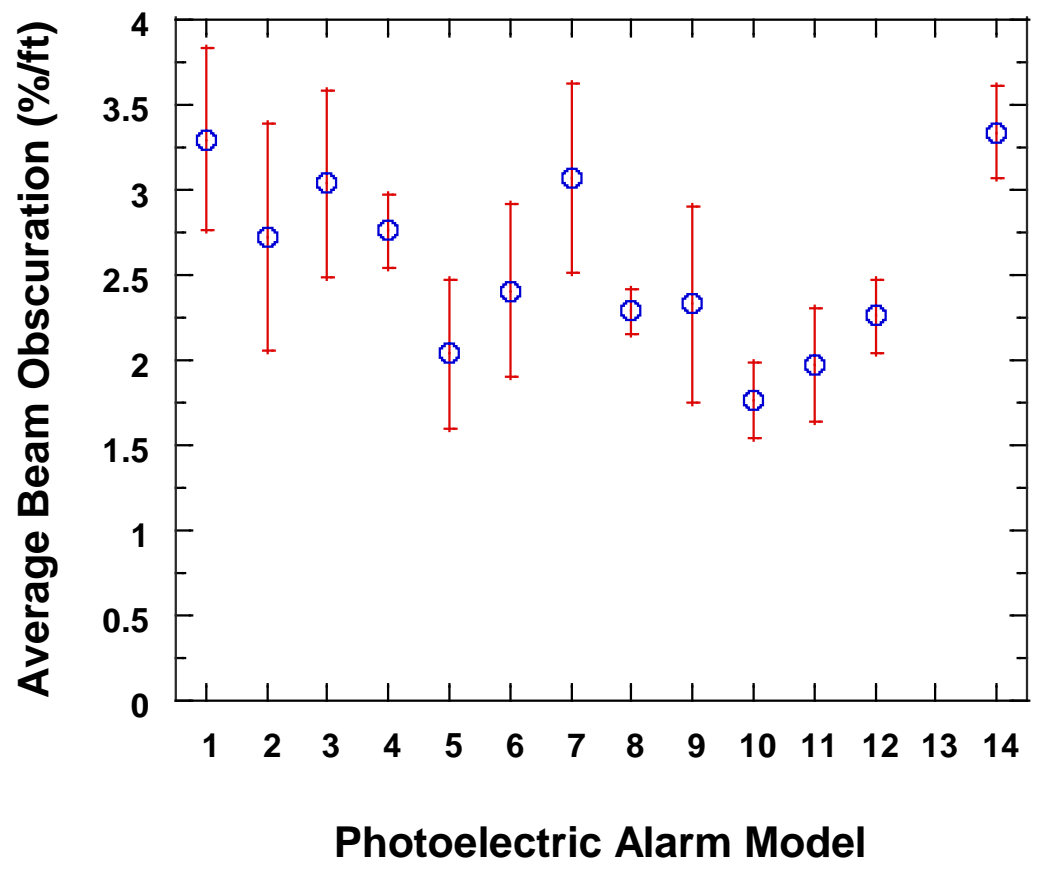

Figure 60. Average beam obscuration of the photoelectric alarm model results.

The smoke box results for photoelectric / carbon monoxide alarm models are presented in Figures 61-67 and for photoelectric / thermal alarm models in Figures 68 and 69. 


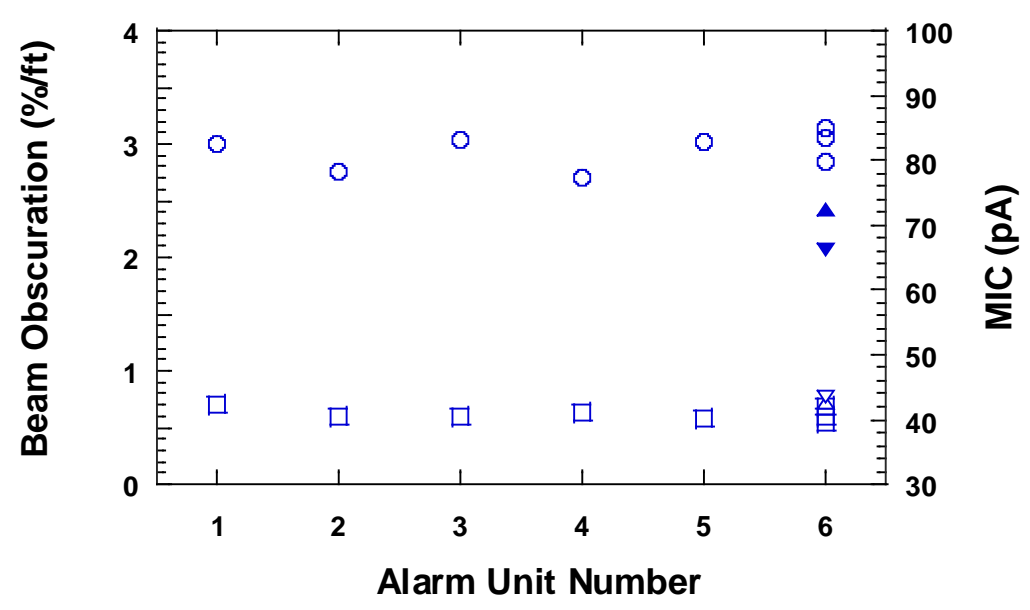

Figure 61. Smoke box results for photoelectric / carbon monoxide alarm PCO01. $\mathrm{u}_{\mathrm{c}, \mathrm{r}}(\mathrm{beam})=4.0 \%$, $\mathrm{u}_{\mathrm{c}}(\mathrm{MIC})=0.2 \mathrm{pA}$.

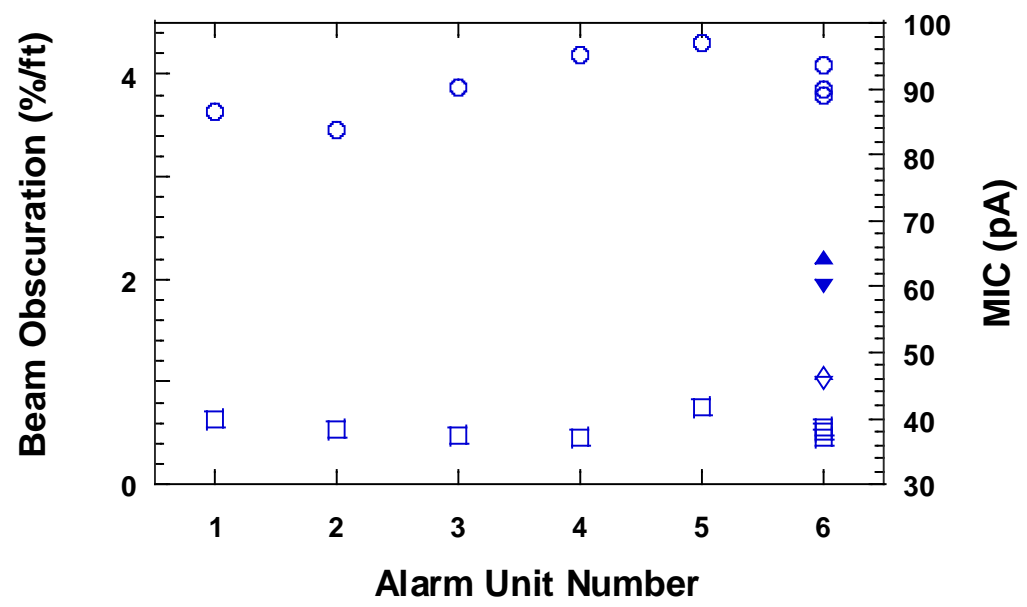

Figure 62. Smoke box results for photoelectric / carbon monoxide alarm PCO02. $\mathrm{u}_{\mathrm{c}, \mathrm{r}}(\mathrm{beam})=4.0 \%$, $\mathrm{u}_{\mathrm{c}}(\mathrm{MIC})=0.2 \mathrm{pA}$.

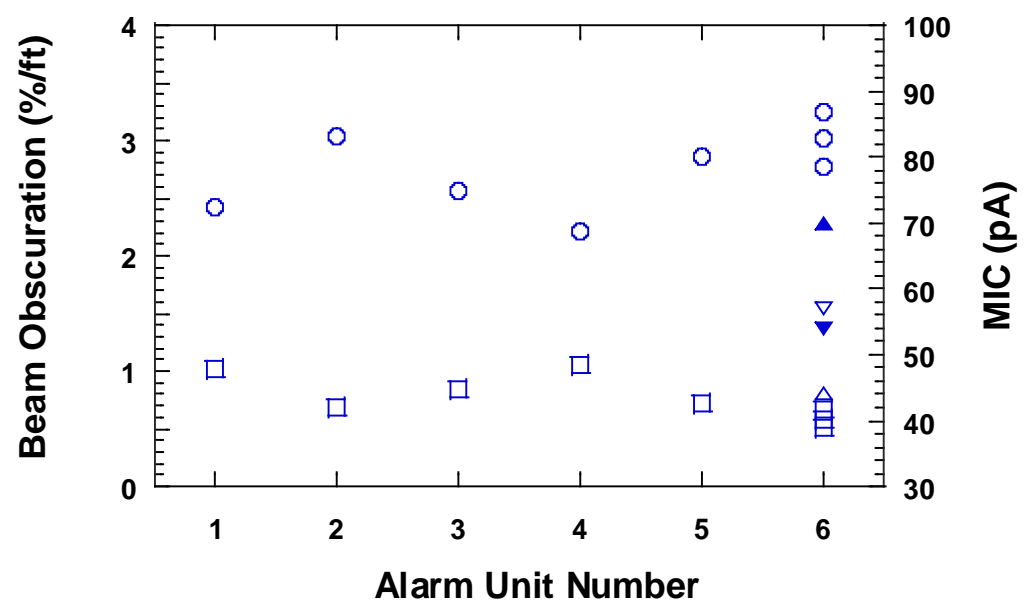

Figure 63. Smoke box results for photoelectric / carbon monoxide alarm PCO03. $\mathrm{u}_{\mathrm{c}, \mathrm{r}}(\mathrm{beam})=4.0 \%$, $\mathrm{u}_{\mathrm{c}}(\mathrm{MIC})=0.2 \mathrm{pA}$. 


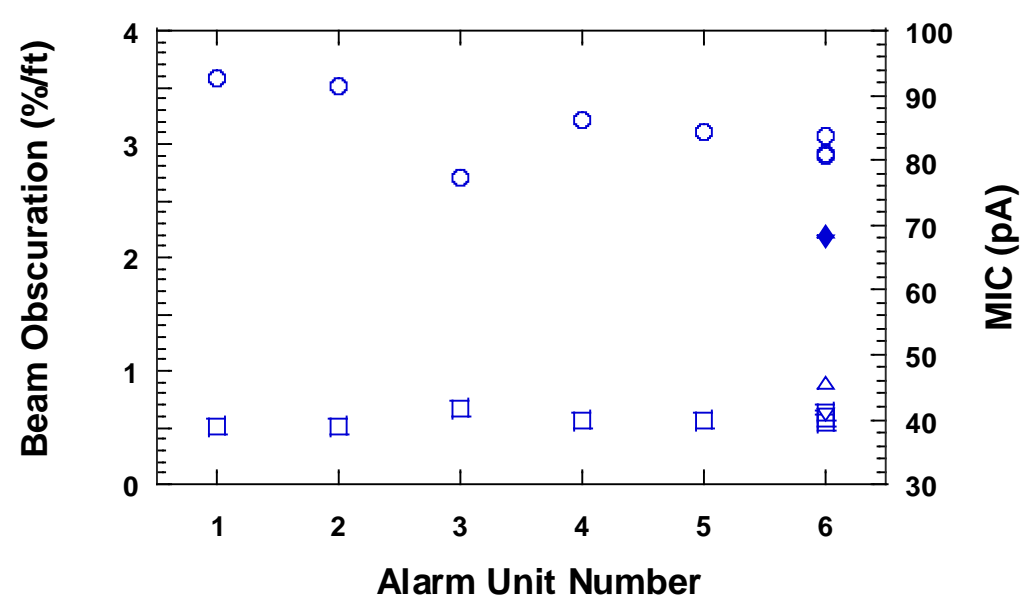

Figure 64. Smoke box results for photoelectric / carbon monoxide alarm PCO04. $\mathrm{u}_{\mathrm{c}, \mathrm{r}}(\mathrm{beam})=4.0 \%$, $\mathrm{u}_{\mathrm{c}}(\mathrm{MIC})=0.2 \mathrm{pA}$.

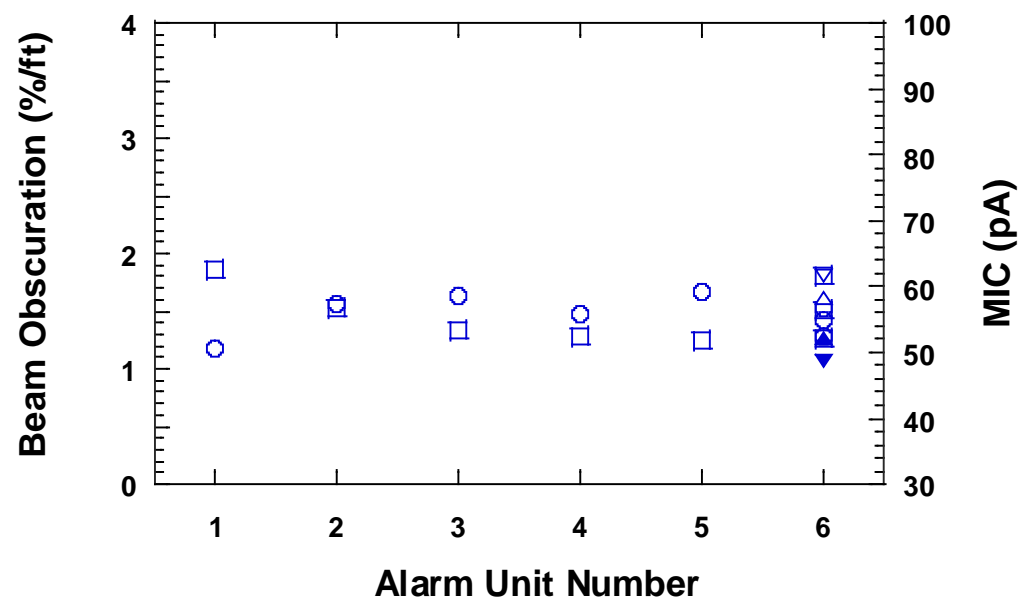

Figure 65. Smoke box results for photoelectric / carbon monoxide alarm PCO05. $\mathrm{u}_{\mathrm{c}, \mathrm{r}}(\mathrm{beam})=4.0 \%$, $\mathrm{u}_{\mathrm{c}}(\mathrm{MIC})=0.2 \mathrm{pA}$.

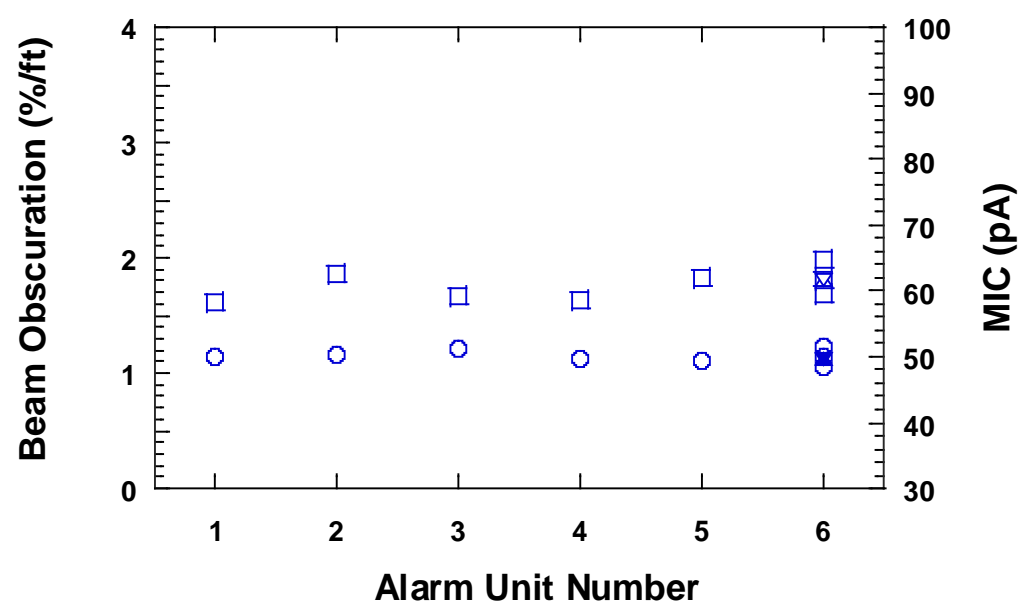

Figure 66. Smoke box results for photoelectric / carbon monoxide alarm PCO06. $\mathrm{u}_{\mathrm{c}, \mathrm{r}}(\mathrm{beam})=4.0 \%$, $\mathrm{u}_{\mathrm{c}}(\mathrm{MIC})=0.2 \mathrm{pA}$. 


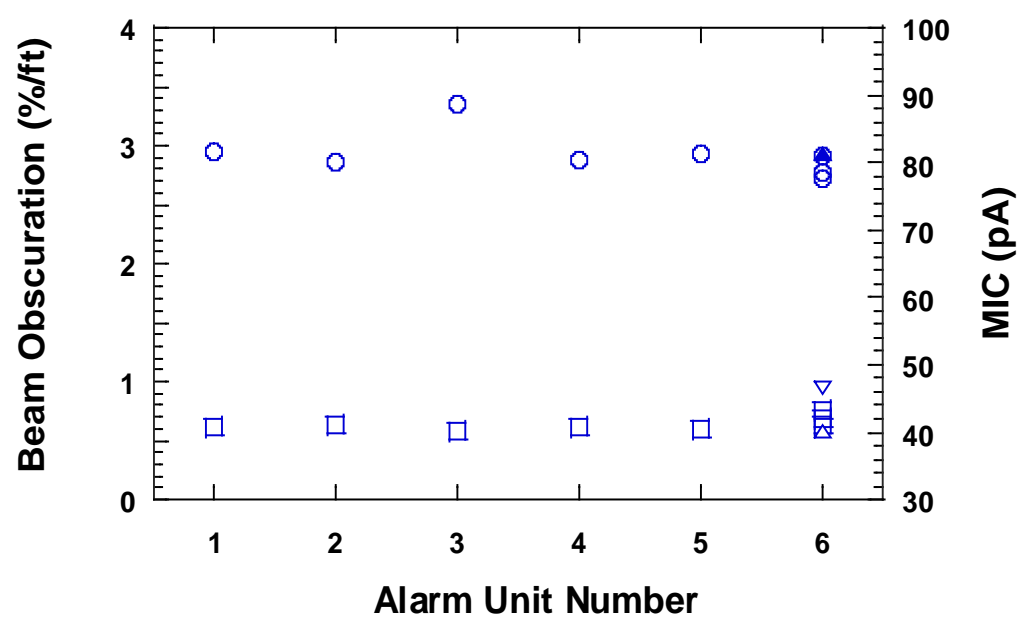

Figure 67. Smoke box results for photoelectric / carbon monoxide alarm PCO07. $\mathrm{u}_{\mathrm{c}, \mathrm{r}}(\mathrm{beam})=4.0 \%$, $\mathrm{u}_{\mathrm{c}}(\mathrm{MIC})=0.2 \mathrm{pA}$.

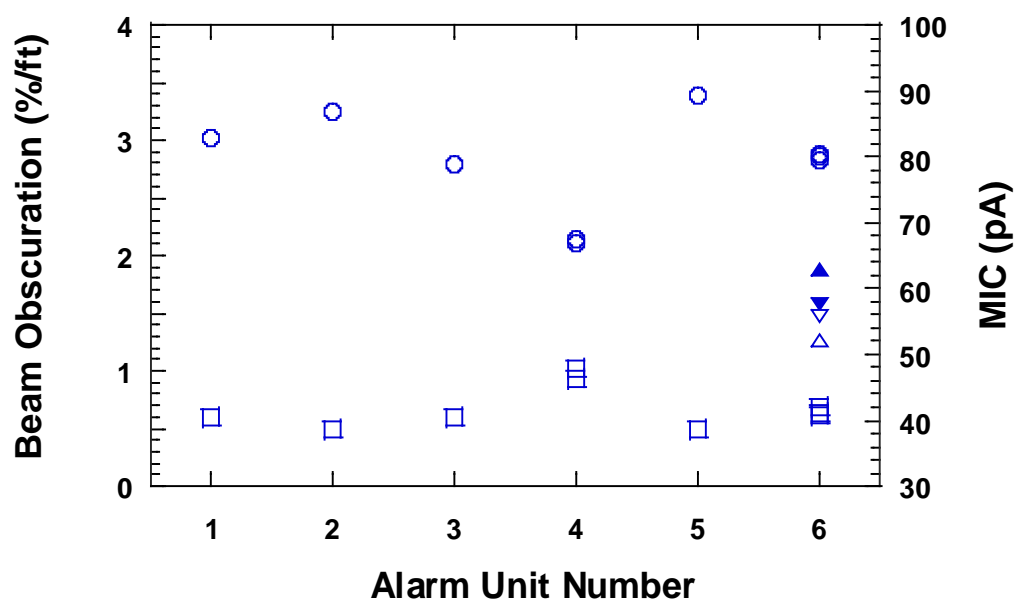

Figure 68. Smoke box results for photoelectric / thermal alarm PT01. $\mathrm{u}_{\mathrm{c}, \mathrm{r}}(\mathrm{beam})=4.0 \%, \mathrm{u}_{\mathrm{c}}(\mathrm{MIC})=0.2$ pA.

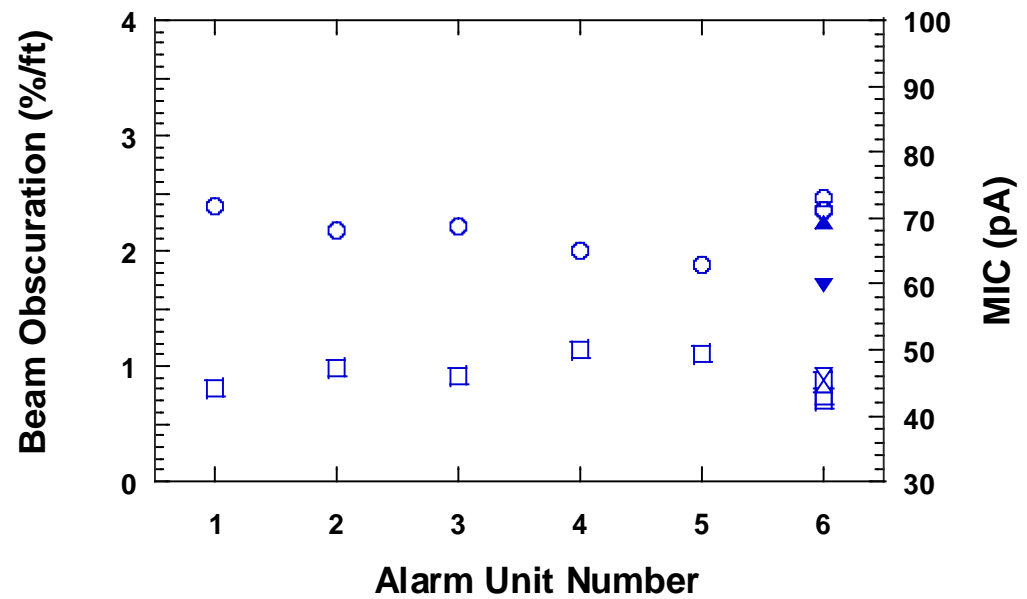

Figure 69. Smoke box results for photoelectric / thermal alarm PT02. $\mathrm{u}_{c, \mathrm{r}}(\mathrm{beam})=4.0 \%$, $\mathrm{u}_{\mathrm{c}}(\mathrm{MIC})=0.2$ 
pA.

Similar to the photoelectric sensor models, the best-case orientation and worst-case orientation at twice the velocity results were typically more sensitive than the standard worst-case orientation results, with the worst-case orientation at twice the velocity usually more sensitive than the best-case orientation. The average beam obscuration for the worst-case orientation of each photoelectric / carbon monoxide alarm model and photoelectric / thermal alarm model is shown in Figure 70. The error bars are \pm one standard deviation. The maximum and minimum sensitivity range of these nine models was $1.1 \% / \mathrm{ft}$ (3.6 $\% / \mathrm{m})$ and $3.9 \% / \mathrm{ft}(12.2 \% / \mathrm{m})$ respectively, about $80 \%$ of the allowable range in the standard $(0.50 \% / \mathrm{ft}$ $(1.63 \% / \mathrm{m})$ to $4.00 \% / \mathrm{ft}(12.53 \% / \mathrm{m}))$. and a much wider range than the alarm models with only photoelectric sensors.

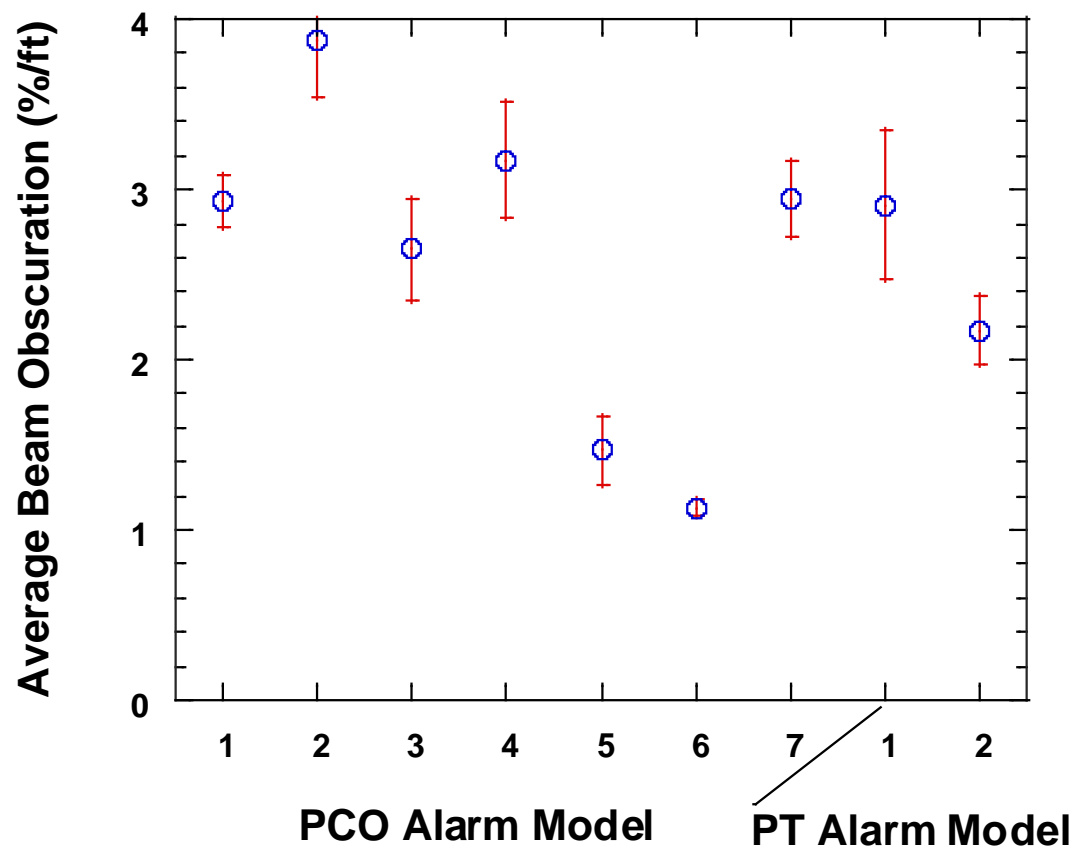

Figure 70. Average beam obscuration of the PCO and PT alarm model results.

\subsection{Test Room Fire and Cooking Source Profiles}

Representative experimental results are presented in this section. Data files for each experiment can be found in the companion data documentation located at http://doi.org/10.18434/T4530X.

\subsubsection{Flaming Polyurethane Foam}

ANSI/UL 217-2015 specifies a flaming polyurethane foam smoke profile in terms of the bounds on the ceiling beam transmittance as a function of time and the ceiling beam transmittance versus MIC current. Figures 71 and 72 show the approximate bounding curves for flaming polyurethane foam and three 
representative experimental results. The flaming foam experiments conducted in this study met the smoke profile specifics to a large extent.

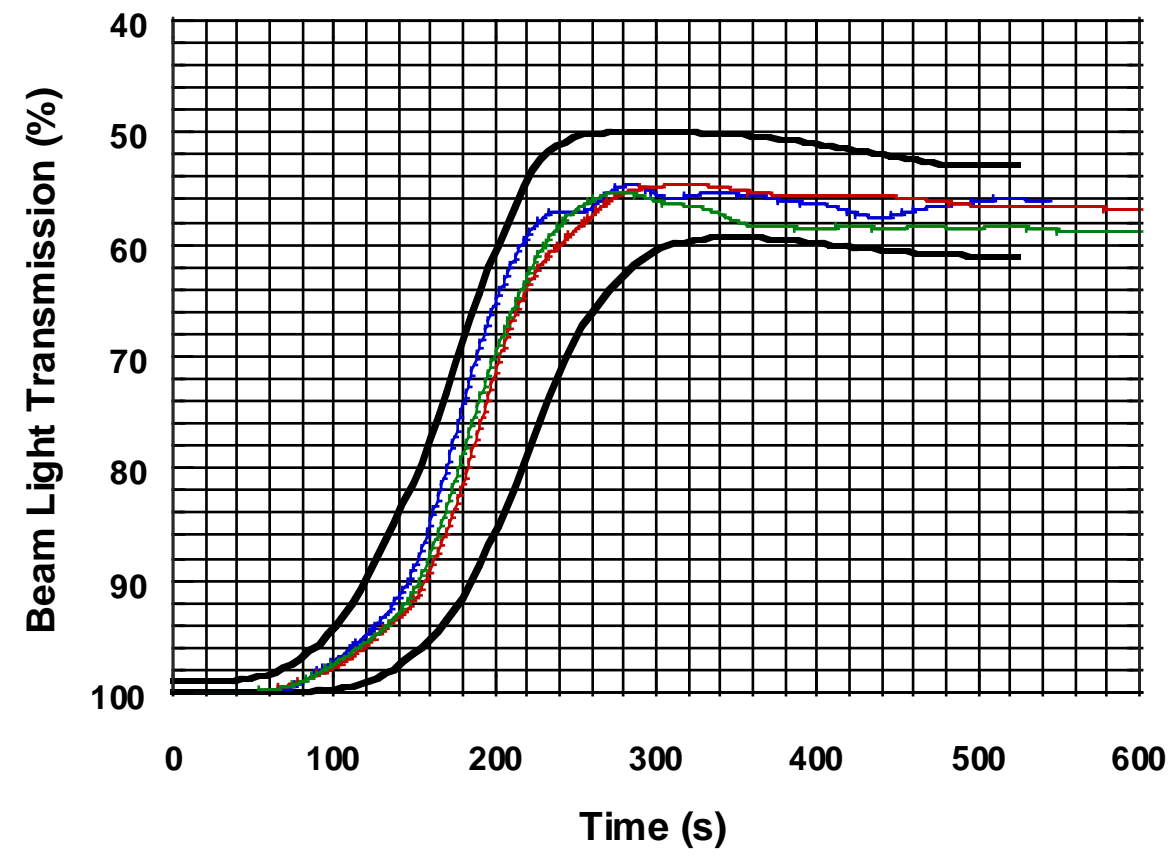

Figure 71. Beam light transmission for flaming foam experiments. Thick lines are bounding curves from the Standard. $\mathrm{u}_{\mathrm{c}, \mathrm{r}}($ beam $)=0.054 \times(100$-light transmission \%) $\%$.

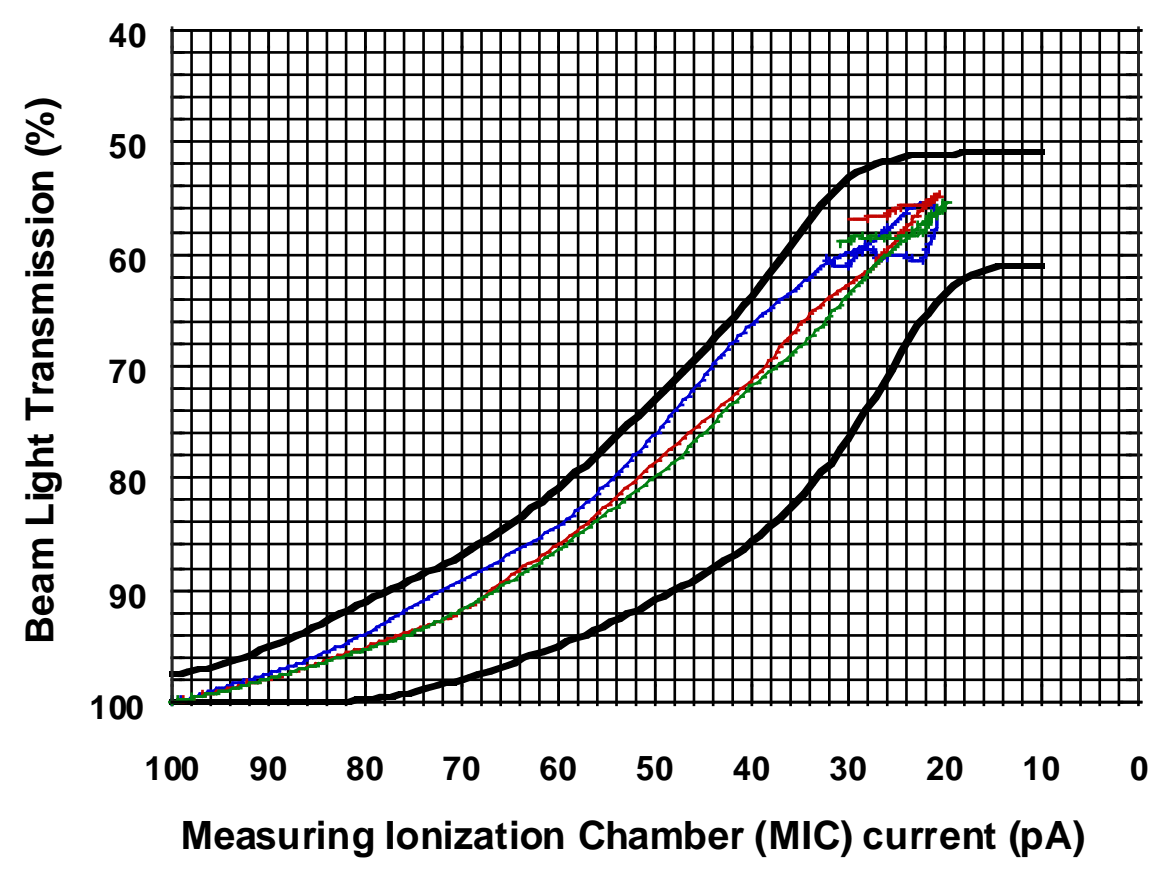

Figure 72. Beam light transmission versus MIC current for the flaming foam experiments. Thick lines are 
bounding curves from the Standard. $\mathrm{u}_{\mathrm{c}}(\mathrm{MIC})=0.2 \mathrm{pA}$.

Figure 73 shows representative results for measurements at the ceiling for air temperature and relative humidity. The experiments were conducted during the summer and the initial temperature and humidity at times deviated from the specified range in the standard of between $40 \%$ to $60 \%$ relative humidity, and between $20^{\circ} \mathrm{C}$ to $27^{\circ} \mathrm{C}$. Representative results for carbon dioxide, carbon monoxide and hydrogen cyanide are shown in Figures 74 and 75.

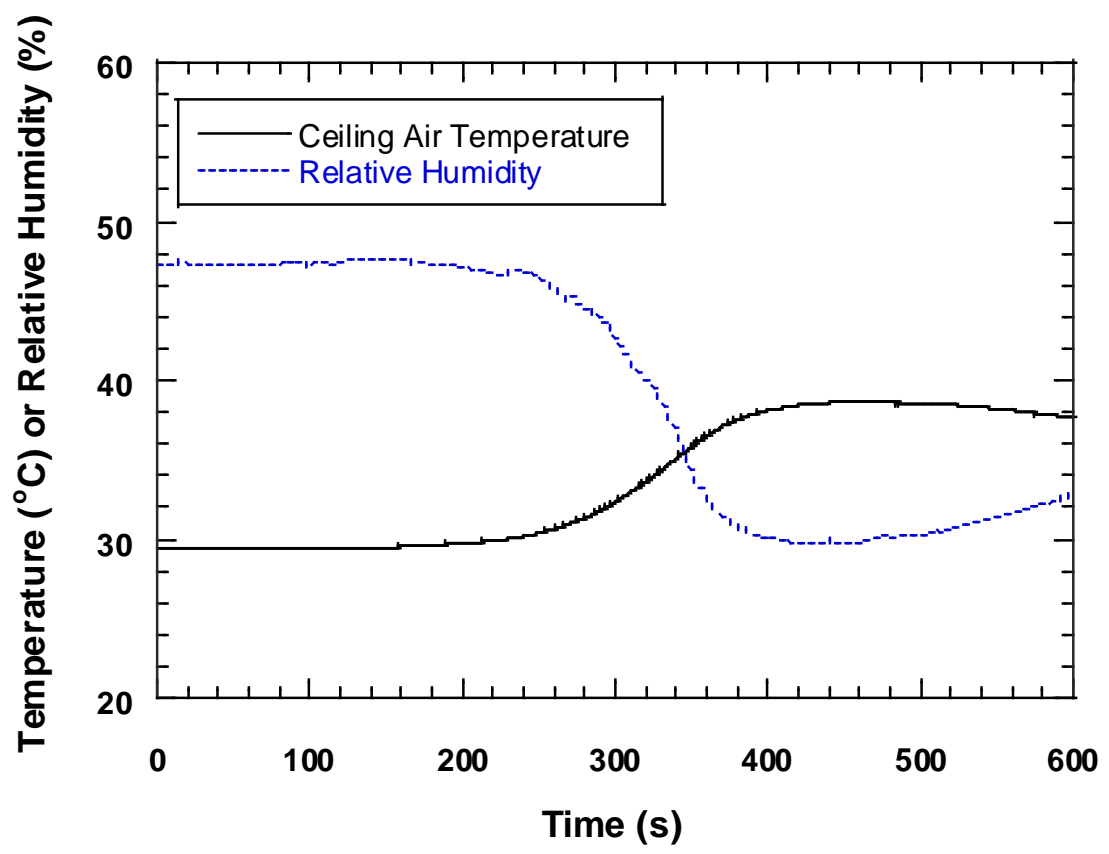

Figure 73. Temperature and relative humidity for a flaming foam experiment. $\mathrm{u}_{\mathrm{c}}(\mathrm{T})=1.0{ }^{\circ} \mathrm{C}, \mathrm{u}_{\mathrm{c}}(\mathrm{RH})=$ $5.0 \%$.

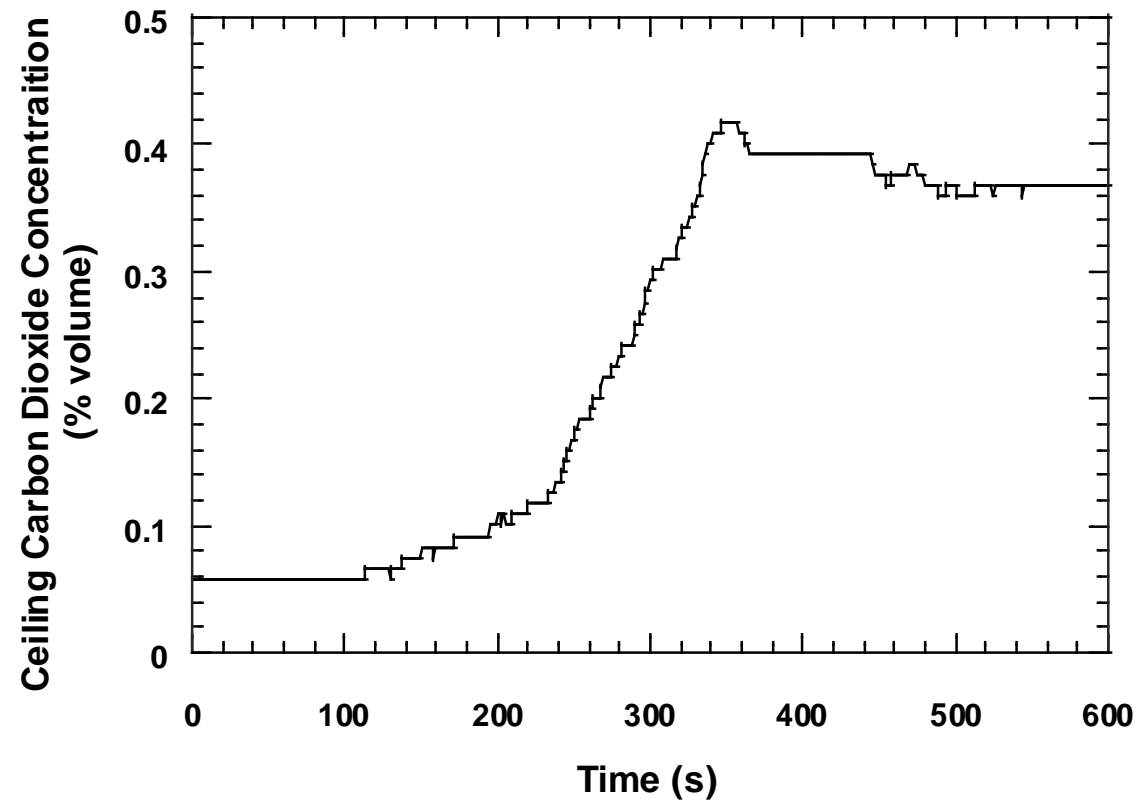


Figure 74. Carbon dioxide concentration for a flaming foam experiment. $\mathrm{u}_{\mathrm{c}}(\mathrm{CO} 2)=0.005 \%$ vol.

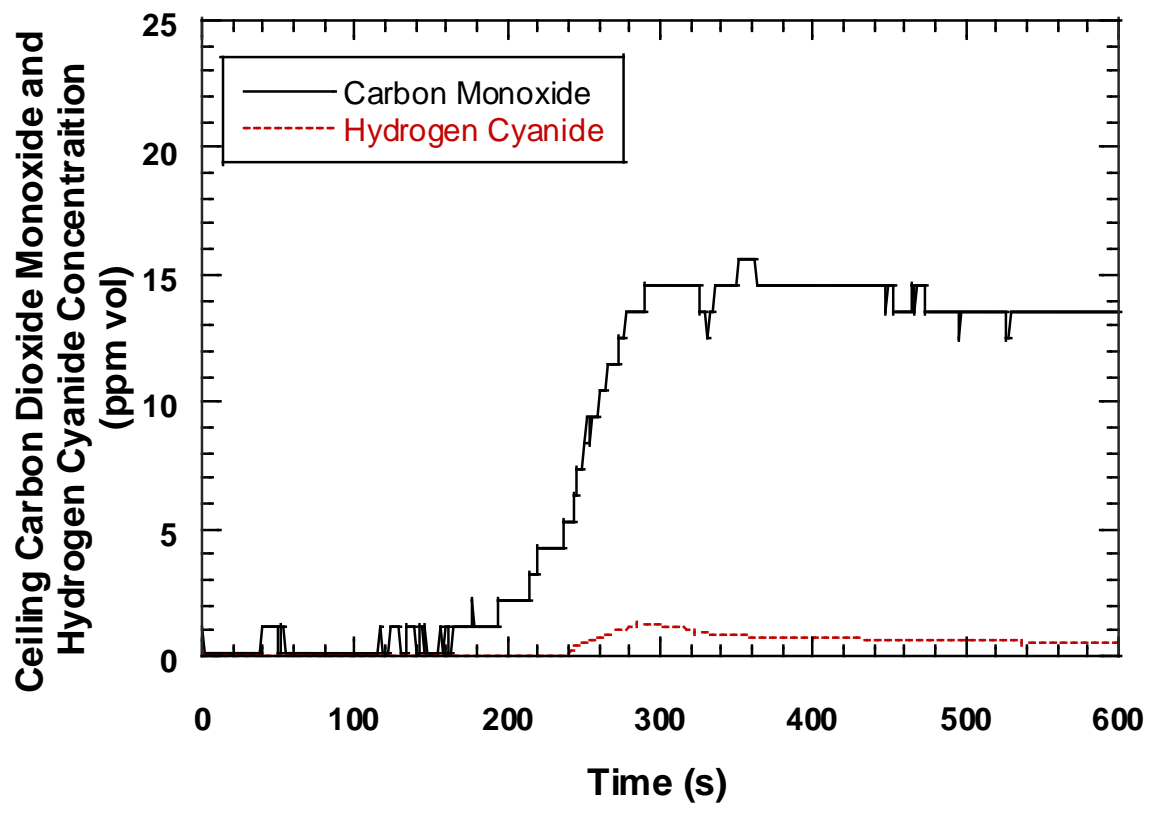

Figure 75. Carbon monoxide and $\mathrm{HCN}$ concentration for a flaming foam experiment. $\mathrm{u}_{\mathrm{c}}(\mathrm{CO})=2 \mathrm{ppm}$ vol., $\mathrm{u}_{\mathrm{c}}(\mathrm{HCN})=0.1 \mathrm{ppm}$ vol.

\subsubsection{Smoldering Polyurethane Foam}

ANSI/UL 217-2015 specifies a smoldering polyurethane foam smoke profile in terms of bounds on the ceiling beam transmittance as a function of time and the ceiling beam transmittance versus MIC current. Figures 76 and 77 show the approximate bounding curves for the smoldering polyurethane foam and three representative experiments conducted in this study. The beam obscuration smoke development curve was offset to a position where its value at $1.00 \% / \mathrm{ft}(3.24 \% / \mathrm{m})$ is aligned to a time of $2500 \mathrm{~s}$, as is specified in the Standard. The results show that the experimental beam light transmission results tended to fall within the bounding curves specified in the Standard, but the beam versus MIC results fell outside the bounding curves specified in the Standard where the beam light transmission is somewhat lower for a given MIC current than the bounding curves. This implies different smoke properties, most-likely differences in the particle size distribution. The exact differences are beyond the scope of this study. In order to assess smoke alarm performance in these experiments and relate them to expected performance of smoldering fire tests that follow the beam transmission versus MIC bounds in the Standard it is assumed that the beam obscuration can be used to assess smoke alarms that have photoelectric sensors, and that the MIC current can be used to assess smoke alarms that have ionization sensors. The performance limits are detailed in the analysis section. 


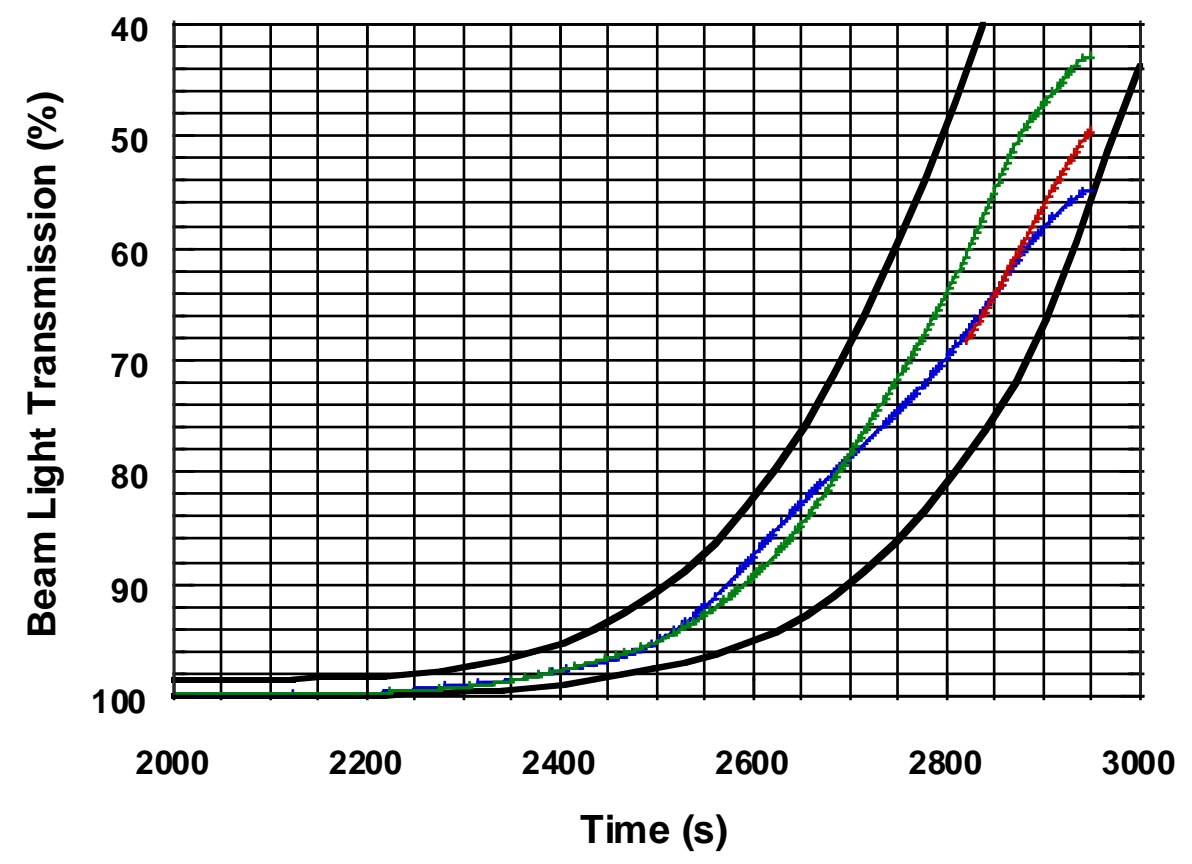

Figure 76. Beam light transmission for smoldering foam experiments. Thick lines are bounding curves from the Standard. $\mathrm{u}_{\mathrm{c}, \mathrm{r}}($ beam $)=0.054 \times(100$-light transmission \%) $\%$.

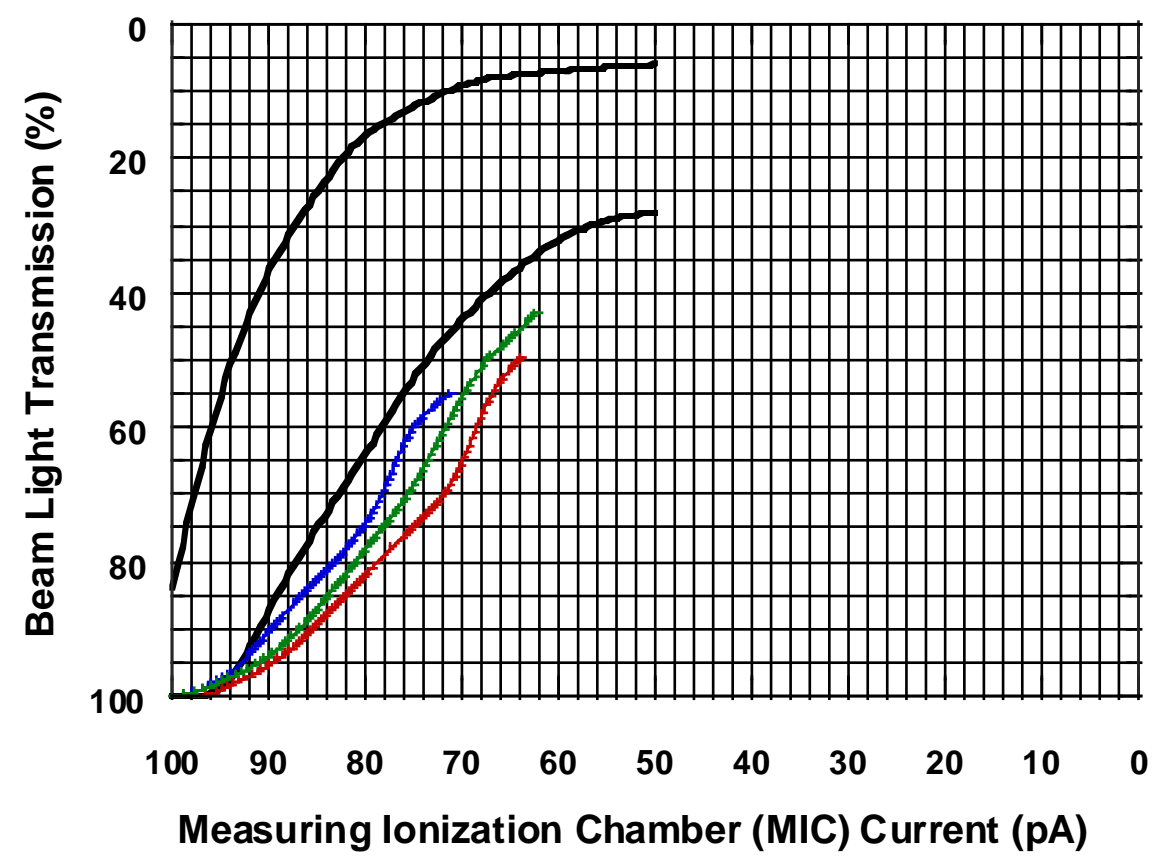


Figure 77. Beam light transmission versus MIC current for smoldering foam experiments. Thick lines are bounding curves from the Standard. $\mathrm{u}_{\mathrm{c}}(\mathrm{MIC})=0.2 \mathrm{pA}$.

Figures 78 shows representative results for measurements at the ceiling for air temperature and relative humidity. Representative results for carbon dioxide, carbon monoxide and hydrogen cyanide are shown in Figures 79 and 80.

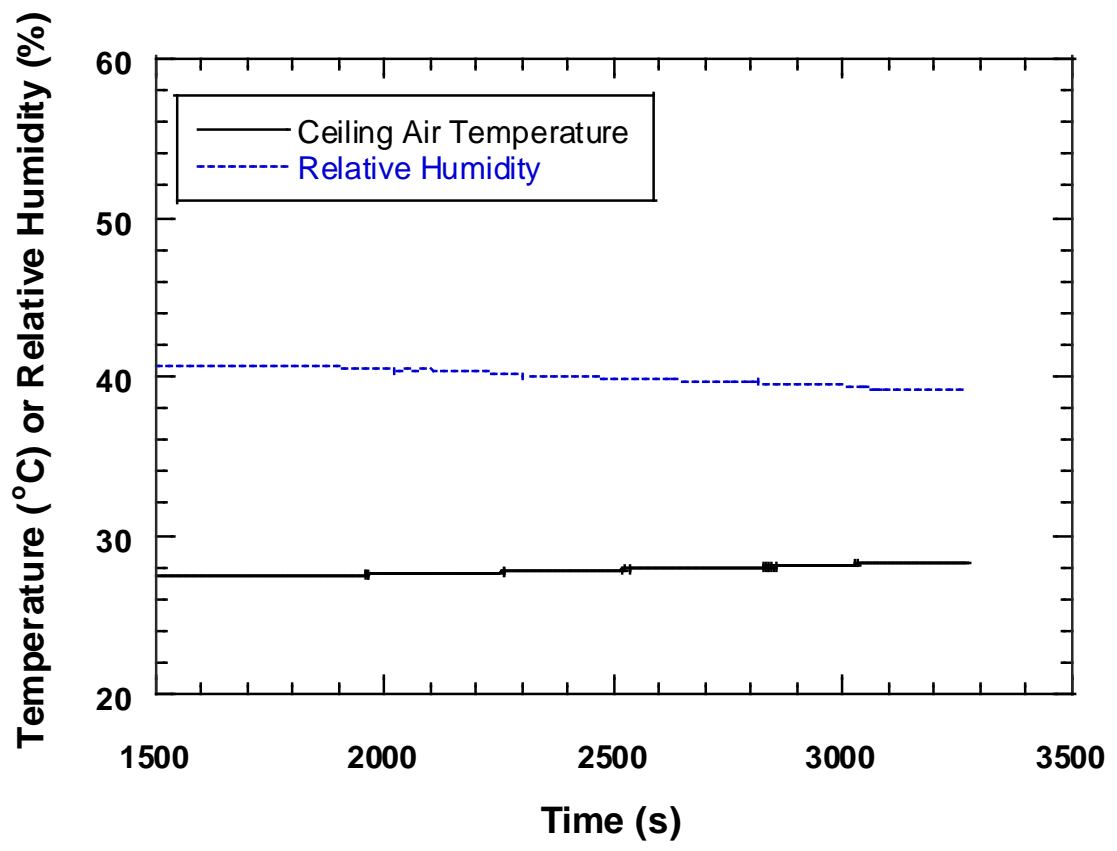

Figure 78. Temperature and relative humidity for a smoldering foam experiment. $\mathrm{u}_{\mathrm{c}}(\mathrm{T})=1.0^{\circ} \mathrm{C}, \mathrm{u}_{\mathrm{c}}(\mathrm{RH})$ $=5.0 \%$.

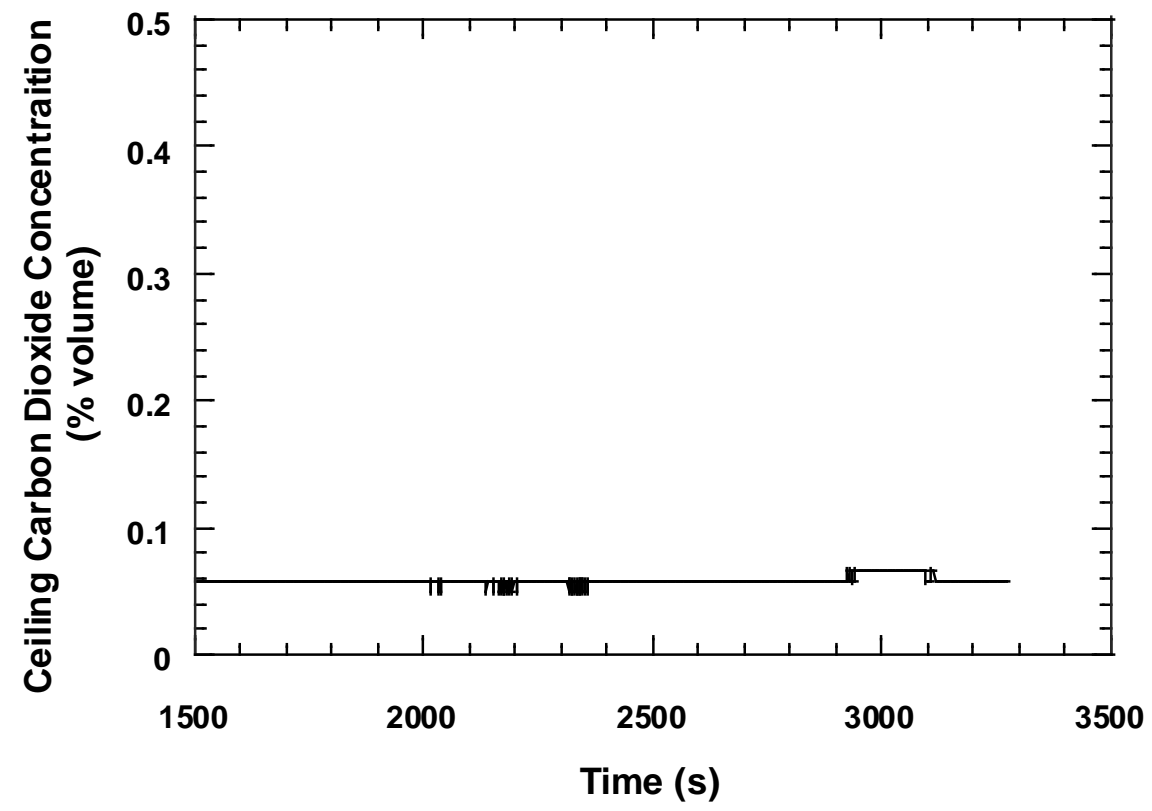


Figure 79. Carbon dioxide concentration for a smoldering foam experiment. $\mathrm{u}_{\mathrm{c}}(\mathrm{CO} 2)=0.005 \%$ vol.

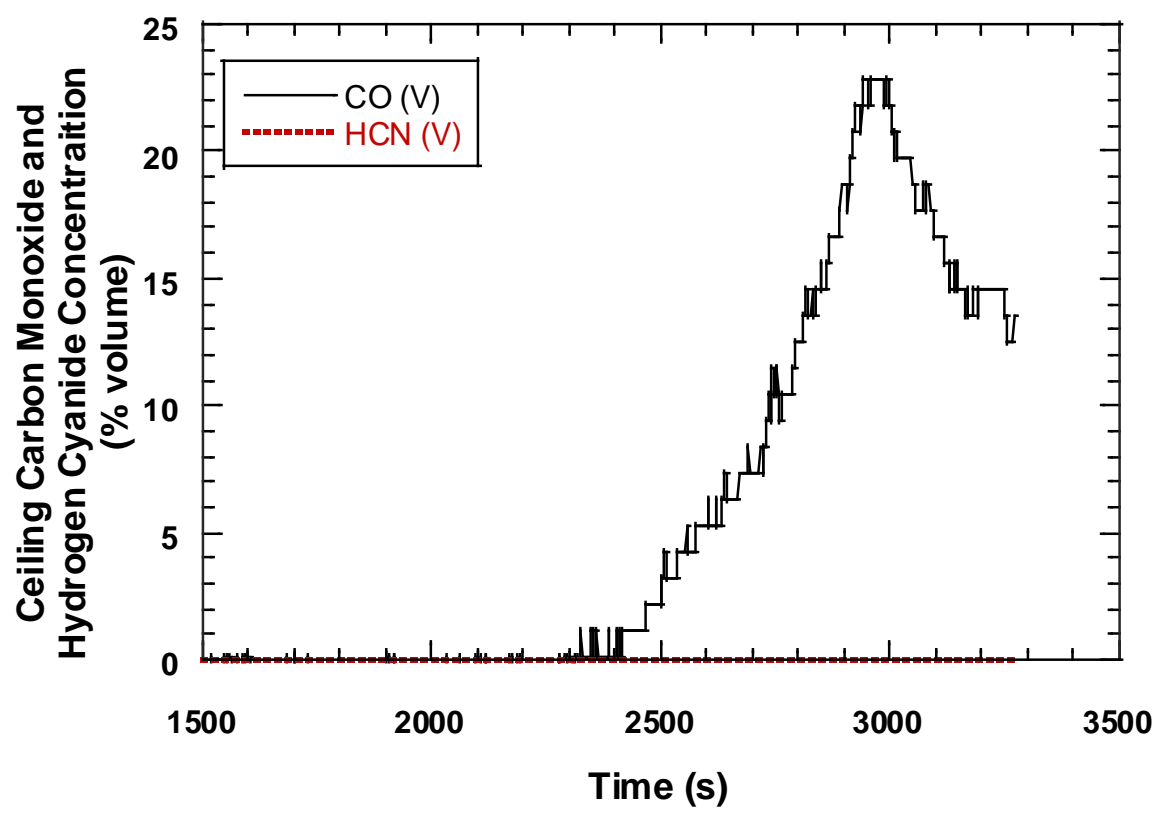

Figure 80. Carbon monoxide and $\mathrm{HCN}$ concentration for a smoldering foam experiment. $\mathrm{u}_{\mathrm{c}}(\mathrm{CO})=2 \mathrm{ppm}$ vol., $\mathrm{u}_{\mathrm{c}}(\mathrm{HCN})=0.1 \mathrm{ppm}$ vol.

During the development of the smoldering foam procedure, experiments were conducted by heating foam with the radiant heaters at higher heater set point temperatures and by igniting the foam using only a lit cigarette and cover fabric. Figures 81 and 82 show the beam profiles and the beam versus MIC curves for two such experiments and an example of the NIST procedure used in the smoke alarm experiments. The experimental result for the beam light transmission as a function of time were time-shifted to a point when the light transmission at $95 \%$ equaled 2500 s. The beam light transmission curves for both the radiant heater exposure and the cigarette ignition without radiant heating deviate from the bounding curves at about $2750 \mathrm{~s}$, while the radiant heating with cigarette ignition falls within the bounding curves. However, all three smoldering procedures fall outside the beam transmission versus MIC current bounding curves. The cigarette ignition and cigarette ignition with radiant heating are closer to the lower bounding curve than the radiant heating only procedure.

Figures 83-85 show photos of foam samples after the end of the experiments for the three smoldering initiation methods. For the smoldering foam sample initiated by the radiant panel, the darkened surface was indicative of the heat flux pattern from the radiant heaters. The foam had a rigid char / melt layer on the surface. After the surfaced regressed to some depth the smoke production essentially stopped.

Smoldering initiated by a cigarette on a piece of cotton duck fabric on top of the foam produced a sample after the end of the experiment that looked much different than the radiant heater exposed sample. The sample shown in Figure 84 was extinguished with a water spray after the smoldering slowed down. Smoldering stopped by itself in other experiments. The char was very fragile and extended in depth and radially as indicated by the dark orange ring. The foam sample exposed to the low radiant flux and ignited by a cigarette smoldered all the way to the bottom of the foam slab. There was some radial 
smoldering progression, but these samples stop smoldering by themselves when the smoldering reaches the slab bottom.

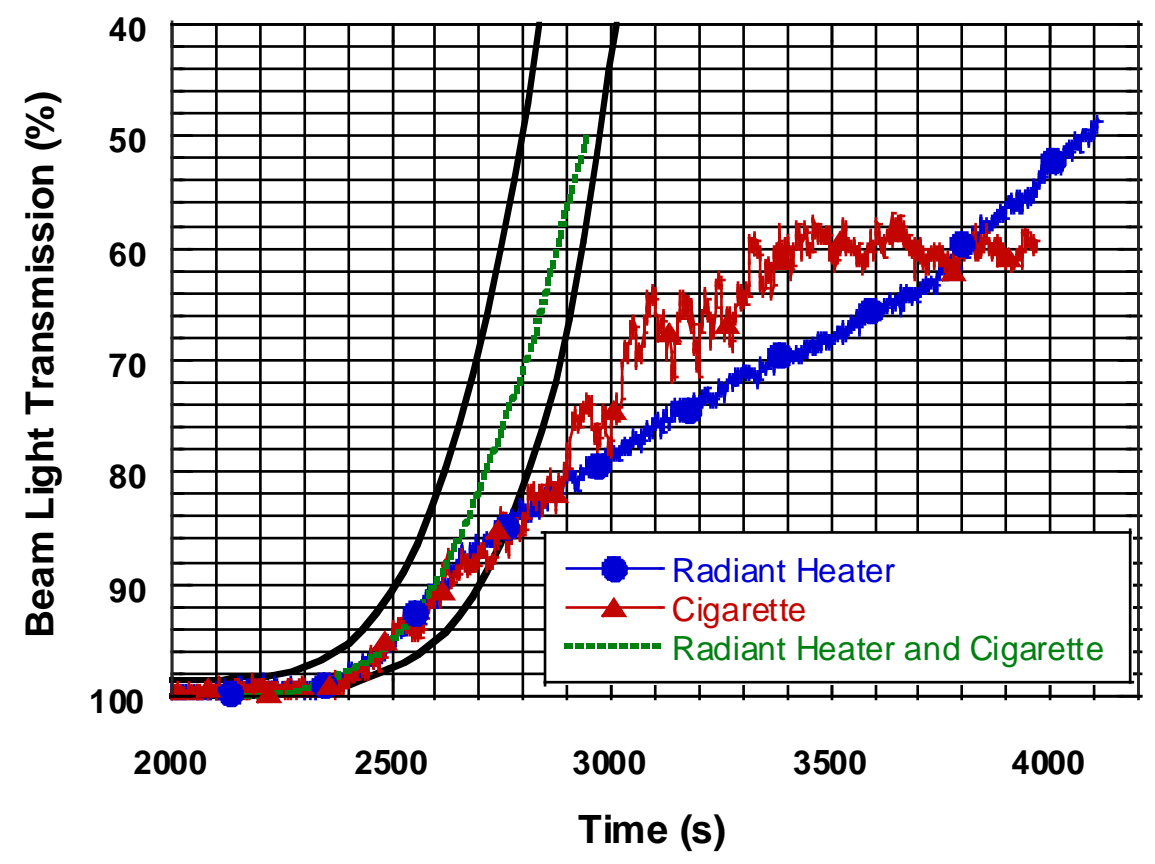

Figure 81. Beam light transmission for different smoldering foam initiations. Thick lines are bounding curves for the smoldering foam from the Standard. $\mathrm{u}_{\mathrm{c}, \mathrm{r}}($ beam $)=0.054 \times(100$-light transmission $\%) \%$.

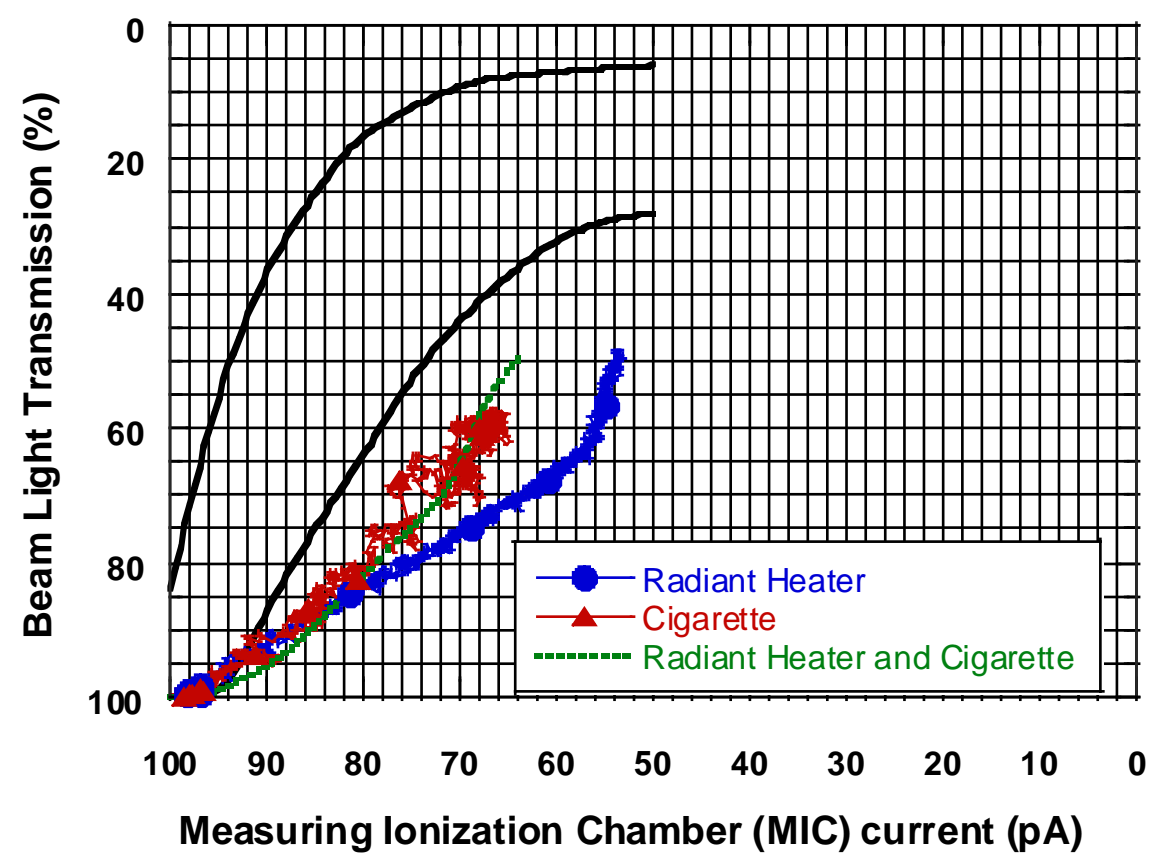


Figure 82. Beam light transmission versus MIC current for different smoldering foam initiations. Thick lines are bounding curves for the smoldering foam from the Standard. $\mathrm{u}_{\mathrm{c}, \mathrm{r}}($ beam $)=0.054 \times(100$-light transmission \%) \%. $\mathrm{u}_{\mathrm{c}}(\mathrm{MIC})=0.2 \mathrm{pA}$

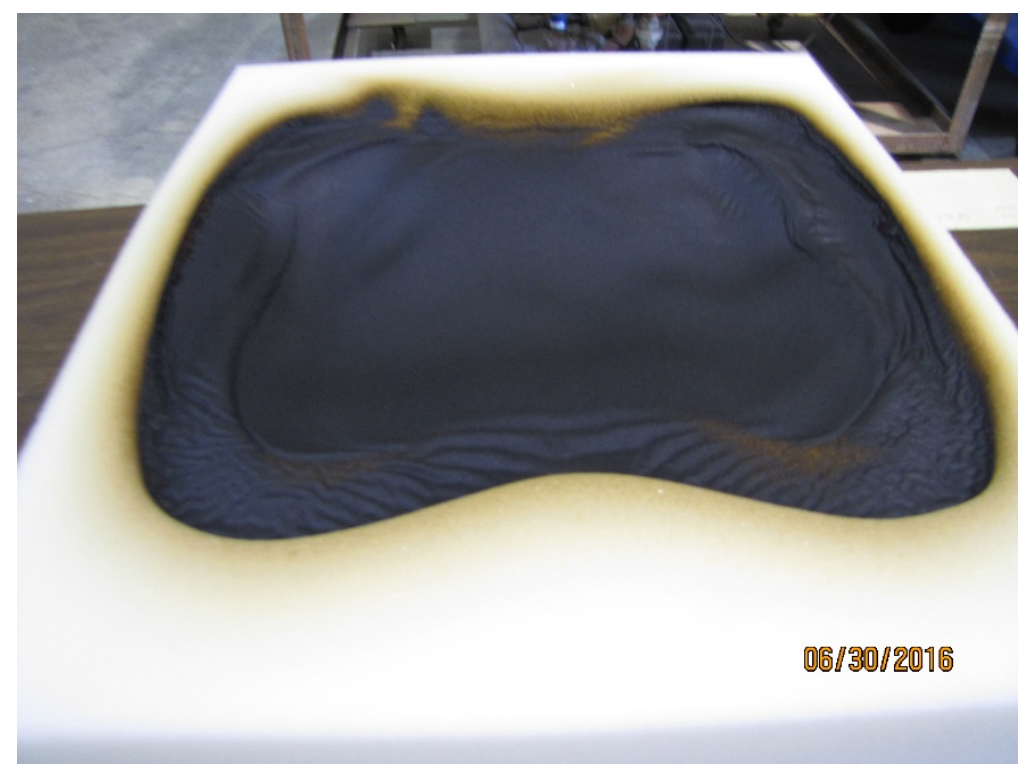

Figure 83. Post-experiment view for smoldering initiated by radiant panels .

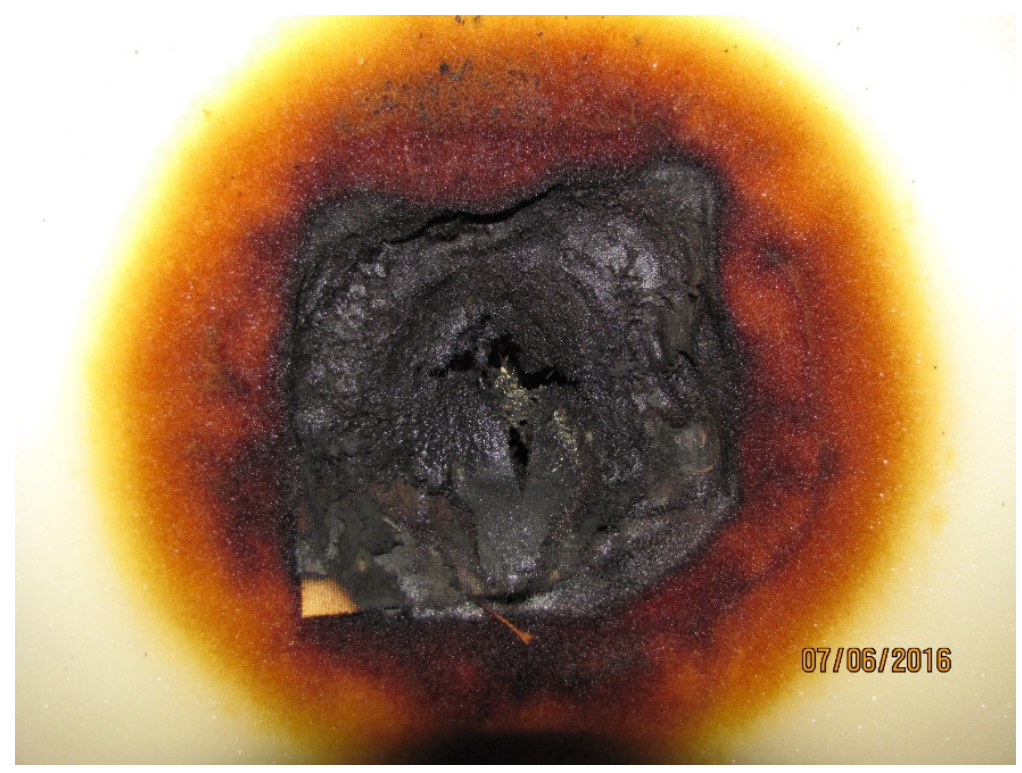

Figure 84. Post experiment view for smoldering initiated by a cigarette on fabric. 


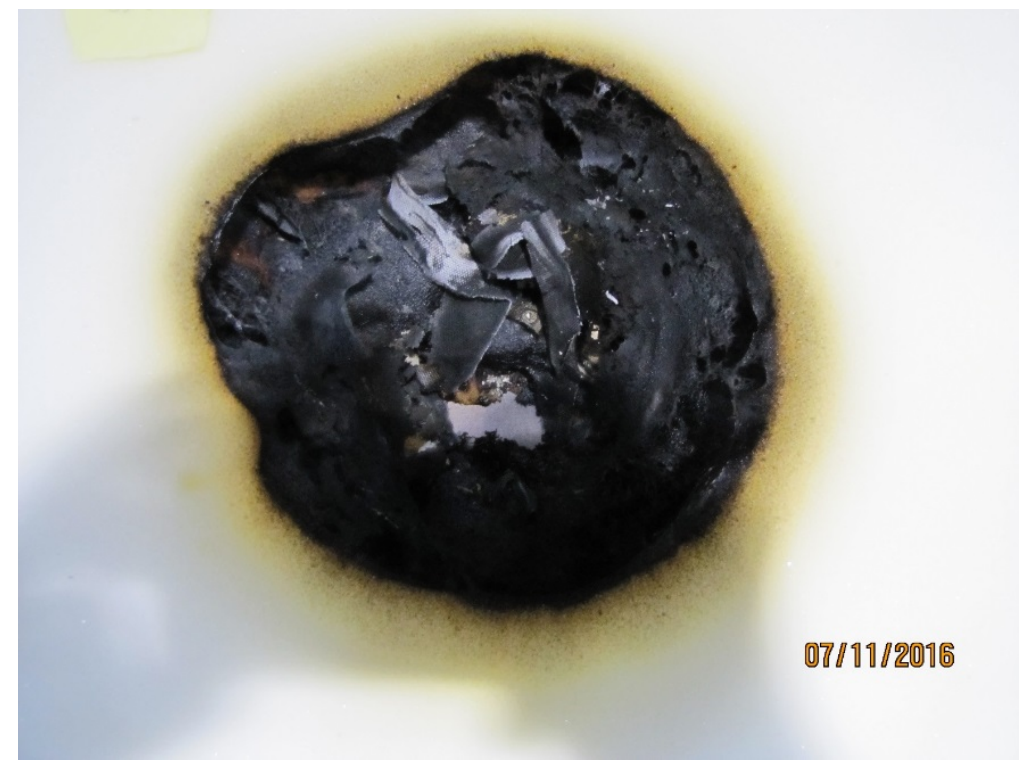

Figure 85 Post experiment view for smoldering initiated by a cigarette on fabric with radiant heating.

\subsubsection{Broiling Hamburgers}

ANSI/UL 217-2015 specifies a cooking aerosol profile in terms of bounds on the ceiling beam transmittance as a function of time and the ceiling beam obscuration versus MIC current. Figures 86 - 88 show the approximate bounding curves for the broiling hamburgers experiment and three representative experiments. The experimental times were shifted backwards $150 \mathrm{~s}$ to better align with the Standard's bounding curves. The obscuration and MIC current versus time curves do not fall within the bounding curves throughout the experiments even with the time shift. It appears that the hamburgers are producing cooking aerosols at a slower rate initially than the bounding curves, implying that the energy available to cook the hamburgers is somewhat lower. Possible explanations include location of the hamburger patties relative the range element (both distance and angle), element power or broiler pan configuration.

The obscuration versus MIC current results usually fall within the bounding curves suggesting the cooking aerosol is similar to what is supposed to be produced. 


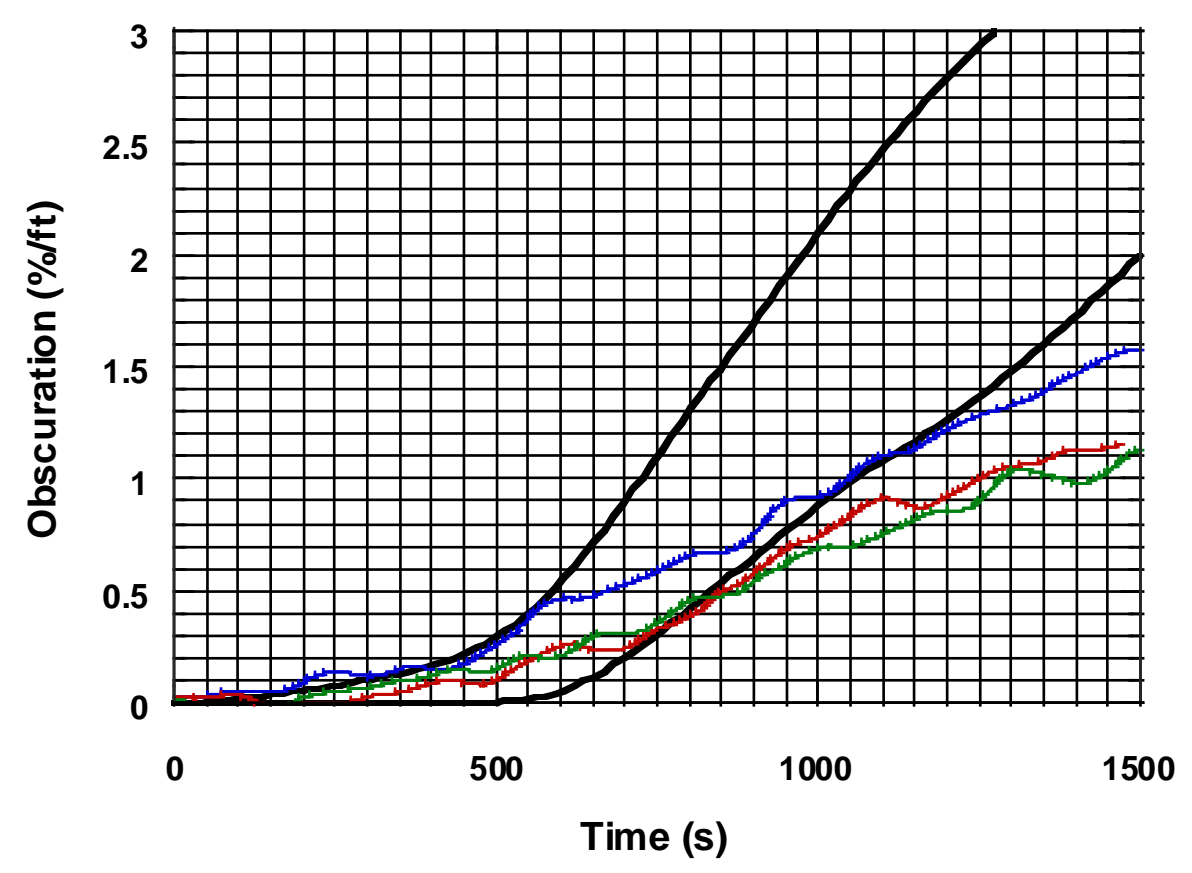

Figure 86. Beam obscuration for broiling hamburgers experiments. Thick lines are bounding curves from the Standard. $\mathrm{u}_{\mathrm{c}, \mathrm{r}}(\mathrm{beam})=4.0 \%$.

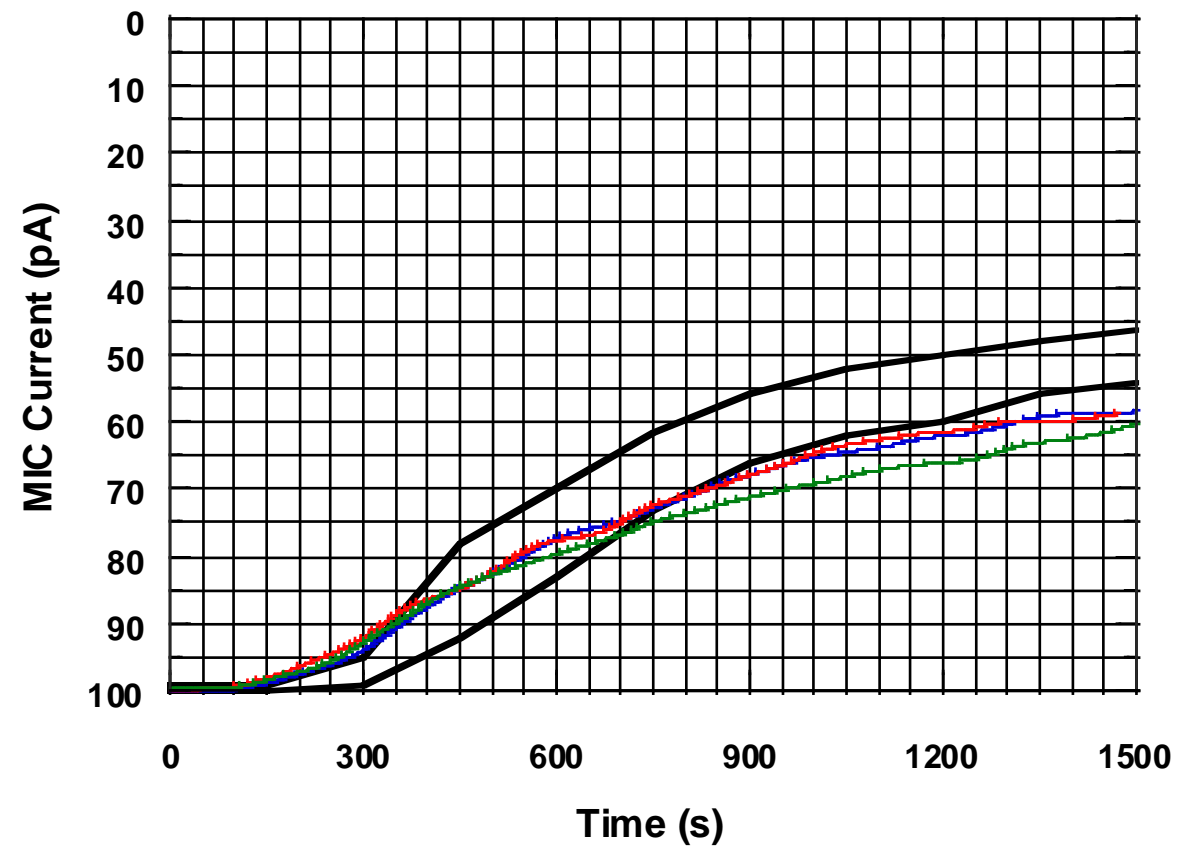

Figure 87. MIC current for broiling hamburgers experiments. Thick lines are bounding curves from the Standard. $\mathrm{u}_{\mathrm{c}}(\mathrm{MIC})=0.2 \mathrm{pA}$. 


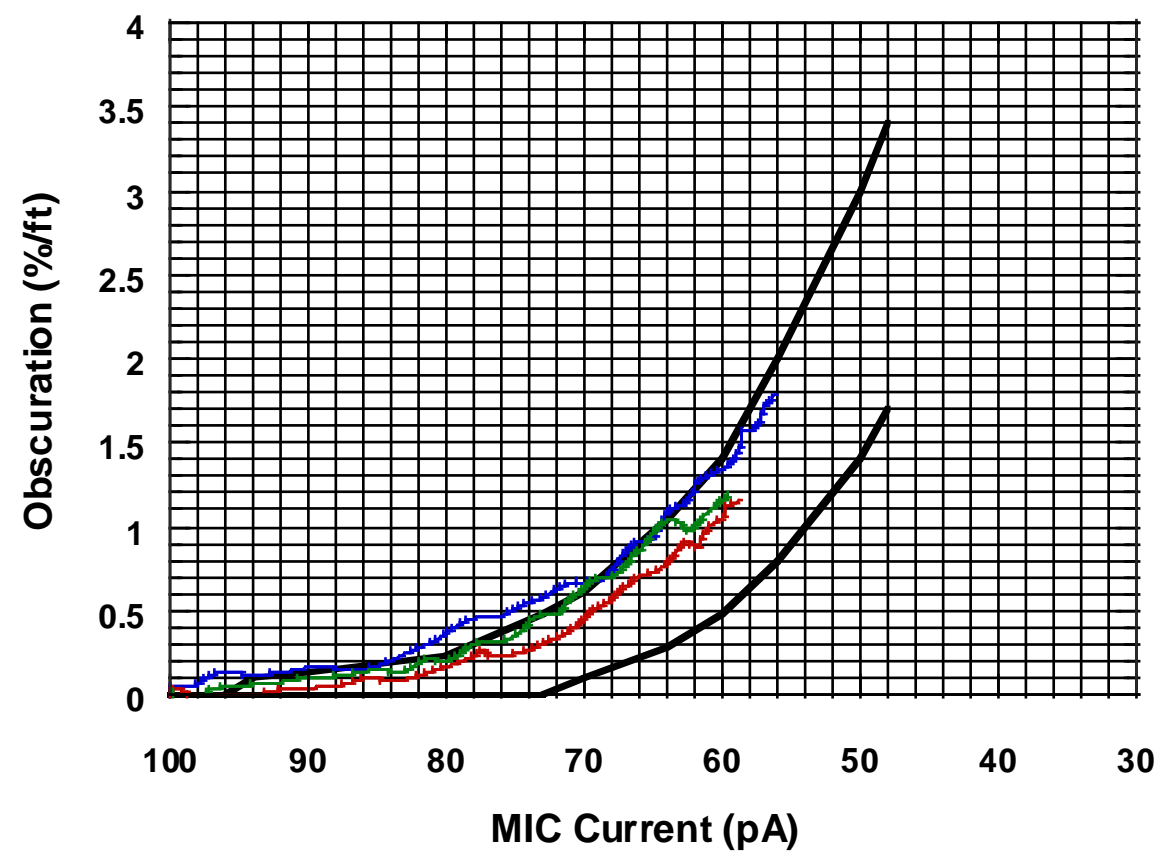

Figure 88. Beam light transmission versus MIC current for broiling hamburgers experiments. Thick lines are bounding curves from the Standard. $\mathrm{u}_{\mathrm{c}, \mathrm{r}}($ beam $)=4.0 \%$. $\mathrm{u}_{\mathrm{c}}(\mathrm{MIC})=0.2 \mathrm{pA}$

Figures 89 shows representative results for measurements at the ceiling for air temperature and relative humidity. Representative results for carbon monoxide are shown in Figure 90. No measureable change in carbon dioxide from background levels or measurable hydrogen cyanide was observed in the broiling hamburger experiments. The power to the broiler element is shown in Figure 91. The time is not shifted and it shows the power to the stove was applied at $60 \mathrm{~s}$. The power is essentially constant throughout the experiment. 


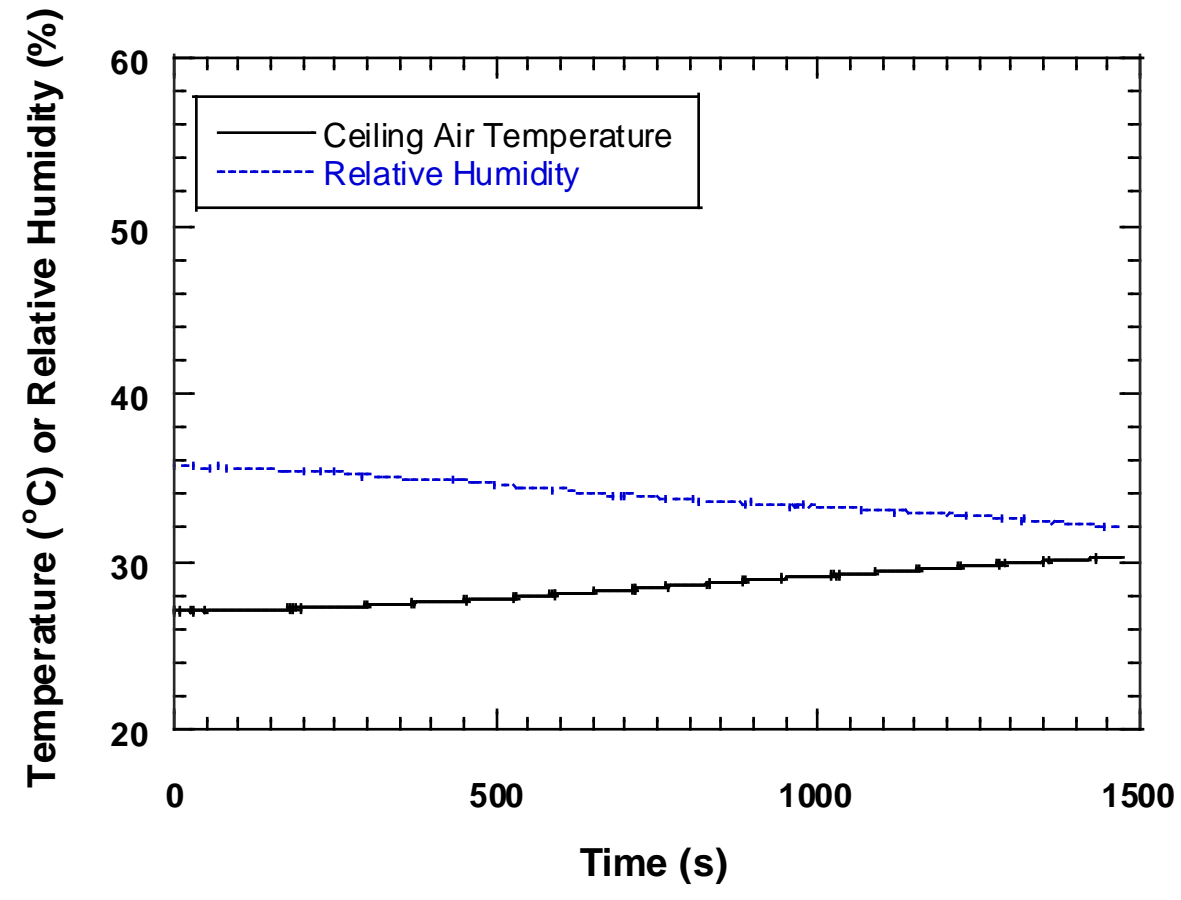

Figure 89. Temperature and relative humidity for a broiling hamburger experiment. $\mathrm{u}_{\mathrm{c}}(\mathrm{T})=1.0^{\circ} \mathrm{C}$, $\mathrm{u}_{\mathrm{c}}(\mathrm{RH})=5.0 \%$.

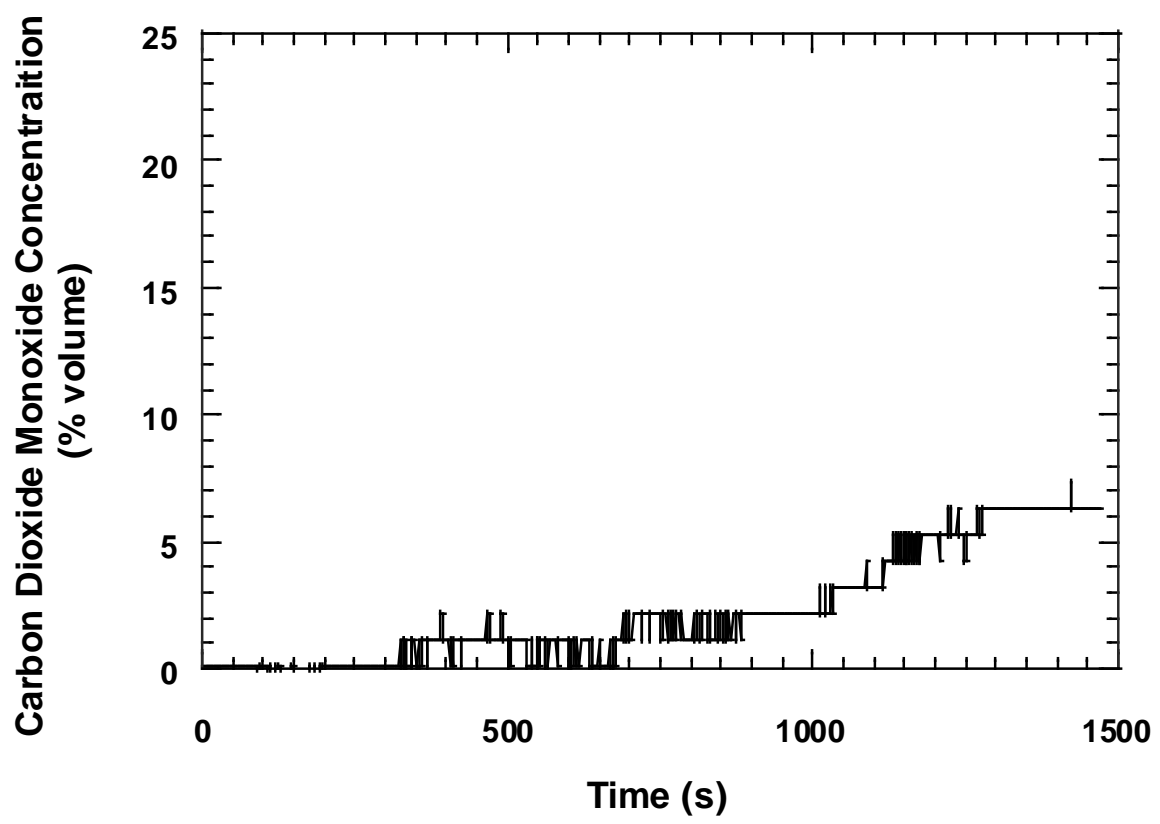

Figure 90. Carbon monoxide concentration for a broiling hamburger experiment. $\mathrm{u}_{\mathrm{c}}(\mathrm{CO})=2 \mathrm{ppm}$ vol. 


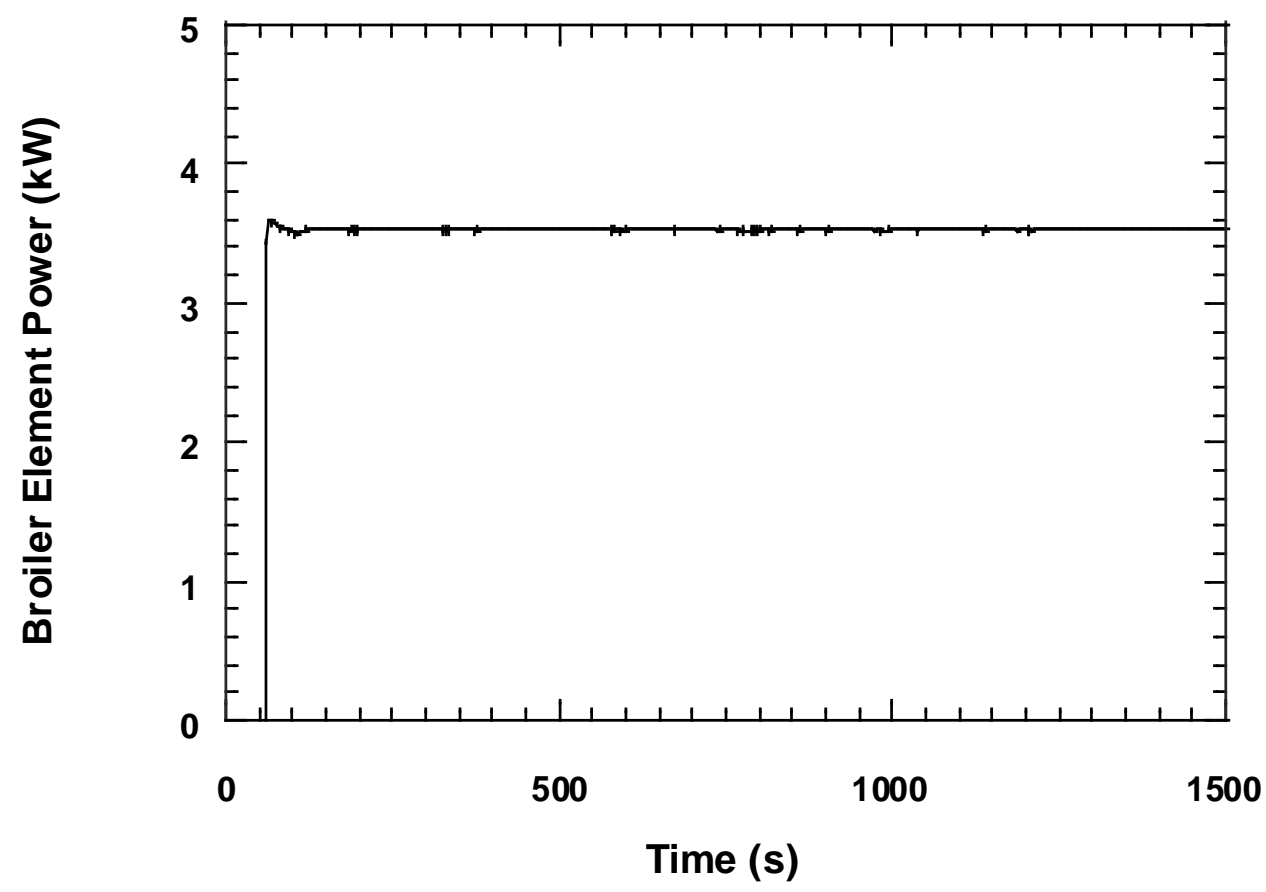

Figure 91. Power to the oven broiler element during a broiling hamburger experiment. uc(ER) $=0.05$ $\mathrm{kW}$.

\subsubsection{Frying Hamburgers}

Figures 92, 93 and 94 show obscuration and MIC versus test time, and obscuration versus MIC for three representative experiments along with the approximate bounding curves for the broiling hamburgers test.

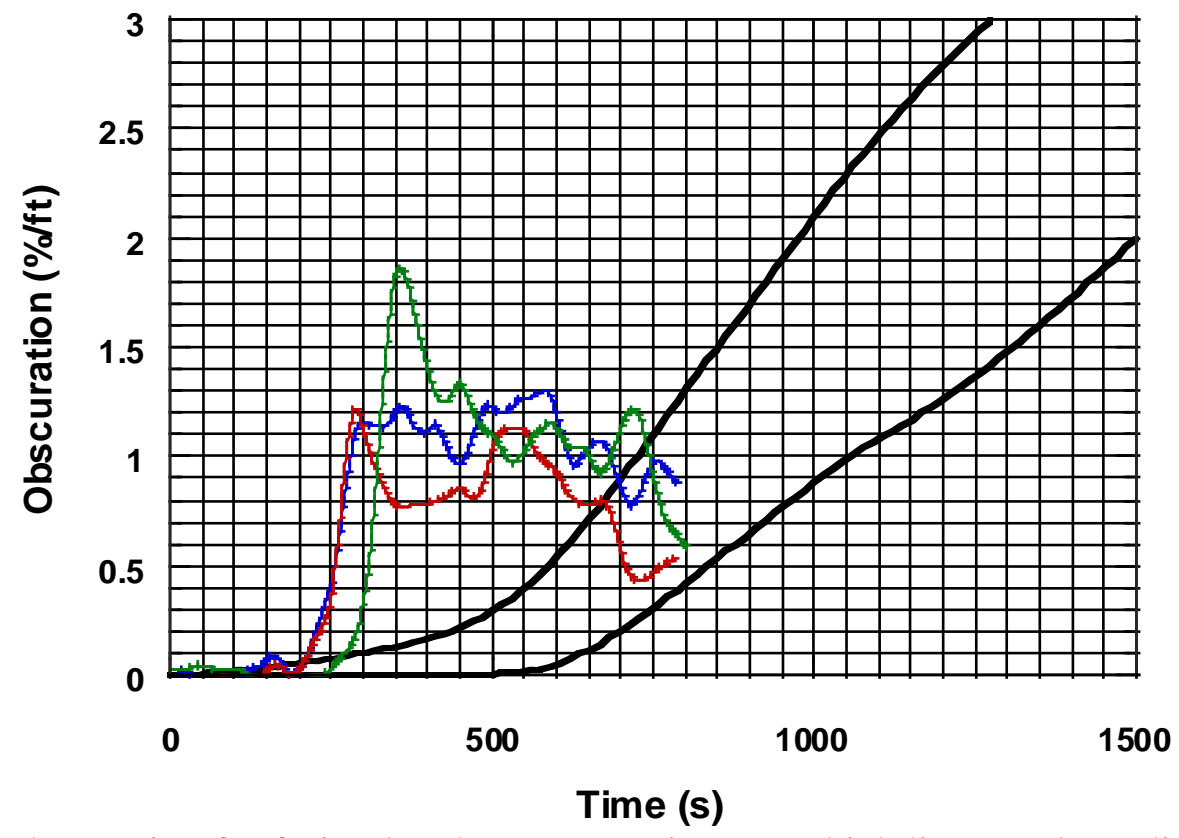

Figure 92. Beam obscuration for frying hamburger experiments. Thick lines are bounding curves for the broiling hamburgers test from the Standard. $\mathrm{u}_{\mathrm{c}, \mathrm{r}}(\mathrm{beam})=4.0 \%$. 


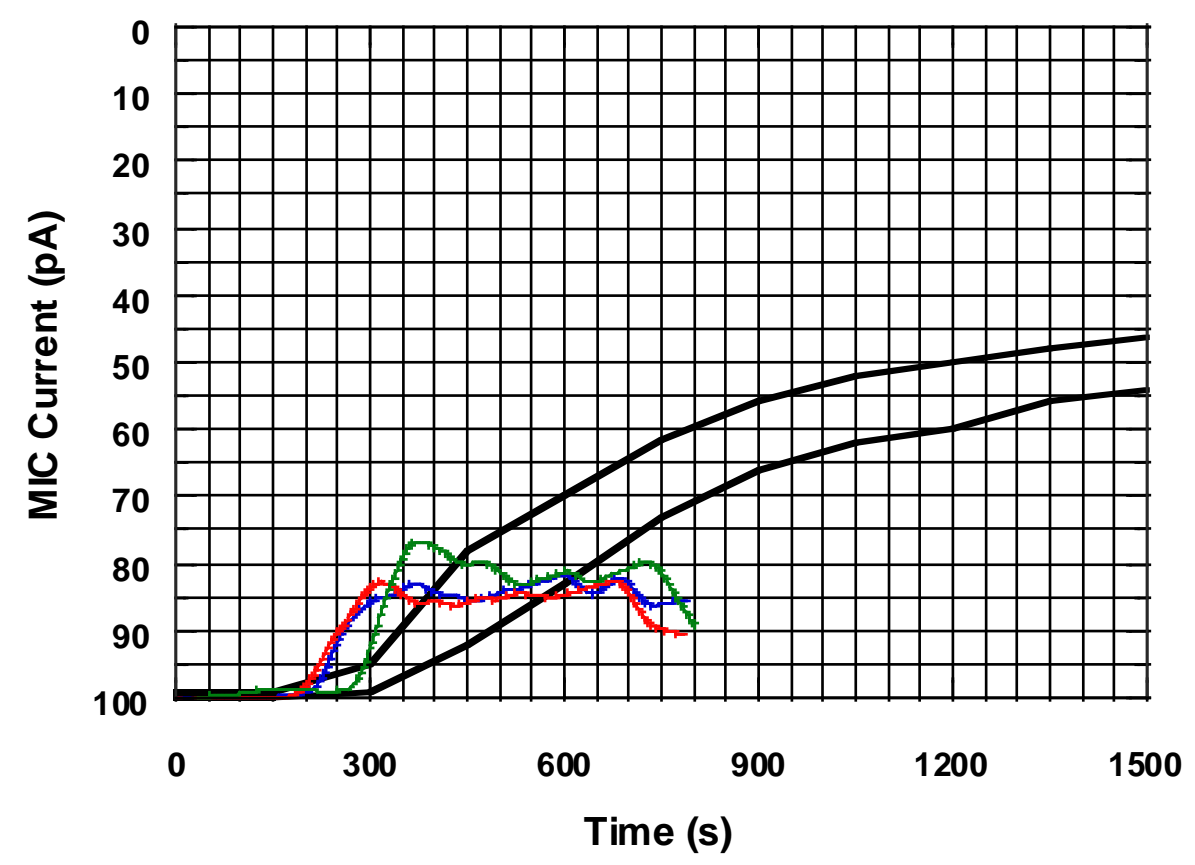

Figure 93. MIC current for frying hamburger experiments. Thick lines are bounding curves for the broiling hamburgers test from the Standard. $\mathrm{u}_{\mathrm{c}}(\mathrm{MIC})=0.2 \mathrm{pA}$.

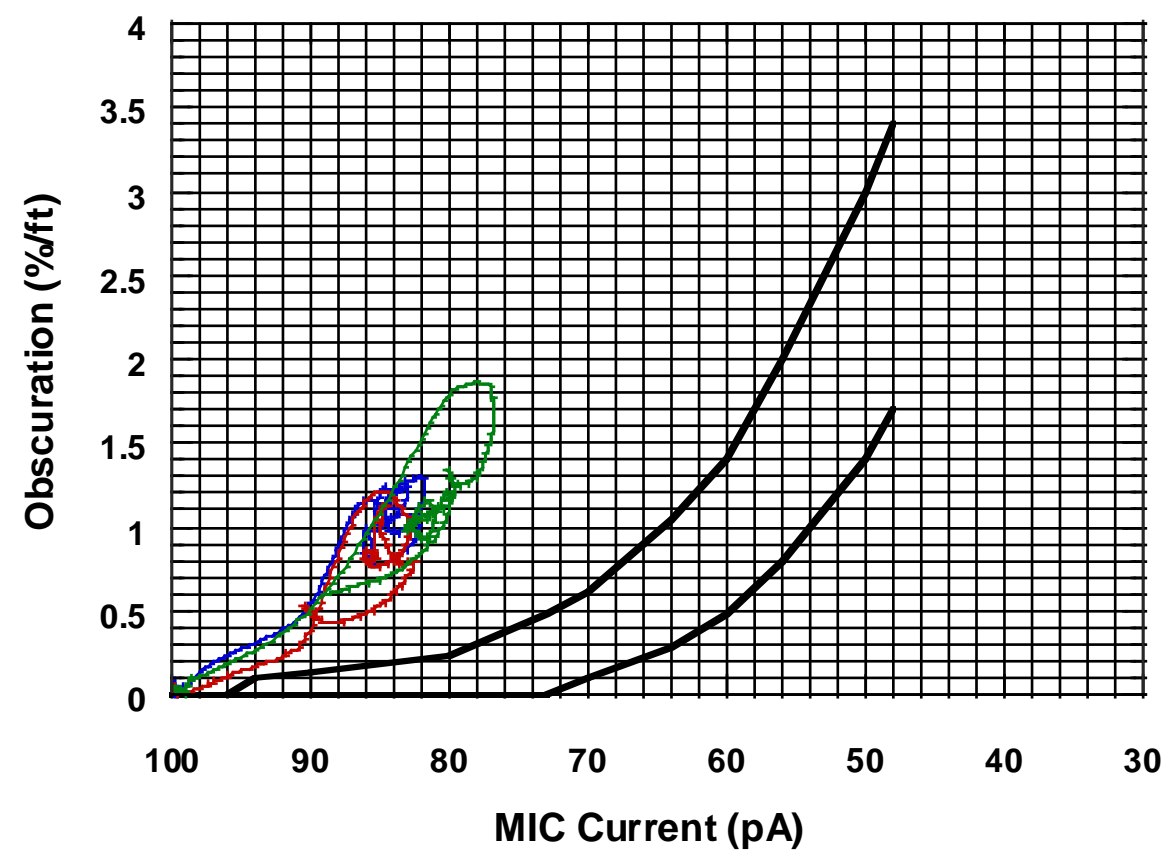

Figure 94. Beam obscuration versus MIC current for frying hamburger experiments. Thick lines are bounding curves for the broiling hamburgers test from the Standard. $\mathrm{u}_{\mathrm{c}, \mathrm{r}}(\mathrm{beam})=4.0 \%$. $\mathrm{u}_{\mathrm{c}}(\mathrm{MIC})=0.2$ pA. 
Figures 95 shows representative results for measurements at the ceiling for air temperature and relative humidity. There was no measureable change in carbon dioxide from background levels or measurable carbon monoxide or hydrogen cyanide in the frying hamburger experiments. The power to the stove element is show in Figure 96. The power is essentially constant when set to the high setting (10), then cycles between the nominal high power and off when the setting is changed to medium (6).

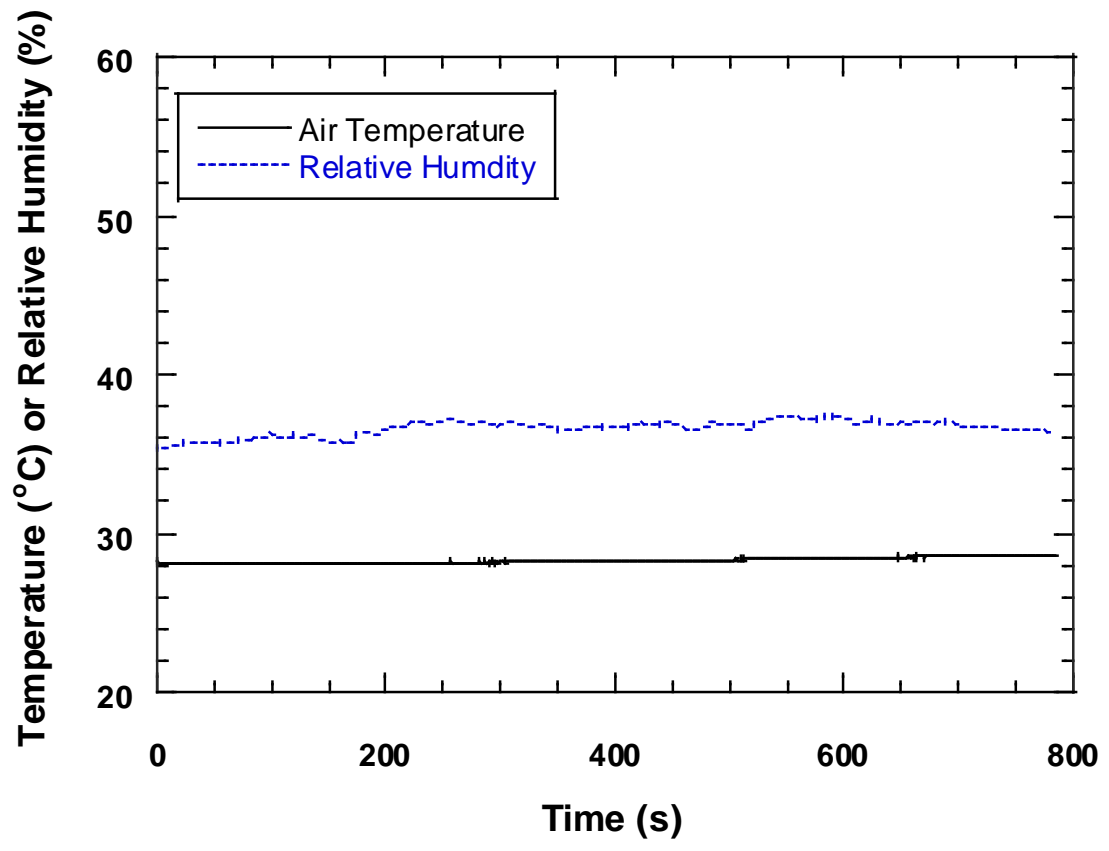

Figure 95. Temperature and relative humidity for a frying hamburger experiment. $\mathrm{u}_{c}(\mathrm{~T})=1.0^{\circ} \mathrm{C}, \mathrm{u}_{\mathrm{c}}(\mathrm{RH})$ $=5.0 \%$.

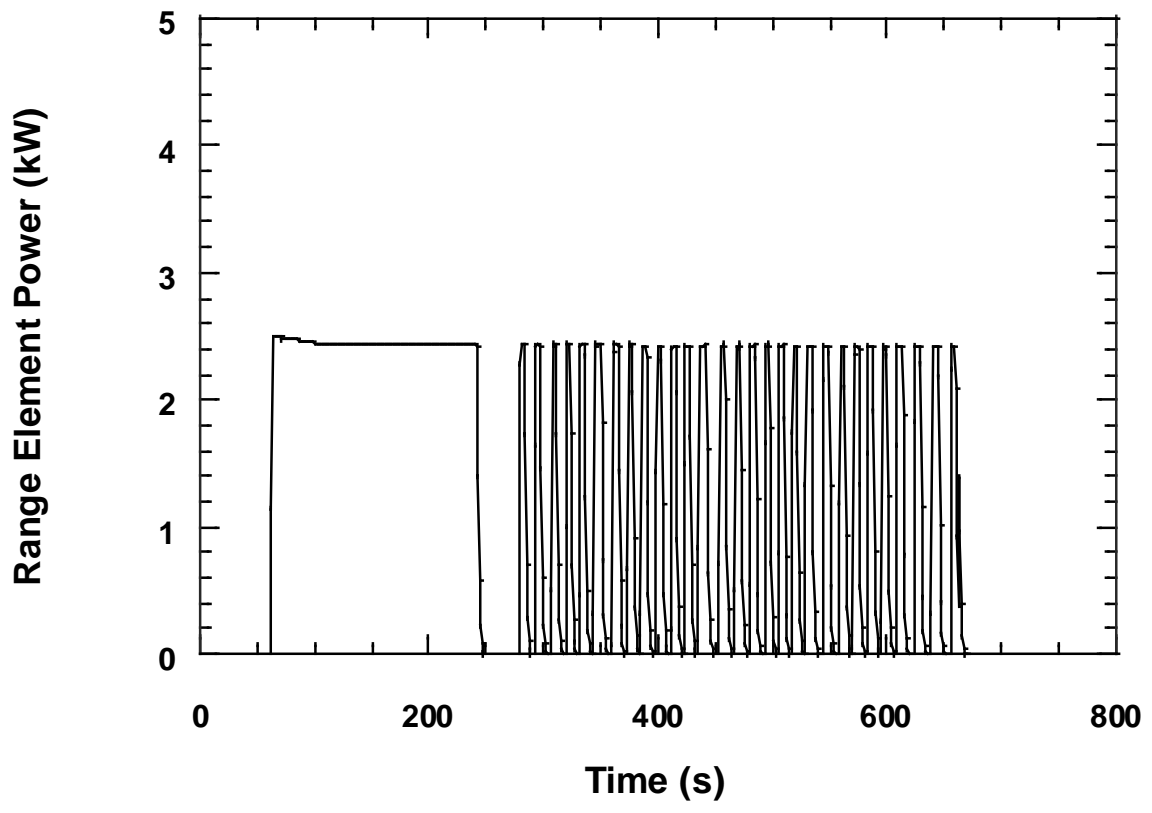

Figure 96. Power to the range top element during a frying hamburger experiment. uc(ER) $=0.05 \mathrm{~kW}$. 


\subsubsection{Stir-Frying Vegetables}

Figures 97, 98 and 99 show obscuration and MIC versus test time, and obscuration versus MIC for three representative experiments along with the approximate bounding curves for the broiling hamburgers test.

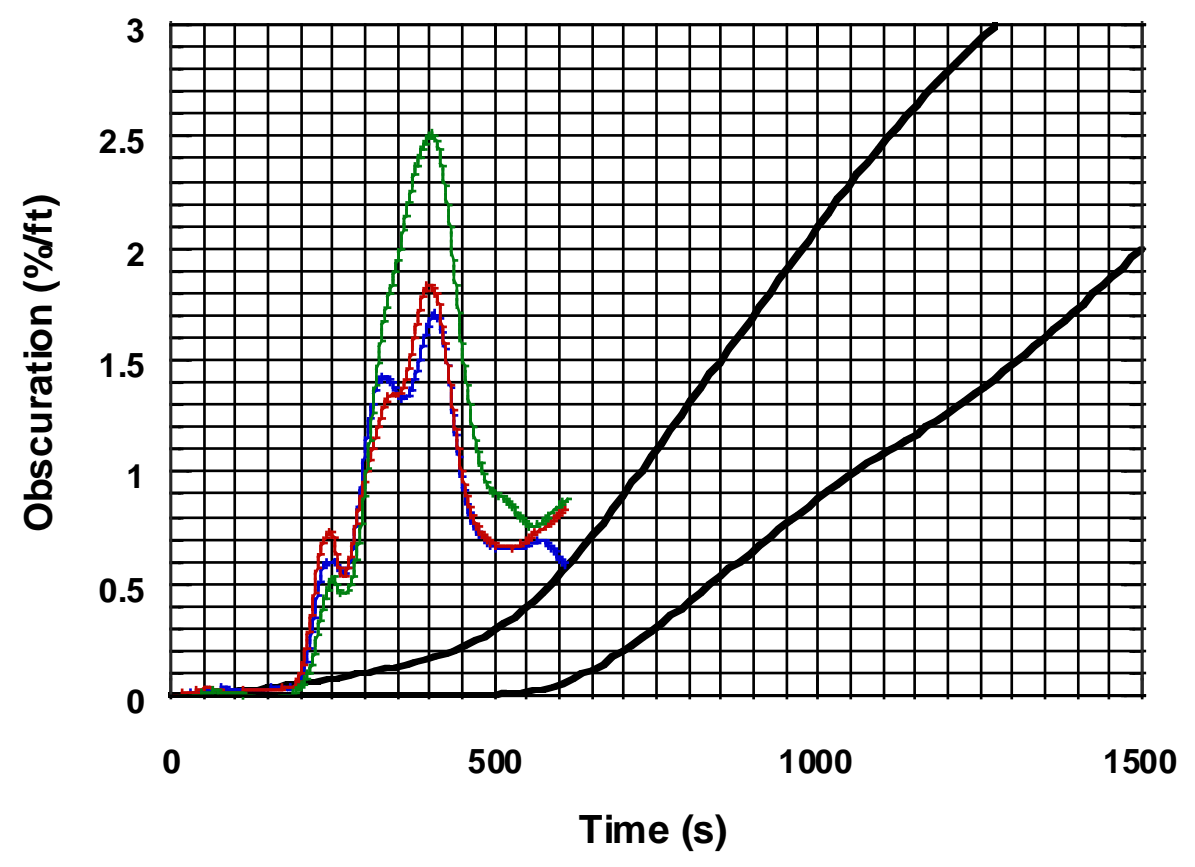

Figure 97. Beam obscuration for stir-frying vegetables experiments. Thick lines are bounding curves for the broiling hamburgers test from the Standard. $\mathrm{u}_{\mathrm{c}, \mathrm{r}}($ beam $)=4.0 \%$.

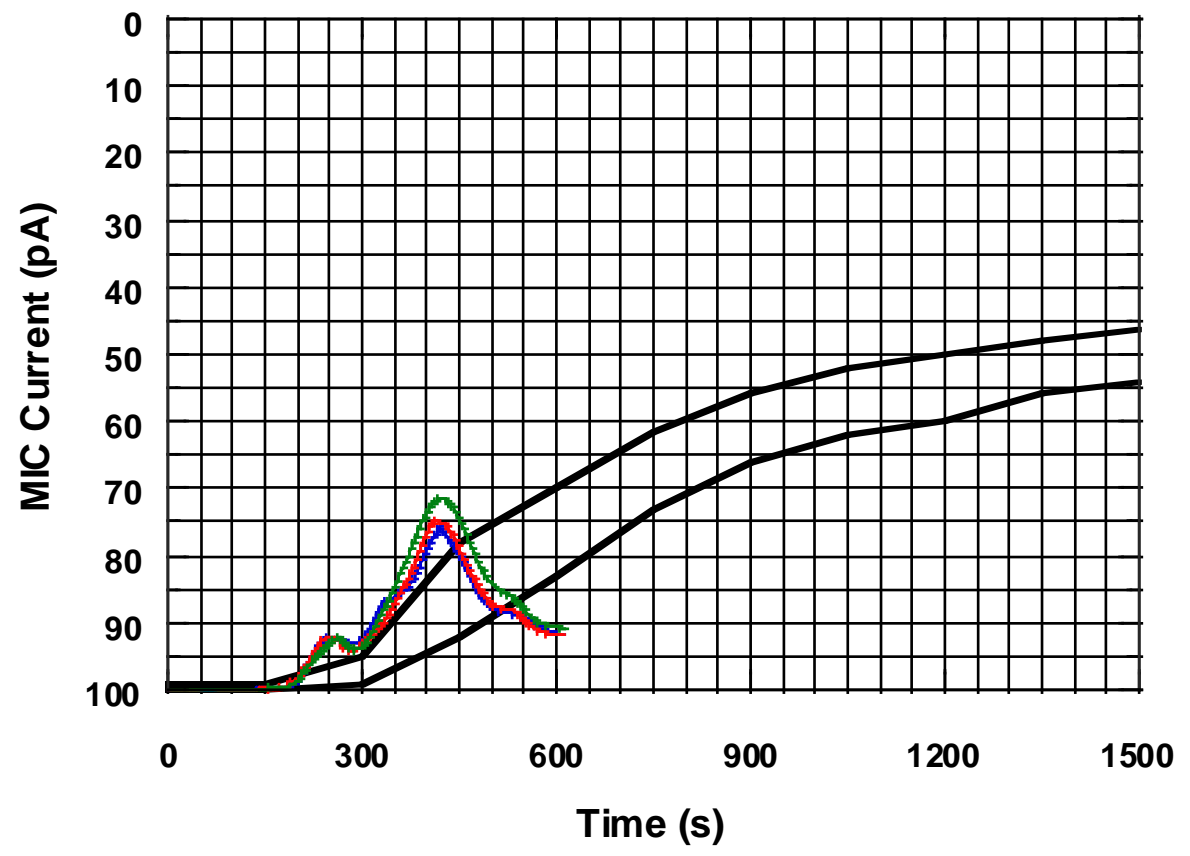

Figure 98. MIC current for stir-frying vegetables experiments. Thick lines are bounding curves for the broiling hamburgers test from the Standard. $\mathrm{u}_{\mathrm{c}}(\mathrm{MIC})=0.2 \mathrm{pA}$. 


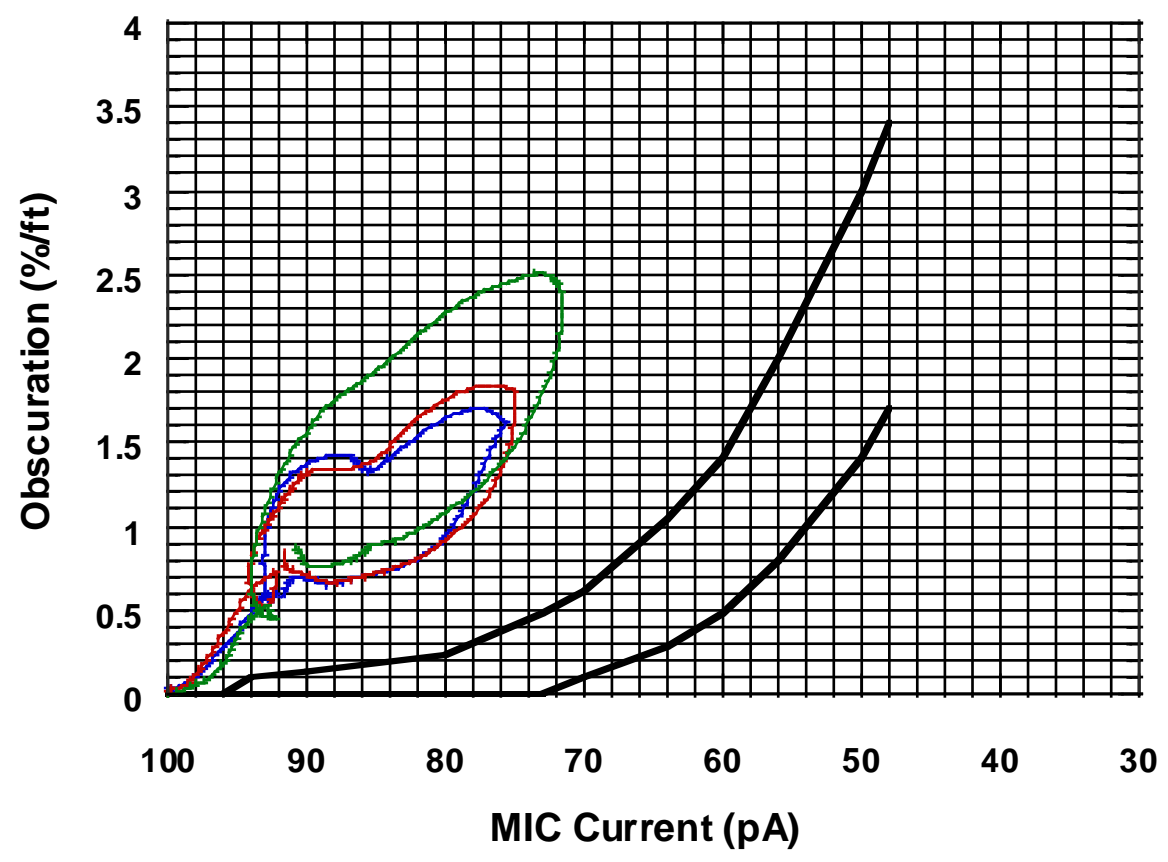

Figure 99. Beam obscuration versus MIC current for stir-frying vegetables experiments. Thick lines are bounding curves for the broiling hamburgers test from the Standard. $\mathrm{u}_{\mathrm{c}, \mathrm{r}}(\mathrm{beam})=4.0 \%$. $\mathrm{u}_{\mathrm{c}}(\mathrm{MIC})=0.2$ pA.

Figure 100 shows representative results for measurements at the ceiling for air temperature and relative humidity. There was no measureable change in carbon dioxide from background levels or measurable carbon monoxide or hydrogen cyanide in the frying hamburger experiments. The power to the stove was not recorded during these experiments. The current meter induced noise in the light beam photocell. When this was discovered, the current meter was de-powered. A digital wattmeter continued to provide visual readings. The power output during the stir-frying was essentially the same as the frying hamburger experiments for the two settings used, i.e., the power was essentially constant when set to the high setting (10) the cycled between the nominal high power and off when the setting is changed to medium (6). 


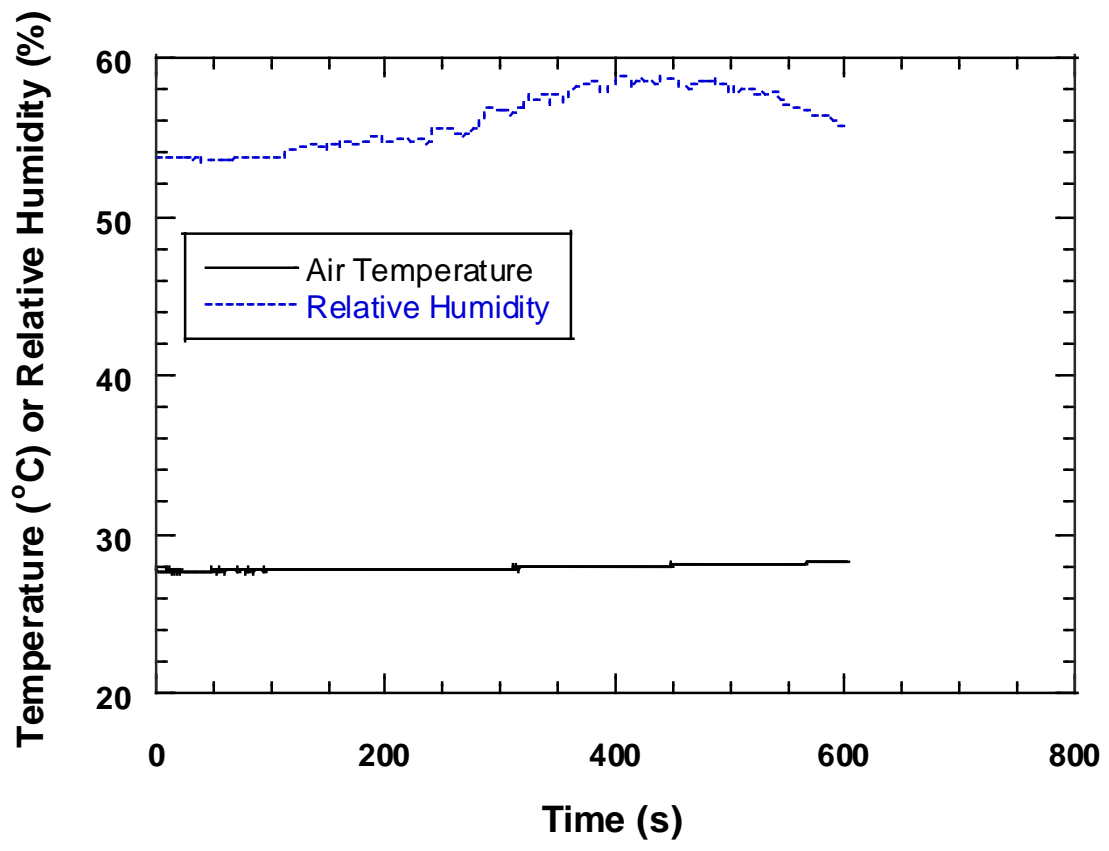

Figure 100. Temperature and relative humidity for a stir-frying vegetables experiment. $\mathrm{u}_{\mathrm{c}}(\mathrm{T})=1.0^{\circ} \mathrm{C}$, $\mathrm{u}_{\mathrm{c}}(\mathrm{RH})=5.0 \%$.

\subsubsection{Toasting Bread}

Figure 101, shows the MIC versus test time data for three representative experiments along with the approximate bounding curves for the broiling hamburgers test.

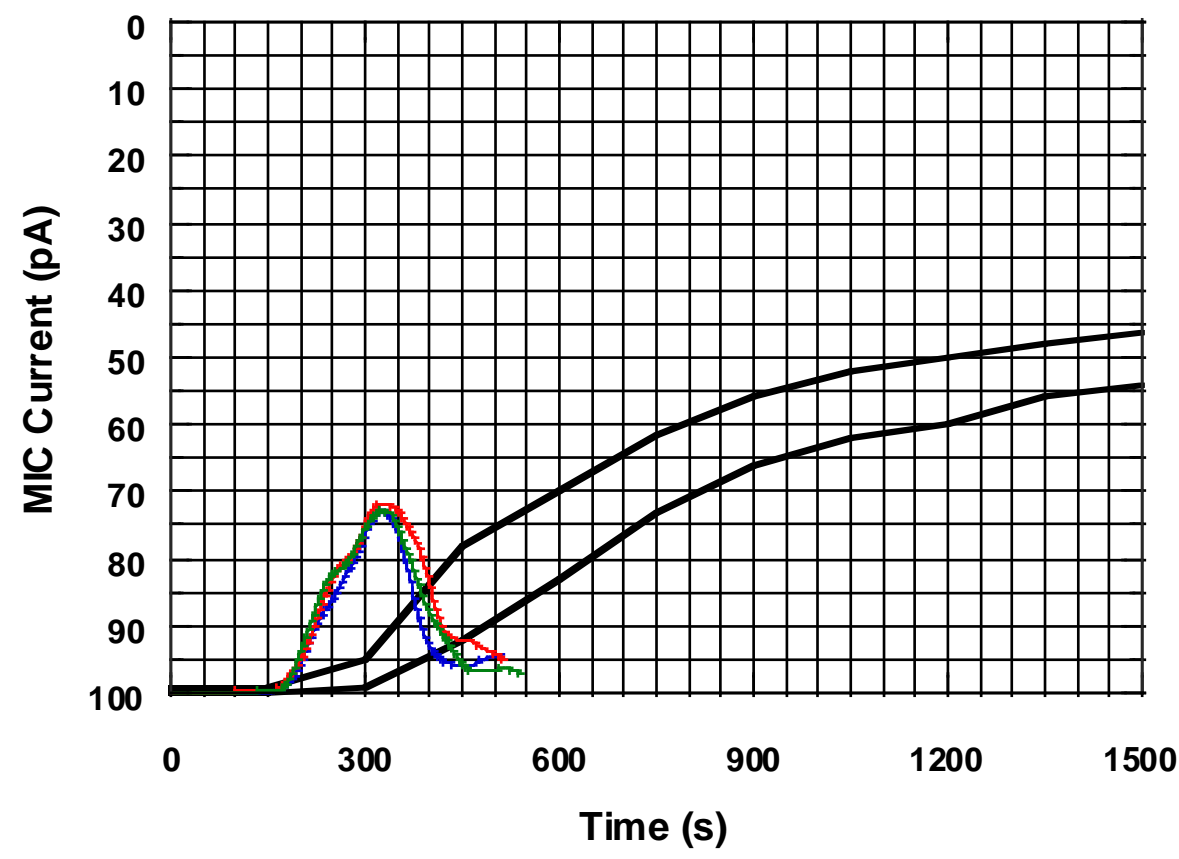

Figure 101. MIC current for toasting bread experiments. Thick lines are bounding curves for the broiling hamburgers test from the Standard. $\mathrm{u}_{\mathrm{c}}(\mathrm{MIC})=0.2 \mathrm{pA}$. 
Figures 102 shows representative results for measurements at the ceiling for air temperature and relative humidity. There was no measureable change in carbon dioxide from background levels or measurable carbon monoxide or hydrogen cyanide in the toasting bread experiments.

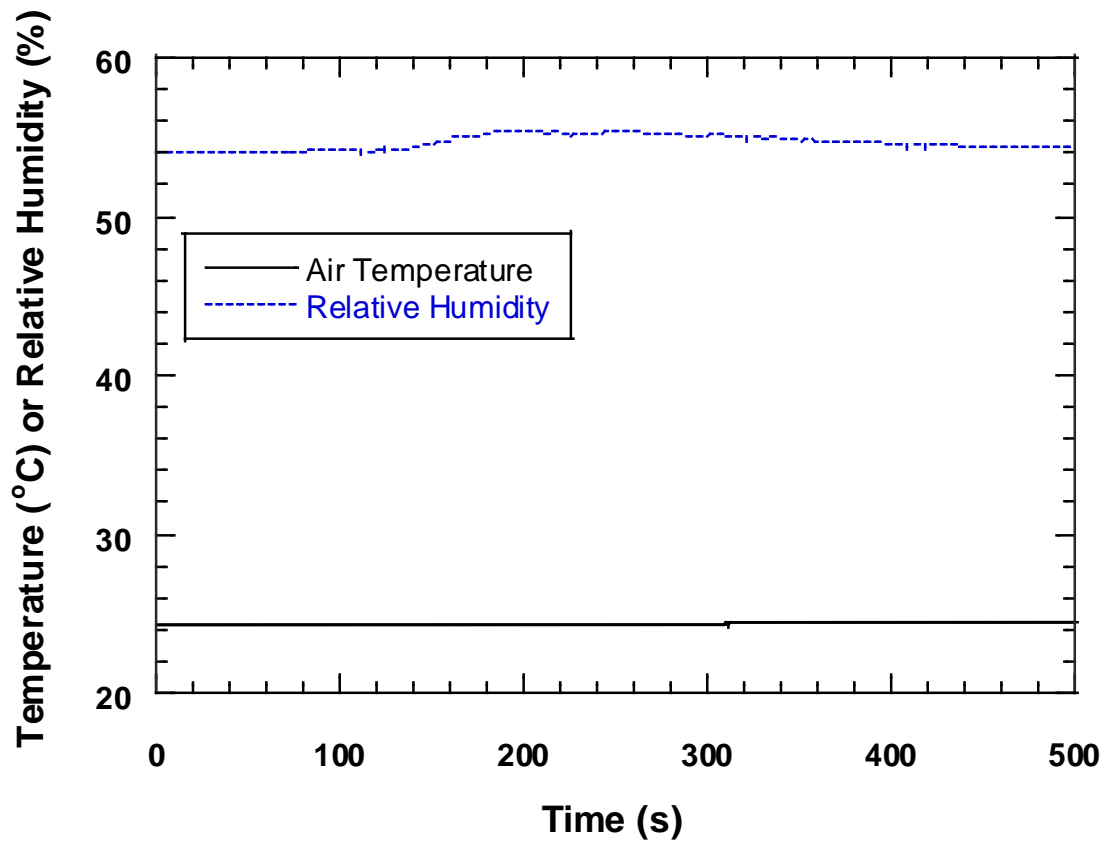

Figure 102. Temperature and relative humidity for a toasting bread experiment. $\mathrm{u}_{\mathrm{C}}(\mathrm{T})=1.0^{\circ} \mathrm{C}, \mathrm{u}_{\mathrm{c}}(\mathrm{RH})=$ $5.0 \%$.

\subsection{Test Room Alarm Response Results}

\subsubsection{Ionization Alarm Model Response Results}

The beam obscuration at alarm was determined from the recorded alarm times and the beam obscuration measurements. (The MIC current was determined for the toasting bread scenario since no beam obscuration was produced.) One unit of each of the 45 alarm models was used for three repeated experiments of the fire or cooking nuisance scenarios. The beam obscuration or MIC current values at alarm response are shown in Figures 103 - 108 for each fire or cooking scenario. Open symbols represent the level at alarm and closed symbols represent the experimental maximum with no alarm response. The spread between repeated experiments is less than the spread between the 14 alarm models. 


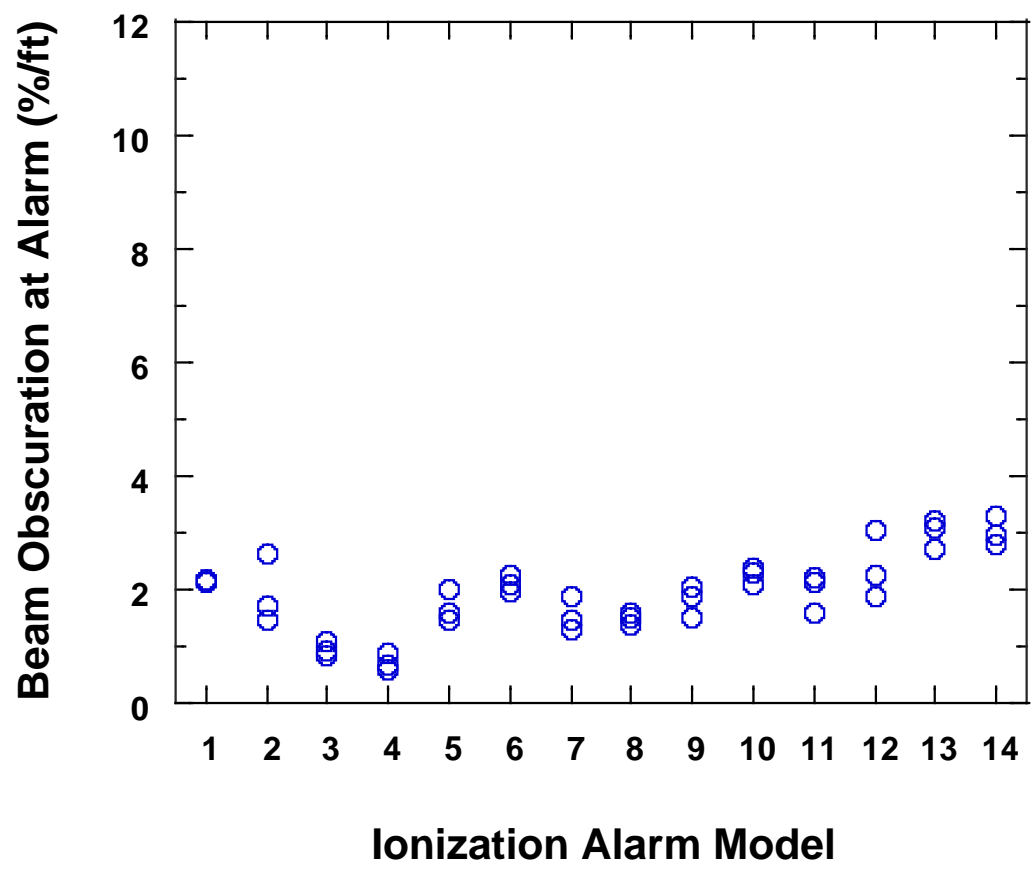

Figure 103. Flaming foam test experimental results for ionization alarms. Closed symbols - test maximum with no alarm. $\mathrm{u}_{\mathrm{c}, \mathrm{r}}($ beam $)=4.0 \%$.

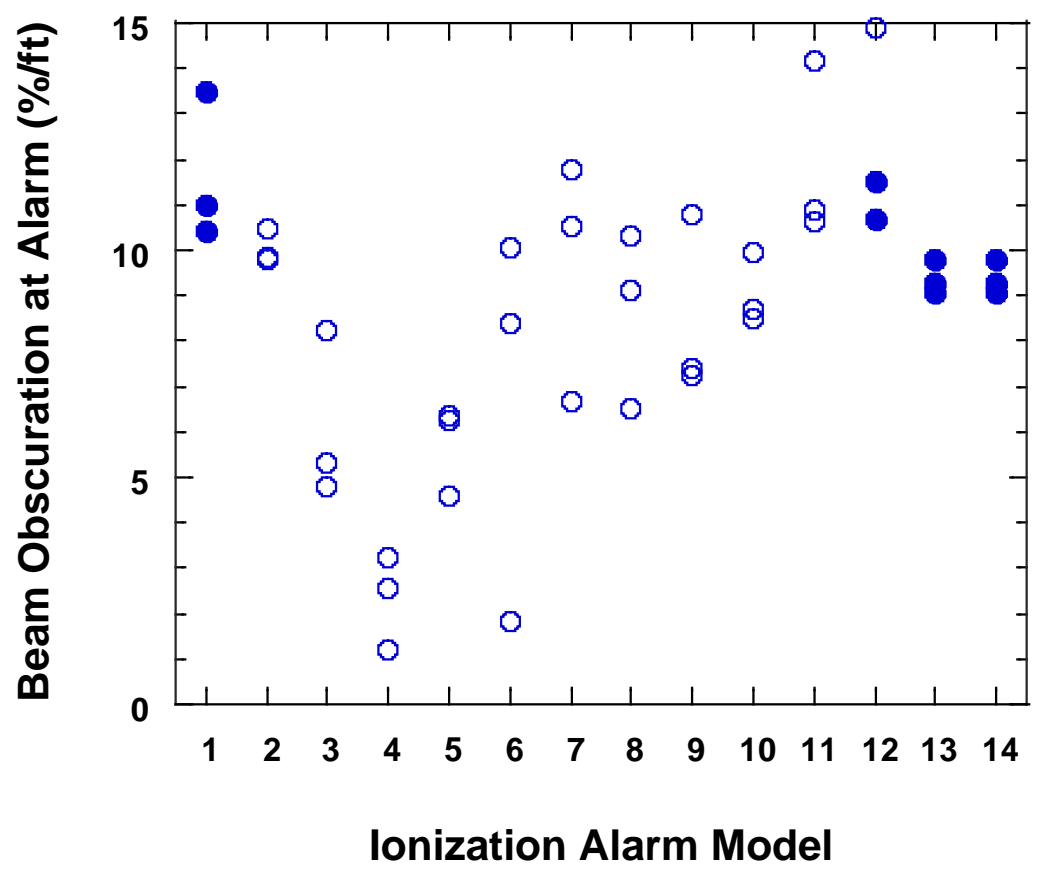

Figure 104. Smoldering foam test experimental results for ionization alarms. Closed symbols - test maximum with no alarm. $\mathrm{u}_{\mathrm{c}, \mathrm{r}}($ beam $)=4.0 \%$. 


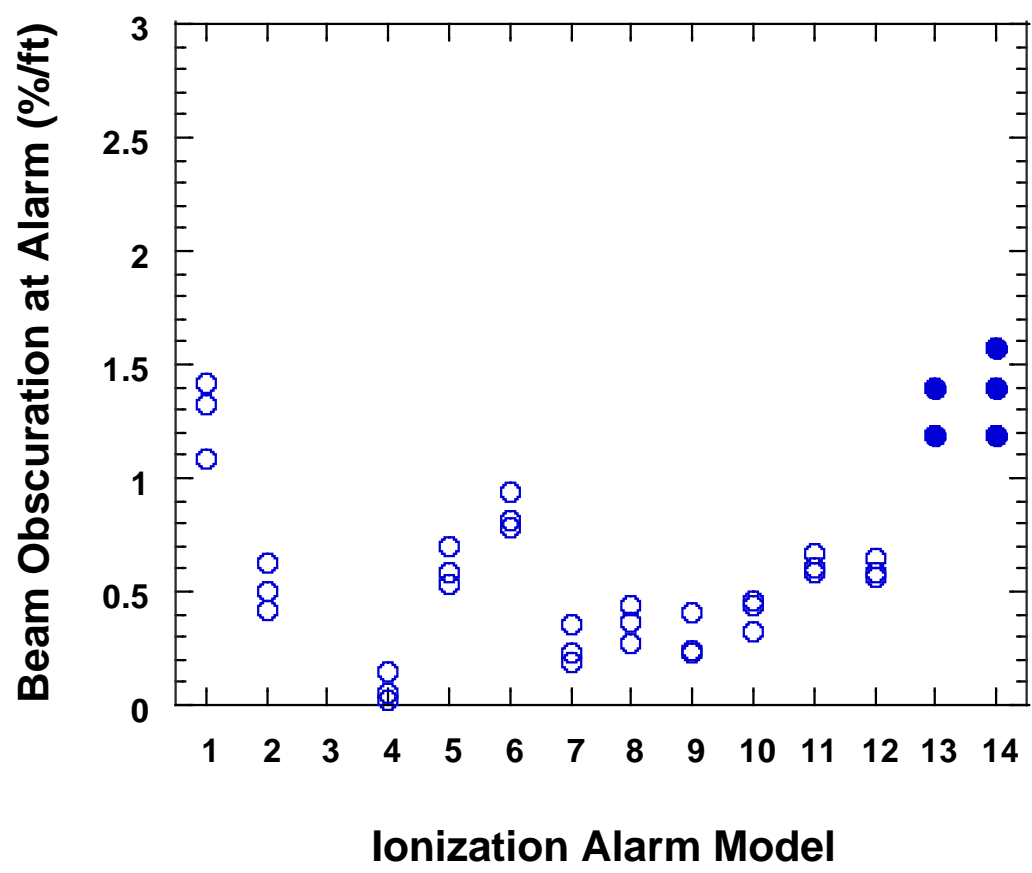

Figure 105. Broiling hamburgers test experimental results for ionization alarms. Closed symbols - test maximum with no alarm. $\mathrm{u}_{\mathrm{c}, \mathrm{r}}(\mathrm{beam})=4.0 \%$.

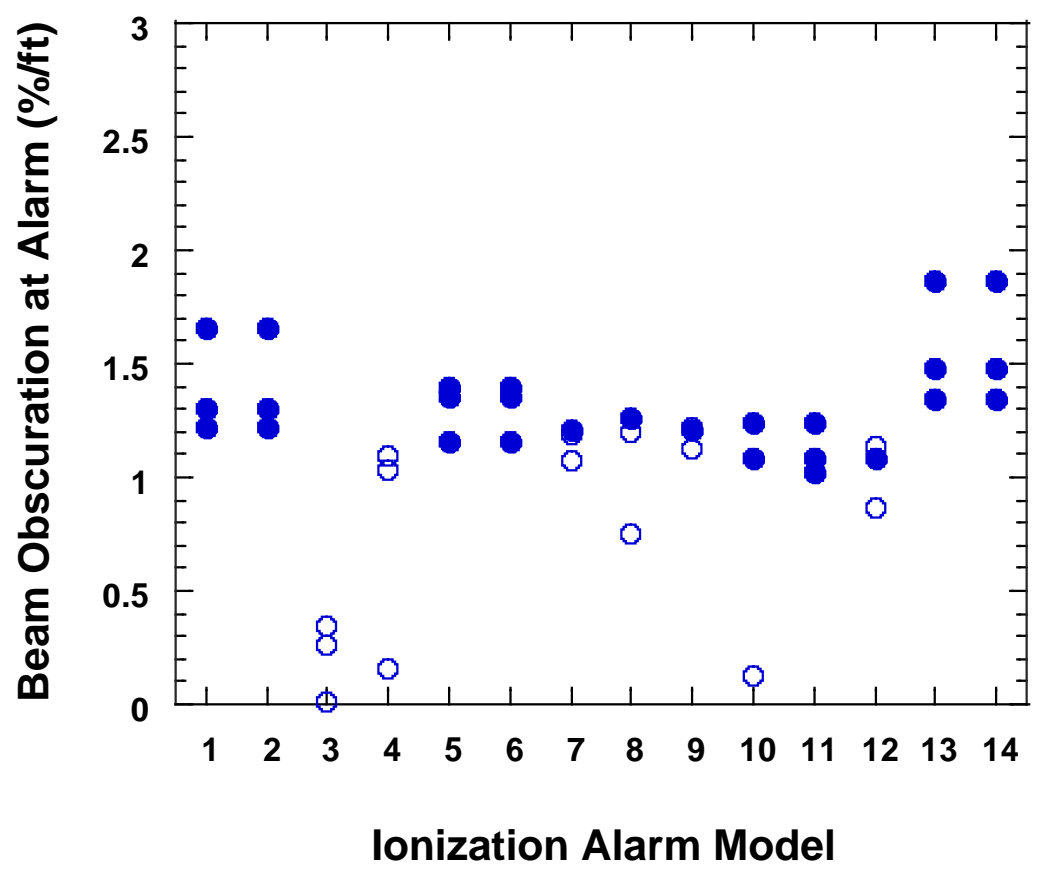

Figure 106. Frying hamburger experimental results for ionization alarms. Closed symbols - test maximum with no alarm. $\mathrm{u}_{\mathrm{c}, \mathrm{r}}($ beam $)=4.0 \%$. 


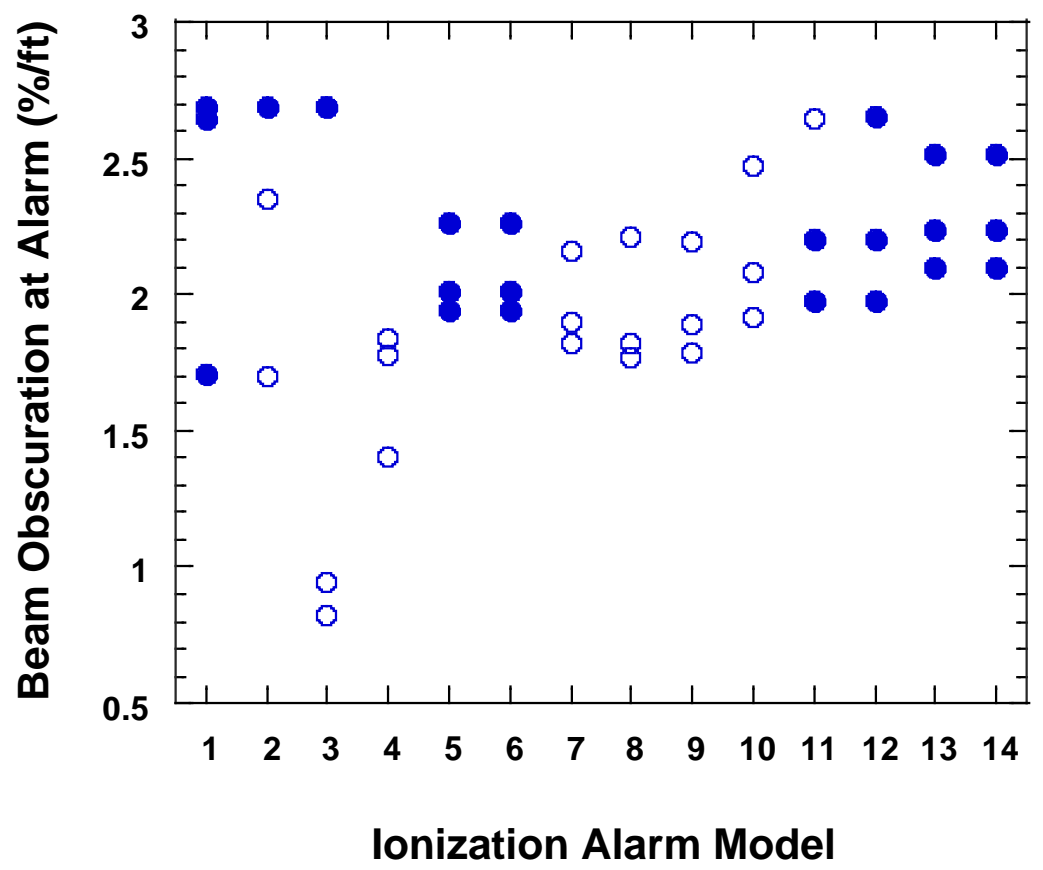

Figure 107. Stir-frying vegetables experimental results for ionization alarms. Closed symbols - test maximum with no alarm. $\mathrm{u}_{\mathrm{c}, \mathrm{r}}(\mathrm{beam})=4.0 \%$.

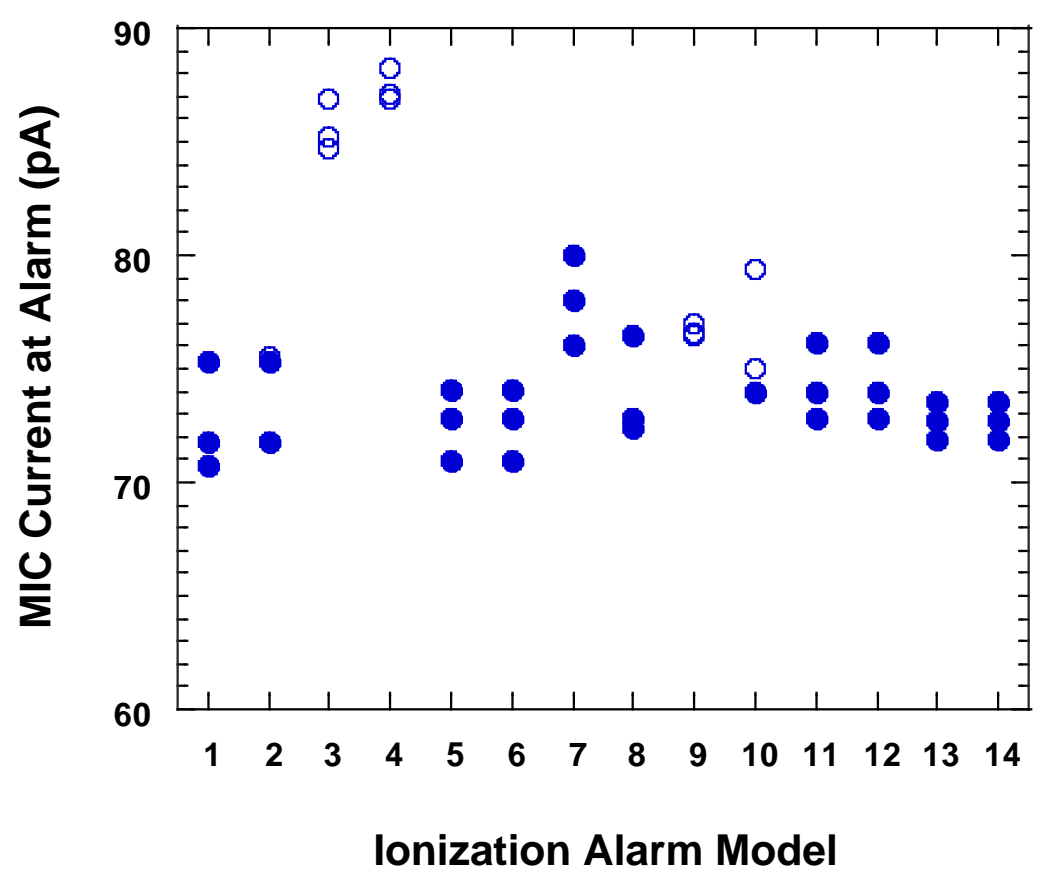

Figure 108. Toasting bread experimental results for ionization alarms. Closed symbols - test minimum with no alarm. $\mathrm{u}_{\mathrm{c}}(\mathrm{MIC})=0.2 \mathrm{pA}$. 


\subsubsection{Ionization / Photoelectric and Ionization / Carbon Monoxide Combination Alarm Model Response Results}

The beam obscuration or MIC current values at alarm response are shown in Figures 109 - 114 for each fire or cooking scenario for alarms containing ionization and photoelectric or carbon monoxide sensors. Open symbols represent the level at alarm and closed symbols represent the experimental maximum with no alarm response. For both the ionization / photoelectric and ionization / carbon monoxide alarms the spread between repeated experiments is less than the spread between the four alarm models.

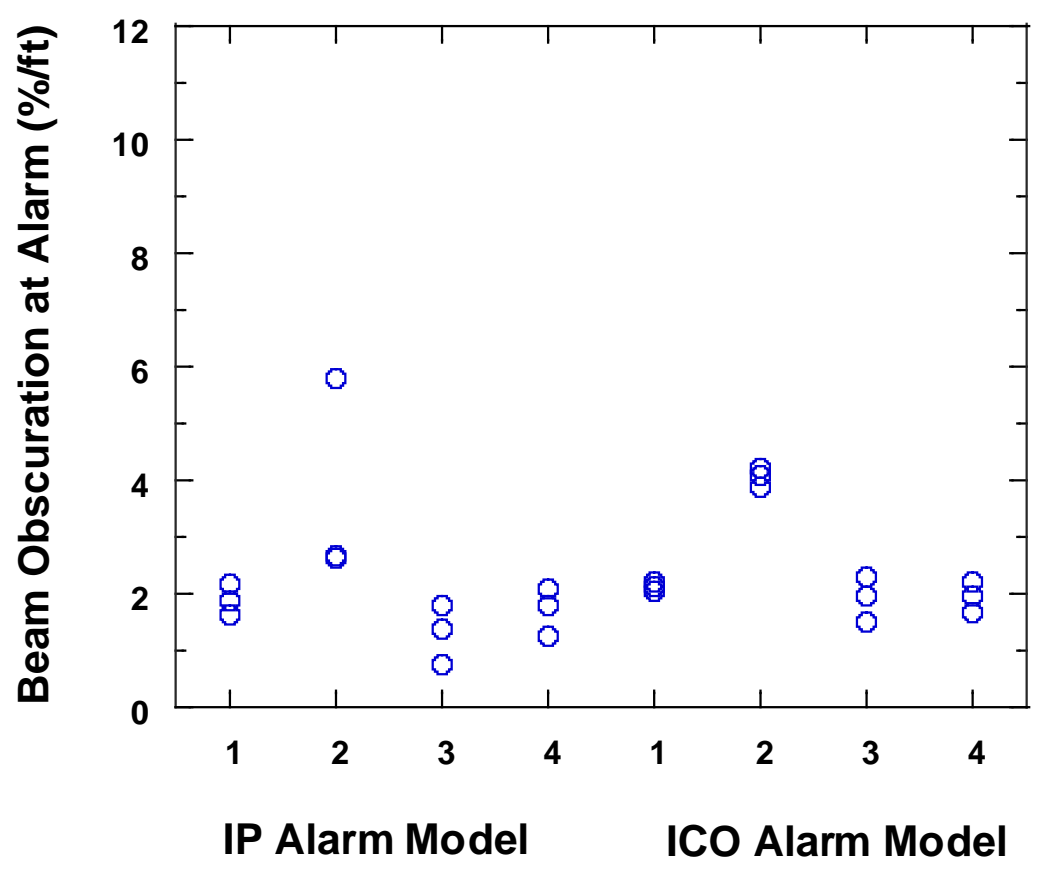

Figure 109. Flaming foam test experimental results for IP and ICO alarms. Closed symbols - test maximum with no alarm. $\mathrm{u}_{\mathrm{c}, \mathrm{r}}($ beam $)=4.0 \%$. 


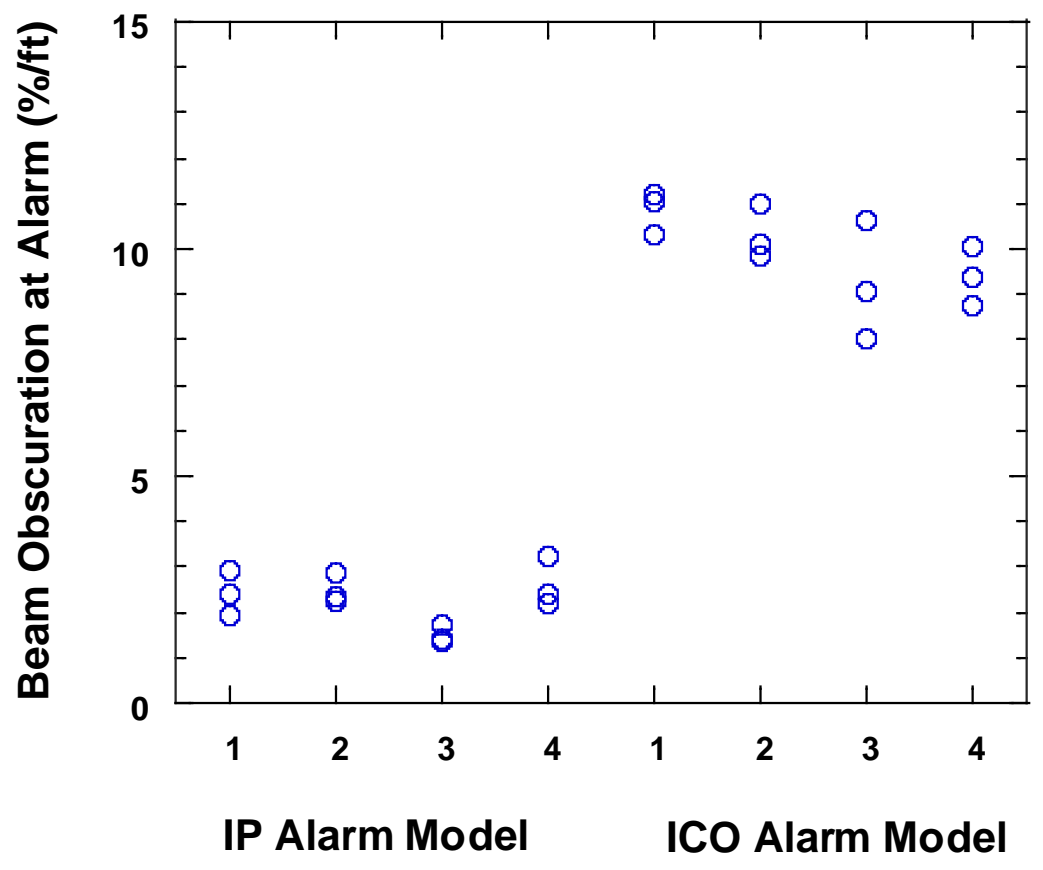

Figure 110. Smoldering foam test experimental results for IP and ICO alarms. Closed symbols - test maximum with no alarm. $\mathrm{u}_{\mathrm{c}, \mathrm{r}}($ beam $)=4.0 \%$.

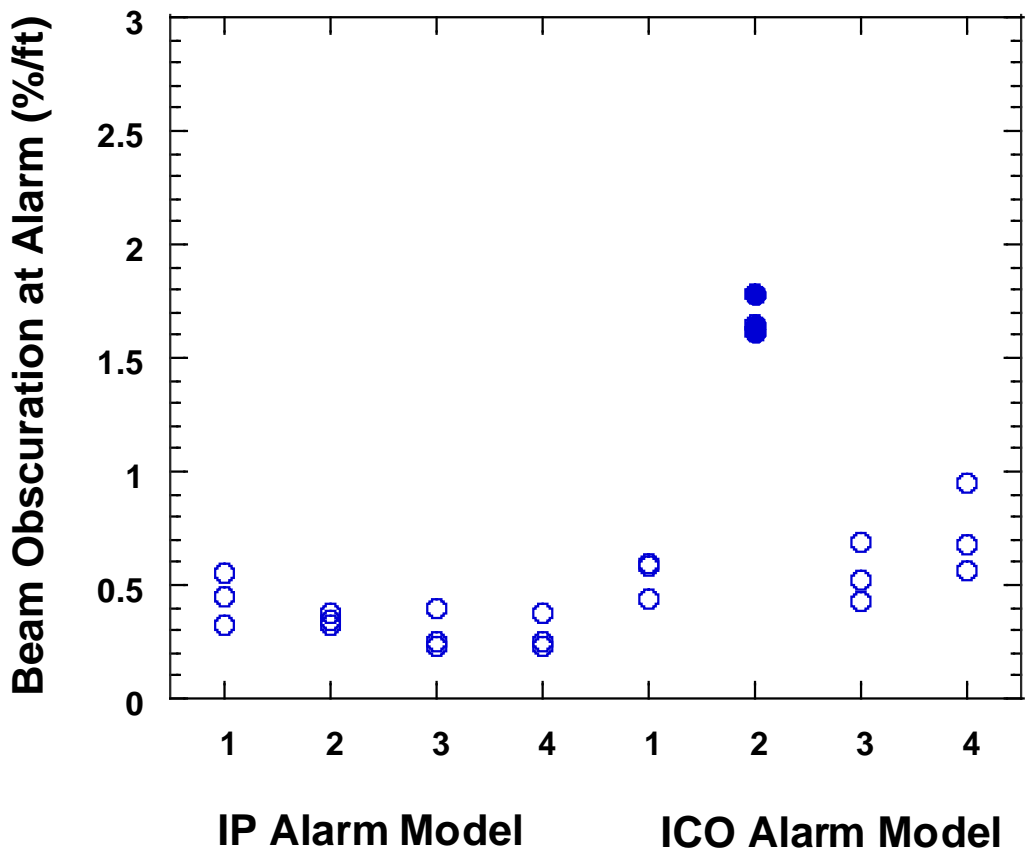

Figure 111. Broiling hamburgers test experimental results for IP and ICO alarms. Closed symbols - test maximum with no alarm. $\mathrm{u}_{\mathrm{c}, \mathrm{r}}($ beam $)=4.0 \%$. 


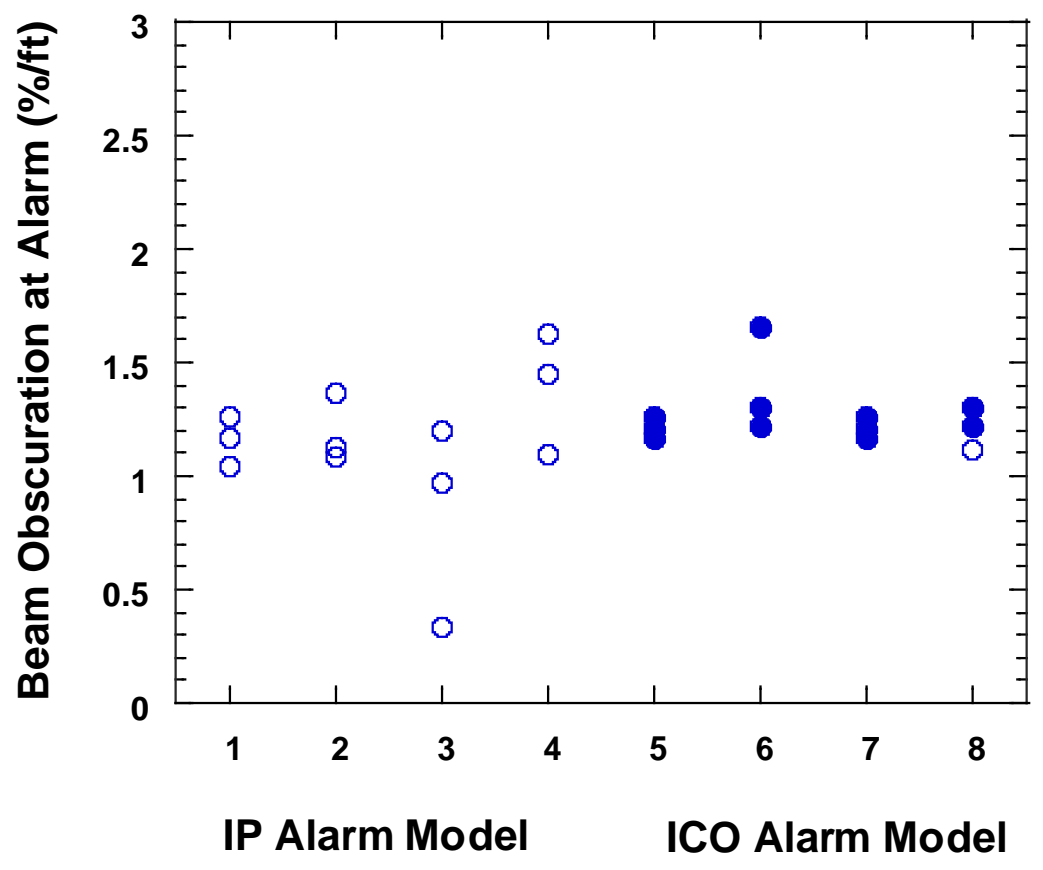

Figure 112. Frying hamburger experimental results for IP and ICO alarms. Closed symbols - test maximum with no alarm. $\mathrm{u}_{\mathrm{c}, \mathrm{r}}($ beam $)=4.0 \%$.

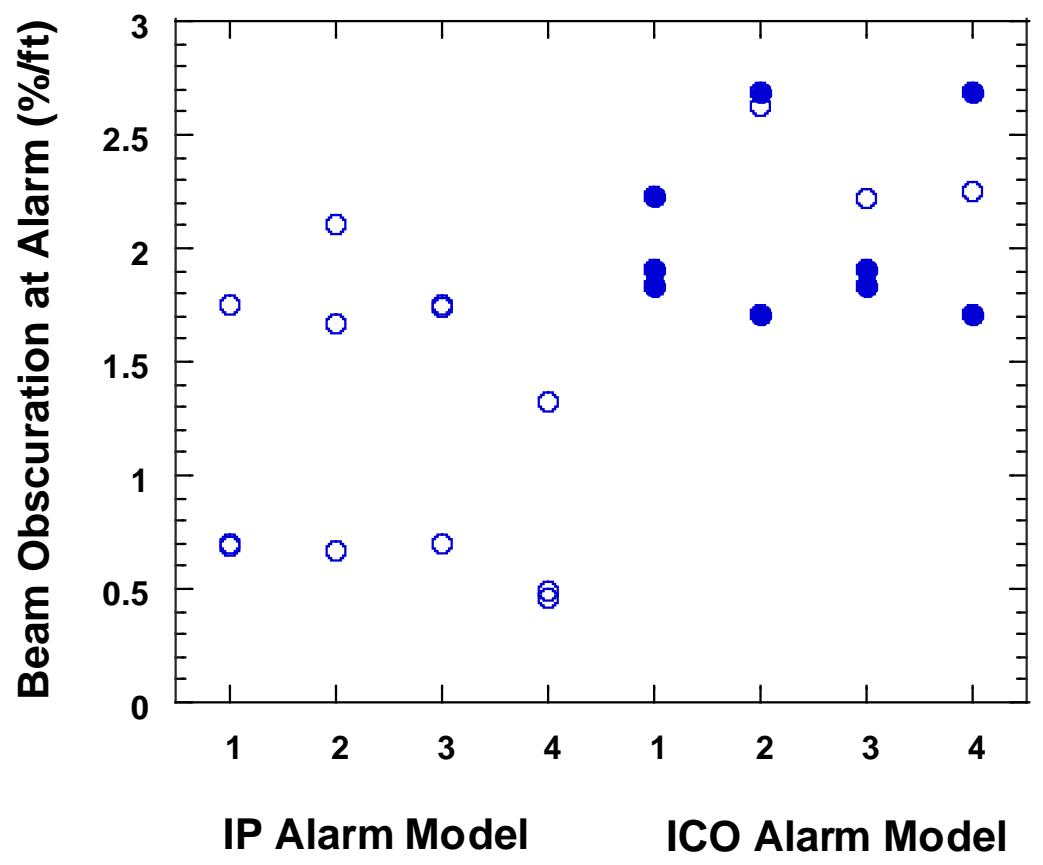

Figure 113. Stir-frying vegetables experimental results for IP and ICO alarms. Closed symbols - test maximum with no alarm. $\mathrm{u}_{\mathrm{c}, \mathrm{r}}($ beam $)=4.0 \%$. 


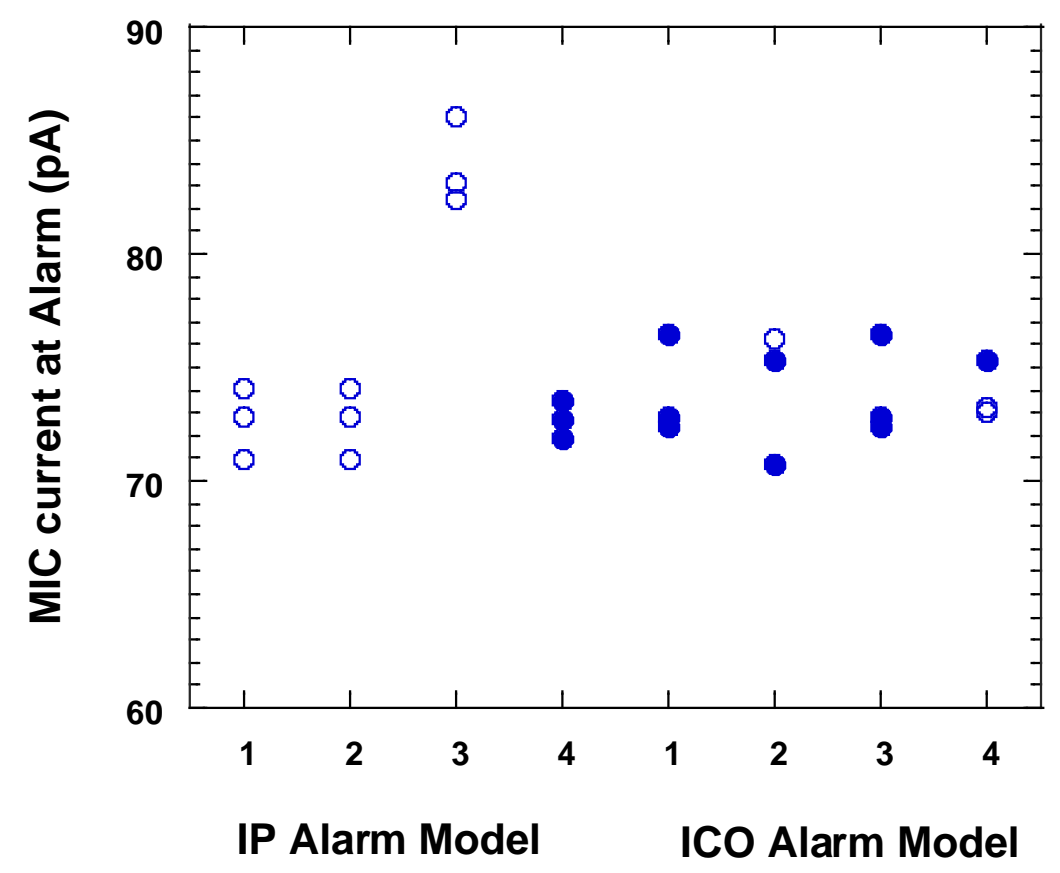

Figure 114. Toasting bread experimental results for IP and ICO alarms. Closed symbols - test minimum with no alarm. $\mathrm{u}_{\mathrm{c}}(\mathrm{MIC})=0.2 \mathrm{pA}$.

\subsubsection{Photoelectric Alarm Model Response Results}

The beam obscuration at alarm was determined from the recorded alarm times and the beam obscuration measurements. (No photoelectric, photoelectric / carbon monoxide or photoelectric / thermal alarm models responded during the toasting bread experiments.) The beam obscuration values at alarm response are shown in Figures 115 - 120 for each fire or cooking scenario. Open symbols represent the level at alarm and closed symbols represent the experimental maximum with no alarm response. 


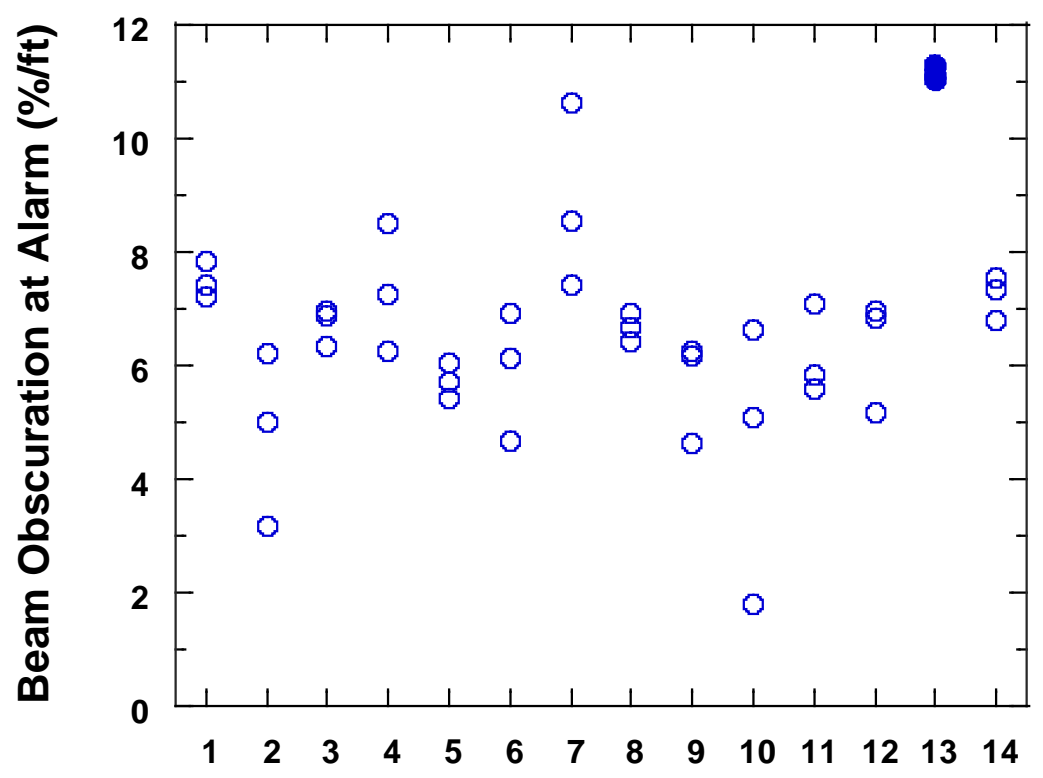

\section{Photoelectric Alarm Model}

Figure 115. Flaming foam test experimental results for photoelectric alarms. Closed symbols - test maximum with no alarm. $\mathrm{u}_{\mathrm{c}, \mathrm{r}}($ beam $)=4.0 \%$.

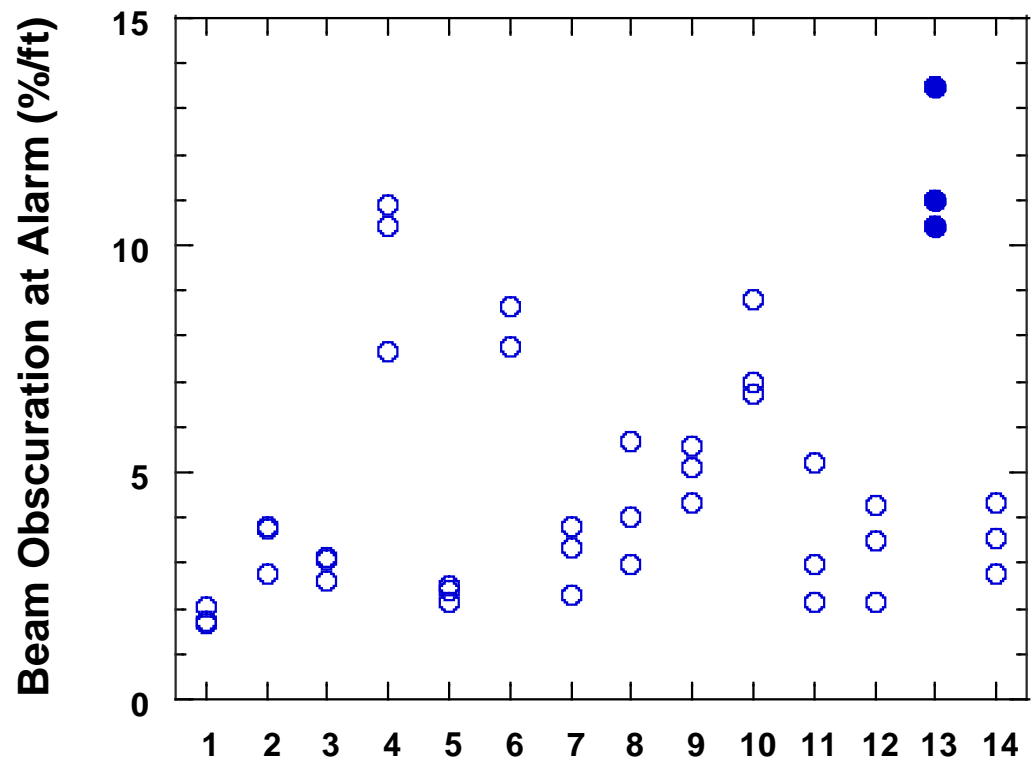

Photoelectric Alarm Model

Figure 116. Smoldering foam test experimental results for photoelectric alarms. Closed symbols - test maximum with no alarm. $\mathrm{u}_{\mathrm{c}, \mathrm{r}}($ beam $)=4.0 \%$. 


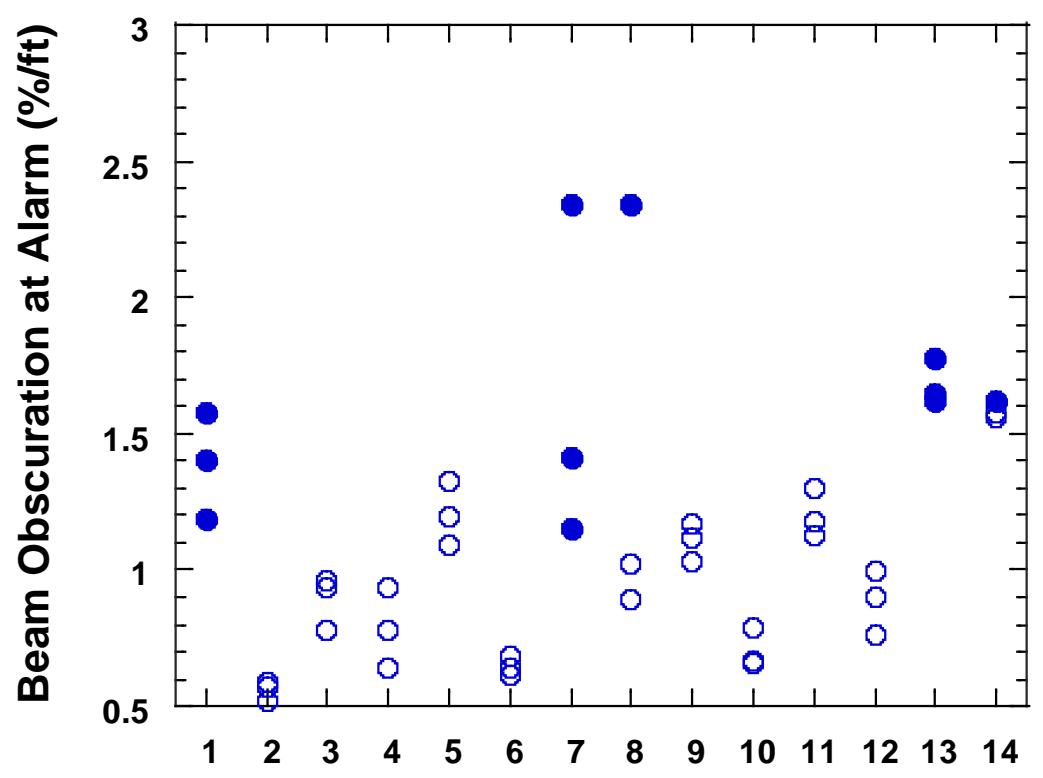

\section{Photoelectric Alarm Model}

Figure 117. Broiling hamburgers test experimental results for photoelectric alarms. Closed symbols - test maximum with no alarm. $\mathrm{u}_{\mathrm{c}, \mathrm{r}}($ beam $)=4.0 \%$.

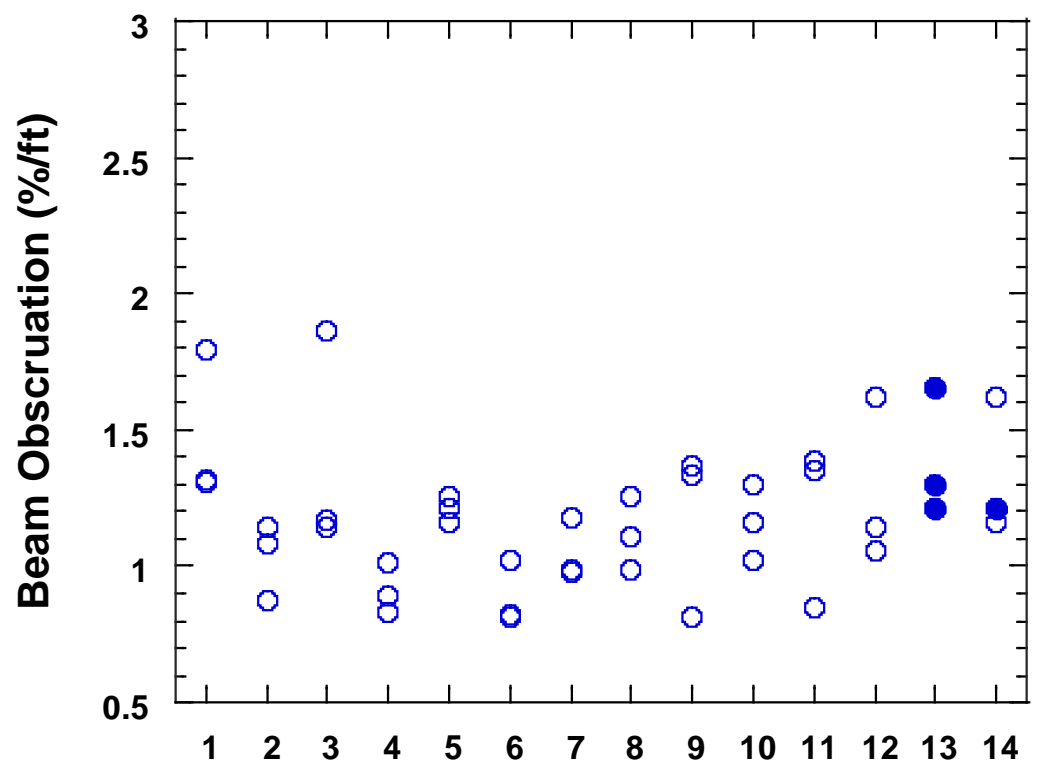

Photoelectric Alarm Model

Figure 118. Frying hamburger experimental results for photoelectric alarms. Closed symbols - test maximum with no alarm. $\mathrm{u}_{\mathrm{c}, \mathrm{r}}($ beam $)=4.0 \%$. 


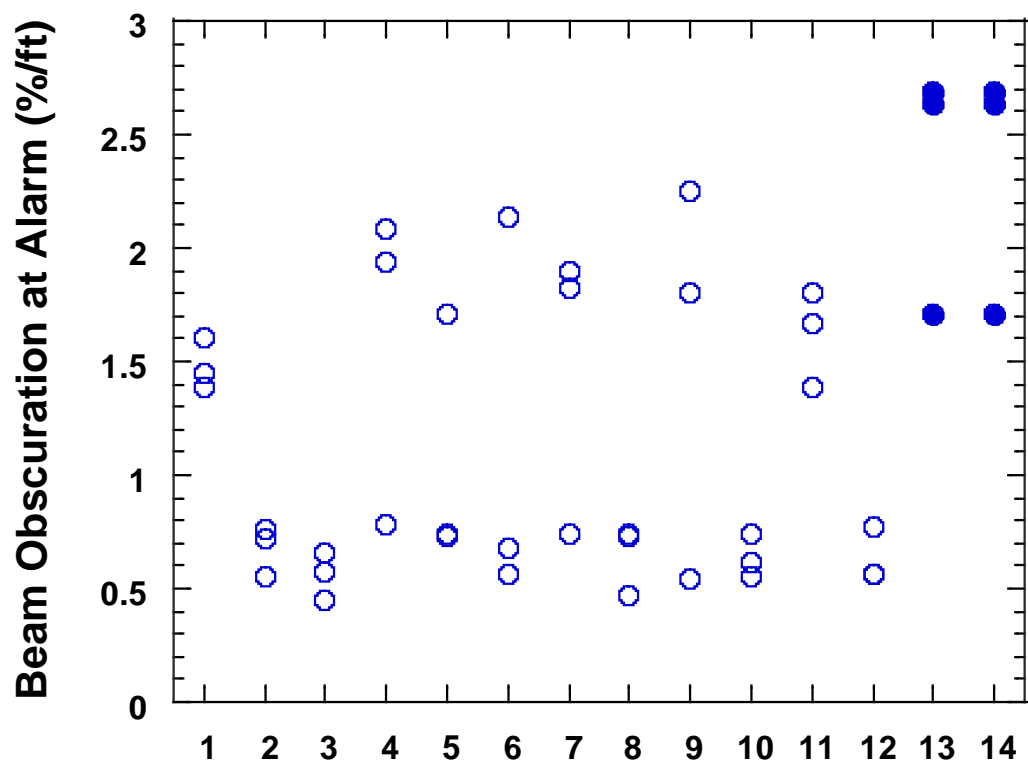

\section{Photoelectric Alarm Model}

Figure 119. Stir-frying vegetables experimental results for photoelectric alarms. Closed symbols - test maximum with no alarm. $\mathrm{u}_{\mathrm{c}, \mathrm{r}}($ beam $)=4.0 \%$.

\subsubsection{Photoelectric / Carbon Monoxide and Photoelectric / Thermal Combination Alarm Model Response Results}

The beam obscuration values at alarm response are shown in Figures 120 - 124 for each fire or cooking scenario. Open symbols represent the level at alarm and closed symbols represent the experimental maximum with no alarm response. 


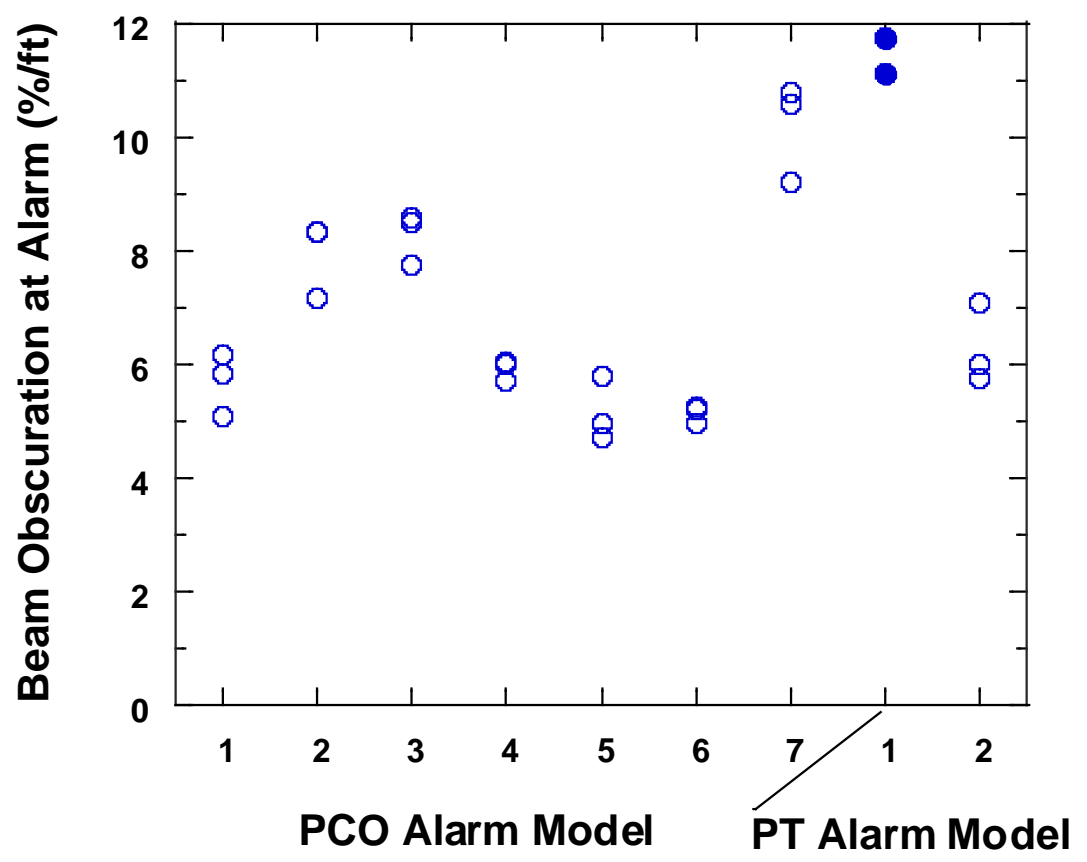

Figure 120. Flaming foam test experimental results for PCO and PT alarms. Closed symbols - test maximum with no alarm. $\mathrm{u}_{\mathrm{c}, \mathrm{r}}($ beam $)=4.0 \%$.

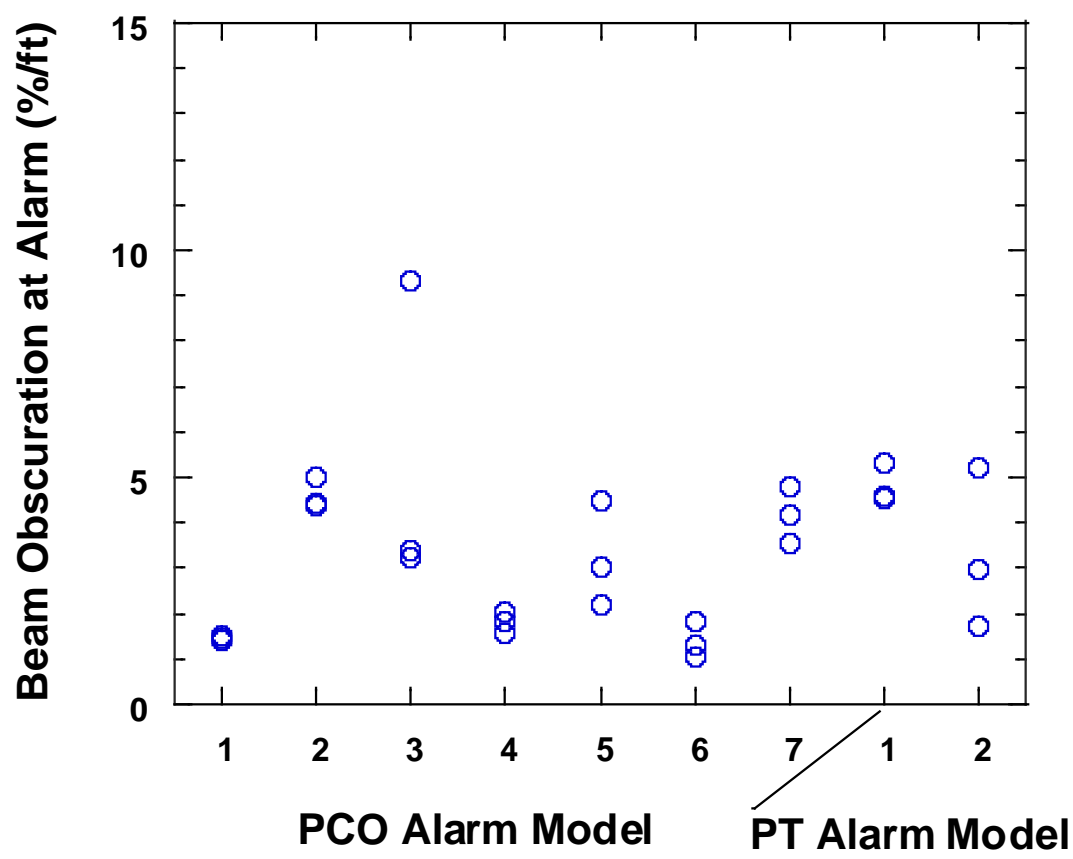

Figure 121. Smoldering foam test experimental results for PCO and PT alarms. Closed symbols - test maximum with no alarm. $\mathrm{u}_{\mathrm{c}, \mathrm{r}}($ beam $)=4.0 \%$. 


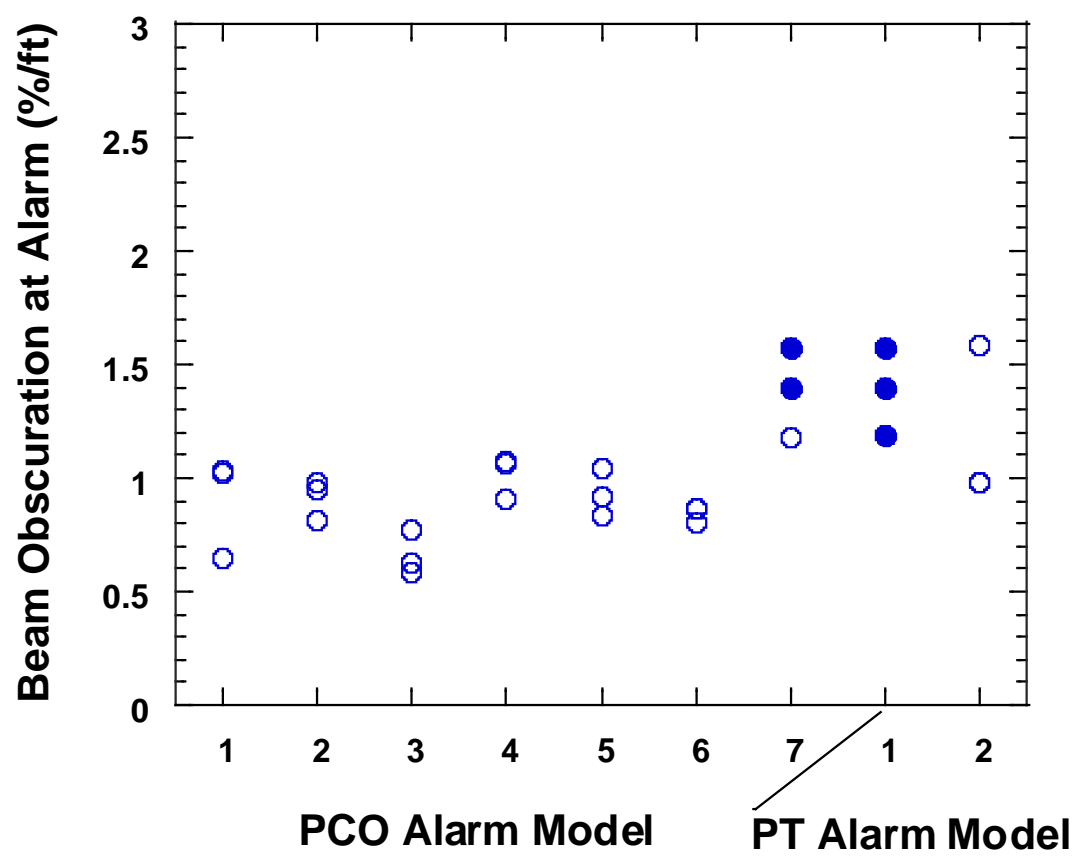

Figure 122. Broiling hamburgers test experimental results for PCO and PT alarms. Closed symbols - test maximum with no alarm. $\mathrm{u}_{\mathrm{c}, \mathrm{r}}(\mathrm{beam})=4.0 \%$.

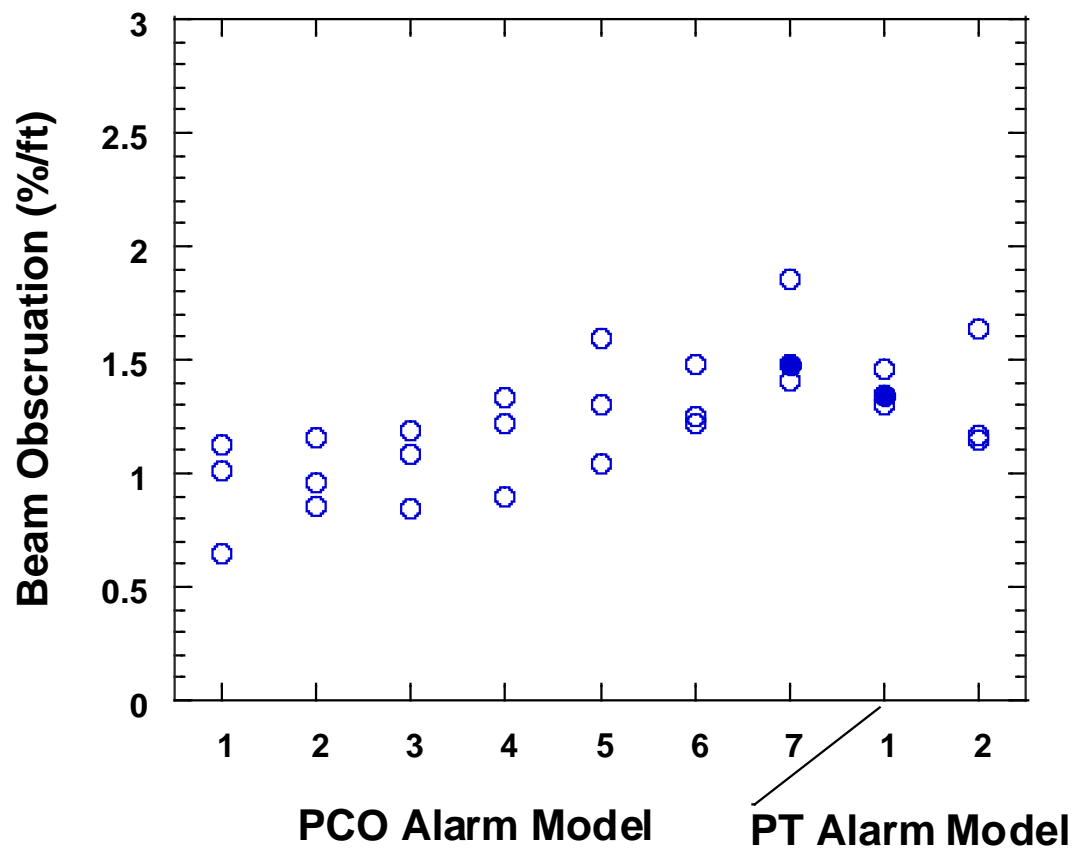

Figure 123. Frying hamburger experimental results for PCO and PT alarms. Closed symbols - test maximum with no alarm. $\mathrm{u}_{\mathrm{c}, \mathrm{r}}($ beam $)=4.0 \%$. 


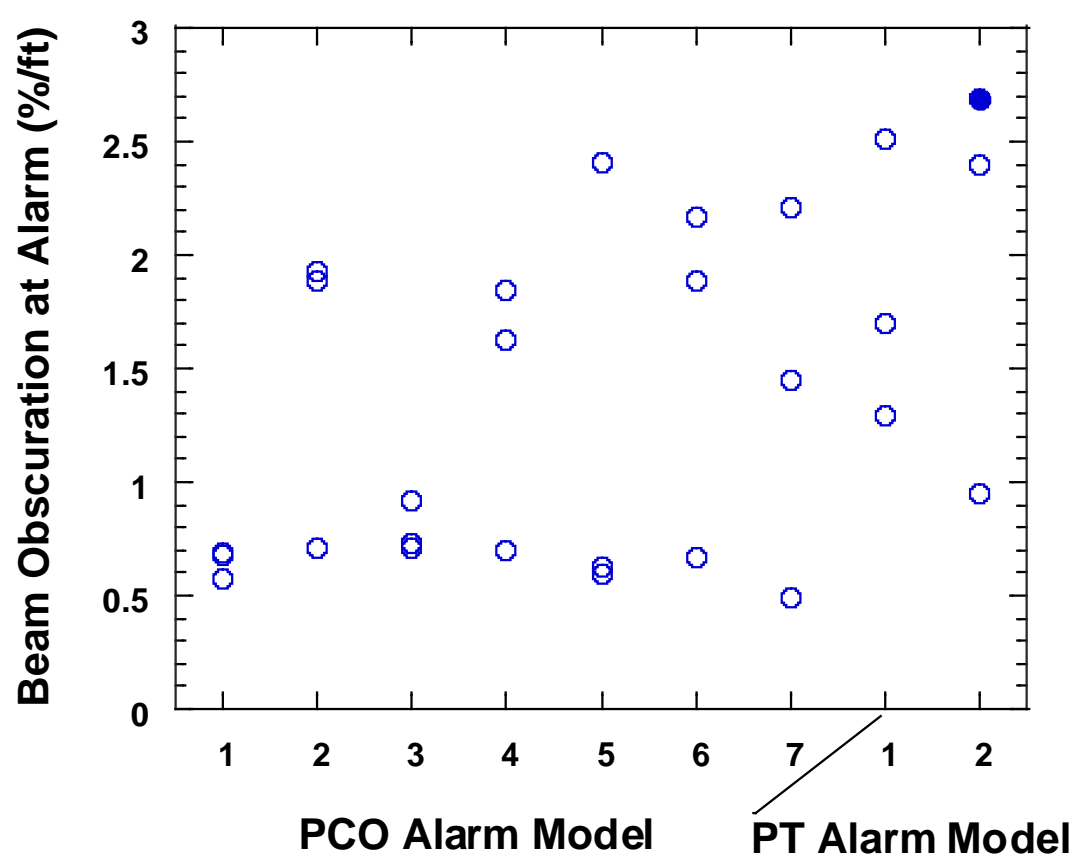

Figure 124. Stir-frying vegetables experimental results for PCO and PT alarms. Closed symbols - test maximum with no alarm. $\mathrm{u}_{\mathrm{c}, \mathrm{r}}($ beam $)=4.0 \%$. 


\section{$4 \quad$ Analysis of Current Smoke Alarm Performance}

The 45 alarm models represent a wide range of sensitivities as determined by the smoke box experiments. It was presumed that smoke alarms purchased in the US would meet the current ANSI/UL 217 standard in force when they were manufactured ( $5^{\text {th }}$ through $7^{\text {th }}$ Edition). Only one model, P13, did not meet the alarm response range in the smoke box as specified in the Standard, and in fact did not respond in any room test. It's concluded the six units of this model tested would not meet the requirements of ANSI/UL 217 and should not be considered representative of a photoelectric alarm that would meet the requirements of any recent previous version of the Standard.

\subsection{Smoke Alarm Performance in the New Fire and Nuisance Tests}

Some of the smoke alarm models appear to meet the performance criteria for some of the new tests in ANSI/UL 217-2015. For instance, alarms containing ionization sensors do well as a group to the flaming polyurethane foam test, while alarms containing photoelectric sensors do well with the exception of P13 to the smoldering polyurethane foam test.

A ranking scheme to evaluate the performance of each smoke alarm model to the three new tests was devised. The responses of a smoke alarm model to threshold limit values that correspond to the performance criteria of ANSI/UL 217-2015, and values that are somewhat less restrictive and somewhat more restrictive were determined. Each smoke alarm model was evaluated by tabulating the number of times out of three repeated experiments an alarm model responded to the particular test exposure for each of the three performance levels. A combined performance rank was determined by tabulating the number of three out of three successes over the three test scenarios for a particular performance level. A rank of 3 at the performance levels specified for the new tests would suggest that the particular smoke alarm model would meet the performance criteria of the new tests in ANSI/UL 217-2015.

For the flaming polyurethane foam test an alarm must produce an alarm signal at or before $5.00 \% / \mathrm{ft}$ obscuration limit (denoted here as $\mathrm{M}$ ). A higher sensitivity limit (denoted here as $\mathrm{H}$ ) of $3.00 \% / \mathrm{ft}$ and a lower sensitivity limit (denoted hear as $\mathrm{L}$ ) of $7.00 \%$ /ft were defined to estimate performance for somewhat more or less stringent performance levels.

For the smoldering polyurethane foam test, a smoke alarm must produce an alarm signal at or below the $12.00 \% / \mathrm{ft}$ obscuration limit (M). For this test, higher and lower sensitivity limits of 8.00\%/ft and 16.00 $\% / \mathrm{ft}$ were defined when obscuration was the proper measurand to estimate performance for somewhat more or less stringent performance levels. Since the beam / MIC profiles for the NIST experiments were outside the acceptable bounds specified in the Standard (see Figure 77), sensitivity limits based on the MIC current were specified for ionization and ionization/ carbon monoxide alarms to better represent the expected performance of such alarms to the smoldering polyurethane foam test. The MIC current limits followed the lower bounding beam / MIC profile curve shown in Figure 77, and were 68 pA (L), 75 pA (M), and $81 \mathrm{pA}(\mathrm{H})$ for obscurations of $16 \% / \mathrm{ft}, 12 \% / \mathrm{ft}$ and $8 \% / \mathrm{ft}$ respectively.

For the broiling hamburgers cooking nuisance test, an alarm must not produce an alarm signal at or below $1.50 \% / \mathrm{ft}$ obscuration limit (M). For this test higher and lower performance limits of $2.00 \% / \mathrm{ft}(\mathrm{H})$ and $1.00 \% / \mathrm{ft}(\mathrm{L})$ below which alarms shall not produce alarm signals were defined. 
Table 7 shows the results for models containing photoelectric, photoelectric / carbon monoxide and photoelectric / thermal sensors. Table 8 shows the results for models that contain ionization, ionization / photoelectric, and ionization / carbon monoxide sensors.

Table 7. Number of experiments where alarms met the threshold limits and the performance ranking at each threshold level for photoelectric, photoelectric / carbon monoxide and photoelectric / thermal sensor models.

\begin{tabular}{|c|c|c|c|c|c|c|c|c|c|c|c|c|}
\hline \multirow[t]{2}{*}{ Model } & \multicolumn{3}{|c|}{\begin{tabular}{|l|} 
Smoldering fire \\
tests meeting limit
\end{tabular}} & \multicolumn{3}{|c|}{$\begin{array}{l}\text { Flaming fire } \\
\text { tests meeting limit }\end{array}$} & \multicolumn{3}{|c|}{$\begin{array}{l}\text { Broiling hamburgers } \\
\text { tests meeting limit }\end{array}$} & \multicolumn{3}{|c|}{ Performance rank } \\
\hline & $\mathrm{L}$ & $\mathrm{M}$ & $\mathrm{H}$ & $\mathrm{L}$ & $\mathrm{M}$ & $\mathrm{H}$ & $\mathrm{L}$ & $\mathrm{M}$ & $\mathrm{H}$ & $\mathrm{L}$ & $\mathrm{M}$ & $\mathrm{H}$ \\
\hline P01 & 3 & 3 & 3 & 0 & 0 & 0 & 3 & 3 & 0 & 2 & 2 & 1 \\
\hline P02 & 3 & 3 & 3 & 3 & 1 & 0 & 0 & 0 & 0 & 2 & 1 & 1 \\
\hline P03 & 3 & 3 & 3 & 3 & 0 & 0 & 0 & 0 & 0 & 2 & 1 & 1 \\
\hline P04 & 3 & 3 & 3 & 2 & 0 & 0 & 0 & 0 & 0 & 1 & 1 & $\mathbf{0}$ \\
\hline P05 & 3 & 3 & 3 & 3 & 0 & 0 & 3 & 0 & 0 & 3 & 1 & 1 \\
\hline P06 & 3 & 3 & 3 & 3 & 1 & 0 & 0 & 0 & 0 & 2 & $\mathbf{0}$ & $\mathbf{0}$ \\
\hline P07 & 3 & 3 & 3 & 1 & 0 & 0 & 3 & 3 & 3 & 2 & 2 & 2 \\
\hline P08 & 3 & 3 & 3 & 3 & 0 & 0 & 2 & 1 & 1 & 3 & 1 & 1 \\
\hline P09 & 3 & 3 & 3 & 3 & 1 & 0 & 3 & 0 & 0 & 3 & 1 & 1 \\
\hline P10 & 3 & 3 & 3 & 3 & 1 & 1 & 0 & 0 & 0 & 2 & 1 & 1 \\
\hline P11 & 3 & 3 & 3 & 2 & 0 & 0 & 3 & 0 & 0 & 2 & 1 & 1 \\
\hline P12 & 3 & 3 & 3 & 3 & 0 & 0 & 0 & 0 & 0 & 2 & 1 & 1 \\
\hline P13 & 0 & 0 & 0 & 0 & 0 & 0 & 0 & 0 & 0 & 0 & 0 & 0 \\
\hline P14 & 3 & 3 & 3 & 1 & 0 & 0 & 3 & 3 & 0 & 2 & 2 & 1 \\
\hline PCO01 & 3 & 3 & 3 & 1 & 1 & 1 & 2 & 0 & 0 & 1 & 1 & 1 \\
\hline PCO02 & 3 & 3 & 3 & 0 & 0 & 0 & 0 & 0 & 0 & 1 & 1 & 1 \\
\hline PCO03 & 3 & 3 & 2 & 0 & 0 & 0 & 0 & 0 & 0 & 1 & 1 & 0 \\
\hline PCO04 & 3 & 3 & 3 & 1 & 1 & 1 & 2 & 0 & 0 & 1 & 1 & 1 \\
\hline PCO05 & 3 & 3 & 3 & 3 & 2 & 0 & 1 & 0 & 0 & 2 & 1 & 1 \\
\hline PCO06 & 3 & 3 & 3 & 3 & 1 & 0 & 0 & 0 & 0 & 2 & 1 & 1 \\
\hline PCO07 & 3 & 3 & 3 & 0 & 0 & 0 & 3 & 3 & 0 & 2 & 2 & 1 \\
\hline PT01 & 3 & 3 & 3 & 0 & 0 & 0 & 3 & 1 & 0 & 2 & 1 & 1 \\
\hline PT02 & 3 & 3 & 3 & 2 & 0 & 0 & 1 & 1 & 0 & 2 & 1 & 1 \\
\hline
\end{tabular}


Table 8. Number of experiments where alarms met the threshold limits and the performance ranking at each threshold level for ionization, ionization / carbon monoxide and ionization / photoelectric sensor models.

\begin{tabular}{|c|c|c|c|c|c|c|c|c|c|c|c|c|}
\hline \multirow[t]{2}{*}{ Model } & \multicolumn{3}{|c|}{$\begin{array}{l}\text { Smoldering fire } \\
\text { tests meeting limit }\end{array}$} & \multicolumn{3}{|c|}{$\begin{array}{l}\text { Flaming fire } \\
\text { tests meeting limit }\end{array}$} & \multicolumn{3}{|c|}{$\begin{array}{l}\text { Broiling hamburgers } \\
\text { tests meeting limit }\end{array}$} & \multicolumn{3}{|c|}{ Performance rank } \\
\hline & $\mathrm{L}$ & $\mathrm{M}$ & $\mathrm{H}$ & $\mathrm{L}$ & $\mathrm{M}$ & $\mathrm{H}$ & $\mathrm{L}$ & $\mathrm{M}$ & $\mathrm{H}$ & $\mathrm{L}$ & $\mathrm{M}$ & $\mathrm{H}$ \\
\hline I01 & 0 & 0 & 0 & 3 & 3 & 3 & 3 & 0 & 0 & 2 & 1 & 1 \\
\hline I02 & 2 & 0 & 0 & 3 & 3 & 3 & 0 & 0 & 0 & 1 & 1 & 1 \\
\hline I03 & 3 & 3 & 0 & 3 & 3 & 3 & 0 & 0 & 0 & 2 & 2 & 1 \\
\hline I04 & 3 & 3 & 3 & 3 & 3 & 3 & 0 & 0 & 0 & 2 & 2 & 2 \\
\hline $\mathrm{I} 05$ & 3 & 3 & 1 & 3 & 3 & 3 & 0 & 0 & 0 & 2 & 2 & 1 \\
\hline I06 & 3 & 1 & 1 & 3 & 3 & 3 & 0 & 0 & 0 & 2 & 1 & 1 \\
\hline I07 & 2 & 0 & 0 & 3 & 3 & 3 & 0 & 0 & 0 & 1 & 1 & 1 \\
\hline I08 & 3 & 1 & 0 & 3 & 3 & 3 & 0 & 0 & 0 & 2 & 1 & 1 \\
\hline I09 & 3 & 0 & 0 & 3 & 3 & 3 & 0 & 0 & 0 & 2 & 1 & 1 \\
\hline I10 & 3 & 0 & 0 & 3 & 3 & 3 & 0 & 0 & 0 & 2 & 1 & 1 \\
\hline I11 & 0 & 0 & 0 & 3 & 3 & 3 & 0 & 0 & 0 & 1 & 1 & 1 \\
\hline I12 & 0 & 0 & 0 & 3 & 3 & 2 & 0 & 0 & 0 & 1 & 1 & 0 \\
\hline I13 & 0 & 0 & 0 & 3 & 3 & 1 & 3 & 1 & 0 & 2 & 1 & 0 \\
\hline I14 & 0 & 0 & 0 & 3 & 3 & 2 & 3 & 1 & 0 & 2 & 1 & 0 \\
\hline ICO01 & 1 & 0 & 0 & 3 & 3 & 3 & 0 & 0 & 0 & 1 & 1 & 1 \\
\hline ICO02 & 2 & 0 & 0 & 3 & 3 & 0 & 3 & 3 & 1 & 2 & 2 & $\mathbf{0}$ \\
\hline ICO03 & 3 & 0 & 0 & 3 & 3 & 3 & 0 & 0 & 0 & 2 & 1 & 1 \\
\hline ICO04 & 2 & 0 & 0 & 3 & 3 & 3 & 0 & 0 & 0 & 1 & 1 & 1 \\
\hline IP01 & 3 & 3 & 3 & 3 & 3 & 3 & 0 & 0 & 0 & 2 & \begin{tabular}{|l|}
2 \\
\end{tabular} & 2 \\
\hline IP02 & 3 & 3 & 3 & 3 & 2 & 2 & 0 & 0 & 0 & 2 & 1 & 1 \\
\hline IP03 & 3 & 3 & 3 & 3 & 3 & 3 & 0 & 0 & 0 & 2 & 2 & 2 \\
\hline IP04 & 3 & 3 & 3 & 3 & 3 & 3 & 0 & 0 & 0 & 2 & 2 & 2 \\
\hline
\end{tabular}

No models met the new performance criteria specified in ANSI/UL 217-2015. Three photoelectric and one photoelectric / carbon monoxide model met two out of three criteria and two photoelectric models met none of the criteria. Three photoelectric models have a rank of three at the lower performance levels. Three out of 14 ionization models, three out of four ionization / photoelectric models, and one out of four ionization / carbon monoxide models met two of three performance criteria specified in ANSI/UL 2172015. No ionization sensor containing models achieved a rank of three at the lower performance level.

Three quarters of the alarm models meet only one or none of the new performance criteria specified in ANSI/UL 217-2015, and only three out of 45 meet the three performance criteria at the lower performance level. Clearly, the addition of the new tests in ANSI/UL 217-2015 would challenge current smoke alarms, and may require re-engineering of essentially all smoke alarms listed to earlier editions of the Standard. 
The average ranks of alarms containing a photoelectric sensor but not an ionization sensor (and not considering P13) are 1.9, 1.1 and 0.9 for sensitivity levels of $\mathrm{L}, \mathrm{M}$ and $\mathrm{H}$ respectively. For alarms containing an ionization sensor but not a photoelectric sensor the average ranks are 1.7, 1.2 and 0.8 for sensitivity levels of $\mathrm{L}, \mathrm{M}$ and $\mathrm{H}$ respectively. A rank of three is required at the performance level $\mathrm{M}$ to meet the performance level in ANSI/UL 217-2015. Thus, it is concluded that smoke alarms meeting the performance criteria in ANSI/UL 217-2015 would demonstrate significantly improved overall performance by expanding range of fire scenarios alarms must respond to while requiring greater resistance to nuisance alarms than a wide range of currently available models.

In general, the ionization/ photoelectric models performed better against the two new fire tests than the majority of the other models examined with average ranking of 2.0, 1.8 and 1.8 for sensitivity levels of L, $\mathrm{M}$ and $\mathrm{H}$ respectively. This observation illustrates the complementary nature of the ionization and photoelectric sensors when responding to flaming or smoldering sources. However, the tradeoff appears to be increased sensitivity to a wider range of cooking nuisance sources. Given the need to achieve some level of nuisance alarm resistance, it may be a challenge for manufacturers to meet the requirements by simply using both photoelectric and ionization sensors, and may be difficult to design alarms meeting the new test requirements including the cooking nuisance test that will perform as well against the new fire tests as combination ionization / photoelectric models examined.

\subsection{Smoke Alarm Performance in the Cooking Nuisance Source Tests}

The broiling hamburgers test is meant to cover a range of cooking scenarios such that meeting the test performance criteria will translate into alarm response resistance to a range of cooking scenarios. The choice for the performance criterion was somewhat subjective, but apparently chosen to challenge current smoke alarms. For instance, a total of 35 out of 45 alarm models did not meet the $1.5 \% / \mathrm{ft}$ nonalarm criterion in any of the three repeated experiments, while only five models did.

A comparison of the broiling hamburgers results to the other cooking nuisance experiments was made to assess the appropriateness of the single nuisance test in terms of reducing alarm response to a range of cooking scenarios. Figure 125 shows the ceiling smoke obscuration as a function of time for three cooking scenarios that produce measurable obscuration. Both the frying hamburger and stir-frying vegetables scenarios have more rapid smoke obscuration build-up than the broiling hamburgers scenario. Figure 126 shows the MIC current as a function of time for all four cooking scenarios. The toasting, frying hamburger and stir frying vegetables scenarios have more rapid MIC current reduction than the broiling hamburgers scenario.

The obscuration versus MIC current results for the frying hamburger and stir-frying vegetables experiments typically yielded higher obscuration values at a given MIC current than the broiling hamburgers experiments. While toasting bread experiments typically produced no measurable obscuration, but MIC current levels that caused some alarms to respond. 


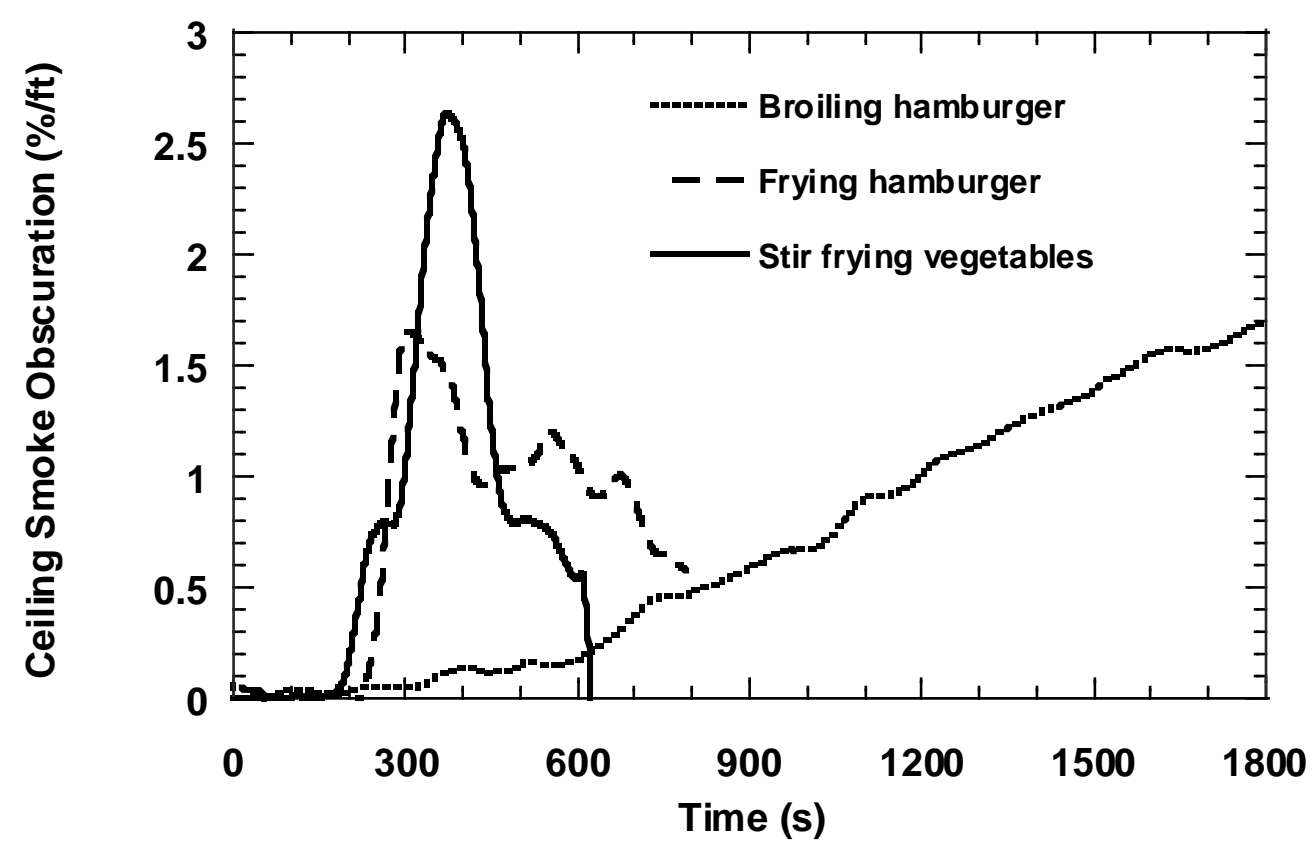

Figure 125.Ceiling smoke obscuration versus time for three cooking scenarios. $\mathrm{u}_{\mathrm{c}, \mathrm{r}}(\mathrm{beam})=4.0 \%$.

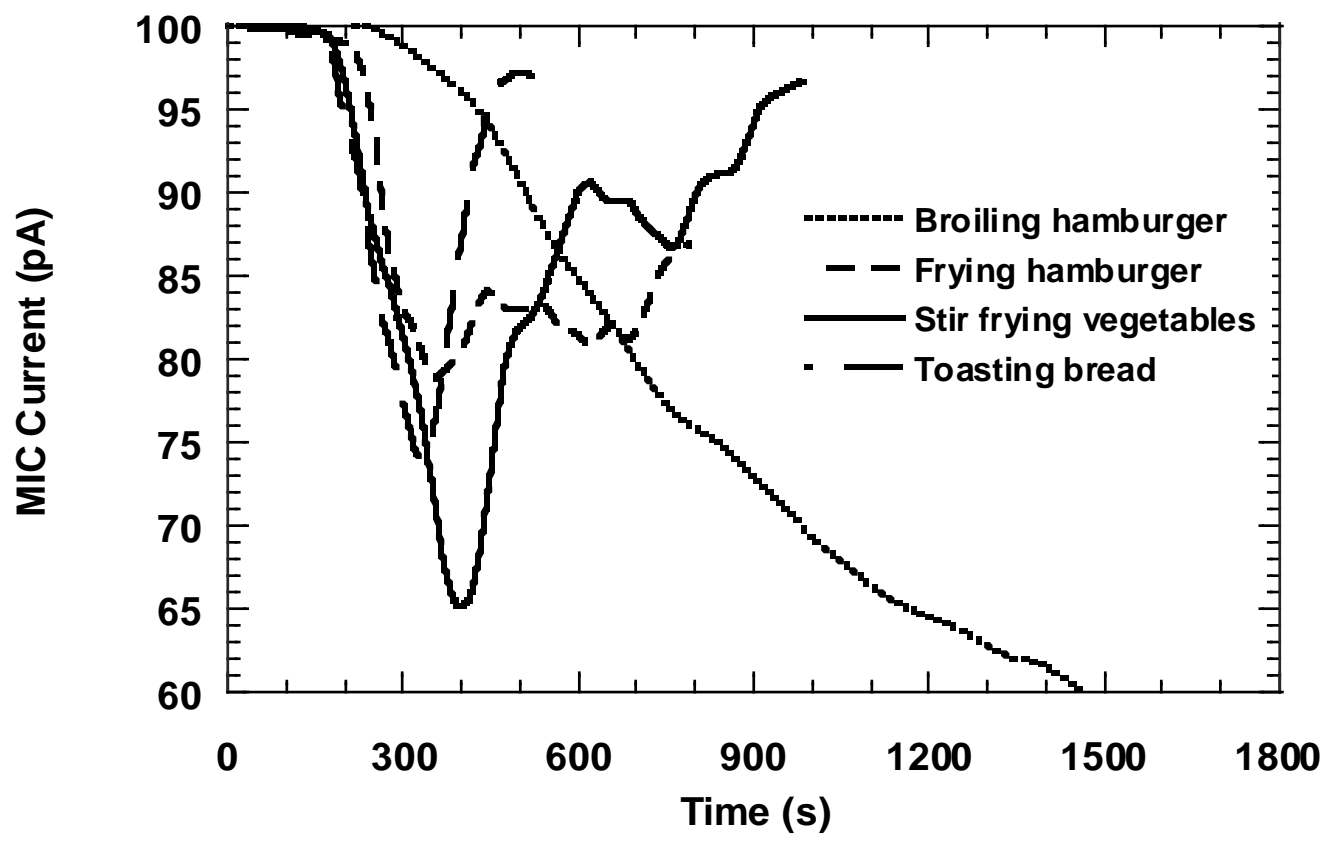

Figure 126. MIC current versus time for four cooking scenarios. $\mathrm{u}_{\mathrm{c}}(\mathrm{MIC})=0.2 \mathrm{pA}$. 
Figure 127 shows the average beam obscuration at alarm for repeated experiments with the photoelectric model alarms. For those models that alarmed, the range was $0.5 \% / \mathrm{ft}$ to $1.6 \% / \mathrm{ft}$ obscuration. For the three cooking scenarios, there does not appear to be a strong correspondence between the average beam obscuration for each alarm model.

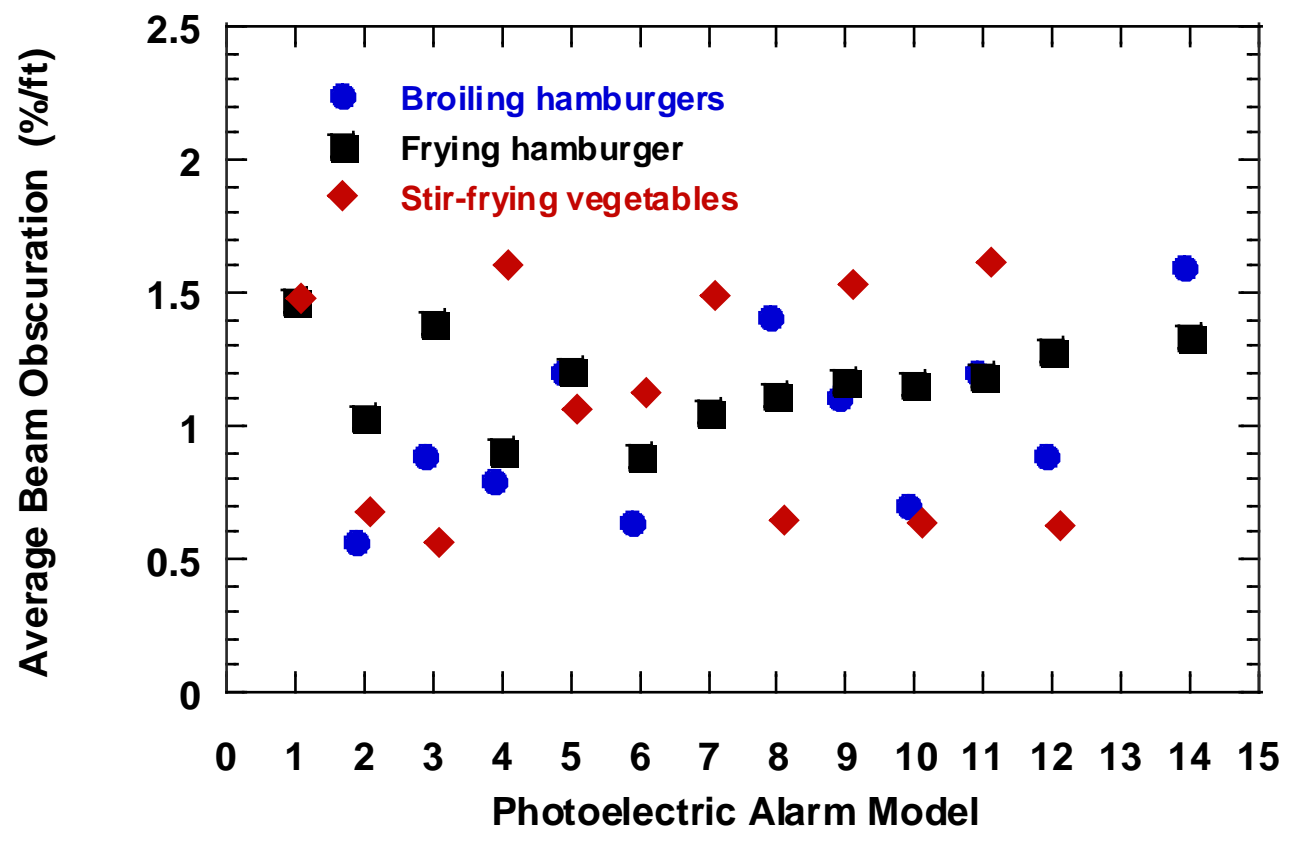

Figure 127. Average beam obscuration of photoelectric alarm models for three cooking scenarios.

Figure 128 shows the average MIC current at alarm for repeated experiments with the ionization model alarms. For those models that alarmed, the range was $95 \mathrm{pA}$ to $68 \mathrm{pA}$. There appears to be some correspondence between the average MIC current for each alarm model with the broiling hamburgers, stir-frying vegetables and toasting bread scenarios. The frying hamburgers scenario results depart from the other cooking scenario results, almost always responding at a higher average MIC current irrespective of alarm model. 


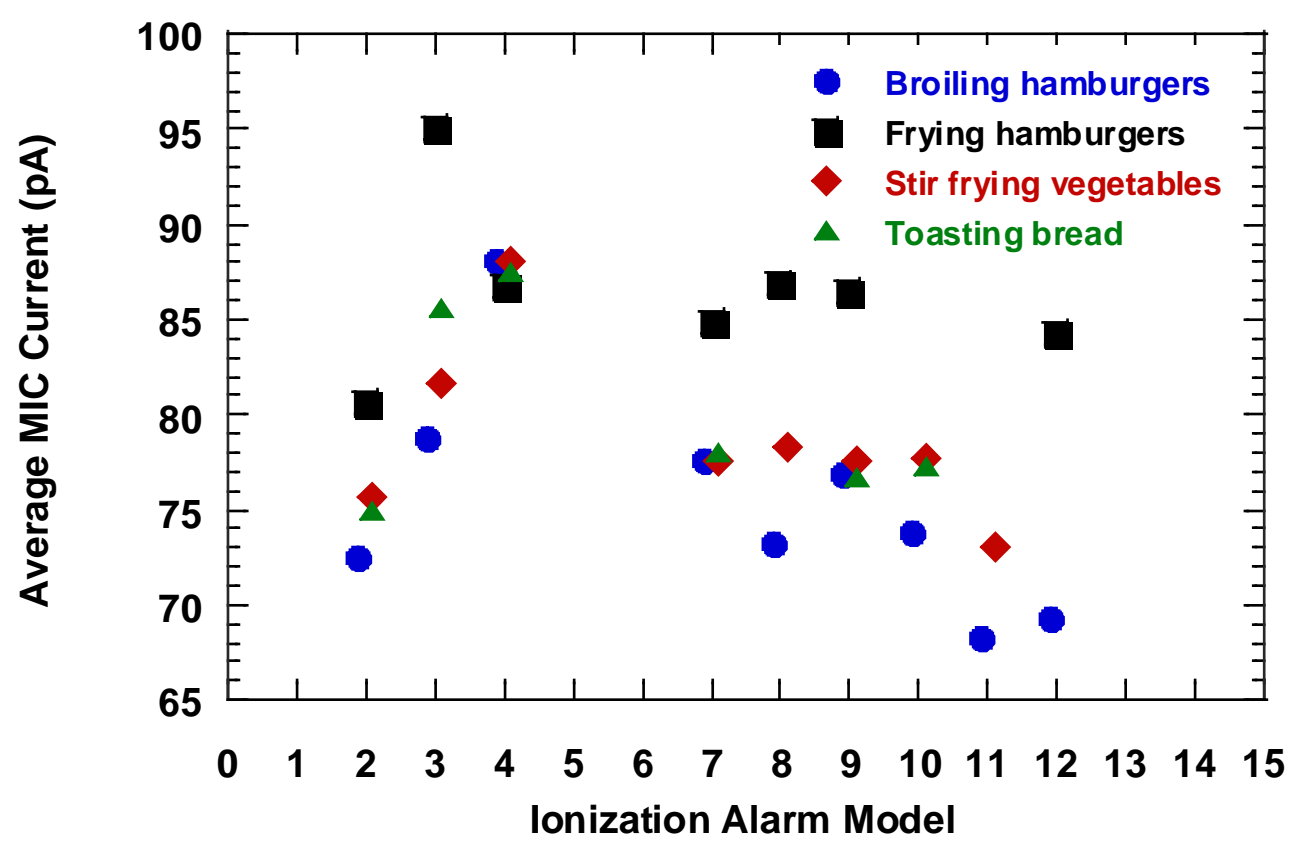

Figure 128. Average MIC current of ionization alarm models for four cooking scenarios.

The broiling hamburgers test produces an aerosol that causes majority of alarm models studied to respond at low enough levels that could be characterized as a nuisance, and it appears to be a conservative test in that respect. However, the observed differences in the cooking aerosol production rates and aerosol properties appear to affect the alarm response for photoelectric and ionization alarms for the cooking activities examined. Thus, it cannot be definitively concluded that the broiling hamburger test is appropriate as the model test for all cooking nuisance sources. Ultimately, experiments on a range of smoke alarms that pass ANSI/UL 217-2015 which demonstrate sufficient alarm resistance to a range of cooking scenarios will confirm the appropriateness of the broiling hamburgers cooking nuisance scenario as the model test. 


\section{Conclusions}

The research performed in this study was designed to more fully understand the degree of performance enhancement that might be realized by a complete change in smoke alarm design due to new tests in ANSI/UL 217-2105, Standard for Safety of Smoke Alarms. The objectives of the research were to gather data for a snap shot of a wide range of currently available smoke alarms on their performance to the new tests and to additional cooking scenarios, and analyze the data to answer the questions:

- To what extent will the new tests challenge current smoke alarm designs?

- What is the potential performance enhancement of new smoke alarm designs?

- How appropriate is a single nuisance cooking test in representing a range of cooking activities?

The research findings are:

1. Analysis of the results show that no current smoke alarm model would meet the performance level required in ANSI/UL 217-2015. Of the smoke alarms tested, three models, all photoelectric sensor alarms, came closest to meeting the new requirements.

2. An across the board increase in the level of performance to that specified in ANSI/UL 217-2015 would significantly improve the overall performance of smoke alarms by expanding range of fire scenarios alarms must respond to while requiring resistance to nuisance alarms.

3. The changes in the ANSI/UL 217-2015, which include the new performance fire tests and the new nuisance resistance test, may make it challenging for manufacturers to meet the requirements by simply using a combination of photoelectric and ionization sensors, or designing alarms that perform as well against the new fire tests as the combination ionization / photoelectric models examined.

4. The cooking aerosol production rates and beam / MIC relationship between the sources varied significantly and appeared to have an impact on the alarm response.

5. Toasting bread produced essentially no measurable obscuration, carbon monoxide nor significant heat, thus alarms that use sensors to detect these characteristics will most likely not alarm during normal toasting scenarios. The toasting bread aerosols produced particles that caused the ionization alarms to responded, which was similar to the measuring ionization chamber (MIC) current as the broiling hamburgers experiments.

6. The broiling hamburgers nuisance test challenged the majority of smoke alarms included in this study, and therefore may be considered a conservative test. Ultimately, cooking nuisance experiments on a range of smoke alarms that pass ANSI/UL 217-2015 will confirm the appropriateness of the broiling hamburgers cooking nuisance scenario as the model test. 


\section{References}

[1] ANSI/UL 217-2015: Standard for Safety Smoke Alarms, Underwriters Laboratories Inc., Northbrook, IL, 2015.

[2] Bukowski, R. W., Peacock, R. D., Averill, J. D., Cleary, T. G., Bryner, N. P., Walton W. D., Reneke, P. A., and Kuligowski, E. D. Performance of Home Smoke Alarms, Analysis of the Response of Several Available Technologies in Residential Fire Settings, Natl. Inst. Stand. Technol., Tech. Note 1455-1 (2008).

[3] NFPA 72, National Fire Alarm and Signaling Code, 2013 Edition, National Fire Protection Association, Quincy, MA (August, 2012).

[4] Fabian, T.Z., and Gandhi, P.D., "Smoke Characterization Project: Technical Report," UL, Northbrook, IL, April 2007.

[5] Cleary,T.G. NIST Technical Note 1837, Improving Smoke Alarm Performance - Justification for New Smoldering and Flaming Test Performance Criteria, Washington, DC: U.S. Department of Commerce, National Institute of Standards and Technology, 2014. http://dx.doi.org/10.6028/NIST.TN.1837

[6] Cleary, T.G., Results from a Full-Scale Smoke Alarm Sensitivity Study, Fire Technology, May 2014, Vol. 50, Issue 3, pp 775-790 http://dx.doi.org/10.1007/s10694-010-0152-2

[7] Cleary, T.G., An Analysis of the Performance of Smoke Alarms, Fire Safety Science 10: 823836, 2010. http://dx.doi.org/10.3801/IAFSS.FSS.10-823

[8] Lee, A., and Pineda D., "Smoke Alarms - Pilot Study of Nuisance Alarms Associated with Cooking,” US Consumer Products Safety Commission, Bethesda, MD, March 2010.

[9] NFPA 72, National Fire Alarm and Signaling Code, 2010 Edition, NFPA, Quincy MA.

[10] NFPA 72, National Fire Alarm and Signaling Code, 2013 Edition, NFPA, Quincy MA.

[11] NFPA 72, National Fire Alarm and Signaling Code, 2016 Edition, NFPA, Quincy MA.

[12] Cleary,T.G., and Chernovsky, A. NIST Technical Note 1784, Smoke Alarm Performance in Kitchen Fires and Nuisance Alarm Scenarios, Washington, DC: U.S. Department of Commerce, National Institute of Standards and Technology, 2013. http://dx.doi.org/10.6028/NIST.TN.1784

[13] Fire Protection Research Foundation report: "Smoke Alarm Nuisance Source Characterization: Experimental Results" Joshua B. Dinaburg and Dr. Daniel T. Gottuk, Ph.D., Jensen Hughes Date of issue: August 2015 